EDUARDO DE SENZI ZANCUL

\title{
Gestão do ciclo de vida de produtos: seleção de sistemas PLM com base em modelos de referência
}

Tese apresentada à Escola de Engenharia de São Carlos, da Universidade de São Paulo, para obtenção do título de Doutor em Engenharia de Produção.

Orientador: Prof. Titular Henrique Rozenfeld

São Carlos 
AUTORIZO A REPRODUÇÃO E DIVULGAÇÃO TOTAL OU PARCIAL DESTE TRABALHO, POR QUALQUER MEIO CONVENCIONAL OU ELETRÔNICO, PARA FINS DE ESTUDO E PESQUISA, DESDE QUE CITADA A FONTE.

Ficha catalográfica preparada pela Seção de Tratamento da Informação do Serviço de Biblioteca - EESC/USP

Zancul, Eduardo de Senzi

227g Gestão do ciclo de vida de produtos : seleção de sistemas PLM com base em modelos de referência / Eduardo de Senzi Zancul ; orientador Henrique Rozenfeld. -- São Carlos, 2009.

Tese (Doutorado-Programa de Pós-Graduação em e Área de Concentração em Engenharia de Produção) -- Escola de Engenharia de São Carlos da Universidade de São Paulo, 2009 .

1. Gestão do ciclo de vida de produtos. 2. Sistemas PLM. 3. Modelo de referência. I. Título. 
FOLHA DE JULGAMENTO

Candidato: Engenheiro EDUARDO DE SENZI ZANCUL

Tese defendida e julgada em 16/03/2009 perante a Comissão Julgadora:
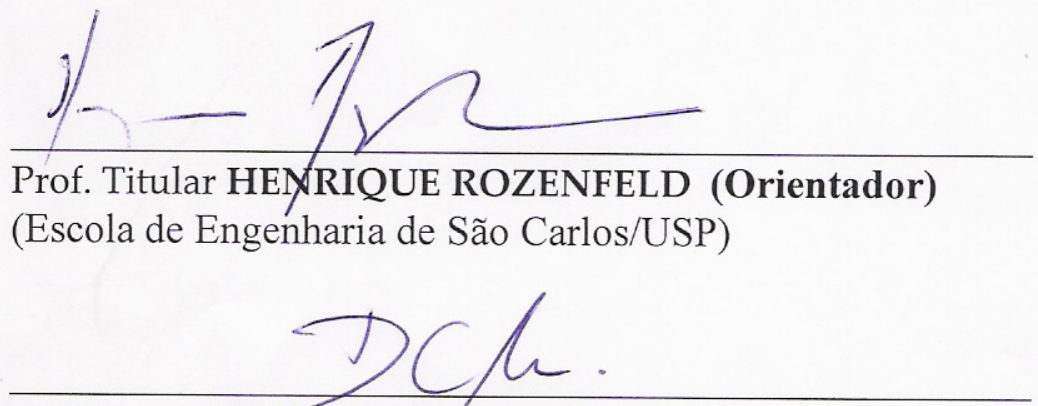

eprovedo

Prof. Dr. DANIEL CAPALDO AMARAL

(Escola de Engenharia de São Carlos/USP)

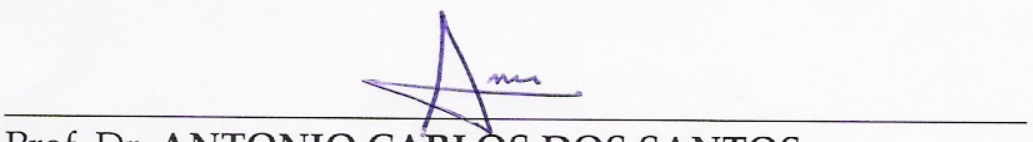

Prof. Dr. ANTONIO CARLOS DOS SANTOS

(Universidade Federal de São Carlos/UFSCar)
Alexandrou Augusta Pereira Ken Dra ${ }^{\mathrm{a}}$. ALEXANDRA AYGUSTA PEREIRA KLEN (Ad Hoc/ Tecnologia de negócio Digital)

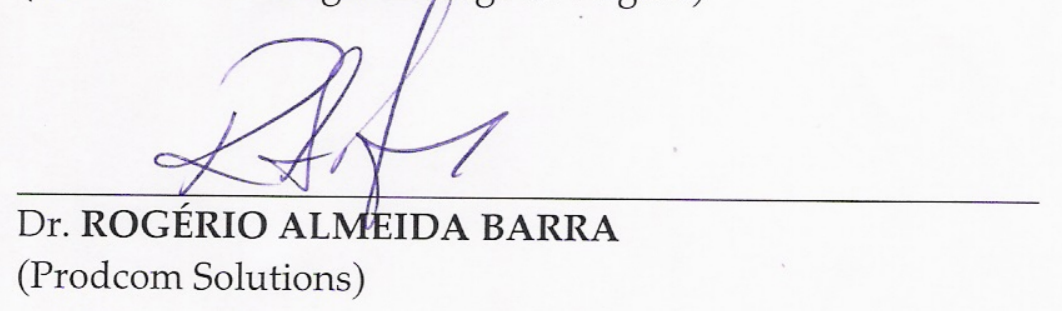

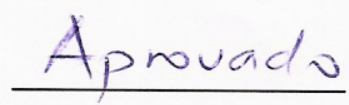

Aprovado

Aprovado

Remal do T. Coule

Prof. Associado REGINALDO TEIXEIRA COELHO

Coordenador do Programa de Pós-Graduação em Engenharia de Produção

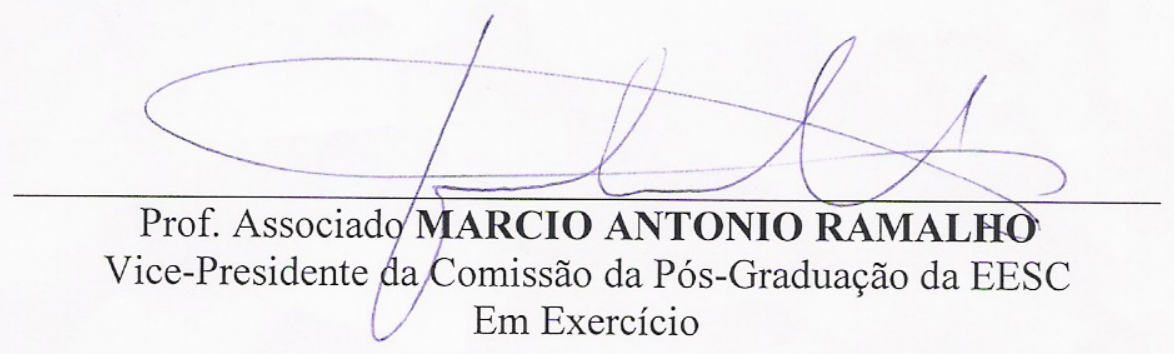


Dedico este trabalho aos meus pais, Almir e Cristina, pelo amor, carinho, incentivo e pelos exemplos de vida 


\section{AGRADECIMENTOS}

Este trabalho foi realizado ao longo de cinco anos intensos e importantes para mim, com a participação e a ajuda de pessoas muito especiais a quem eu gostaria de agradecer.

Ao Professor Titular Henrique Rozenfeld pela orientação, pela oportunidade de realizar o doutorado sanduíche na Alemanha, pelo exemplo de atuação acadêmica e pela confiança Muito obrigado.

Ao CNPq e ao DAAD pela bolsa de estudos de doutorado sanduíche na Alemanha e por possibilitar esse intercâmbio tão significativo para o estabelecimento de laços de cooperação entre o Brasil e a Alemanha. Também aos funcionários dessas instituições que trabalham na cooperação internacional, por tornarem o intercâmbio realidade.

Ao Professor Dr. Günther Schuh pela oportunidade de trabalho no WZL da Universidade de Aachen, na Alemanha.

Ao Professor Dr. Daniel Amaral e ao Dr. Rogério Barra, pelas contribuições valiosas durante o exame de qualificação.

Aos colegas do WZL, Alex Gulden, Alex Krauss, Ana Wittek, Christian Nonn, Felix, Jens Arnoscht, Ju-Young, Markus, Sebastian e em especial ao Dirk, Jens Meier e Michael, pelo convívio e trabalho intensos e pela amizade que desenvolvemos.

A todas as empresas e profissionais que gentilmente participaram deste trabalho. Especialmente ao Lucas e à Ana Paula, pela grande colaboração com o trabalho.

Ao José Luiz da Engenharia de Produção, pelo apoio nas questões de organização.

À minha mãe Cristina, à minha avó Lucy e à Luciana pela cuidadosa revisão do texto.

Aos meus pais, Almir e Cristina, pela ajuda na impressão do exemplar final.

Ao Zemar, Indira, Ana Luisa, João, Victor, Beatriz e Edson, por terem sido minha família nos dois anos na Alemanha. Muito obrigado.

Às minhas irmãs Mariana e Juliana, por estarem sempre ao meu lado.

À Luciana, que se juntou a mim ao longo desse caminho, trazendo muita alegria, pelo carinho e pela presença ao meu lado durante o tempo dedicado a essa tese. 


\section{RESUMO}

ZANCUL, E. S. Gestão do ciclo de vida de produtos: seleção de sistemas PLM com base em modelos de referência. 2009. 212f. Tese (Doutorado) - Escola de Engenharia de São Carlos, Universidade de São Paulo, São Carlos, 2009.

A gestão do ciclo de vida de produtos (Product Lifecycle Management) é uma abordagem para a gestão integrada dos processos de negócio e das informações relacionadas aos produtos. Tal abordagem requer a utilização de sistemas de informação (Sistemas PLM) para apoiar a colaboração na empresa estendida, ao longo de todo o ciclo de vida. O problema prático que motiva a realização deste trabalho é a dificuldade enfrentada pelas empresas, atualmente, em avaliar os sistemas PLM existentes no mercado e em selecionar a alternativa mais adequada aos seus processos de negócio. A análise da situação atual da pesquisa na área indica que faltam métodos e instrumentos para apoiar a seleção de sistemas PLM. Visando preencher essa lacuna e propor uma solução para o problema identificado, o trabalho tem como objetivos definir um modelo de referência de sistemas PLM, que represente de forma genérica as funcionalidades que caracterizam esse tipo de sistema, e desenvolver um método para a seleção de sistemas PLM baseado em modelos de referência. A fim de atingir esses objetivos, são gerados quatro resultados principais. O primeiro resultado do trabalho é o framework conceitual de elementos do PLM, que organiza o conhecimento existente sobre PLM de forma estruturada, para que ele possa servir de referência em projetos de implantação da gestão do ciclo de vida de produtos em empresas. O segundo resultado é o modelo de referência de sistemas PLM, que permite estabelecer uma base comum para a comparação entre os diversos sistemas PLM disponíveis comercialmente. O terceiro resultado é o modelo integrado processo-sistemas PLM e a ferramenta para utilização desse modelo integrado na prática. Por fim, o quarto resultado é o método de seleção de sistemas PLM com base em modelos de referência, que utiliza o modelo integrado processo-sistemas PLM para orientar a seleção do sistema mais adequado a uma empresa específica. A avaliação dos resultados indica que os instrumentos e o método propostos neste trabalho contribuem para auxiliar as empresas, especialmente as empresas de médio porte, na identificação de um sistema PLM adequado para atender aos requisitos de seus processos de negócio.

Palavras-chave: Gestão do ciclo de vida de produtos. Sistemas PLM. Modelo de referência. 


\section{ABSTRACT}

ZANCUL, E. S. Product lifecycle management: PLM systems selection based on reference models. 2009. 212f. Thesis (Doctoral) - Escola de Engenharia de São Carlos, Universidade de São Paulo, São Carlos, 2009.

Product Lifecycle Management is an approach to the integrated management of business processes and product-related information. This approach requires information systems (PLM Systems) to provide collaboration support throughout the business and across product lifecycle. The practical problem that gave rise to this research was the challenge companies currently face in assessing existing PLM systems and in selecting the best alternative for their business processes. Examining the status of the research carried out in the field to date shows that there is a lack of methods and tools to effectively support companies in choosing their PLM Systems. Aiming at closing this gap and offering a solution for this problem, the goals of this study are: to provide a definition for PLM system reference models that generally represents the functionalities that characterize this kind of system, and to develop a method for choosing PLM systems based on the reference models. In meeting these goals, this research arrived at four main results. Firstly, at a conceptual framework of PLM elements providing an organized structure of the existing knowledge developed so far on PLM. This framework can be used as a reference in projects to implement product lifecycle management in companies. Secondly, at a PLM system reference model that establishes a common basis for comparing the many PLM systems available in the market. Thirdly, at an integrated PLM process-system model and tool for using this integrated model in practice. Lastly, at a method for selecting PLM systems based on the reference model, that uses the integrated PLM process-system model to support and guide users in choosing the best system for a certain company. The assessment of the results shows that the proposed tools and method effectively help companies, specially medium-sized businesses, in identifying the most adequate PLM system to meet their business process requirements.

Keywords: Product lifecycle management. PLM Systems. Reference model. 


\section{LISTA DE FIGURAS}

Figura 1. Estrutura do capítulo 1.

Figura 2. Balança comercial de produtos da indústria de transformação por intensidade

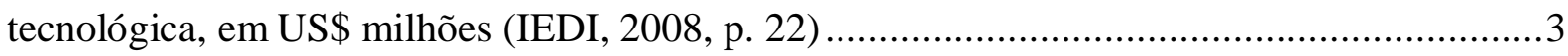

Figura 3. Tendências de evolução na indústria e impactos nas empresas ...............................5

Figura 4. Temas atuais de pesquisa na área de PLM ..........................................................

Figura 5. Situação atual da aplicação do PLM na indústria .............................................. 10

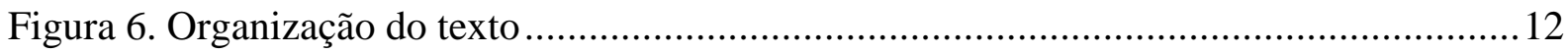

Figura 7. Capítulos da síntese da bibliografia fundamental .............................................14

Figura 8. Fases típicas da melhoria de processos de negócio e organização do capítulo.........15

Figura 9. Fases típicas do ciclo de vida de um produto .....................................................16

Figura 10. Visões sobre a gestão do ciclo de vida de produtos (adaptado de WESTKAMPER;

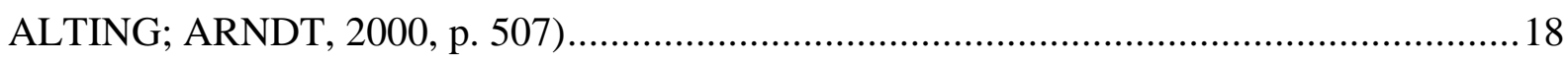

Figura 11. Definição de Life Cycle Engineering e métodos empregados ..............................19

Figura 12. Informações geradas ao longo do ciclo de vida de produtos (adaptado de BOOS;

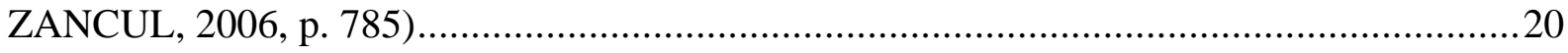

Figura 13. Definição de gestão do ciclo de vida de produtos.............................................22

Figura 14. Distinção entre PLM como abordagem e como sistema de informação ................24

Figura 15. Delimitação entre a gestão de dados de produto com CAD, PDM e PLM (adaptado

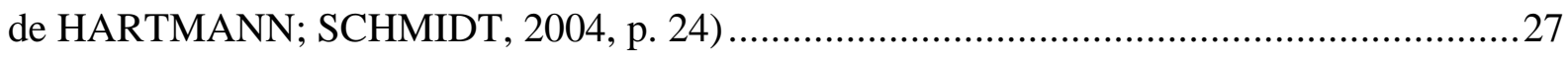

Figura 16. Visão de processos de negócio aplicada à gestão do ciclo de vida de produtos

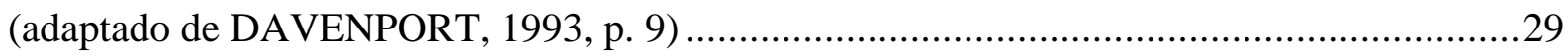

Figura 17. Geração e utilização de modelos de referência (baseado em SCHWEGMANN;

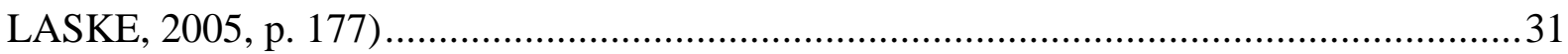

Figura 18. Processos de gestão do ciclo de vida de produtos...............................................39

Figura 19. Práticas de gestão do ciclo de vida de produtos ................................................43

Figura 20. Integração da avaliação de idéias, com planejamento de projetos e gestão do portfolio (exemplo ilustrativo) .................................................................................4

Figura 21. Papel da estrutura de produto na integração de informações no ciclo de vida .......45

Figura 22. Aspectos da gestão de configuração (adaptado de ARNOLD et al., 2005, p. 74 )..46

Figura 23. Utilização de sistemas de informação nas fases do ciclo de vida de produtos (adaptado de SCHUH, 2006, p. 10) 
Figura 24. Nível de utilização dos sistemas PLM, CRM e SCM ao longo do ciclo de vida (adaptado de CIMDATA, 2001b, p. 14).

Figura 25. Origem dos sistemas existentes e posicionamento de mercado dos fornecedores (ASSMUS et al., 2006, p. 17) 51

Figura 26. Funcionalidades típicas de sistemas PLM ..................................................52

Figura 27. Relação entre as práticas e os benefícios de PLM.............................................56

Figura 28. Impacto do PLM no fluxo de caixa de um produto - conceitual (adaptado de

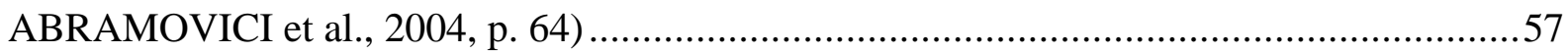

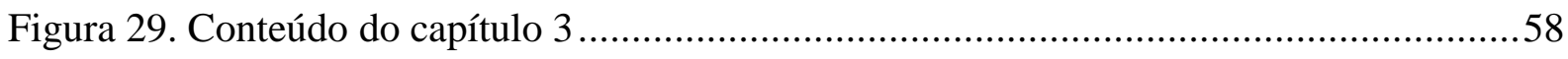

Figura 30. Método de comparação de modelos (KIRCHMER, 1998, p. 114) .......................62

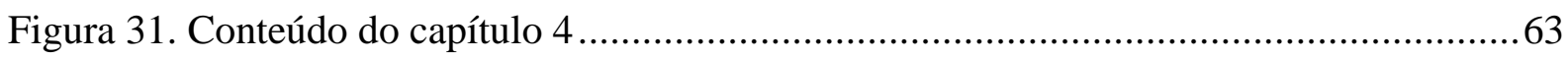

Figura 32. Comparação entre as alternativas de posicionamento da seleção de sistemas de informação no escopo de projetos de implantação de software. .66

Figura 33. Problema prático, perguntas de pesquisa, objetivo do trabalho e método científico 73

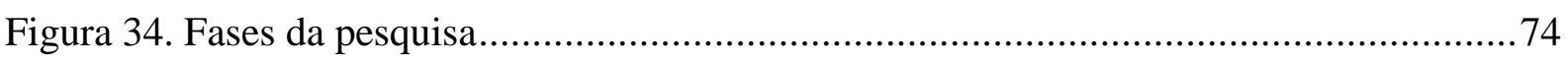

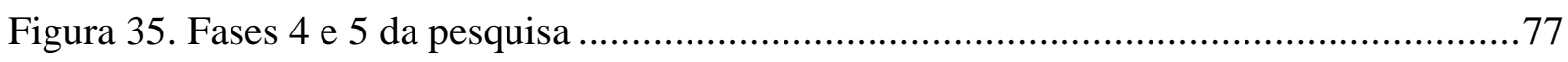

Figura 36. Framework conceitual de elementos do PLM ................................................84

Figura 37. Localização do relacionamento entre o modelo do processo e o modelo de sistemas PLM no framework conceitual de elementos do PLM...................................................86

Figura 38. Níveis de detalhamento do solution map da SAP (SAP, 2008b) ..........................88

Figura 39. Especificação do relacionamento entre atividades do modelo de processo e

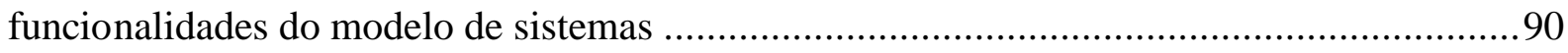

Figura 40. Estrutura do modelo de referência de sistemas PLM ........................................94

Figura 41. Módulos do modelo de referência de sistemas PLM..........................................95

Figura 42. Grupos de funcionalidades do modelo de referência de sistemas PLM ................97

Figura 43. Comparação do status atual do desenvolvimento dos módulos de sistemas PLM106 Figura 44. Escopo do modelo integrado processo-sistemas PLM complementado com a descrição do perfil de sistemas PLM disponíveis comercialmente. 109

Figura 45. Estrutura de relacionamento entre os modelos de processos e de sistemas PLM e a base de dados de capacitações de sistemas comerciais (conceitual) ...................................110

Figura 46. Modelo de referência integrado processo-sistemas PLM ..................................113

Figura 47. Delimitação do escopo em termos de atividades do processo e funcionalidades de sistemas PLM 
Figura 48. Detalhamento das transações necessárias 116

Figura 49. Base de dados de capacitações dos sistemas PLM disponíveis comercialmente..117 Figura 50. Resultados da análise da adequação dos sistemas comerciais aos requisitos .......118 Figura 51. Visão geral do método de seleção de sistemas PLM com base em modelos de referência 121

Figura 52. Relação entre o framework conceitual de elementos do PLM e capítulos deste texto 


\section{LISTA DE TABELAS}

Tabela 1 - Atividades típicas de desenvolvimento de produtos no Brasil por setor (ilustrativo) 3

Tabela 2 - Análise comparativa dos modelos de referência - parte 1 ...................................36

Tabela 3 - Análise comparativa dos modelos de referência - parte 2 ..................................37

Tabela 4 - Visão geral de alguns sistemas PLM oferecidos no mercado brasileiro ................54

Tabela 5 - Comparação dos métodos de seleção de sistemas de informação .........................69

Tabela 6 - Elementos do framework conceitual de PLM.................................................82

Tabela 7 - Inter-relações entre os elementos do framework conceitual de PLM ....................83

Tabela 8 - Níveis de detalhamento dos modelos de referência de PLM................................87

Tabela 9 - Classificação dos sistemas participantes da survey (conforme tipos definidos no

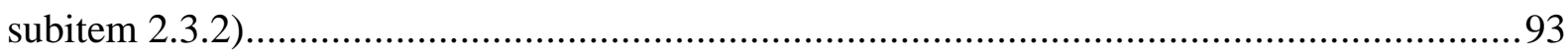

Tabela 10 - Etapas da fase de pré-seleção de métodos de seleção de sistemas de informação 122

Tabela 11 - Resultados das entrevistas de avaliação do método proposto para a seleção de sistemas PLM

Tabela 12 - Relação entre as perguntas de pesquisa, os objetivos e os resultados do trabalho 129

Tabela 13 - Fornecedores de sistemas PLM e fornecedores que participaram da survey - parte 1.

Tabela 14 - Fornecedores de sistemas PLM e fornecedores que participaram da survey - parte 2 


\section{LISTA DE ABREVIATURAS E SIGLAS}

ABS

ANFAVEA

API

BOM

BPMN

BPMI

CAD

CAE

CAM

CAPP

CIIU

CIM

CMMI

CPM

CRM

DFD

DFE

DFES

DFX

EAP

ECO

ECR

EPC

ERP

IEDI

IGES

LCA

LCC

LCE

MER

NUMA
Antilock Braking System

Associação Nacional dos Fabricantes de Veículos Automotores Application Programming Interface

Bill of Materials

Business Process Modeling Notation

Business Process Management Initiative

Computer Aided Design

Computer Aided Engineering

Computer Aided Manufacturing

Computer Aided Process Planning

Classificação Industrial Internacional Uniforme

Computer Integrated Manufacturing

Capability Maturity Model Integration

Critical Path Method

Customer Relationship Management

Design for Disassembly

Design for Environment

Design for Energy Saving

Design for $X$

Estrutura Analítica de Projeto

Engineering Change Order

Engineering Change Request

Event-Driven Process Chain

Enterprise Resource Planning

Instituto de Estudos para o Desenvolvimento Industrial

Initial Graphics Exchange Specification

Life Cycle Assessment

Life Cycle Cost

Life Cycle Engineering

Modelo de Entidade-Relacionamento

Núcleo de Manufatura Avançada 
OICA

OMG

PAPP

PDM

PDP

PLC

PLM

PORE

RFID

RFP

RFQ

RWTH

SCM

SEI

SFB

SOA

STEP

TFB

TI

UML

USP

WZL

XML
The International Organization of Motor Vehicle Manufacturers Object Management Group

Production Part Approval Process

Product Data Management

Processo de Desenvolvimento de Produtos

Product Life Cycle

Product Lifecycle Management

Procurement-Oriented Requirements Engineering

Radio Frequency Identification

Request for Proposal

Request for Quotation

Rheinisch-Westfälische Technische Hochschule Aachen

Supply Chain Management

Software Engineering Institute

Sonderforschungsbereich

Service Oriented Architecture

Standard for the Exchange of Product Model Data

Transferbereich

Tecnologia da Informação

Unified Modeling Language

Universidade de São Paulo

Werkzeugmaschinenlabor

Extensible Markup Language 


\section{SUMÁRIO}

1 INTRODUÇÃO

1.1 Importância da gestão do ciclo de vida de produtos para a competitividade da indústria no Brasil 2

1.2 Situação atual da pesquisa e da aplicação do PLM nas empresas 6

1.3 Perguntas de pesquisa e objetivos do trabalho 10

1.4 Delimitação do escopo do trabalho 11

1.5 Organização deste texto 12

\section{GESTÃO DO CICLO DE VIDA DE PRODUTOS: DEFINIÇÕES, MODELOS DE} REFERÊNCIA E SISTEMAS DE INFORMAÇÃO _ 14

2.1 Conceitos fundamentais para a gestão do ciclo de vida de produtos__ 15

2.1.1 Fases do ciclo de vida de produtos__ 15

2.1.2 Visões existentes para a gestão do ciclo de vida __ 17

2.1.3 Definição de gestão do ciclo de vida de produtos __ 21

2.1.4 Delimitação entre o PLM como abordagem e como sistema de informação_ 23

2.1.5 Evolução histórica da gestão do ciclo de vida de produtos _ 25

2.2 Modelos de referência, processos e práticas de gestão do ciclo de vida de produtos 28

2.2.1 Aplicação da abordagem de processos de negócio à gestão do ciclo de vida de produtos 28

2.2.2 Definição de modelo de referência___ 30

2.2.3 Modelos de referência existentes para apoiar a gestão do ciclo de vida de produtos 32

2.2.4 Processos de gestão do ciclo de vida de produtos __ 38

2.2.5 Práticas associadas à gestão do ciclo de vida de produtos__ 42

2.3 Sistemas de informação para a gestão do ciclo de vida de produtos___ 47

2.3.1 Composição e abrangência de soluções para o PLM__ 48

2.3.2 Tipos de sistemas PLM

2.3.3 Funcionalidades de sistemas PLM 52

2.3.4 Descrição de sistemas disponíveis comercialmente___ 53

2.4 Benefícios da gestão do ciclo de vida de produtos __ 54

3 CONCEITOS DE MODELAGEM DE EMPRESAS _ 58

3.1 Os objetivos da modelagem de empresas _ 58

3.2 Métodos de modelagem__ 59

3.3 Método de comparação de modelos _ 61

4 TÓPICOS SOBRE A SELEÇÃO DE SISTEMAS DE INFORMAÇÃO _ _ 63

4.1 Importância da seleção de sistemas ___ 63 
4.2 Localização da fase de seleção da solução em projetos de implementação de sistemas de informação 65

4.3 Métodos de seleção de sistemas de informação 67

5 PROCEDIMENTOS METODOLÓGICOS 71

5.1 Método 71

5.2 Fases do trabalho e procedimentos técnicos de pesquisa 74

6 FRAMEWORK CONCEITUAL DE ELEMENTOS DO PLM 80

6.1 Estrutura do framework conceitual de elementos do PLM 80

6.2 Relacionamento entre as atividades do processo e as funcionalidades de sistemas PLM 85

7 MODELO DE REFERÊNCIA DE SISTEMAS PLM 91

7.1 Desenvolvimento do modelo de referência de sistemas PLM 91

7.2 Visão geral do modelo de referência de sistemas PLM 93

7.3 Status atual do desenvolvimento de sistemas PLM 105

7.4 Tendências de evolução de sistemas PLM 107

8 MODELO DE REFERÊNCIA INTEGRADO PROCESSO-SISTEMAS PLM _ 109

8.1 Relacionamento entre os modelos de referência dos processos e de sistemas PLM110

8.2 Ferramenta de utilização do modelo de referência integrado processo-sistemas PLM

9 MÉTODO DE SELEÇÃO DE SISTEMAS PLM

9.1 Fases e etapas do método de seleção de sistemas PLM 119

9.2 Avaliação do método proposto 126

10 CONCLUSÕES 129

10.1 Resultados do trabalho 129

10.2 Sugestão para trabalhos futuros 132

APÊNDICE A - LISTA DE FORNECEDORES DE SISTEMAS PLM E FORNECEDORES QUE PARTICIPARAM DA SURVEY 133

APÊNDICE B - MODELO DE REFERÊNCIA DE SISTEMAS PLM 135

APÊNDICE C - MODELO DE REFERÊNCIA DA GESTÃO DO CICLO DE VIDA DE PRODUTOS COM INDICAÇÃO DAS FUNCIONALIDADES DE PLM 174

REFERÊNCIAS 205 


\section{INTRODUÇÃO}

A gestão do ciclo de vida de produtos ou Product Lifecycle Management (PLM) é uma abordagem que apóia o gerenciamento dos processos de negócio e das informações relacionadas com o ciclo de vida dos produtos. O PLM visa, principalmente, aumentar a produtividade e melhorar a efetividade dos processos de negócio relacionados com o planejamento, o desenvolvimento, a fabricação, a manutenção e a retirada de produtos do mercado. Para atingir esses objetivos, o PLM contempla métodos e ferramentas para aumentar o nível de integração dos processos, das informações e das pessoas envolvidas ao longo de todas as etapas do ciclo de vida, desde a idéia inicial até a disposição final dos produtos após o uso. A maior integração resulta em benefícios como a redução do tempo de desenvolvimento de novos produtos e a diminuição dos custos.

Neste trabalho sobre gestão do ciclo de vida de produtos, o primeiro capítulo apresenta a introdução, que inclui a motivação, as justificativas e os objetivos da pesquisa, além da organização do texto (veja Figura 1). Considerando os potenciais benefícios do PLM, discutese inicialmente como a gestão do ciclo de vida de produtos pode contribuir para melhorar a competitividade da indústria no Brasil (item 1.1). Em seguida, são descritos o estágio atual da pesquisa e a situação da aplicação da gestão do ciclo de vida de produtos nas empresas (item 1.2). Com base na análise da situação atual e nas lacunas existentes na área, são formuladas as perguntas de pesquisa e definidos os objetivos do trabalho (item 1.3). A seguir discute-se a delimitação do escopo do trabalho (item 1.4). Por fim, é apresentada a forma de organização do trabalho (item 1.5).

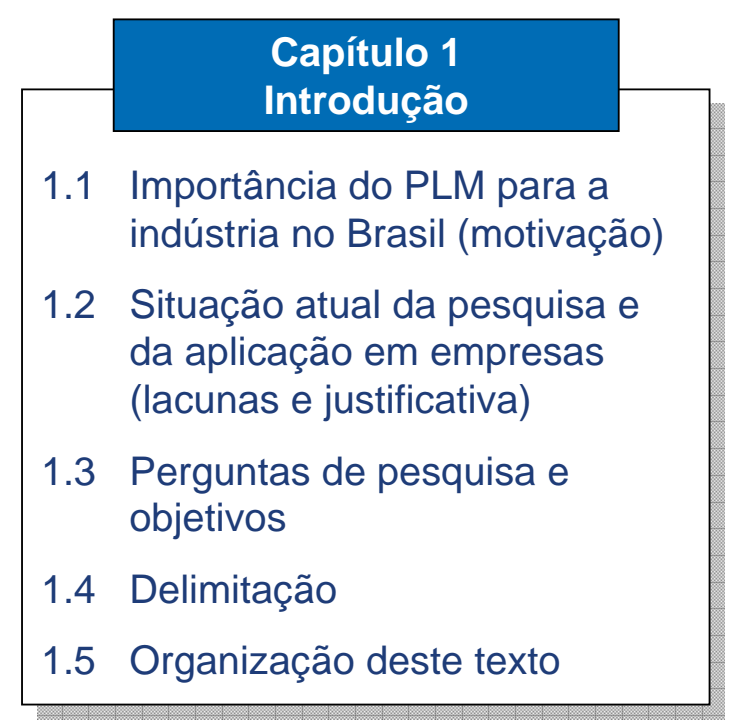

Figura 1. Estrutura do capítulo 1 


\subsection{Importância da gestão do ciclo de vida de produtos para a competitividade da indústria no Brasil}

Os setores da indústria caracterizados por produtos técnicos de maior valor agregado já atingiram um importante nível de desenvolvimento no Brasil. O país é o sétimo maior fabricante de automóveis e de veículos comerciais no mundo, com 2,9 milhões de unidades produzidas em 2007 (ANFAVEA, 2008; OICA, 2008). Também é a sede de desenvolvimento de produtos da Embraer, terceira maior empresa fabricante de aviões. Os setores de bens de capital e eletro-eletrônico se destacam pela variedade de produtos com conteúdo nacional, como, por exemplo, máquinas-ferramenta, plantas para a indústria de processos e aparelhos celulares.

A evolução da indústria de maior intensidade tecnológica no Brasil é atualmente limitada pela concorrência internacional. A competição por custos afeta a produção de bens manufaturados no país, que sofre forte concorrência, principalmente por parte de empresas instaladas na Ásia. Os impactos não são restritos à manufatura, uma vez que uma alta escala de produção é geralmente necessária para justificar o investimento em desenvolvimento de produtos. Outros fatores que têm impacto na capacidade de desenvolvimento de produtos estão relacionados à existência de um ambiente favorável para a inovação tecnológica, incluindo a disponibilidade de mão-de-obra qualificada (ARBIX; SALERNO; DE NEGRI, 2005, p. 434). Nesse critério, a concorrência é mais acirrada com os países industrializados da Europa e da América do Norte e também com alguns países mais desenvolvidos da Ásia.

Por causa da competição, as atividades de desenvolvimento de produtos, importantes para fixar a cadeia produtiva no país e responsáveis por gerar empregos de alta qualificação (SALERNO et al., 2004, p. 70-71), são realizadas ainda de forma limitada no Brasil. No setor de bens de capital, por exemplo, as empresas no Brasil atuam tipicamente no desenvolvimento e fabricação de máquinas padronizadas (e.g. injetoras de plástico) e na engenharia e construção de plantas para a indústria de processos. Por outro lado, as máquinas sofisticadas, focadas em nichos de mercado (e.g. máquinas-ferramenta de alta precisão), são, em geral, importadas. Apenas a adaptação e a montagem final são realizadas no Brasil. As atividades de desenvolvimento de produtos realizadas no Brasil em setores selecionados da indústria estão apresentadas de maneira ilustrativa na Tabela 1. 
Tabela 1 - Atividades típicas de desenvolvimento de produtos no Brasil por setor (ilustrativo)

\begin{tabular}{l|l}
\hline \multicolumn{1}{c|}{ Setor } & \multicolumn{1}{c}{ Atividades típicas de desenvolvimento de produtos realizadas no Brasil } \\
\hline \multirow{3}{*}{ Automotivo } & $\begin{array}{l}\text { Tropicalização de autopeças (e.g. sistema de injeção eletrônica) } \\
\text { Tropicalização de plataformas / veículos desenvolvidos no exterior (e.g. VW Polo) } \\
\text { Desenvolvimento local de plataformas e de veículos de baixo custo (VW Fox e Fiat Palio) } \\
\text { Desenvolvimento local de veículos comerciais (VW Caminhões) }\end{array}$ \\
\hline Aeroespacial & $\begin{array}{l}\text { Desenvolvimento local da arquitetura do produto e coordenação dos projetos de } \\
\text { desenvolvimento (Embraer) }\end{array}$ \\
\hline Bens de capital & $\begin{array}{l}\text { Desenvolvimento local de máquinas padronizadas (e.g. injetoras de plástico) } \\
\text { importadas (e.g. linhas de produção para a indústria de bebidas) }\end{array}$ \\
\hline \multirow{2}{*}{$\begin{array}{l}\text { Eletro- } \\
\text { eletrônico }\end{array}$} & $\begin{array}{l}\text { Fabricação de componentes padronizados } \\
\text { Desenvolvimento local de produtos simples de categorias específicas (e.g. telefone } \\
\text { celular) }\end{array}$ \\
\hline
\end{tabular}

A concorrência em custos de produção e a limitada capacidade de desenvolvimento de produtos no país resultam em falta de competitividade dos produtos tecnológicos brasileiros. A conseqüência é um significativo déficit na balança comercial de produtos de intensidade tecnológica considerada alta e média-alta ${ }^{1}$ (Figura 2).

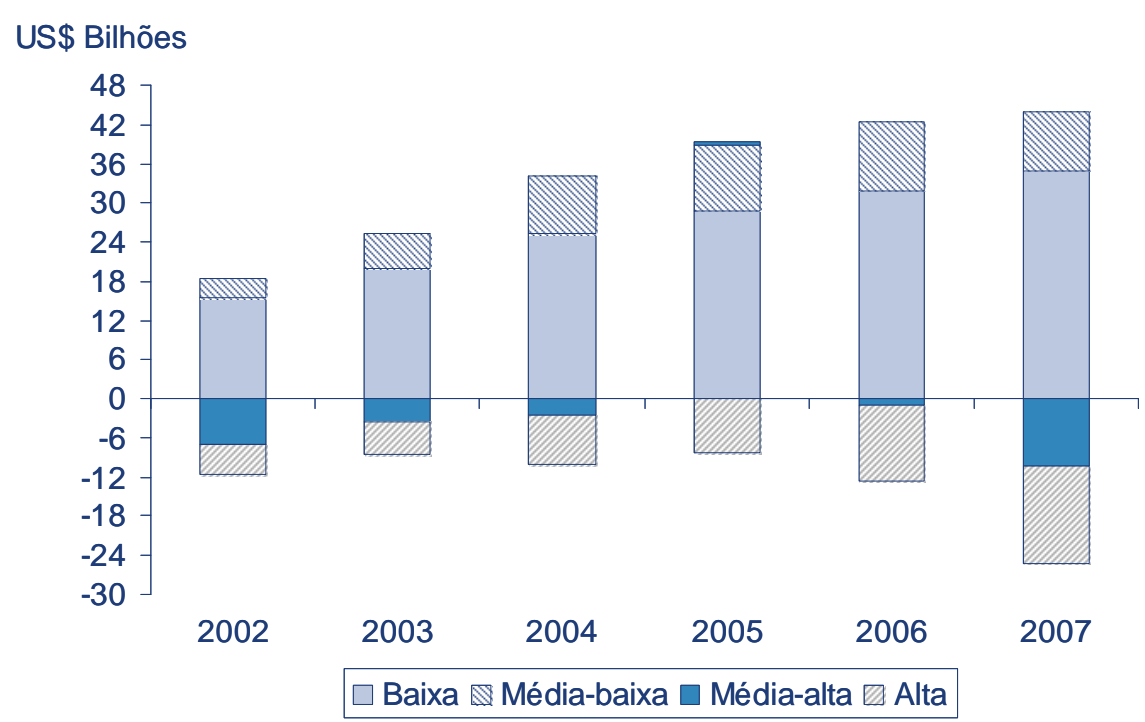

Figura 2. Balança comercial de produtos da indústria de transformação por intensidade tecnológica, em US\$ milhões (IEDI, 2008, p. 22)

${ }^{1}$ Classificação por intensidade tecnológica baseada na Classificação Industrial Internacional Uniforme (CIIU, revisão 3). Indústria de alta tecnologia: aeronáutica e aeroespacial; farmacêutica; material de escritório e informática; equipamentos de rádio, TV e comunicação; instrumentos médicos de ótica e precisão. Indústria de média-alta tecnologia: máquinas e equipamentos elétricos; veículos automotores, reboques e semi-reboques; produtos químicos; equipamentos para ferrovia e material de transporte; máquinas e equipamentos mecânicos. 
O aumento da competitividade da indústria de alta / média-alta tecnologia instalada no Brasil depende tanto de iniciativas setoriais amplas como de iniciativas específicas de melhoria do desempenho das empresas. Este trabalho trata das iniciativas que podem ser executadas pelas próprias empresas para melhorar a sua competitividade. Nesse nível, um tema central é a capacidade das empresas em lidar com a crescente complexidade dos produtos e de todo o processo produtivo (GOTTFREDSON; ASPINALL, 2005; SCHUH, 2005; SUH, 2005).

Em relação aos produtos de alta / média-alta tecnologia, observa-se nos últimos anos a tendência de aumento da variedade de produtos oferecidos no mercado (GOTTFREDSON; ASPINALL, 2005, p. 63). Simultaneamente, as empresas reduzem o tempo médio de vida dos produtos. Isso faz com que o tempo disponível para lançar novos produtos também seja menor (FILIPPINI; SALMASO; TESSAROLO, 2004, p. 200-201). Com o avanço da mecatrônica, os produtos adquirem novas funções que integram os componentes mecânicos, eletrônicos e de software. Alguns exemplos dessa tendência no setor automotivo são os sistemas de freios ABS (Antilock Braking System) e de suspensão ativa (ISERMANN, 2008, p. 16).

As tendências de mercado e de produto têm implicações nos processos de negócio das empresas. Com o aumento da sofisticação dos produtos, diversas disciplinas (mecânica, eletrônica, software, entre outras especialidades) precisam trabalhar conjuntamente de maneira efetiva (ISERMANN, 2008, p. 17). As competências necessárias estão distribuídas entre várias empresas, seguindo uma tendência de maior especialização e de foco em atividades-chave, exigindo maior integração entre parceiros na cadeia de valor. Há também maior necessidade de padronização de informações e de integração entre os sistemas de tecnologia da informação (TI), uma vez que as atividades de desenvolvimento de produtos e de planejamento da produção são, cada vez mais, realizadas com auxílio de softwares e da simulação (KRASTEL; MERKT, 2004, p. 8-9). Além da padronização das informações, os processos também precisam ser adaptados para atender aos procedimentos e controles exigidos pelas normas internacionais.

Uma das principais conseqüências das tendências citadas anteriormente é o aumento da complexidade dos produtos e dos processos para o seu desenvolvimento e produção (Figura 3). 

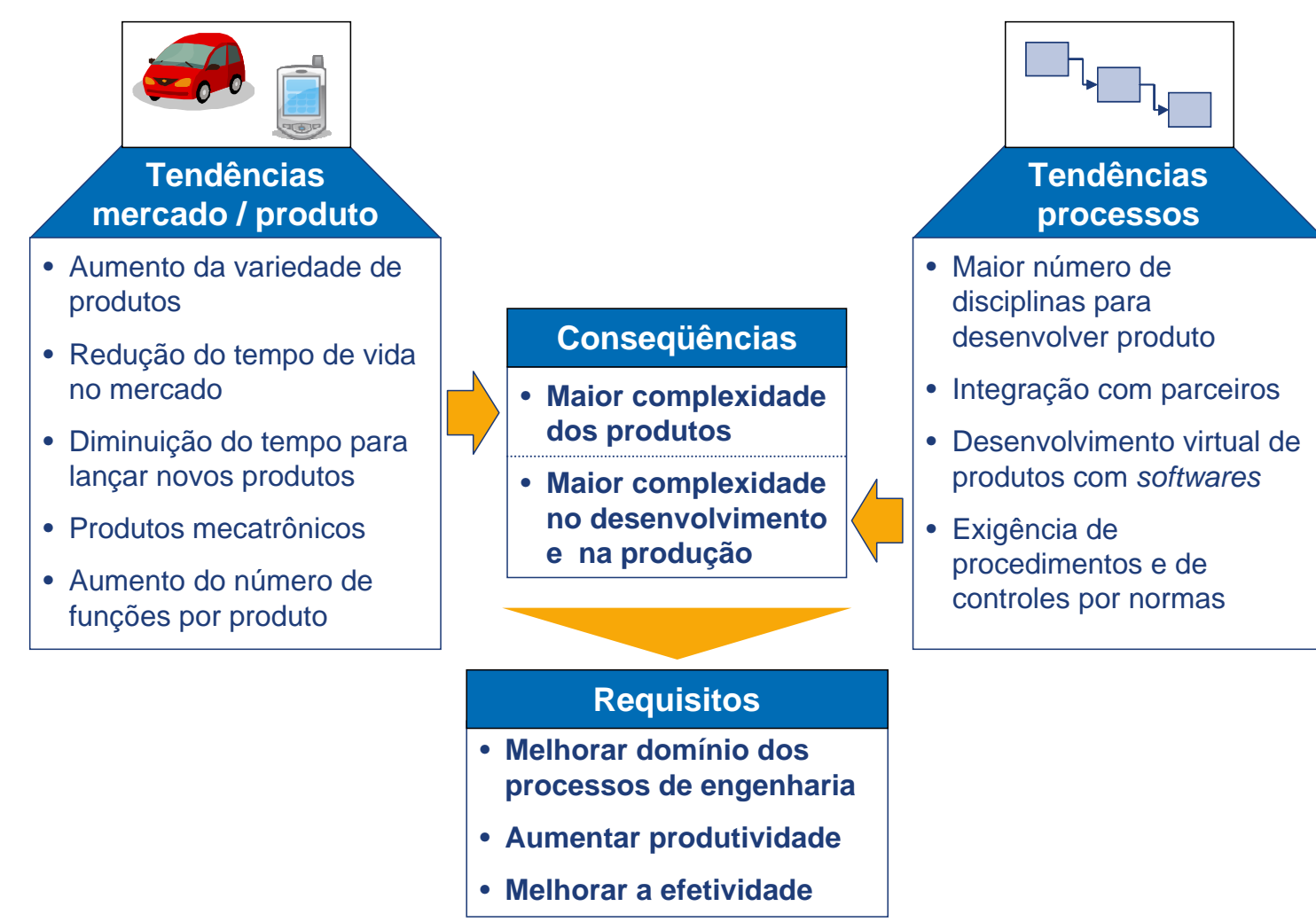

Figura 3. Tendências de evolução na indústria e impactos nas empresas

O aumento da complexidade dificulta a gestão dos processos. O número de atividades e de interações é maior. As próprias atividades tornaram-se mais difíceis de serem executadas. As pessoas envolvidas nas atividades estão dispersas geograficamente. Isso exige que as empresas implementem mecanismos que resultem em maior domínio dos processos de engenharia (Figura 3).

Ao lado da capacitação para a gestão dos processos é necessário melhorar o desempenho dos processos de negócio, pois o desenvolvimento de um novo produto demanda, hoje, mais esforço do que no passado. O risco de não atingir os volumes de vendas planejados também são maiores, devido à grande variedade de opções disponíveis no mercado. A combinação de investimentos elevados em inovação com os riscos altos resultam na necessidade de maior produtividade e efetividade da engenharia (Figura 3).

Nesse contexto, a abordagem integrada da gestão do ciclo de vida de produtos pode contribuir significativamente para aumentar a competitividade da indústria instalada no Brasil. O objetivo do PLM é a configuração otimizada dos processos, especialmente do processo de desenvolvimento de produtos, assim como a gestão de todas as informações do produto ao longo do ciclo de vida. As informações atualizadas podem ser acessadas diretamente por todas as pessoas autorizadas, a qualquer momento. Isso possibilita, por exemplo, reduzir o tempo necessário para desenvolver novos produtos com menores custos (SAAKSVUORI; 
IMMONEN, 2004; ARNOLD et al., 2005; SCHEER et al., 2006; ABRAMOVICI, 2007; FELDHUSEN; GEBHARDT, 2008).

Nas empresas, a implantação da abordagem de gestão do ciclo de vida de produtos na prática está geralmente vinculada à adoção de ferramentas de TI, conhecidas comercialmente como sistemas PLM. É necessário, então, distinguir a definição da abordagem de PLM da definição de PLM como um sistema de informação. Neste trabalho, utiliza-se o termo PLM para a abordagem de gestão do ciclo de vida de produtos baseada na visão ampla de integração dos processos de negócio, conforme discutido nos parágrafos anteriores. O termo sistema PLM, por sua vez, refere-se aos sistemas de informação necessários para viabilizar a adoção da abordagem.

Devido aos seus benefícios em potencial, o PLM tem atraído muita atenção, tanto na área acadêmica como na indústria. O número de publicações acadêmicas sobre PLM cresceu bastante nos últimos anos ${ }^{2}$. No Brasil, empresas como Embraer, Weg e Fiat têm projetos em andamento para implementar a gestão do ciclo de vida de produtos ${ }^{3}$. A situação atual da pesquisa e da aplicação do PLM na indústria é discutida no item a seguir.

\subsection{Situação atual da pesquisa e da aplicação do PLM nas empresas}

A gestão do ciclo de vida é abordada na área acadêmica sob diversos aspectos. As pesquisas sobre PLM podem ser classificadas em três grupos. O primeiro grupo envolve a especificação de processos e a definição de métodos para PLM. O segundo, abrange as questões técnicas de integração de sistemas de informação. O terceiro, trata da aplicação do PLM em diferentes contextos. Essas três dimensões de pesquisa na área de PLM são representadas pelos retângulos maiores na Figura 4. Na mesma figura, o texto nos retângulos em branco define áreas de pesquisa (em negrito) e temas de trabalhos específicos.

${ }^{2}$ A busca com o termo Product Lifecycle Management na base de dados ISI Web of Science da Thomson Reuters indica uma crescente quantidade de artigos científicos publicados nos últimos 5 anos: 14 (2003); 21 (2004); 49 (2005); 49 (2006); 91 (2007). Pesquisa realizada em 14 de dezembro de 2008.

${ }^{3}$ Informação obtida pelo autor por meio de representantes de consultoria na área de PLM. 


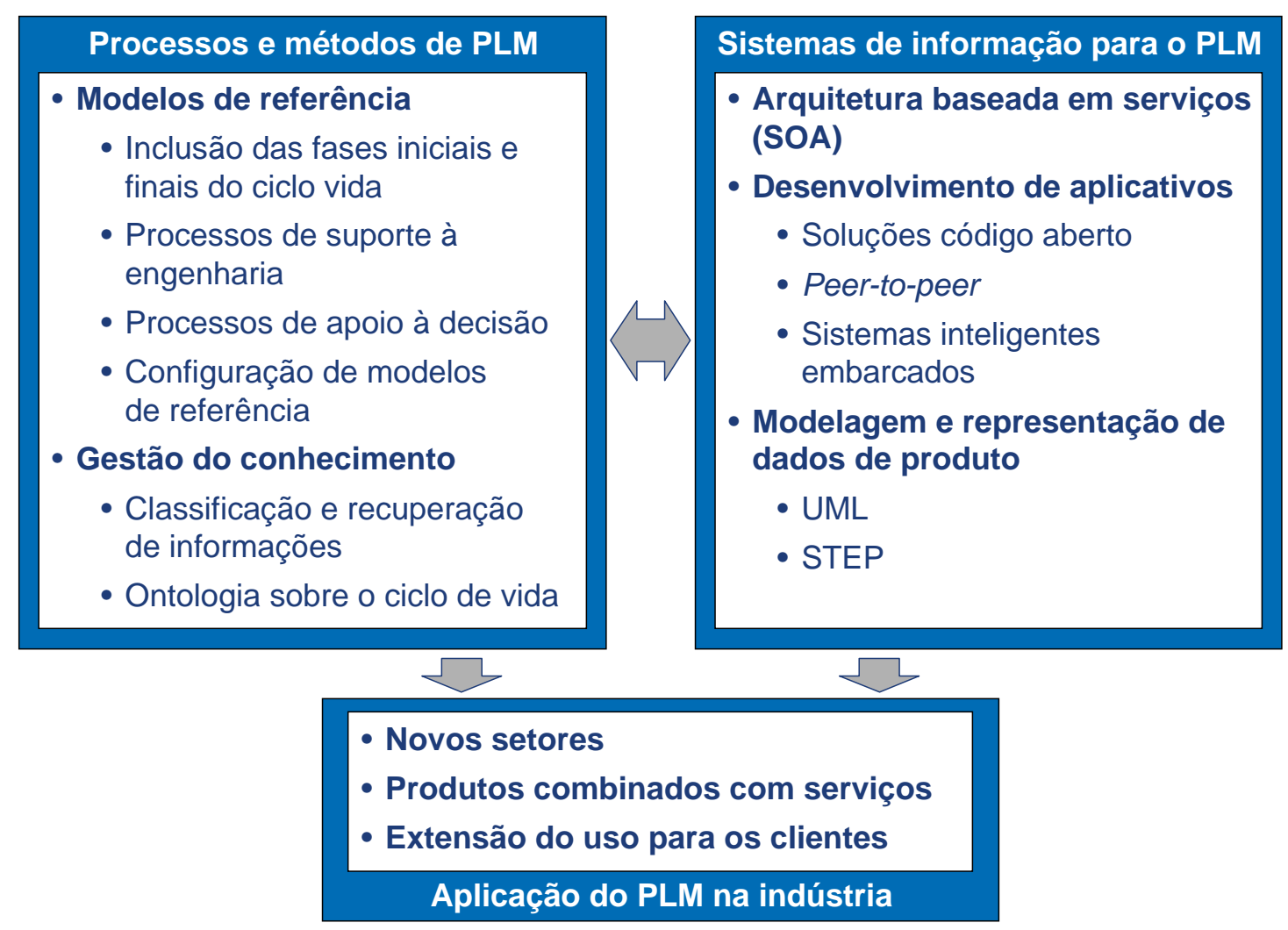

Figura 4. Temas atuais de pesquisa na área de PLM

No grupo de processos e de métodos, uma importante referência é a definição de PLM com base no conceito de processos de negócio (SCHEER et al., 2006, p. 15). Adotando essa perspectiva, alguns trabalhos recentes apresentam modelos de referência para a gestão do ciclo de vida de produtos (ROZENFELD et al., 2006; SCHEER et al., 2006; SCHUH et al., 2008b). O diferencial desses modelos em relação aos modelos anteriores focados no processo de desenvolvimento de produtos é a inclusão de fases iniciais e finais do ciclo de vida.

De acordo com Abramovici (2007, p. 671), os modelos de referência de PLM também estão sendo expandidos para incorporar processos de apoio à engenharia (e.g. gestão da qualidade) e processos de apoio à tomada de decisões sobre produtos (e.g. acompanhamento de métricas de produtos e do status de projetos). Um tema adicional de pesquisa nessa área trata da customização de modelos de referência de acordo com o tipo de empresa (SCHUH; ASSMUS; ZANCUL, 2006).

$\mathrm{Na}$ área da gestão de conhecimentos, as pesquisas recentes abordam o aperfeiçoamento da gestão do conhecimento em projetos de engenharia por meio do emprego de soluções PLM na classificação e recuperação de informações (FELDHUSEN et al., 2004) e o desenvolvimento de uma ontologia para a área (DORI; SHPITALNI, 2005).

No grupo de sistemas de informação para o PLM (Figura 4), um dos temas mais importantes é a aplicação da arquitetura baseada em serviços - Service Oriented Architecture 
(SOA) - para especificar os recursos de TI necessários para o PLM (CIMDATA, 2006). Trabalhos na área de desenvolvimento de aplicativos para PLM abordam o uso de soluções de código aberto e peer-to-peer em ambientes PLM (AZIZ et al., 2005) e a utilização de sistemas inteligentes embarcados para coletar dados durante o uso dos produtos (KIRITSIS; BUFARDI; XIROUCHAKIS, 2003; FATHI et al., 2007). Outra área de pesquisa trata da modelagem de dados de produto utilizando padrões (EYNARD et al., 2004; PEAK et al., 2004).

Por fim, as pesquisas na dimensão de aplicação do PLM na indústria enfatizam a extensão da aplicação da gestão do ciclo de vida para novos setores, para diferentes tipos de produto e para novos usuários. Trabalhos recentes tratam da aplicação do PLM em setores nos quais a abordagem ainda é pouco utilizada, como na indústria química (SCHEER et al., 2006, p. 253) e no setor de confecção têxtil (SEN, 2008, p. 575). Abramovici (2007, p. 669) cita projetos de pesquisa relacionados com a aplicação do PLM no setor de serviços e com a extensão do uso do PLM aos clientes, com a finalidade de se obter sugestões sobre o uso dos produtos ao longo de sua aplicação.

As áreas de pesquisa discutidas acima descrevem os trabalhos científicos mais avançados sobre PLM. Nos parágrafos seguintes, a situação na pesquisa é comparada com a disponibilidade comercial de sistemas PLM e com a aplicação prática do PLM nas empresas.

No mercado de TI, com a evolução ocorrida nos últimos anos, já existe uma ampla gama de soluções para apoiar a gestão do ciclo de vida de produtos. Uma pesquisa recente executada no âmbito deste trabalho de doutorado - identificou, apenas no mercado europeu, 57 sistemas comerciais que apóiam a gestão do ciclo de vida de produtos (Apêndice A). Trata-se de um mercado novo, bastante fragmentado, formado por softwares que evoluíram a partir de sistemas de engenharia ou de sistemas corporativos. Tais características do mercado dificultam realizar a comparação dos sistemas existentes. Deve-se notar também, que os principais sistemas comerciais existentes são proprietários e baseados no paradigma de funcionalidades. Existe um contraste com as tendências atuais de pesquisa na área, que enfatizam a aplicação de softwares abertos e de uma arquitetura baseada em serviços. Tais paradigmas são, teoricamente, mais adequados para atender os requisitos de PLM de integração ampla em ambientes heterogêneos, mas a aplicação comercial ainda é restrita.

Na indústria, mesmo com a disponibilidade de modelos de referência para alguns setores e com o desenvolvimento de novos métodos de gestão do ciclo de vida, observa-se que a maior parte das implantações de PLM ainda está em um estágio inicial. Grande parte das implantações enfatizam apenas aspectos parciais, como a gestão de documentos de 
engenharia, sem a perspectiva ampla necessária para a gestão do ciclo de vida completo. Além disso, muitas empresas restringem a iniciativa de gestão do ciclo de vida somente ao projeto de implantação de sistemas de TI, sem a necessária ênfase na abordagem como um todo. Mesmo com foco em TI, as empresas enfrentam muita dificuldade para avaliar os sistemas PLM existentes e para selecionar a alternativa mais adequada aos seus processos de negócio. Conseqüentemente, muitos projetos atrasam e não produzem os benefícios esperados ${ }^{4}$.

A dimensão da lacuna entre a situação atual na indústria e o estado da arte é analisada por um amplo estudo realizado na Europa (ABRAMOVICI; SCHLUTE, 2004, p. 286). De acordo com o estudo, a aplicação do PLM na indústria automobilística encontra-se três a cinco anos atrasada em relação ao estado da arte. No setor de máquinas e de equipamentos, o atraso adicional é de mais três a cinco anos em relação ao setor automotivo. A lacuna é ainda maior em empresas médias. No Brasil, ainda não existem estudos similares, mas a situação é semelhante em unidades brasileiras de empresas multinacionais ou em grandes empresas nacionais com atuação global.

Um resumo da situação atual da aplicação do PLM é apresentado na Figura 5. Tal figura é organizada nas mesmas três dimensões utilizadas para classificar as pesquisas científicas sobre PLM - processos e métodos de PLM; sistemas de informação para o PLM; aplicação do PLM na indústria. O foco aqui é na situação encontrada na prática em cada uma dessas dimensões.

${ }^{4}$ Informação baseada em dados coletados em cinco estudos de caso conduzidos pelo pesquisador durante o seu estágio de pesquisa de dois anos no WZL da RWTH Aachen. 


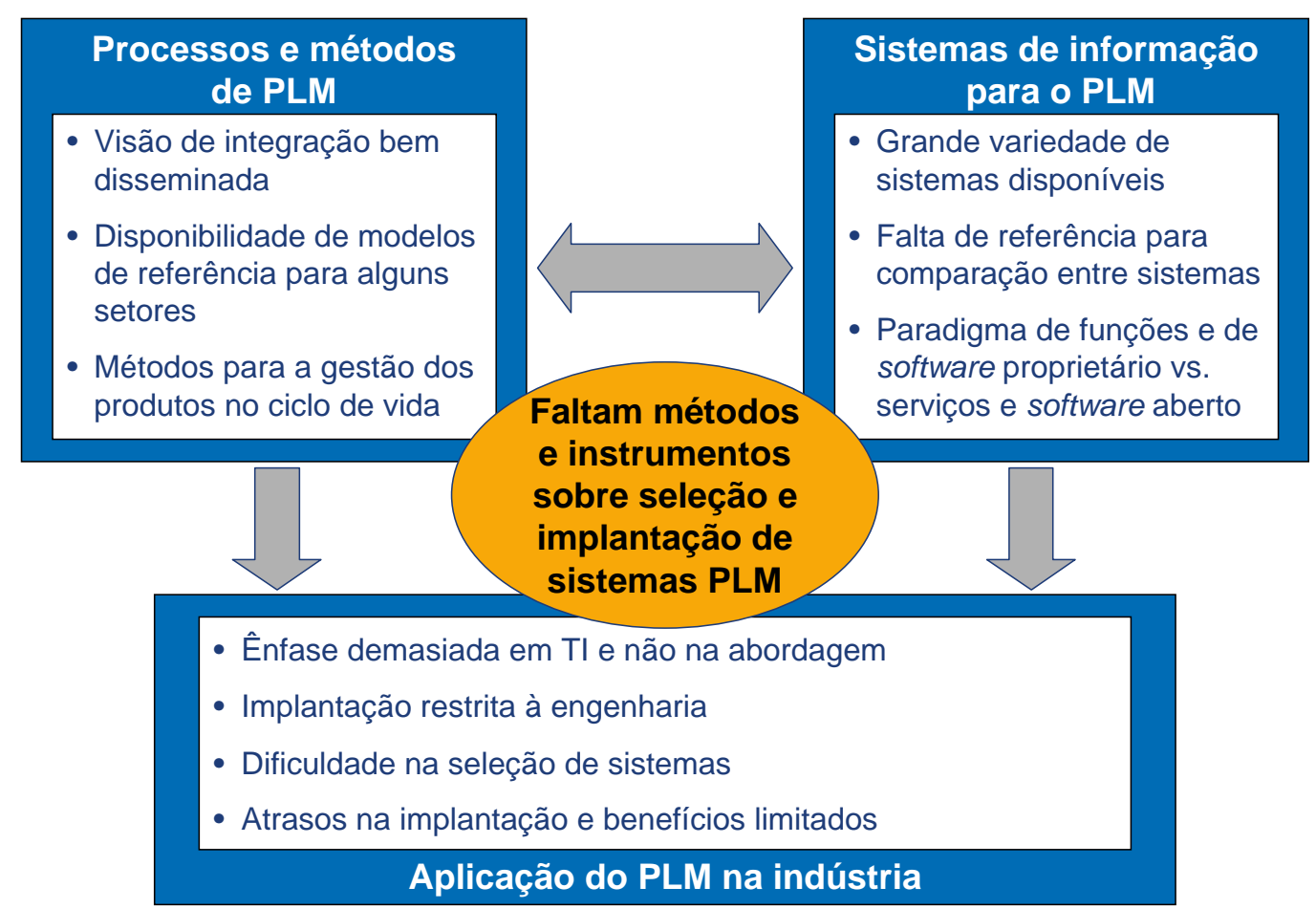

Figura 5. Situação atual da aplicação do PLM na indústria

A análise da situação atual indica que existe um potencial de melhoria na aplicação dos conceitos de gestão do ciclo de vida de produtos nas empresas. Com o apoio de um método e de instrumentos para a seleção de sistemas PLM, as empresas podem identificar o sistema mais adequado para atender aos requisitos de seus processos de negócio. A seleção deve ser realizada considerando a definição ampla da abordagem de PLM, além dos limites tradicionais da engenharia e do desenvolvimento de produtos. A identificação de um sistema adequado aos processos das empresas permitirá reduzir atrasos na implantação e possibilitará a transferência do foco de implantação da TI para a abordagem de PLM. Essa mudança de foco deve resultar em maior aproveitamento dos benefícios da gestão do ciclo de vida de produtos.

\subsection{Perguntas de pesquisa e objetivos do trabalho}

A partir do estado da arte da pesquisa sobre PLM e da situação atual da aplicação do PLM nas empresas, definem-se as seguintes perguntas de pesquisa:

1. Quais as funcionalidades características de sistemas de informação que apóiam a gestão do ciclo de vida de produtos? Como essas funcionalidades podem ser representadas em um modelo de referência de sistemas PLM? 
2. Como modelos de referência de processos de gestão do ciclo de vida de produtos e de sistemas PLM podem ser inter-relacionados?

3. Como as empresas podem selecionar sistemas PLM com base em modelos de referência?

Para responder as perguntas de pesquisa, foram formulados dois objetivos principais:

\section{Definir um modelo de referência de sistemas PLM.}

\section{Desenvolver um método para a seleção de sistemas PLM baseado em modelos de referência.}

\subsection{Delimitação do escopo do trabalho}

O escopo deste trabalho é focado nos setores de manufatura de bens de consumo duráveis e de bens de capital produzidos em série ou configuráveis, dentre os quais pode-se citar, por exemplo, as indústrias aeroespacial, automotiva e de máquinas e equipamentos. Essa delimitação é baseada em três argumentos principais. Primeiro, a abordagem de PLM originou-se e desenvolveu-se mais intensamente nesses setores. Dessa forma, esse é o foco da maior parte das pesquisas e da bibliografia disponível na área. Segundo, o trabalho de doutorado foi desenvolvido no Núcleo de Manufatura Avançada (NUMA) da USP de São Carlos. Durante o doutorado, o pesquisador trabalhou durante dois anos como pesquisador no Werkzeugmaschinenlabor (WZL) da RWTH Aachen, na Alemanha. Ambas instituições atuam na área de manufatura, com ênfase nas indústrias aeroespacial, automotiva e de bens de capital. Essas também são as principais indústrias de especialização do pesquisador. O terceiro e último argumento para a delimitação do trabalho é necessidade de pesquisas nessa área no Brasil (veja o item 1.1 Importância da gestão do ciclo de vida de produtos para a competitividade da indústria no Brasil).

O foco do trabalho na manufatura de bens de consumo duráveis e de bens de capital produzidos em série ou configuráveis é compatível com o tema da pesquisa e com os objetivos propostos. Os setores considerados nesse escopo (aeroespacial, automotivo, bens de capital etc.) têm muitos requisitos semelhantes para a gestão do ciclo de vida de produtos (por exemplo, estruturas de produto complexas, com a possibilidade de definição de produtos variantes). Os sistemas PLM para a manufatura podem ser geralmente customizados para os 
setores citados anteriormente. Dessa forma, é possível definir tanto um modelo de referência genérico como um método de seleção de sistemas PLM com esse enfoque.

O leitor deve levar em consideração o foco deste trabalho ao procurar aplicá-lo a outras indústrias. Mesmo que vários conceitos aqui discutidos também sejam válidos em outras indústrias, o conteúdo precisará ser adaptado no caso de aplicação além da delimitação definida.

\subsection{Organização deste texto}

Este texto está estruturado em dez capítulos, organizados de acordo com a seqüência ilustrada na Figura 6 abaixo.

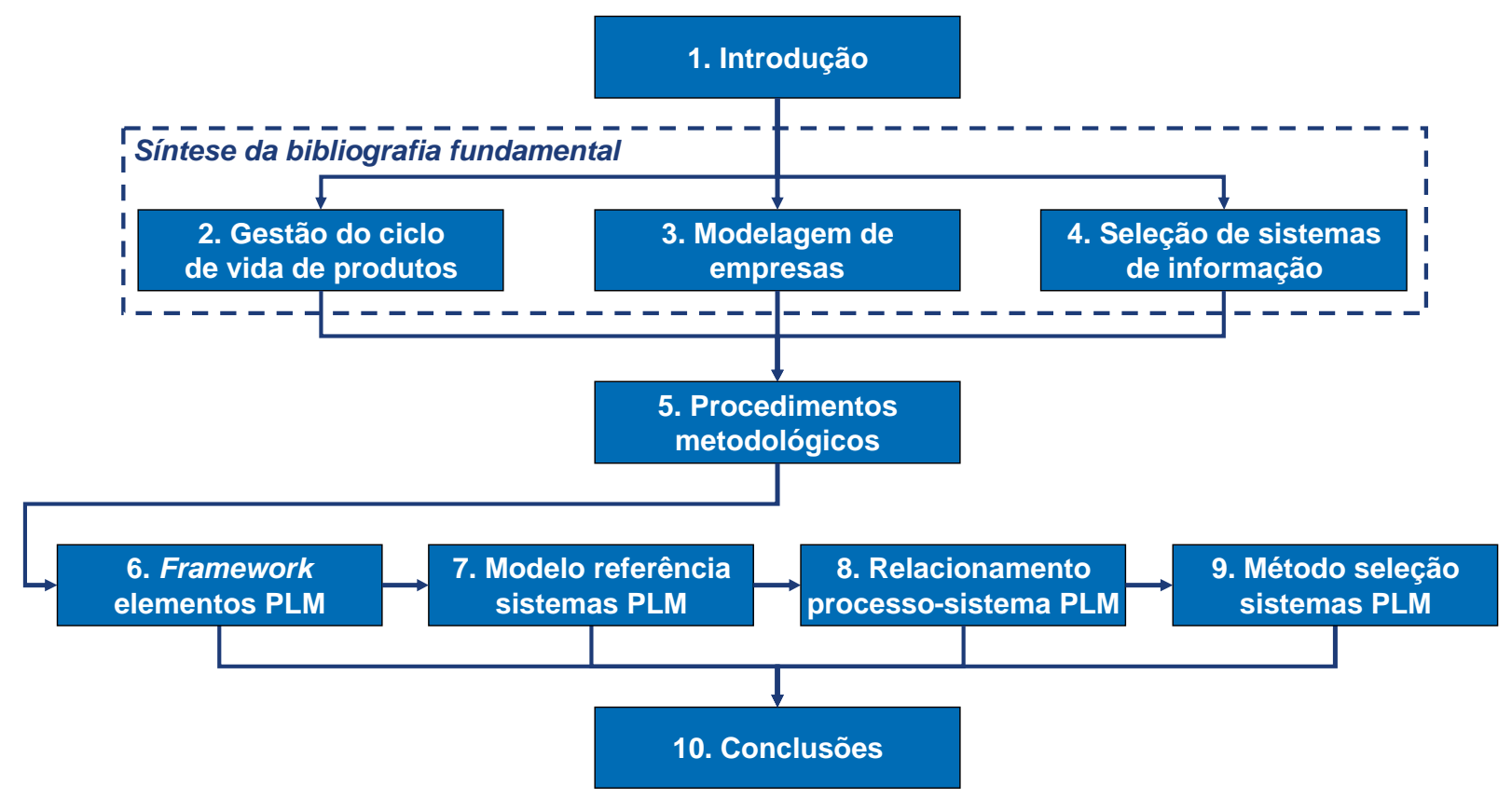

Figura 6. Organização do texto

No capítulo 1 (Introdução), são apresentados o contexto e os objetivos do trabalho. O contexto compreende a discussão da importância do PLM para a indústria no Brasil e a análise da situação atual da pesquisa e da aplicação do PLM em empresas. O entendimento da situação atual permite a identificação de uma lacuna de pesquisa - faltam trabalhos e instrumentos sobre a seleção e a implantação de sistemas PLM. A fim de preencher essa lacuna, são detalhadas as perguntas de pesquisa e são definidos os objetivos do trabalho.

A síntese da bibliografia fundamental está organizada em três capítulos (capítulos, 2, 3 e 4). No capítulo 2, são apresentados conceitos de gestão do ciclo de vida de produtos, tema principal do trabalho. No capítulo 3, são discutidos conceitos e métodos de modelagem de empresas. Tais métodos são necessários para a construção de modelos de referência da gestão 
do ciclo de vida de produtos. Por fim, no capítulo 4, são analisados os atuais métodos para a seleção de sistemas de informação. Deve-se ressaltar que, na síntese da bibliografia fundamental, é dada maior ênfase ao capítulo 2, pois se pretende que este texto seja uma referência na área de gestão de ciclo de vida de produtos no Brasil, dada a carência de obras na área. Já os capítulos 3 e 4 são apresentados de forma sucinta, enfocando apenas a base teórica necessária para embasar o trabalho.

O método de pesquisa, incluindo as técnicas de coleta de dados aplicadas no trabalho, é descrito no capítulo 5. Nesse capítulo, as fases da pesquisa são apresentadas de forma detalhada.

Em seguida, os resultados do trabalho são apresentados em quatro capítulos (capítulos 6, 7, 8 e 9). O primeiro resultado do trabalho, apresentado no capítulo 6, é um framework teórico que inter-relaciona de forma conceitual os elementos envolvidos na implantação do PLM (modelos de referência do processo, recursos de TI, conhecimentos, entre outros). O framework indica a possibilidade de utilização de modelos de referência de sistemas para relacionar modelos do processo com sistemas de TI específicos disponíveis comercialmente. Nesse sentido, o segundo resultado do trabalho, apresentado no capítulo 7, é um modelo de referência de sistemas PLM. Tal modelo de sistemas PLM é relacionado com um modelo de referência de processos de PLM. O resultado é um modelo de referência único e coeso que, para cada atividade do processo, indica as funcionalidades de TI necessárias dadas pelo modelo de referência dos sistemas PLM (capítulo 8). Por fim, no capítulo 9 é apresentado um método para a seleção de sistemas PLM baseado em modelos de referência.

O texto é encerrado com o capítulo 10, no qual são discutidas as conclusões e apresentadas as sugestões para trabalhos futuros na área de pesquisa. 


\section{GESTÃO DO CICLO DE VIDA DE PRODUTOS: DEFINIÇÕES, MODELOS DE REFERÊNCIA E SISTEMAS DE INFORMAÇÃO}

A síntese da bibliografia fundamental está organizada em três capítulos, dedicados a cada uma das principais áreas do conhecimento que constituem a base conceitual deste trabalho: gestão do ciclo de vida de produtos, modelagem de empresas, seleção de sistemas de informação (veja Figura 7).

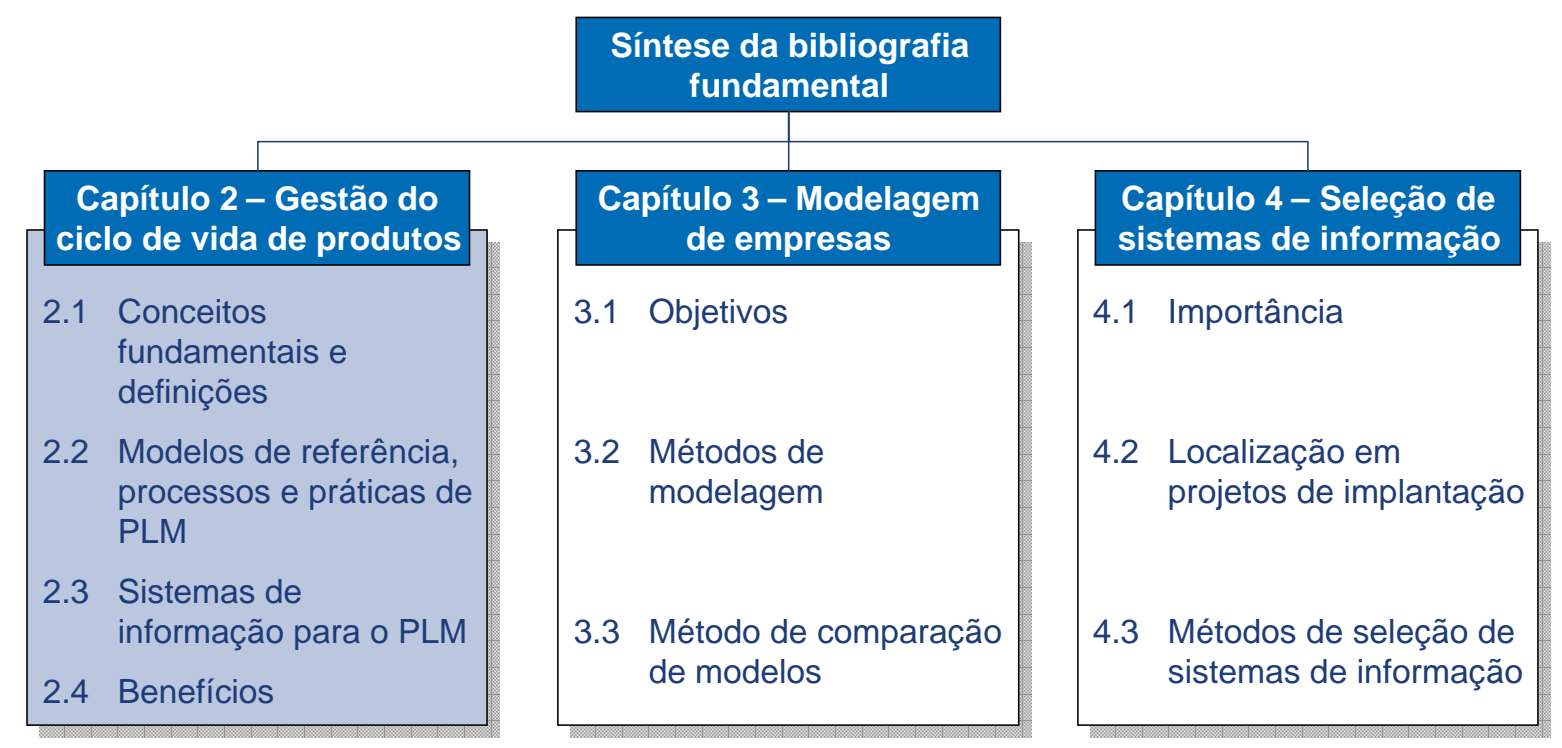

Figura 7. Capítulos da síntese da bibliografia fundamental

Este capítulo se refere à gestão do ciclo de vida de produtos. A primeira parte do capítulo aborda os conceitos fundamentais e as definições necessárias para a compreensão da abordagem de PLM (item 2.1). Com base na definição de PLM, discute-se o emprego do paradigma de processos de negócio ao PLM e apresentam-se modelos de referência relacionados à gestão do ciclo de vida de produtos (item 2.2). Os processos de PLM podem ser apoiados por sistemas de informação analisados na penúltima parte do capítulo (item 2.3). O capítulo é finalizado com a discussão dos benefícios relacionados à adoção do PLM (item 2.4).

A organização desse capítulo nos quatro itens citados acima segue a lógica das fases de um projeto de melhoria dos processos de negócio (SCHEER et al., 2006, p. 27). O entendimento do conceito de PLM serve de base para definir os objetivos que a empresa tem ao realizar a gestão do ciclo de vida de produtos. Essa primeira fase pode ser chamada de estratégia de PLM. A partir da definição da estratégia de PLM, são desenhados os processos de negócio. Os processos especificam os requisitos para a seleção e implementação dos 
sistemas de informação que devem apoiá-los. Fechando o ciclo, a medição dos resultados indica os benefícios alcançados e as melhorias necessárias (Figura 8).

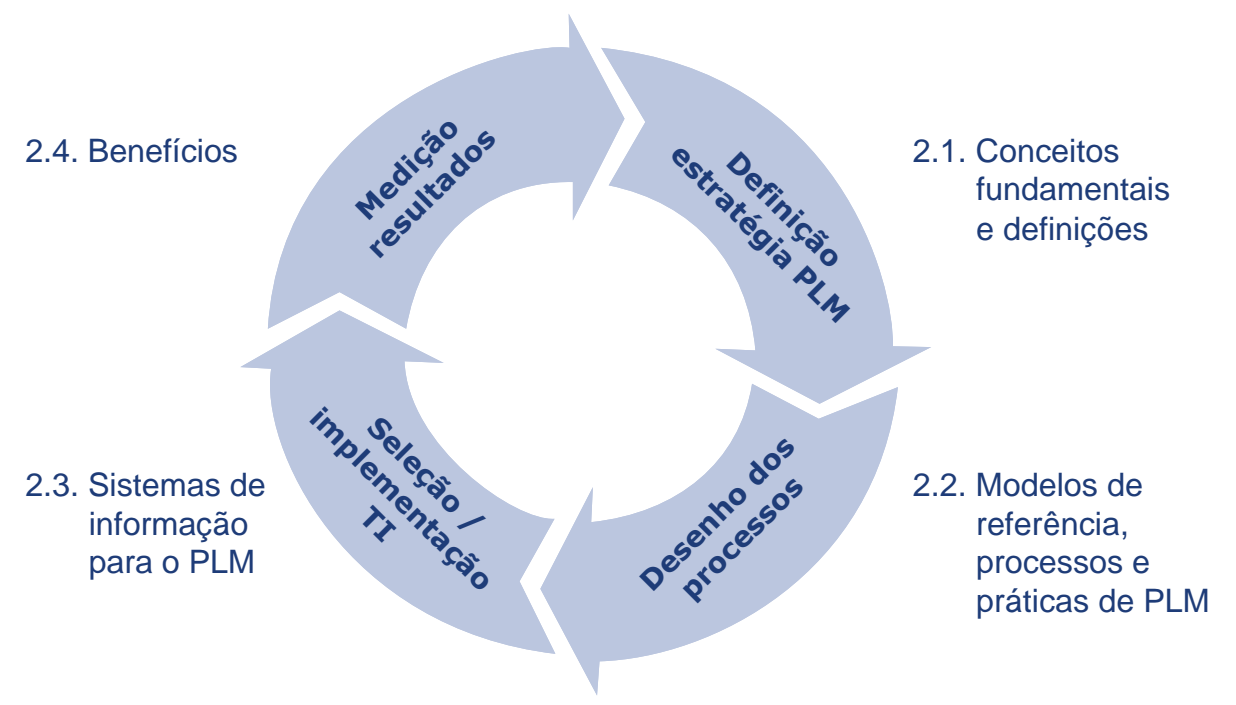

Figura 8. Fases típicas da melhoria de processos de negócio e organização do capítulo

A Figura 8 apresenta as fases típicas de iniciativas de melhoria de processos de negócio relacionadas com a organização do capítulo, iniciado, a seguir, com a discussão dos conceitos fundamentais e da definição de PLM.

\subsection{Conceitos fundamentais para a gestão do ciclo de vida de produtos}

Esta primeira parte da síntese da bibliografia fundamental aborda os conceitos básicos necessários para a compreensão da abordagem de gestão do ciclo de vida de produtos. O ponto de partida é o entendimento das fases pelas quais um produto passa, desde a sua concepção até o seu descarte (subitem 2.1.1). Em seguida, são discutidas as diversas visões empregadas hoje na gestão do ciclo de vida de produtos (subitem 2.1.2). Uma das visões de PLM bastante difundida atualmente é a visão empregada por fornecedores de sistemas de informação. É necessário, então, discutir a definição de PLM utilizada neste trabalho (subitem 2.1.3) e as diferenças entre o PLM como abordagem de gestão e como recurso de tecnologia da informação (subitem 2.1.4). Por fim, apresenta-se a evolução histórica dos conceitos e dos sistemas de gestão de dados de produto até chegar ao atual estágio de desenvolvimento do PLM (subitem 2.1.5).

\subsubsection{Fases do ciclo de vida de produtos}

O ciclo de vida de um produto compreende todas as fases pelas quais o produto passa, desde a sua concepção, até a destinação final após o seu uso. De maneira genérica, o ciclo de 
vida pode ser organizado em quatro macrofases típicas: desenvolvimento do produto, produção, uso do produto em conjunto com serviços agregados, descarte (WESTKAMPER; ALTING; ARNDT, 2000, p. 505; REBITZER et al., 2004, p. 702). Cada uma dessas quatro macrofases do ciclo de vida é composta por fases mais específicas, como aquelas representadas pelas setas em branco, na Figura 9.

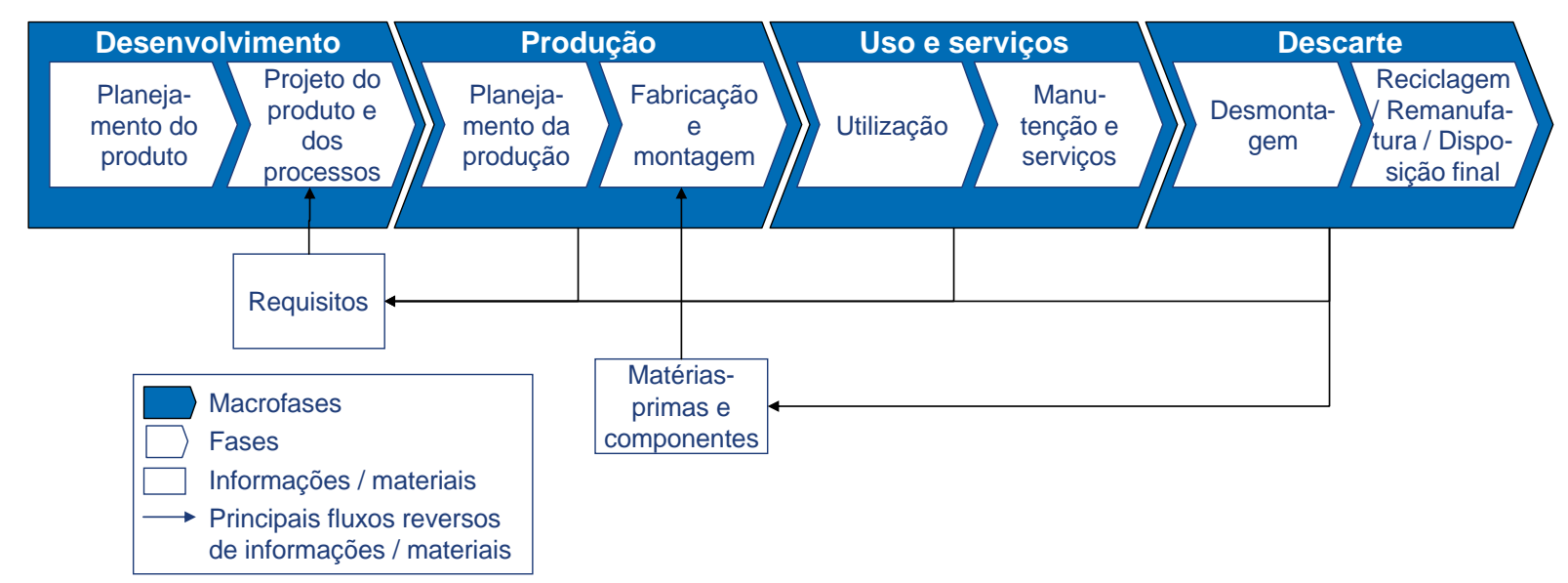

Figura 9. Fases típicas do ciclo de vida de um produto

O ciclo de vida é iniciado a partir da análise de oportunidades de mercado, na fase de planejamento do produto. Nessa fase, o portfólio de produtos e de projetos é definido levando em consideração o posicionamento estratégico da empresa (ROZENFELD et al., 2006, p. 4546). Os produtos selecionados pela empresa passam para a fase de projeto de engenharia e dos processos de manufatura. Tal fase é de fundamental importância, pois nela são definidas características do produto que têm impacto ao longo de todo o ciclo de vida. De acordo com Asiedu e Gu (1998, p. 883), o projeto influencia entre 70\% e 85\% do custo total do produto. Da mesma forma, as decisões de projeto, como a seleção de materiais e a definição de processos de produção, determinam cerca de 70\% do impacto ambiental do produto ao longo de todo o seu ciclo de vida (REBITZER et al., 2004, p. 702). Por esse motivo, é importante que o projeto considere os requisitos das demais fases do ciclo de vida (Figura 9).

A produção é iniciada com o planejamento do uso dos recursos de manufatura. De acordo com esse planejamento, o produto é fabricado e montado. Ao final da macrofase de produção, o produto pode ser entregue ao cliente que irá utilizá-lo.

O uso de um produto envolve, em muitos casos, a realização de serviços, como a manutenção, a substituição de peças e a atualização de softwares. O tempo em que o produto permanece em uso varia muito dependendo da categoria.

Após o uso, o produto é descartado. O descarte envolve a desmontagem. Peças recicláveis ou que possam ser remanufaturadas são reaproveitadas, enquanto que os demais 
itens são destinados para disposição final. O ciclo de vida é concluído com o fluxo de informações e de materiais das fases finais para as fases iniciais (Figura 9).

Ao longo das fases do ciclo de vida descritas anteriormente é gerada uma grande quantidade de informações que precisam ser gerenciadas. Além da gestão das informações, as empresas precisam gerenciar o desempenho dos produtos ao longo do ciclo de vida em relação ao potencial de mercado, aos custos e ao impacto no meio ambiente. Essas várias perspectivas, existentes atualmente de gestão dos diferentes aspectos do ciclo de vida de produtos, são discutidas a seguir.

\subsubsection{Visões existentes para a gestão do ciclo de vida}

A gestão do ciclo de vida é um tema de pesquisa abrangente, estudado por disciplinas da engenharia, da administração de empresas e da tecnologia de informação. A abrangência do tema e a variedade de disciplinas envolvidas resultaram no desenvolvimento de diversas visões sobre o gerenciamento do ciclo de vida de produtos. Dentre todos os enfoques possíveis sobre o tema, cinco visões principais se destacam atualmente pela quantidade de publicações acadêmicas: marketing, engenharia de desenvolvimento de produtos, gestão ambiental, gestão de custos e gestão de dados de produto.

Cada uma dessas visões possui um foco de atuação diferenciado. Ou seja, cada uma das visões se propõe a resolver problemas distintos. Por exemplo, na visão do marketing, uma das principais questões é a otimização da curva de vendas dos produtos, desde a introdução até a retirada do mercado (GOLDER; TELLIS, 2004, p. 208). Na visão da gestão ambiental, as questões principais são a mensuração e a redução dos impactos ambientais ao longo do ciclo de vida (REBITZER et al., 2004, p. 702). Dado o enfoque diferenciado, cada visão atua em macrofases distintas do ciclo de vida e possui um conjunto próprio de abordagens, de métodos e de ferramentas (Figura 10). 


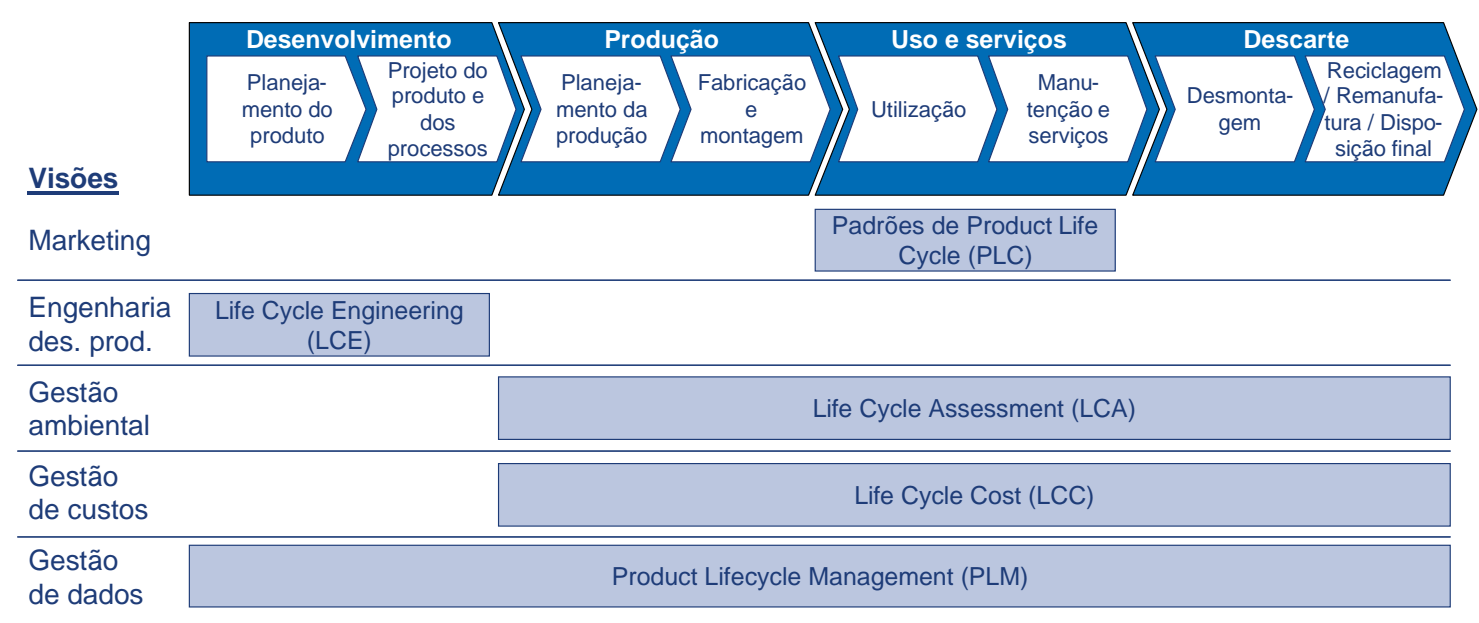

Abordagens, métodos e ferramentas

Figura 10. Visões sobre a gestão do ciclo de vida de produtos (adaptado de WESTKAMPER; ALTING; ARNDT, 2000, p. 507)

O marketing trata do ciclo de vida após a introdução do produto no mercado, ou seja, o foco é na macrofase de uso dos produtos. São geralmente considerados quatro estágios do ciclo de vida, relacionados ao padrão de vendas no mercado (BAYUS, 1994, p. 302): introdução (do início da comercialização até o início do crescimento rápido nas vendas), crescimento (período de rápido crescimento nas vendas), maturidade (vendas desaceleram e se estabilizam) e declínio (período de vendas em queda até a retirada do mercado) ${ }^{5}$. Considerando essas quatro fases, as principais pesquisas com a visão do marketing tratam da modelagem dos padrões de vendas e da generalização desses padrões para diferentes setores da indústria (GOLDER; TELLIS, 2004, p. 207).

Na visão da engenharia, o foco é no desenvolvimento de produtos que considerem os requisitos de desempenho, de impacto no meio-ambiente e de custos das fases posteriores do ciclo de vida (WANYAMA et al., 2003, p. 307). A abordagem de projetos aplicada nesse sentido é chamada de Life Cycle Engineering (LCE). Essa abordagem emprega vários métodos de projeto, que têm como objetivo considerar, durante o desenvolvimento do produto, as questões críticas que terão impacto somente mais tarde, i.e. em outras fases posteriores do ciclo de vida. Tais métodos de projeto ficaram conhecidos pela sigla DFX (Design for $X$ ), na qual a letra $\mathrm{X}$ é alterada conforme o método específico. Na Figura 11 são

${ }^{5}$ O termo comumente utilizado na área de marketing para designar esses quatro estágios é Product Life Cycle (PLC). 
listados alguns exemplos desses métodos, como o DFE (Design for Environment) ${ }^{6}$, o DFES (Design for Energy Saving), o DFD (Design for Disassembly) ${ }^{7}$.

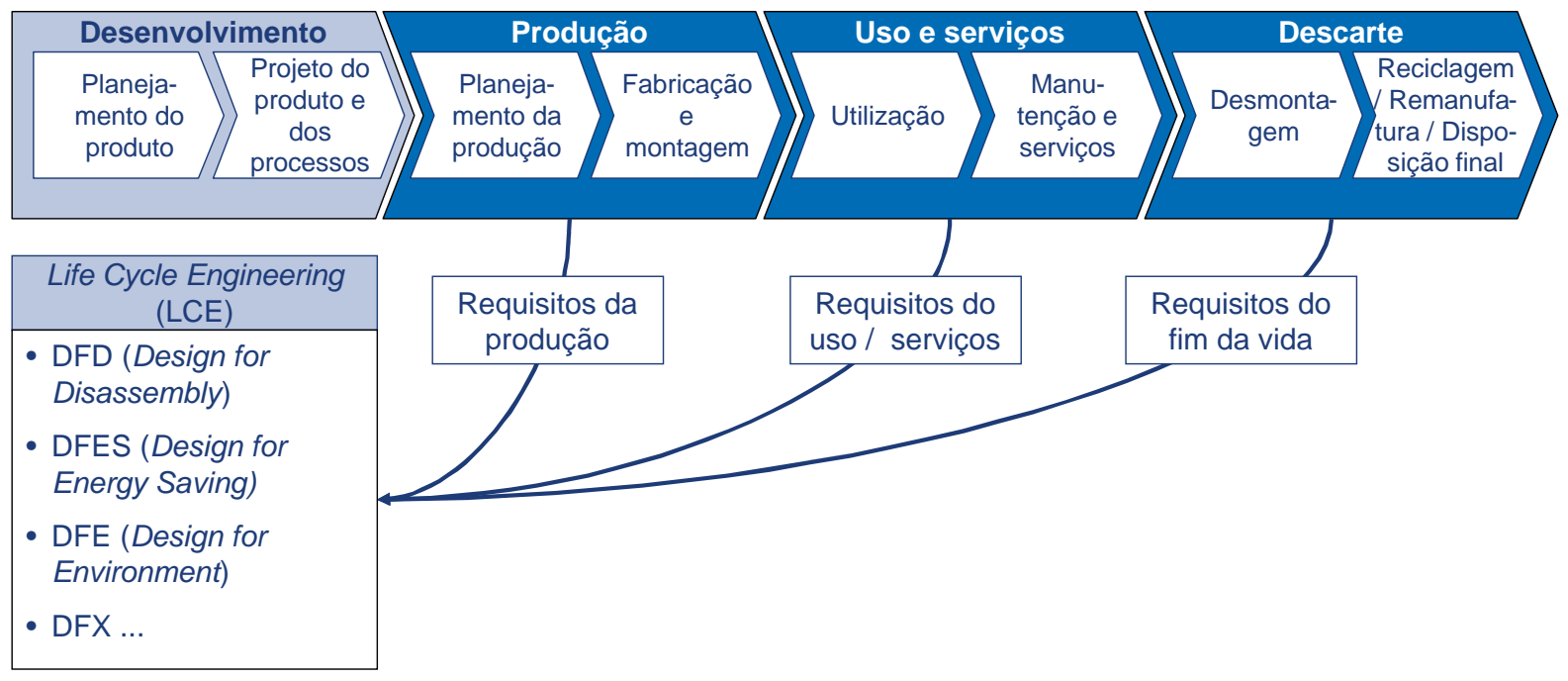

Figura 11. Definição de Life Cycle Engineering e métodos empregados

Na visão da gestão ambiental, a ênfase é dada à estimativa e à avaliação dos impactos ambientais que podem ser atribuídos a um produto ao longo de todo o seu ciclo de vida consumo de energia, emissões, entre outros aspectos. O método empregado para medir o impacto ambiental ao longo do ciclo de vida é conhecido por Life Cycle Assessment (LCA).

Na aplicação do LCA, são consideradas principalmente as macrofases de produção, de uso e de descarte dos produtos (Figura 10). O desenvolvimento é geralmente desconsiderado, pois nele os impactos no meio ambiente são comparativamente muito menores. No entanto, deve-se observar que as decisões realizadas no desenvolvimento determinam grande parte dos impactos ambientais nas fases seguintes do ciclo de vida (REBITZER et al., 2004, p. 702). Isso evidencia a inter-relação entre os métodos de Life Cycle Engineering e de Life Cycle Assessment. Segundo Alting (1995, p. 570), Life Cycle Engineering é a abordagem de projeto do ciclo de vida que direciona as escolhas sobre o conceito do produto, a estrutura, os materiais e os processos. Já a Life Cycle Assessment é um método que indica as conseqüências dessas escolhas no meio ambiente e no uso de recursos.

${ }^{6}$ Para uma discussão detalhada sobre DFE veja: WESTKAMPER, E.; ALTING, L.; ARNDT, G. Life cycle management and assessment: Approaches and visions towards sustainable manufacturing. CIRP AnnalsManufacturing Technology, 49, 2, 501-522, 2000.

${ }^{7}$ Para uma discussão detalhada sobre DFES e DFD ver: ALTING, L. Life Cycle Engineering and Design. Ibid.44, 569-580, 1995. 
A gestão de custos tem semelhanças com a gestão ambiental. Enquanto o desenvolvimento determina entre 70\% e 85\% do custo total do produto (ASIEDU; GU, 1998, p. 883), a maior parte dos custos é incorrida, efetivamente, nas fases posteriores do ciclo de vida. Dessa forma, é importante prover os projetistas de informações sobre custos para direcionar as decisões de engenharia. Nesse sentido, são empregados métodos de análise do Life Cycle Cost (LCC), que possibilitam a estimativa do custo total com o desenvolvimento, a produção, o uso e o descarte de produtos (ASIEDU; GU, 1998, p. 902).

Por fim, na visão da gestão de dados, a ênfase principal é no apoio à criação, à gestão, à disseminação e ao uso das informações de produtos ao longo do ciclo de vida (CIMDATA, 2002, p. 1). Dentre as informações de produtos geradas no ciclo de vida estão: listas de requisitos, estruturas de produtos, modelos em CAD (Computer Aided Design), planos de processo de fabricação, programas de controle numérico, resultados de manutenções, entre outros (Figura 12).

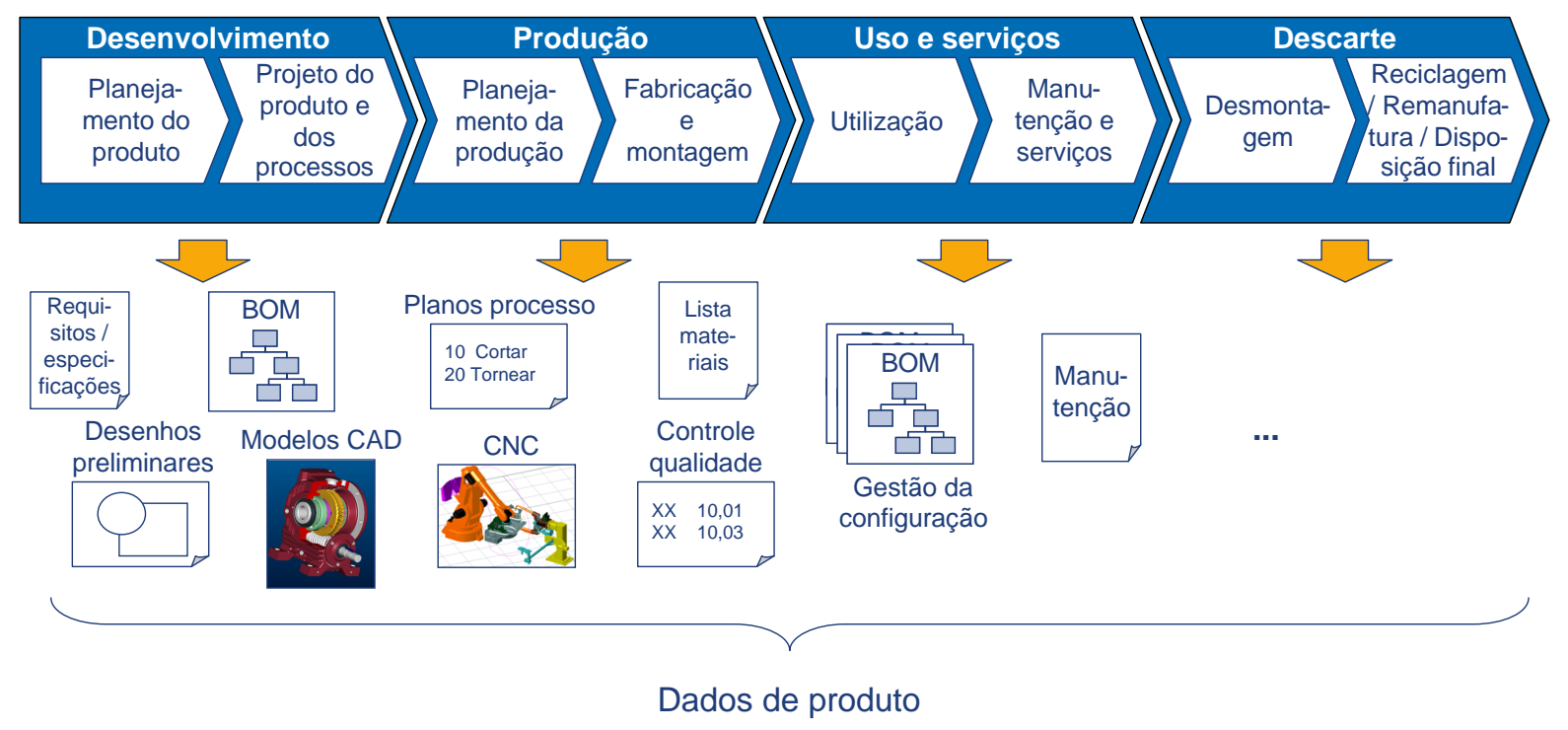

Figura 12. Informações geradas ao longo do ciclo de vida de produtos (adaptado de BOOS; ZANCUL, 2006, p. 785)

Idealmente, tais informações precisam estar atualizadas e disponíveis para acesso ao longo de todo o ciclo de vida. Isso evidencia a necessidade de gestão eficiente das informações do ciclo de vida. Nessa área, o termo PLM vêm sendo utilizado para designar tanto a abordagem como as soluções técnicas de sistemas de informação para a gestão de dados de produtos (MA; FUH, 2008, p. 107).

Dentre as cinco visões principais sobre a gestão do ciclo de vida discutidas anteriormente (marketing, engenharia de desenvolvimento de produtos, gestão ambiental, gestão de custos e gestão de dados de produto), dado o escopo deste trabalho, é adotada a 
visão da gestão de dados de produto. Considerando essa visão, a definição de gestão do ciclo de vida de produtos é discutida no próximo subitem.

\subsubsection{Definição de gestão do ciclo de vida de produtos}

A definição atual de diversos autores para PLM é semelhante, enfatizando a gestão integrada das informações e dos processos relacionados aos produtos no ciclo de vida. A maior parte das definições destaca também que o PLM não é limitado apenas aos sistemas de informação, mas deve ser entendido como uma abordagem ampla de integração e de gestão dos processos, que requer sistemas de informação para a sua implantação. Ou seja, hoje existe praticamente um consenso sobre a nomenclatura, a definição e a abrangência da gestão do ciclo de vida de produtos. Tal consenso pode ser verificado analisando as definições dos principais autores na área.

Uma das definições de PLM mais citadas é a da empresa de pesquisa de mercado e de consultoria CIMData. O CIMData (2002, p. 1) define PLM como uma abordagem estratégica de negócios que aplica um conjunto de soluções para apoiar a criação, a gestão, a disseminação e o uso de informações dos produtos de forma colaborativa na empresa estendida, desde o conceito inicial até o fim do ciclo de vida, integrando pessoas, processos, sistemas e informações. CIMData (2008b) destaca que o PLM não é somente tecnologia, mas deve ser considerado principalmente uma abordagem de negócios para solucionar o problema de gestão das informações de produto.

De forma semelhante, Saaksvuori e Immonen (2004, p.3-4) também definem o PLM como um conceito de gestão. De acordo com esses autores, o PLM é um conceito para a gestão dos processos e para o controle das informações relacionadas aos produtos ao longo de todo o ciclo de vida.

Partindo da definição de PLM como um conceito, Scheer et al. (2006, p.13) enfatizam a aplicação da visão de processos de negócio à gestão do ciclo de vida. De acordo com os autores, o objetivo do PLM é a configuração otimizada dos processos, especialmente do processo de desenvolvimento de produtos, assim como a garantia de disponibilidade das informações do produto ao longo do ciclo de vida.

O papel da TI para viabilizar o PLM é destacado por Arnold et al. (2005, p. 13). Os autores definem PLM como um conceito de integração, baseado em TI, para a organização das informações sobre os produtos e sobre os seus processos, ao longo de todo o ciclo de vida. A importância fundamental da TI no PLM também é enfatizada por Ma e Fuh (2008, p. 107). Segundo esses autores, o PLM é uma abordagem abrangente de gestão de empresas baseada 
em um sistema de informação integrado, que pode atender aos requisitos de informação de produtos e de processos em um ambiente dinâmico e colaborativo.

Em resumo, as definições de gestão do ciclo de vida citadas anteriormente ressaltam os seguintes aspectos:

$\Psi$ PLM é uma abordagem de gestão integrada relacionada com os produtos;

- Suporta os processos de negócio relacionados aos produtos;

- Apóia a gestão de informações de produtos;

$\Psi$ PLM é aplicado do início ao fim do ciclo de vida de produtos para apoiar a colaboração na empresa estendida;

$\Psi$ PLM requer infra-estrutura de TI para sua implantação efetiva.

Com base nesse resumo, optou-se por formular uma definição de PLM para este trabalho, considerando os principais aspectos do PLM apontados por vários autores. A definição apresentada aqui é portanto uma generalização das definições citadas anteriormente (Figura 13).

\title{
PLM...
}

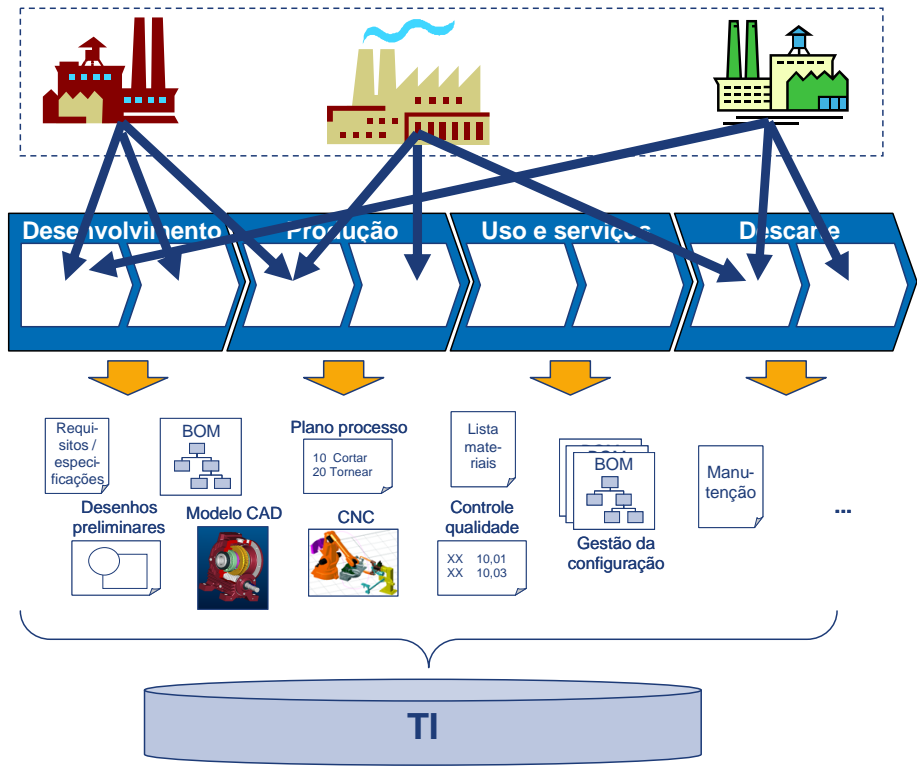
e.. apóia a colaboração na
empresa estendida...

... do início ao fim do ciclo de vida,

suportando os processos de negócio ...

... e a gestão de informações de produtos...

Definição

\begin{abstract}
A gestão do ciclo de vida de produtos (Product Lifecycle Management) é uma abordagem para a gestão integrada dos processos de negócio e das informações relacionadas aos produtos. Tal abordagem requer a utilização de sistemas de informação integrados para apoiar a colaboração na empresa estendida, ao longo de todo o ciclo de vida.
\end{abstract}

Figura 13. Definição de gestão do ciclo de vida de produtos 
A abordagem de PLM inova ao definir o produto como um elemento central que pode ser usado para agregar diversas informações da empresa e da cadeia de suprimentos. Além disso, o PLM define o ciclo de vida completo como a dimensão de tempo mais ampla para a integração dessas informações. As informações atualizadas podem ser acessadas diretamente por todas as pessoas autorizadas, a qualquer momento. Isso possibilita, por exemplo, reduzir o tempo necessário para desenvolver novos produtos com menores custos.

Como explicado, a implantação da abordagem de gestão do ciclo de vida de produtos na prática, nas empresas, está geralmente vinculada à adoção de um conjunto de ferramentas de TI. Dessa forma, é necessário distinguir a definição da abordagem de PLM da definição de PLM como um sistema de informação.

\subsubsection{Delimitação entre o PLM como abordagem e como sistema de informação}

Conforme discutido no subitem anterior, a maioria dos autores define gestão do ciclo de vida de produtos, ou PLM, como uma abordagem de negócios, que geralmente requer a aplicação de sistemas de informação para a sua implantação. Alguns autores são bastante enfáticos ao defender que PLM é uma abordagem que não pode ser confundida somente com sistemas de informação. Abramovici e Schulte (2004, p. 283), afirmam que PLM não é um sistema de informação, mas um conceito amplo para designar a integração de diversas abordagens de gestão e a integração de vários sistemas de informação na área de engenharia. Essa é a definição de PLM defendida na literatura acadêmica.

Por outro lado, com a consolidação da sigla PLM como referência de integração na engenharia - um objetivo perseguido há muitos anos - passou a ser interessante, do ponto de vista de marketing no mercado de software, vincular sistemas de TI na área de gestão de dados de produto ao PLM. Assim, vários fornecedores de TI passaram a utilizar o termo sistemas PLM para designar a sua oferta de soluções nessa área.

Uma pesquisa realizada no âmbito deste trabalho de doutorado, com fornecedores de sistemas de gestão de dados de produto na Europa, indicou que um terço dos fornecedores utiliza o termo sistema PLM para denominar o seu software na área de gestão de dados de produto (ASSMUS et al., 2006, p. 17). É o caso, por exemplo, da solução da SAP $^{8}$ nessa área, chamada de SAP Product Lifecycle Management (SAP, 2008a). Como os fornecedores de software têm grande influência como formadores de opinião para empresas industriais, o

\footnotetext{
${ }^{8}$ SAP é um importante fornecedor de softwares de gestão empresarial
} 
termo sistema PLM passou a ser utilizado correntemente na indústria. Ou seja, apesar das restrições da literatura acadêmica, na prática, a sigla PLM passou a ser utilizada para designar também sistemas de informação.

Como PLM é usado para se referir tanto à abordagem como aos sistemas de informação, é importante distinguir quando o termo se refere a cada um desses dois significados. Por exemplo, a implantação do PLM (abordagem) envolve mudanças de processos e a revisão de conceitos utilizados na empresa (como a revisão do sistema de classificação de itens, entre outros). Já a implantação do PLM (solução de TI) enfatiza a instalação de um novo sistema de informação. Isso pode exigir a realização de mudanças nos processos, mas a ênfase maior é em possibilitar a utilização de novos recursos de TI.

A distinção entre os significados de PLM é relevante no contexto deste trabalho, uma vez que se busca definir aqui a relação entre a abordagem e os sistemas de informação de gestão do ciclo de vida de produtos. Por isso, é importante adotar uma definição e uma nomenclatura que permita distinguir o conceito de PLM das soluções de TI ao longo do texto. Nesse sentido, optou-se por utilizar como base as definições acadêmicas e também considerar os usos observados do termo PLM nos fornecedores de software e na indústria.

Assim, neste trabalho, utiliza-se o termo gestão do ciclo de vida de produtos, ou PLM, para designar a abordagem de gestão integrada dos processos de negócio e dos dados de produto, conforme a definição acadêmica discutida no subitem anterior (subitem 2.1.3). Os termos sistema PLM e solução PLM, por sua vez, referem-se aos sistemas de informação necessários para viabilizar a adoção da abordagem de gestão do ciclo de vida (Figura 14).

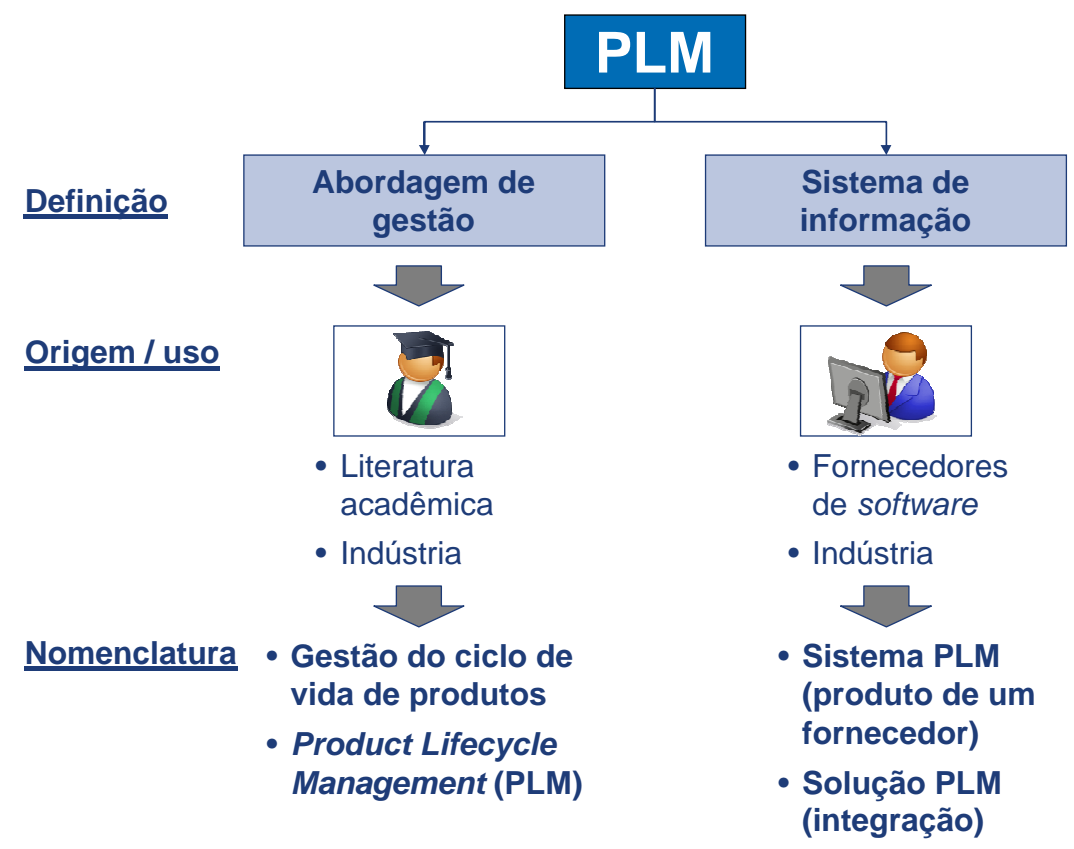

Figura 14. Distinção entre PLM como abordagem e como sistema de informação 
Na nomenclatura adotada para o trabalho, o termo sistema PLM é utilizado para designar um software de gestão de dados de produto de um fornecedor específico (sistema monolítico). Por outro lado, o termo solução PLM refere-se à integração de diversas classes de sistemas para compor uma solução completa para apoiar a gestão do ciclo de vida de produtos (Figura 14). A integração de vários sistemas geralmente é necessária para atender aos requisitos de gestão de dados de produto ao longo de todo o ciclo de vida. Em uma integração desse tipo, em regra, o sistema PLM tem um papel central (veja item 2.3).

Considerando a delimitação entre a abordagem e os sistemas aqui apresentada, no próximo subitem discute-se como o conceito de gestão do ciclo de vida e os sistemas PLM evoluíram concomitantemente ao longo dos últimos anos até chegar ao seu estágio atual.

\subsubsection{Evolução histórica da gestão do ciclo de vida de produtos}

O atual estágio de desenvolvimento da gestão do ciclo de vida de produtos é resultado da evolução das abordagens de gestão de dados de produtos e dos avanços da tecnologia da informação nos últimos vinte anos.

A gestão do ciclo de vida de produtos baseia-se nos conceitos de integração definidos originalmente nos anos 80 pela abordagem conhecida como Computer Integrated Manufacturing (CIM) ou manufatura integrada por computador (ABRAMOVICI; SCHLUTE, 2004, p. 278-282; SCHEER et al., 2006, p. 8-10). O CIM introduziu a visão de integração dos dados de engenharia com os dados de produção. O objetivo é possibilitar o fluxo de informações entre os departamentos de uma empresa, integrando os sistemas de informação por meio de bases de dados compartilhadas (SCHEER, 1987). Apesar dos grandes benefícios potenciais da integração, as tentativas iniciais para implementar o CIM não atingiram os resultados esperados. Isso por causa de uma série de limitações técnicas e organizacionais existentes na época (ABRAMOVICI; SCHLUTE, 2004, p. 279-280) ${ }^{9}$.

O CIM, na sua concepção mais ampla, não funcionou nas empresas naquele momento. Entretanto, o seu conceito fundamental - a visão de integração - serviu de referência para o desenvolvimento futuro de diversas abordagens de gestão e de novos sistemas de

\footnotetext{
${ }^{9}$ Para uma discussão detalhada das dificuldades de implantação do CIM veja: ABRAMOVICI, M.;
} SCHLUTE, S. PLM - logische Fortsetzung der PDM-Ansätze oder Neuauflage des CIM-Debakels? In: VDIBerichte Nr. 1819. VDI, 2004. 275-296. 
informação ${ }^{10}$. Na prática, a visão ampla de solução única de integração do CIM foi fracionada em aspectos parciais, menos complexos e mais fáceis de serem aplicados. Na área de engenharia, os conceitos do CIM serviram de base para o desenvolvimento dos sistemas PDM (Product Data Management), focados na gestão dos dados de produto (ABRAMOVICI; SCHLUTE, 2004, p. 281).

O PDM surgiu para atender à necessidade de gerenciar dados de engenharia. Com a disseminação dos sistemas CAD 3D, os projetos antes realizados empregando desenhos em duas dimensões, passaram a ser executados com base em modelos tridimensionais. Os desenhos em duas dimensões podem ser gerenciados em arquivos físicos (papel ou microfilme), pois as informações sobre os itens são representadas no próprio desenho. Os modelos tridimensionais, por sua vez, armazenam uma quantidade maior de informações, como, por exemplo, dados do relacionamento entre os itens. Isso exige que os modelos sejam gerenciados eletronicamente (ARNOLD et al., 2005, p. 8). Para atender a essa demanda, a primeira geração de sistemas PDM, desenvolvida nos anos 80, tinha como foco o gerenciamento de documentos de CAD (CIMDATA, 2003, p. 6).

Ao mesmo tempo em que os sistemas CAD se disseminavam, vários outros sistemas de informação passaram a ser utilizados na engenharia. Tal mudança resultou em um aumento significativo na quantidade de arquivos digitais nas empresas, dificultando a localização de informações e, principalmente, o controle de mudanças de engenharia.

Visando solucionar esses problemas, os sistemas PDM evoluíram e passaram a incorporar novas funcionalidades, como a gestão da estrutura de produto e o controle das mudanças de engenharia. Além disso, foram incluídas funções de gestão do fluxo de trabalho (workflow) e recursos para visualização de arquivos (CIMDATA, 2003, p.6).

Os pioneiros na adoção dos sistemas PDM foram as empresas dos setores automotivo e aeroespacial que produzem produtos técnicos complexos. A adoção de PDM foi inicialmente limitada às empresas grandes, devido ao alto investimento necessário tanto em licenças de uso de software como na configuração do sistema. Nesse período inicial de adoção do PDM, o uso do sistema foi geralmente restrito à área de engenharia do produto.

A abordagem de gestão do ciclo de vida de produtos surgiu com a necessidade de integração dos dados de produto da engenharia com as demais áreas da empresa. Esse era um dos objetivos iniciais do CIM. Atualmente, tal objetivo é viável devidos aos recentes avanços

${ }^{10}$ A evolução do CIM nos últimos 20 anos é discutida em: SCHEER, A. W. 20 Jahre Gestaltung industrieller Geschäftsprozesse. Industrie Management, 1, 2004. 
conceituais e na área de informática. Conceitualmente, o PLM evoluiu bastante nos últimos anos com a publicação de diversas obras especializadas no assunto (SAAKSVUORI; IMMONEN, 2004; ARNOLD et al., 2005; SCHEER et al., 2006; ABRAMOVICI, 2007; FELDHUSEN; GEBHARDT, 2008). Ao mesmo tempo, os fornecedores de softwares na área continuaram ampliando os seus sistemas, com a inclusão de novas funcionalidades para a gestão das fases iniciais e finais do ciclo de vida. Dentre as funcionalidades aprimoradas estão a gestão de requisitos e a gestão da configuração. Além disso, hoje a integração é mais fácil devido à existência de padrões e ao desenvolvimento de recursos de comunicação.

A evolução, descrita nos parágrafos anteriores, é ilustrada na Figura 15, que apresenta os limites conceituais da gestão de dados no CAD, do PDM e do PLM em relação às fases do ciclo de vida (no eixo horizontal) e ao escopo de atuação (no eixo vertical).

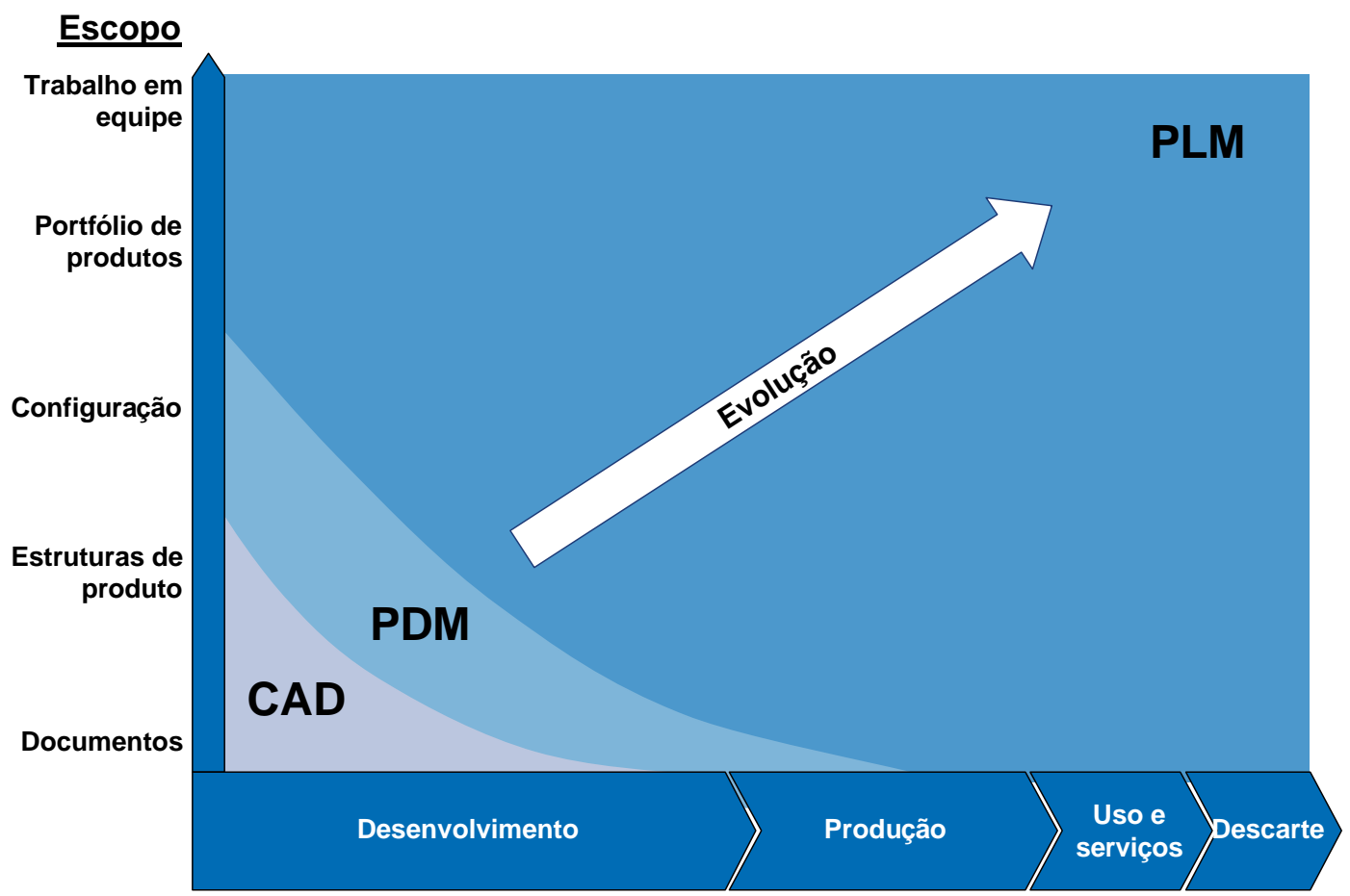

Figura 15. Delimitação entre a gestão de dados de produto com CAD, PDM e PLM (adaptado de HARTMANN; SCHMIDT, 2004, p. 24)

A gestão de dados de produto no CAD era focada na macrofase de desenvolvimento e restrita aos documentos de produto, especialmente aos arquivos do próprio CAD (Figura 15). O PDM ampliou o escopo de atuação, incorporando a gestão de estruturas de produto e da configuração, mas se restringe às fases iniciais do ciclo de vida. O PLM, tanto no sentido de abordagem como no de solução de TI, cobre teoricamente todas as fases do ciclo de vida. Além disso, o PLM tem um escopo de atuação muito mais abrangente, envolvendo a gestão do portfólio de produtos e o suporte ao trabalho colaborativo em equipes. 
A revisão da evolução histórica do PLM encerra a discussão dos conceitos fundamentais da gestão do ciclo de vida de produtos, apresentada neste item 2.1 do texto. No próximo item, os conceitos definidos anteriormente são utilizados como base para a aplicação da visão de processos de negócio ao PLM.

\subsection{Modelos de referência, processos e práticas de gestão do ciclo de vida de produtos}

Neste item são apresentados os modelos de referência existentes para a gestão do ciclo de vida de produtos. Tais modelos são representações dos processos de negócio de PLM que podem servir de base (referência) para a aplicação em empresas. O item é iniciado com a discussão da aplicação do conceito de processos de negócio à gestão do ciclo de vida de produtos (subitem 2.2.1). Em seguida, é apresentada a definição de modelos de referência (subitem 2.2.2). Os modelos de referência de PLM existentes atualmente são apresentados e comparados (subitem 2.2.3). Por fim, são apresentados os processos fundamentais de PLM considerados neste trabalho (subitem 2.2.4) e são discutidas as principais práticas de gestão do ciclo de vida de produtos (subitem 2.2.5).

\subsubsection{Aplicação da abordagem de processos de negócio à gestão do ciclo de vida de produtos}

Um processo de negócio é definido como um conjunto de atividades estruturadas e medidas, destinadas a resultar em um produto especificado para um determinado cliente ou mercado (DAVENPORT, 1993, p. 5). A abordagem de processos de negócio é, portanto, uma forma de organizar as atividades das empresas. Tal abordagem está baseada em algumas diretrizes (DAVENPORT, 1993, p. 6-9; HAMMER, 2007, p. 111-142):

Processos devem ser direcionados para atender às necessidades de clientes;

Processos têm começo e fim claramente especificados;

As entradas (inputs) e os produtos (outputs) das atividades dos processos também precisam ser claramente especificadas;

As atividades dos processos geralmente envolvem várias áreas funcionais das empresas, implicando uma visão horizontal do negócio;

Processos requerem responsáveis pela sua execução do início ao fim;

Os resultados dos processos precisam ser medidos e acompanhados;

Deve haver forte ênfase na melhoria da forma como o trabalho é realizado. 
A gestão dos processos de negócio ganhou destaque com a disseminação das abordagens de Qualidade Total e de Reengenharia, no início dos anos 90 (HAMMER, 1990; DAVENPORT, 1993; GARVIN, 1995). Hoje, a visão por processos já é amplamente aplicada nas empresas e o conceito continua atual e relevante. Considerando o contexto deste trabalho, deve-se observar que a abordagem de processos de negócio e as diretrizes listadas acima constituem um referencial teórico importante para viabilizar a adoção da gestão do ciclo de vida de produtos em empresas.

O ciclo de vida de um produto é iniciado com a avaliação de idéias que resultarão em um novo desenvolvimento para um determinado cliente ou mercado. Ao longo do ciclo de vida, diversas atividades são executadas para gerar as informações e para produzir os elementos necessários ao produto e aos serviços relacionados ao produto. Essas atividades seguem uma seqüência lógica e estruturada e são executadas por diversas áreas funcionais nas várias empresas envolvidas com o produto na cadeia de suprimentos. Assim, a gestão do ciclo de vida de produtos exige uma visão horizontal do negócio, tal como definida pela abordagem de gestão de processos. Também deve haver ênfase na medição de resultados e na melhoria dos processos de PLM, pois, segundo Chrissis, Konrad e Shrum (2007, p. 5), a qualidade de um produto é altamente influenciada pela qualidade dos processos empregados para desenvolvê-lo e mantê-lo. Depois do uso do produto pelo cliente, os processos de gestão do ciclo de vida são finalizados com a destinação final do produto (Figura 16).

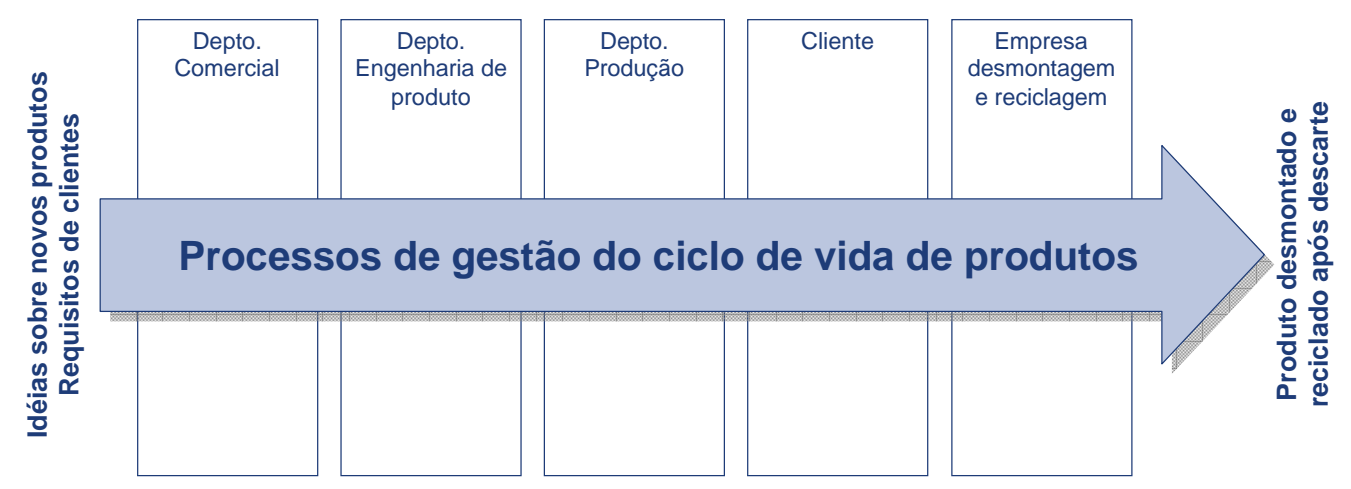

Figura 16. Visão de processos de negócio aplicada à gestão do ciclo de vida de produtos (adaptado de DAVENPORT, 1993, p. 9)

Dada a adequação da abordagem por processos de negócio para o PLM, é necessário discutir como os processos de negócio relacionados ao ciclo de vida de produtos devem ser preparados para apoiar a implantação do PLM. De acordo com Scheer et al. (2006, p. 15), a documentação dos processos de negócio com as atividades, as informações e os recursos de TI constituem o embasamento conceitual fundamental para guiar a implantação do PLM. Os autores também consideram que a documentação dos processos é muito importante para a 
gestão de processos de PLM já implementados. A documentação de processos de negócio por meio de modelos é discutida no subitem a seguir.

\subsubsection{Definição de modelo de referência}

Processos de negócio ocorrem nas empresas independentemente de eles estarem explicitamente documentados. Muitas empresas têm processos que são conhecidos pelas pessoas que os executam no dia-a-dia, mas que não estão sistematizados formalmente. Entretanto, um processo de negócio só pode ser aprimorado se ele puder ser analisado e se as suas ineficiências puderem ser identificadas. Assim, a condução de iniciativas de melhoria requer que os processos estejam documentados nas empresas (ROZENFELD, 1996, p. 27-29).

A documentação de processos de negócio é realizada por meio de modelos dos processos. Um modelo é uma representação da realidade, geralmente com uso de elementos gráficos, que descreve o funcionamento dos processos de maneira esquemática. Existem vários métodos de modelagem de processos (veja item 3.2) e o grau de detalhamento de um modelo de processo depende do objetivo considerado. Independentemente das variações possíveis, os modelos de processo geralmente representam os seguintes elementos: atividades e sua seqüência, informações de entrada e de saída de cada atividade (fluxo de informações), pessoas ou áreas na organização responsáveis pela execução das atividades e recursos utilizados para executar as atividades (e.g. uma funcionalidade de um sistema de informação).

Uma classe especial de modelos de processos de negócio é formada por modelos mais abrangentes, de aplicação ampla e com caráter de benchmark, denominados modelos de referência (ZANCUL, 2000, p. 41).

Modelos de referência de processos de negócio são representações de processos de negócio contendo melhores práticas (best practices) da área de aplicação. Além disso, modelos de referência têm caráter genérico, de forma que eles possam refletir a realidade encontrada em várias empresas e em diversas situações de negócio. Isso possibilita que modelos de referência possam ser adaptados para aplicação em diversos contextos (SCHWEGMANN; LASKE, 2005, p. 175; FETTKE; LOOS, 2006, p. 2).

A especificação de modelos de referência pode ocorrer de duas formas alternativas. Um modelo de referência pode ser criado de maneira indutiva, a partir da compilação do conhecimento de vários casos empíricos, de outros modelos, da documentação de sistemas de informação e de dados obtidos por meio de entrevistas. Alternativamente, modelos de referência podem ser deduzidos da teoria (FETTKE; LOOS; ZWICKER, 2005, p. 477; SCHWEGMANN; LASKE, 2005, p. 176). 
Em termos de aplicação, modelos de referência podem ser usados como base para a configuração de modelos específicos. A instanciação de um modelo específico a partir de um modelo de referência contribui para que melhores práticas possam ser incorporadas no modelo resultante. Com o uso de modelos de referência, espera-se que a confecção do modelo específico seja mais rápida e que o resultado seja de melhor qualidade. Outra aplicação possível para modelos de referência é na avaliação de modelos específicos. Nessa situação, o modelo de referência estabelece uma base de comparação para a identificação de problemas e de oportunidades de melhoria no modelo específico (VERNADAT, 1996, p. 24; SCHWEGMANN; LASKE, 2005, p. 176). Outros propósitos para o uso de modelos de referência de processos são a descrição de processos para facilitar a aprendizagem e para apoiar a implementação de sistemas de informação (AGUILAR-SAVEN, 2004, p. 146). As possibilidades mais comuns para a criação e para a aplicação de modelos de referência são ilustradas na Figura 17.

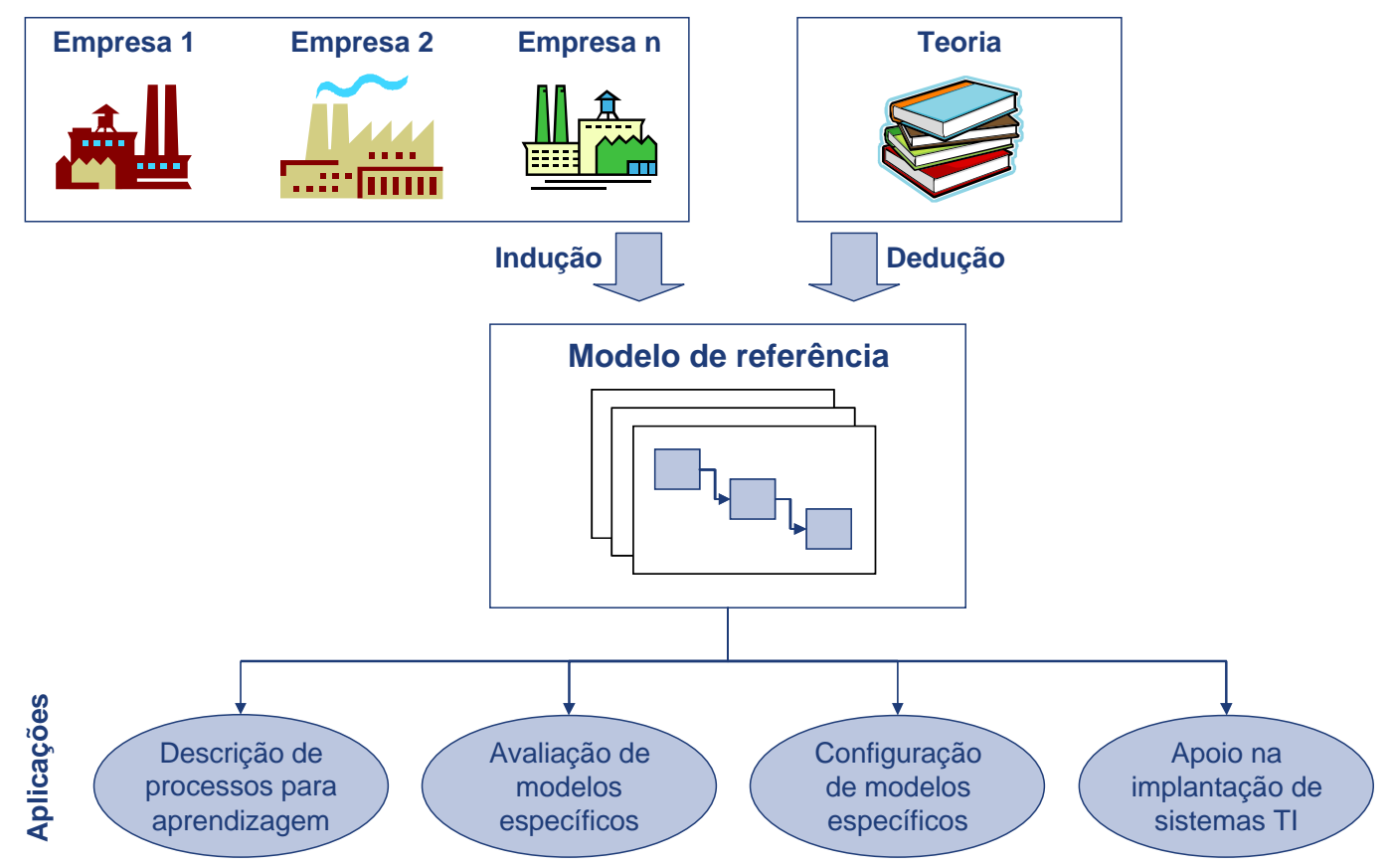

Figura 17. Geração e utilização de modelos de referência (baseado em SCHWEGMANN; LASKE, 2005, p. 177)

Além dos modelos de referência dos processos de negócio, existem outros tipos de modelos de referência. No contexto deste trabalho, os modelos de referência de sistemas de informação são relevantes. Tais modelos representam as soluções disponíveis em um sistema de informação. Um exemplo é o modelo de referência do sistema SAP R/3, que representa as funcionalidades disponíveis nesse software (CURRAN; KELLER; LADD, 1997; KELLER; TEUFEL, 1998). 


\subsubsection{Modelos de referência existentes para apoiar a gestão do ciclo de vida de produtos}

Atualmente já existem alguns modelos de referência que tratam de processos de negócio relacionados à gestão do ciclo de vida de produtos. A maior parte desses modelos é resultado de projetos de pesquisa ou de trabalhos de padronização realizados na indústria. Nesta síntese da bibliografia fundamental são analisados cinco modelos de referência, selecionados devido a sua importância para a área de pesquisa ${ }^{11}$ :

1. Modelo Unificado do PDP ${ }^{12}$ (ROZENFELD et al., 2006);

2. $\mathrm{CMMI}^{13}$ para desenvolvimento (CHRISSIS; KONRAD; SHRUM, 2007);

3. Modelo de referência de PLM do projeto TFB-57 (SCHUH et al., 2008b);

4. Modelo evolutivo de PLM para empresas pequenas e médias do projeto PLM4KMU (ARNOLD et al., 2005);

5. Modelo de referência de PLM da empresa de consultoria IDS Scheer (SCHEER et al., 2006).

Os principais aspectos da origem e do foco desses cinco modelos de referência são descritos resumidamente abaixo. Em seguida, são apresentadas duas tabelas com uma análise comparativa dos cinco modelos de referência.

\section{Modelo Unificado do PDP}

O Modelo Unificado do PDP é o único dos cincos modelos de referência da lista que é inteiramente desenvolvido no Brasil. Esse modelo é resultado de diversos projetos de pesquisa e de consultoria realizados ao longo dos últimos dez anos no NUMA, da USP de São Carlos, e em outros institutos de pesquisa que trabalham em conjunto com o NUMA.

O foco principal do modelo é o processo de desenvolvimento de produtos, considerado com escopo bastante abrangente, incluindo as fases de pré-desenvolvimento e de pósdesenvolvimento. Dessa forma, as principais atividades de PLM estão incluídas no modelo. O modelo está disponível em um livro, que apresenta seu conteúdo de forma didática

${ }^{11}$ Critérios de seleção dos modelos de referência para análise neste trabalho: (1) escopo - cobertura das principais atividades de PLM; (2) relevância - publicação em livro ou resultado de projeto de pesquisa reconhecido academicamente ou de trabalho realizado por entidade de classe; (3) caráter de modelo de referência - contém melhores práticas e é válido para várias aplicações; (4) atualidade - publicação nos último cinco anos.

${ }^{12}$ PDP - Processo de Desenvolvimento de Produtos.

${ }^{13}$ CMMI - Capability Maturity Model Integration. 
(ROZENFELD et al., 2006). Uma versão detalhada do modelo também está disponível na Internet (www.pdp.org.br).

\section{CMMI para desenvolvimento}

O CMMI é um modelo de maturidade para o aprimoramento de processos de desenvolvimento de produtos e serviços. Modelos de maturidade servem para avaliar processos de empresas específicas em relação a uma escala que evolui de processos mais simples (menor grau de maturidade) até processos mais bem gerenciados (maior grau de maturidade).

O CMMI abrange as atividades de desenvolvimento e de serviços ao longo do ciclo de vida do produto. O modelo é desenvolvido pelo Software Engineering Institute (SEI), nos Estados Unidos, e a versão mais atual (1.2) é apresentada em livro (CHRISSIS; KONRAD; SHRUM, 2007).

\section{Modelo de referência de PLM do projeto TFB-57}

Os modelos de referência de PLM resultantes do projeto de pesquisa TFB-57 ${ }^{14}$ são apresentados em conjunto com uma metodologia para a implantação dos processos de negócio em empresas.

O TFB-57 é um projeto de pesquisa liderado pelo WZL, da RWTH Aachen, na Alemanha. O projeto foi iniciado em 2005, com o objetivo de transferir para a indústria alemã os conhecimentos gerados em um projeto de pesquisa anterior, chamado SFB- $361^{15}$, cujo foco era criar métodos e ferramentas para o desenvolvimento integrado de produtos. Os resultados do SFB-361 estão compilados em livro (EVERSHEIM; SCHUH, 2004). Para transferir esses resultados para a prática, no TFB-57 foi formado um consórcio composto por três institutos de pesquisa e por seis empresas ${ }^{16}$.

Os resultados do projeto são modelos de referência que seguem a lógica de níveis de maturidade e uma metodologia para a priorização dos processos de PLM mais críticos para cada empresa e para a sua adaptação a diferentes contextos (SCHUH et al., 2008b). Os

14 TFB-57 - Transferbereich-57 - Systemunabhängige Referenzprozesse für das PLM (tradução do autor: Processos de referência independentes de sistemas de informação).

15 SFB-361 - Sonderforschungsbereich 361 - Modelle und Methoden zur integrierten Produkt- und Prozessgestaltung (tradução do autor: Modelos e métodos para o desenvolvimento de produtos e de processos).

${ }^{16} \mathrm{O}$ autor deste trabalho atuou como membro do grupo de pesquisa do TFB-57 de outubro de 2005 a abril de 2007. 
modelos de referência detalhados podem ser acessados via Internet (www.tfb57.rwthaachen.de).

\section{Modelo evolutivo de PLM do projeto PLM4KMU}

O modelo de referência PLM4KMU também é resultado de um projeto de pesquisa alemão. O objetivo do projeto foi desenvolver uma abordagem para apoiar pequenas e médias empresas na evolução da gestão de informações do ciclo de vida de produtos. Tal abordagem é abrangente e engloba desde a fase de diagnóstico da situação da empresa até a de implantação dos sistemas de informação necessários.

Um dos elementos centrais da abordagem é um modelo de referência, estruturado em níveis de maturidade, para a avaliação do status do PLM na empresa. Esse modelo de referência está organizado em "blocos de funções de PLM", tais como, a gestão de documentos e a estruturação de produtos (ARNOLD et al., 2005). Os "blocos de funções de PLM” podem ser relacionados às práticas de gestão do ciclo de vida de produtos (veja 2.2.5) ou às funcionalidades de sistemas de informação. Portanto, a distinção entre modelo de referência de processos de negócio e de sistemas de informação não é clara nesse caso.

\section{Modelo de referência de PLM da empresa de consultoria IDS Scheer}

Por fim, Scheer et al. (2006) apresentam, em livro, uma descrição dos processos-chave de PLM. O Professor Scheer é um dos principais autores de CIM (SCHEER, 1987), fundador da empresa de consultoria de processos IDS Scheer, além de ser um dos pioneiros na publicação de modelos de referência para a indústria. Em um de seus livros anteriores, são detalhados processos logísticos, de desenvolvimento integrado de produtos e de gestão de informações para empresas industriais (SCHEER, 1998). O livro de 2006, publicado com coautores da IDS Scheer, é focado em PLM. Partindo do conceito de CIM, os autores apresentam uma relação dos processos de PLM e descrevem o conteúdo e os métodos de trabalho aplicados nesses processos.

A fim de avaliar e comparar os cinco modelos de PLM descritos anteriormente, são definidos critérios de análise que abrangem tanto a caracterização geral dos modelos, como o seu conteúdo e o seu formalismo de representação. Tais critérios são adaptados de uma estrutura para a classificação de modelos de referência desenvolvida por Fettke, Loos e Zwicker (2005, p. 470-472) para ser aplicada em surveys de modelos de referência. Os critérios utilizados são:

Caracterização

- Título - denominação do modelo; 
- Autor - nome da instituição que desenvolveu o modelo;

- Origem - distinção entre modelos criados na Universidade (acadêmicos) ou na indústria;

- Fonte - fonte primária na qual o modelo é publicado;

- Descrição - descrição resumida dos aspectos mais relevantes que caracterizam o modelo;

- Acesso - especificação da forma como o modelo pode ser acessado, diferenciado entre modelos abertos (disponíveis para acesso livre na bibliografia ou em meio eletrônico), de acesso limitado (podem ser adquiridos) ou fechados (não disponíveis para consulta);

- Idiomas.

Domínio

- Setores da indústria - setores representados no modelo (e.g. automotivo, aeroespacial, bens de capital);

- Escopo - processos de negócio descritos no modelo;

- Grau de detalhamento - indicação do nível de especificação representado, diferenciado entre alto (inclui descrição de vários dos seguintes aspectos: atividades, métodos de trabalho, informações de entrada e de saída, ferramentas necessárias, indicadores) e baixo (representação gráfica limitada a um ou dois níveis, atividades não descritas individualmente);

Representação - formalismo de representação empregado ${ }^{17}$.

A Tabela 2 e a Tabela 3 resumem os principais resultados da análise dos modelos de referência selecionados em relação aos critérios predefinidos.

\footnotetext{
${ }^{17}$ Os formalismos de representação são discutidos no capítulo 3.
} 
Tabela 2 - Análise comparativa dos modelos de referência - parte 1

\begin{tabular}{|c|c|c|c|c|c|}
\hline Título & Modelo Unificado do PDP & CMMI desenvolvimento & TFB-57 & PLM4KMU & IDS Scheer \\
\hline Autor & $\begin{array}{l}\text { Grupo de professores e } \\
\text { de pesquisadores do } \\
\text { NUMA, UFSCar } \\
\text { (Universidade Federal de } \\
\text { São Carlos) e UFSC } \\
\text { (Universidade Federal de } \\
\text { Santa Catarina) }\end{array}$ & $\begin{array}{l}\text { Software Engineering } \\
\text { Institute }\end{array}$ & $\begin{array}{l}\text { Consórcio de pesquisa } \\
\text { liderado pelo WZL }\end{array}$ & $\begin{array}{l}\text { Consórcio de pesquisa } \\
\text { liderado pelo FZI } \\
\text { (Forschungszentrum } \\
\text { Informatik) da } \\
\text { Universidade de } \\
\text { Karlsruhe }\end{array}$ & $\begin{array}{l}\text { Autores ligados à } \\
\text { empresa de consultoria } \\
\text { IDS Scheer }\end{array}$ \\
\hline Origem & Acadêmico & Acadêmico & Acadêmico & Acadêmico & Indústria \\
\hline Fonte & $\begin{array}{l}\text { (ROZENFELD et al., } \\
2006 \text { ) }\end{array}$ & $\begin{array}{l}\text { (CHRISSIS; KONRAD; } \\
\text { SHRUM, 2007) }\end{array}$ & (SCHUH et al., 2008b) & (ARNOLD et al., 2005) & (SCHEER et al., 2006) \\
\hline Descrição & $\begin{array}{l}\text { Modelo abrangente } \\
\text { desenvolvido no Brasil }\end{array}$ & Modelo de maturidade & $\begin{array}{l}\text { Modelos de maturidade } \\
\text { parte de uma } \\
\text { metodologia para } \\
\text { implantação de processos }\end{array}$ & $\begin{array}{l}\text { Abordagem de evolução } \\
\text { do PLM que utiliza } \\
\text { modelos de referência }\end{array}$ & $\begin{array}{l}\text { Modelo de referência } \\
\text { focado nas atividades dos } \\
\text { processos e no conteúdo } \\
\text { para sua execução }\end{array}$ \\
\hline \multirow[t]{3}{*}{ Acesso } & Aberto & Aberto & Aberto & Fechado & Fechado \\
\hline & Publicado em livro & Publicado em livro com & Publicado em brochura & Publicação não é & Publicação não é \\
\hline & $\begin{array}{l}\text { Disponível em mais } \\
\text { detalhes na internet } \\
\text { (www.pdp.org.br) }\end{array}$ & alto grau de detalhamento & $\begin{array}{l}\text { Disponível em mais } \\
\text { detalhes na internet } \\
\text { (www.tfb57.rwth- } \\
\text { aachen.de) }\end{array}$ & $\begin{array}{l}\text { sutıcientemente } \\
\text { detalhada para } \\
\text { possibilitar aplicação }\end{array}$ & $\begin{array}{l}\text { sufıcıentemente } \\
\text { detalhada para } \\
\text { possibilitar aplicação }\end{array}$ \\
\hline Idioma & Português & Inglês & Alemão & Alemão & Alemão \\
\hline $\begin{array}{l}\text { Setores da } \\
\text { indústria }\end{array}$ & $\begin{array}{l}\text { Bens de consumo } \\
\text { duráveis e bens de capital } \\
\text { com ênfase na tecnologia } \\
\text { mecânica de fabricação }\end{array}$ & Manufatura discreta & Bens de capital & $\begin{array}{l}\text { Manufatura discreta em } \\
\text { pequenas e médias } \\
\text { empresas }\end{array}$ & $\begin{array}{l}\text { Manufatura discreta } \\
\text { Indústria de processos }\end{array}$ \\
\hline $\begin{array}{l}\text { Representação } \\
18\end{array}$ & $\begin{array}{l}\text { Tabular } \\
\text { EPC }\end{array}$ & Própria & BPMN & Própria & EPC \\
\hline
\end{tabular}

${ }^{18}$ Os métodos de representação são detalhados no capítulo 3. 
Tabela 3 - Análise comparativa dos modelos de referência - parte 2

\begin{tabular}{|c|c|c|c|c|c|}
\hline Título & Modelo Unificado do PDP & CMMI desenvolvimento & TFB-57 & PLM4KMU & IDS Scheer \\
\hline Escopo & $\begin{array}{l}\text { Pré-Desenvolvimento } \\
\text { - Planejamento } \\
\text { estratégico dos produtos } \\
\text { - Planejamento do projeto } \\
\text { Desenvolvimento } \\
\text { - Projeto informacional } \\
\text { - Projeto conceitual } \\
\text { - Projeto detalhado } \\
\text { - Preparação produção } \\
\text { - Lançamento do produto } \\
\text { Pós-Desenvolvimento } \\
\text { - Acompanhar produto / } \\
\text { processo } \\
\text { - Descontinuar produto } \\
\text { Processos de apoio } \\
\text { - Gerenciamento de } \\
\text { mudanças engenharia } \\
\text { - Melhoria do processo }\end{array}$ & $\begin{array}{l}\text { Gestão de processos } \\
\text { - Foco em processos } \\
\text { - Definição de processos } \\
\text { - Treinamento } \\
\text { - Desempenho processos } \\
\text { - Inovação e } \\
\text { desenvolvimento } \\
\text { Gestão de projetos } \\
\text { - Planejamento } \\
\text { - Monitoramento e } \\
\text { controle } \\
\text { - Gestão de fornecedores } \\
\text { - Gestão integrada de } \\
\text { projetos } \\
\text { - Gestão de riscos } \\
\text { - Gestão quantitativa } \\
\text { Engenharia } \\
\text { - Desenvolvimento de } \\
\text { requisitos } \\
\text { - Gestão de requisitos } \\
\text { - Solução técnica } \\
\text { - Integração do produto } \\
\text { - Verificação } \\
\text { - Validação } \\
\text { Suporte } \\
\text { - Gestão configuração } \\
\text { - Garantia da qualidade do } \\
\text { produto e do processo } \\
\text { - Medição e análise } \\
\text { - Análise decisão e } \\
\text { solução } \\
\text { - Análise causal e solução }\end{array}$ & $\begin{array}{l}\text { Atendimento de pedidos } \\
\text { Gestão de idéias } \\
\text { Gestão de requisitos } \\
\text { Gestão de funções } \\
\text { Estruturação de produtos } \\
\text { Planejamento do programa } \\
\text { de produtos } \\
\text { Gestão de mudanças } \\
\text { Controle de indicadores de } \\
\text { projetos individuais } \\
\text { Gestão de riscos } \\
\text { Desenvolvimento } \\
\text { colaborativo } \\
\text { Controle de qualidade } \\
\text { Otimização da carga de } \\
\text { trabalho } \\
\text { Seleção e desenvolvimento } \\
\text { de pessoal }\end{array}$ & $\begin{array}{l}\text { Gestão de configuração } \\
\text { Gestão de visões dos } \\
\text { dados } \\
\text { Gestão de documentos } \\
\text { Arquivamento de dados de } \\
\text { produtos } \\
\text { Codificação de itens } \\
\text { Classificação } \\
\text { Gestão de processos com } \\
\text { workflow } \\
\text { Gestão de mudanças } \\
\text { Gestão de projetos }\end{array}$ & $\begin{array}{l}\text { Processos de gestão } \\
\text { - Gestão do portfólio } \\
\text { - Pesquisa de marketing } \\
\text { - Avaliação de riscos } \\
\text { - Gestão dos projetos de } \\
\text { inovação (pesquisa) } \\
\text { - Gestão dos projetos de } \\
\text { produção } \\
\text { Processos centrais } \\
\text { - Gestão de requisitos } \\
\text { - Inovação técnica } \\
\text { - Especificação detalhada } \\
\text { - Desenvolvimento } \\
\text { produtos } \\
\text { - Gestão de mudanças } \\
\text { - Planejamento do } \\
\text { processo de produção } \\
\text { - Gestão de recursos da } \\
\text { produção } \\
\text { - Produção } \\
\text { - Serviços e manutenção } \\
\text { Processos de apoio }\end{array}$ \\
\hline $\begin{array}{l}\text { Nível deta- } \\
\text { lhamento }\end{array}$ & Alto & Alto & Alto & Baixo & Baixo \\
\hline
\end{tabular}


Na análise realizada, quatro características dos modelos são muito importantes para este trabalho: escopo relacionado ao PLM; alto grau de detalhamento; acesso aberto; disponibilidade em português, que facilita seu uso por empresas instaladas no Brasil. Dos cinco modelos analisados, três têm acesso aberto e grau de detalhamento alto (Modelo Unificado do PDP, CMMI para desenvolvimento e TFB-57). Desses três, o modelo do TFB57 não cobre completamente o escopo de PLM, deixando de fora as atividades de pósdesenvolvimento relacionadas com as duas últimas macrofases do ciclo de vida de produtos (uso e serviços e descarte). Dentre os dois outros modelos, apenas o Modelo Unificado do PDP está disponível completamente em Português. Considerando o Modelo Unificado do PDP como base, os processos de gestão do ciclo de vida de produtos são discutidos a seguir.

\subsubsection{Processos de gestão do ciclo de vida de produtos}

A gestão do ciclo de vida de produtos envolve um conjunto amplo de atividades relacionadas com a geração e com o gerenciamento de dados de produtos. As atividades são agrupadas em conjuntos coesos para formar processos e subprocessos. Uma discussão recorrente em empresas e na literatura é a quantidade ideal de processos e a melhor forma de agrupar as atividades. No caso do PLM, observa-se que cada autor adota um agrupamento distinto (Tabela 3, critério escopo).

Apesar de não haver uma regra única sobre a quantidade ideal de processos, em geral, considera-se que estes devem ser abrangentes, o que resulta em poucas subdivisões (ver DAVENPORT, 1993, p.9). Em relação à forma de agrupamento, deve-se manter as atividades afins em conjunto. Partindo desses princípios e da definição de PLM e utilizando o Modelo Unificado do PDP como principal referência teórica, são definidos cinco processos de gestão do ciclo de vida de produtos: planejamento estratégico de produtos e planejamento do projeto; desenvolvimento de produtos; acompanhamento e retirada de produtos; gestão da configuração; melhoria dos processos. A relação desses processos com as fases do ciclo de vida é ilustrada na Figura 18. 


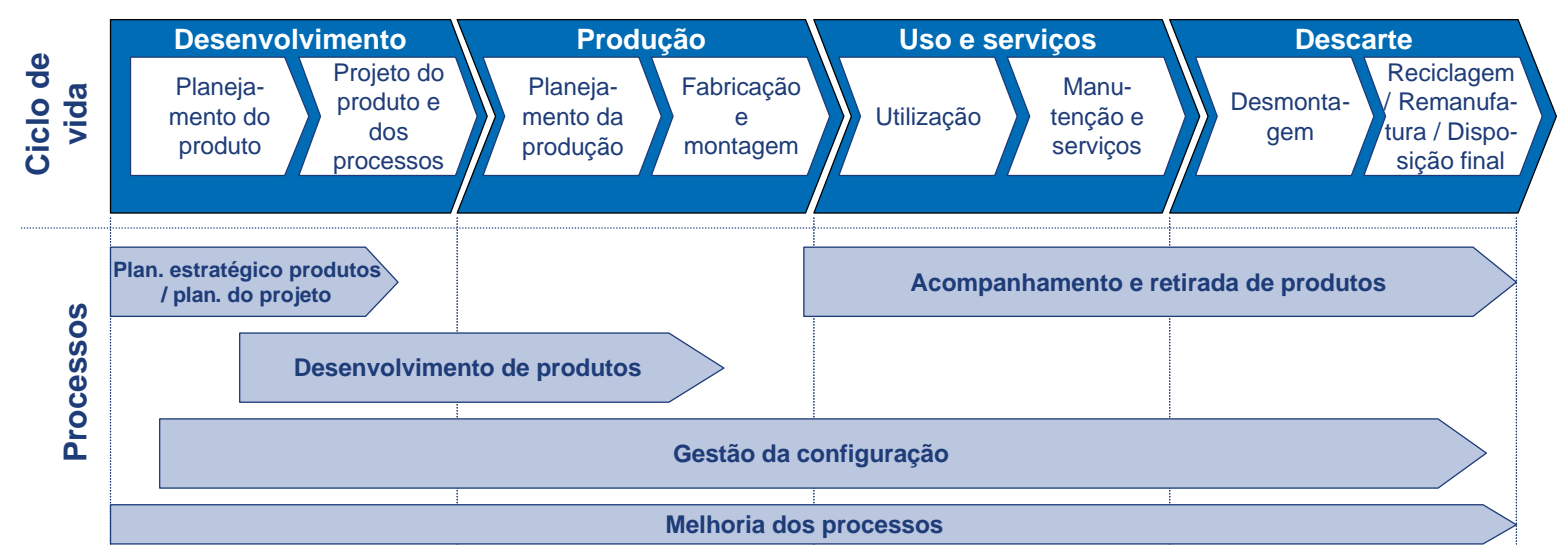

Figura 18. Processos de gestão do ciclo de vida de produtos

Os cinco processos de gestão do ciclo de vida de produtos ilustrados na Figura 18 são descritos resumidamente a seguir ${ }^{19}$.

\section{Planejamento estratégico de produtos e planejamento do projeto}

O planejamento estratégico de produtos visa definir o portfólio de produtos da empresa e especificar as principais características e as metas de novos produtos a serem desenvolvidos. Com base nessas metas, o planejamento do projeto define o plano do projeto de desenvolvimento para o produto específico.

A informação de entrada mais relevante para esse processo é o plano estratégico de negócios da empresa, que descreve os objetivos de crescimento e as prioridades de investimento em mercados e em tecnologias específicas. Com base no plano estratégico, o planejamento de produtos é iniciado com a análise das tendências de evolução dos mercadoschave, com o monitoramento das tecnologias relevantes para a empresa e com a avaliação do desempenho dos produtos do portfólio atual. Considerando essas informações, são propostas mudanças no portfólio, como a introdução de novos produtos para preencher lacunas, e a retirada de produtos existentes do mercado. No caso de novos produtos, são especificadas as principais características de desempenho e são definidas metas, tais como o investimento disponível e a data para lançamento. Além disso, é definido o plano do projeto de desenvolvimento, incluindo as principais atividades, os prazos e os responsáveis.

Os resultados mais importantes do processo são o portfólio de produtos revisado e aprovado, a documentação das principais características e metas dos produtos que serão

${ }^{19}$ A apresentação detalhada dos processos não faz parte do escopo deste trabalho. Para uma discussão detalhada dos processos consultar ROZENFELD, H.; FORCELLINI, F. A.; AMARAL, D. C.; DE TOLEDO, J. C.; DA SILVA, S. L.; ALLIPRANDINI, D. H.; SCALICE, R. K. Gestão de desenvolvimento de produtos uma referência para a melhoria do processo. Saraiva, 2006. 
desenvolvidos pela empresa e o plano do projeto de desenvolvimento (ROZENFELD et al., 2006, p. 115-207).

\section{Desenvolvimento de produtos}

O processo de desenvolvimento de produtos é iniciado com a decisão de desenvolver um novo produto e se estende até o lançamento desse produto no mercado.

Rozenfeld et al. (2006, p. 61) organizam o desenvolvimento de produtos em cinco subprocessos listados abaixo e explicados resumidamente em seguida:

Projeto informacional;

Projeto conceitual;

Projeto detalhado;

Preparação para a produção;

Lançamento.

O projeto informacional abrange o detalhamento dos requisitos do produto e a definição das especificações-meta que servirão de base para guiar as demais atividades de desenvolvimento (ROZENFELD et al., 2006, p. 211-232).

Com base nessas especificações, no projeto conceitual, é definida a estrutura de funções do produto e são selecionadas as soluções tecnológicas para viabilizar as funções. O projeto conceitual inclui ainda a definição do layout, da arquitetura do produto e da lista inicial de componentes (ROZENFELD et al., 2006, p. 235-291).

No projeto detalhado, todas as especificações são desenvolvidas e finalizadas. Os principais resultados desse subprocesso são: estrutura de produtos, especificações dos componentes, desenhos finais com tolerâncias, protótipos, planos de processo e projeto dos recursos necessários para a fabricação (ROZENFELD et al., 2006, p. 293-386).

Na preparação para a produção, os recursos de produção são instalados e o lote piloto é produzido para homologação do processo. Paralelamente, os processos de manutenção são especificados, o pessoal de produção e de serviços é treinado e o produto é certificado (ROZENFELD et al., 2006, p. 394-412).

Por fim, o lançamento, envolve a especificação do processo de vendas, a preparação da documentação comercial e o treinamento da força de vendas, terminando com o lançamento do produto (ROZENFELD et al., 2006, p. 415-431). 


\section{Acompanhamento e retirada de produtos}

Após o lançamento, o produto é adquirido por clientes que passam a utilizá-lo. Desde o início da comercialização, é importante avaliar a satisfação dos clientes e monitorar o desempenho dos produtos durante o uso. Esse acompanhamento indica a necessidade de modificações no produto, além de fornecer informações para guiar novos desenvolvimentos. Com o passar do tempo, o acompanhamento do desempenho do produto em várias dimensões (vendas, custos, impactos no meio ambiente) servirá para fundamentar a decisão de retirada do produto do mercado (ROZENFELD et al., 2006, p. 435-444).

A retirada do produto do mercado é uma atividade complexa que precisa ser planejada. Em vários casos, a empresa que produziu o produto é responsável pela sua destinação final. Nesses casos, é necessário preparar a logística de recebimento, desmontagem e destinação final do produto. Ao mesmo tempo, a descontinuidade da produção deve ser planejada e informada para todos os envolvidos na cadeia de suprimentos. Deve-se levar em conta que a fabricação de peças de reposição é mantida até a finalização do período de suporte ao produto (ROZENFELD et al., 2006, p. 445-452).

\section{Gestão da configuração}

A configuração de um produto pode ser definida como o conjunto de todas as informações relacionadas ao produto. Ela abrange tanto os itens como os documentos e os dados que representam um produto (ROZENFELD et al., 2006, p.458).

Ao longo do ciclo de vida - na macrofase de desenvolvimento ou durante o uso do produto - a configuração pode sofrer mudanças. O objetivo do processo de gestão da configuração é organizar essas mudanças e controlar a evolução na configuração dos produtos até o fim do ciclo de vida.

Nesse sentido, o processo de gestão da configuração envolve atividades para a identificação da configuração, para o controle de mudanças realizadas e para o apoio na verificação da configuração a qualquer momento (ISO-10007, 2003).

\section{Melhoria dos processos de gestão do ciclo de vida}

O quinto e último processo de gestão do ciclo de vida de produtos é responsável por identificar oportunidades de melhoria nos demais processos, avaliar essas oportunidades e implantar ações que resultem nas melhorias esperadas. Após a implantação das ações, a documentação do processo deve ser atualizada e o novo processo é liberado para execução. 


\subsubsection{Práticas associadas à gestão do ciclo de vida de produtos}

A implantação da gestão do ciclo de vida geralmente envolve mudanças na forma como várias atividades são realizadas na empresa e a adoção de uma série de novas práticas. Utiliza-se aqui o termo práticas para designar tanto conceitos, como processos, subprocessos, atividades e métodos de trabalho.

As práticas de PLM estão incorporadas nos processos de negócio relacionados à gestão do ciclo de vida de produtos (discutidos no subitem 2.2.4). Ou seja, as práticas devem ser compreendidas no contexto amplo dado por processos de negócio coesos. Mesmo assim, considera-se que é importante discutir algumas dessas práticas isoladamente. Isso se justifica pois tais práticas de PLM são citadas na maior parte da bibliografia da área como requisito para a gestão efetiva do ciclo de vida. Dessa forma, o seu entendimento ajuda na compreensão das mudanças relacionadas com a implantação da gestão do ciclo de vida de produtos em uma empresa.

Com base em uma análise da literatura na área, foram selecionadas as 10 práticas relacionadas com a gestão do ciclo de vida de produtos citadas mais freqüentemente na literatura consultada (SAAKSVUORI; IMMONEN, 2004; ARNOLD et al., 2005; ROZENFELD et al., 2006; SCHEER et al., 2006; ABRAMOVICI, 2007; FELDHUSEN; GEBHARDT, 2008; SCHUH et al., 2008b). Essas práticas, ilustradas por retângulos na parte inferior da Figura 19, estão posicionadas em relação às fases do ciclo de vida e aos processos de negócio. 


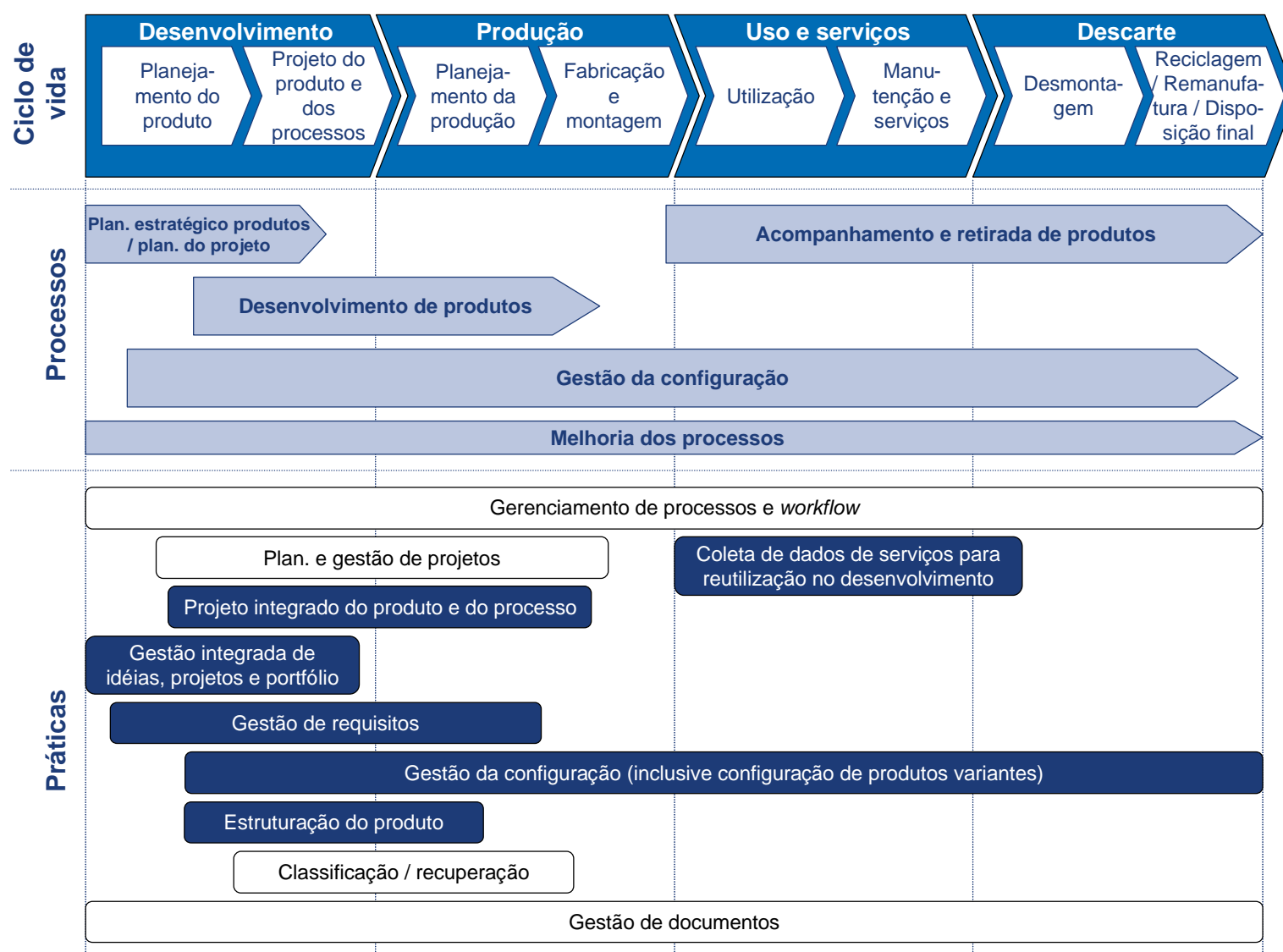

Figura 19. Práticas de gestão do ciclo de vida de produtos

Dentre as dez práticas principais identificadas na literatura, as seis destacadas em azul, na Figura 19, foram selecionadas para serem descritas mais detalhadamente a seguir. As seis práticas escolhidas para serem analisadas em maior detalhe combinam alta relevância para a implantação da gestão do ciclo de vida de produtos com menor disponibilidade de publicações - são, em geral, temas mais recentes. Informações adicionais sobre as outras quatro práticas não detalhadas a seguir podem ser obtidas na literatura: gerenciamento de processos e workflow(VAN DER AALST; VAN HEE, 2002), planejamento e gestão de projetos (KERZNER, 2002; ROZENFELD et al., 2006; DE PAULA; AMARAL; ROZENFELD, 2007), classificação / recuperação (OLIVEIRA, 1999), gestão de documentos (HARTMANN; SCHMIDT, 2004).

\section{Gestão integrada de idéias, projetos e portfólio}

Idéias, projetos e produtos formam uma seqüência de eventos que precisa ser coordenada considerando os objetivos da empresa e as mudanças do mercado. Idéias selecionadas em avaliação tornam-se projetos que, por sua vez, resultam em produtos que são incorporados ao portfólio da empresa. O status dos produtos no portfólio evolui constantemente, desde a introdução até a retirada do mercado (Figura 20). 


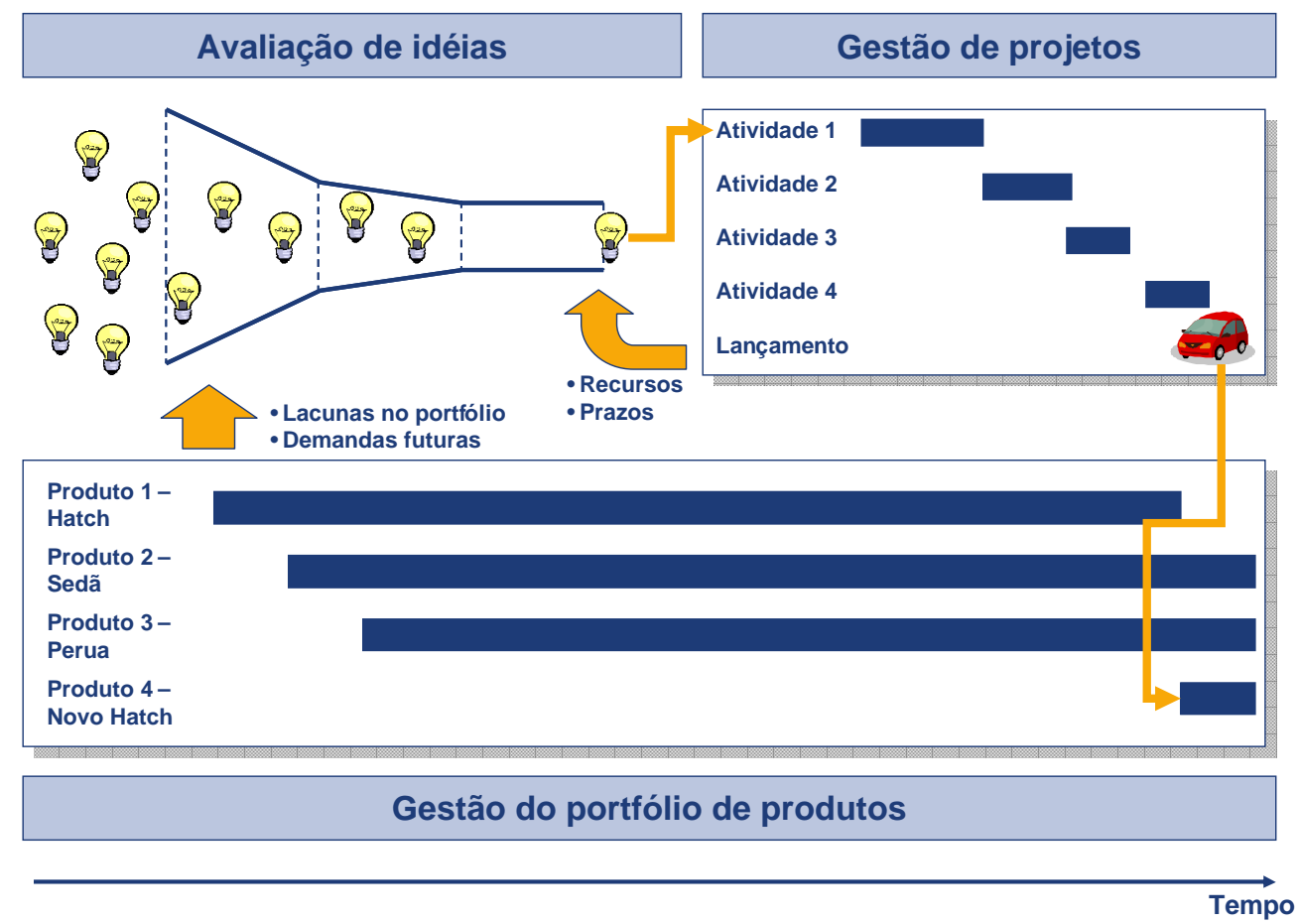

Figura 20. Integração da avaliação de idéias, com planejamento de projetos e gestão do portfolio (exemplo ilustrativo)

A integração da gestão de idéias, de projetos e do portfólio de produtos visa possibilitar o planejamento do futuro portfólio, de acordo com o fluxo de idéias e com a capacidade para executar projetos (SCHUH et al., 2008a, p. 212). A análise da viabilidade de novas idéias deve considerar a sua adequação ao portfólio, além da disponibilidade de recursos para realizar os projetos de desenvolvimento (CLARK; WHEELWRIGHT, 1993). Ao mesmo tempo, lacunas na futura oferta de produtos indicam as prioridades para incentivar a geração de idéias e as prioridades em que se deve focar os recursos de projetos (Figura 20).

A integração das informações da avaliação de idéias, com o planejamento da capacidade de projetos e a gestão do portfólio, permite a identificação de interdependências e, com isso, contribui para a reação rápida a mudanças de mercado.

\section{Gestão de requisitos}

No contexto do PLM, produtos devem ser concebidos considerando os requisitos dos clientes e também de todos os grupos de pessoas envolvidos com o produto ao longo do ciclo de vida (NILSSON; FAGERSTRÖM, 2006, p. 167). Por exemplo, devem ser observados os requisitos de desmontagem e de reciclagem, para garantir que esses aspectos sejam incorporados no produto desde a sua concepção.

Nesse sentido, a gestão de requisitos de produtos é iniciada com a identificação dos grupos de pessoas envolvidas com o produto no ciclo de vida. Os passos seguintes são o 
levantamento dos requisitos desses grupos e a avaliação dos requisitos para a priorização na especificação detalhada do produto. Os requisitos sistematizados servem de base para a especificação das funções e para o detalhamento da estrutura funcional (NILSSON; FAGERSTRÖM, 2006, p. 169-171). Esse é o ponto de partida para a estruturação do produto, discutida a seguir.

\section{Estruturação do produto}

A estrutura de produto tem um papel fundamental na gestão do ciclo de vida de produtos. Segundo Rozenfeld et al. (2006, p.335-338), a estrutura do produto contém a identificação dos itens e a definição do relacionamento entre eles. Ela também relaciona os itens com os seus respectivos dados e documentos (Figura 21).

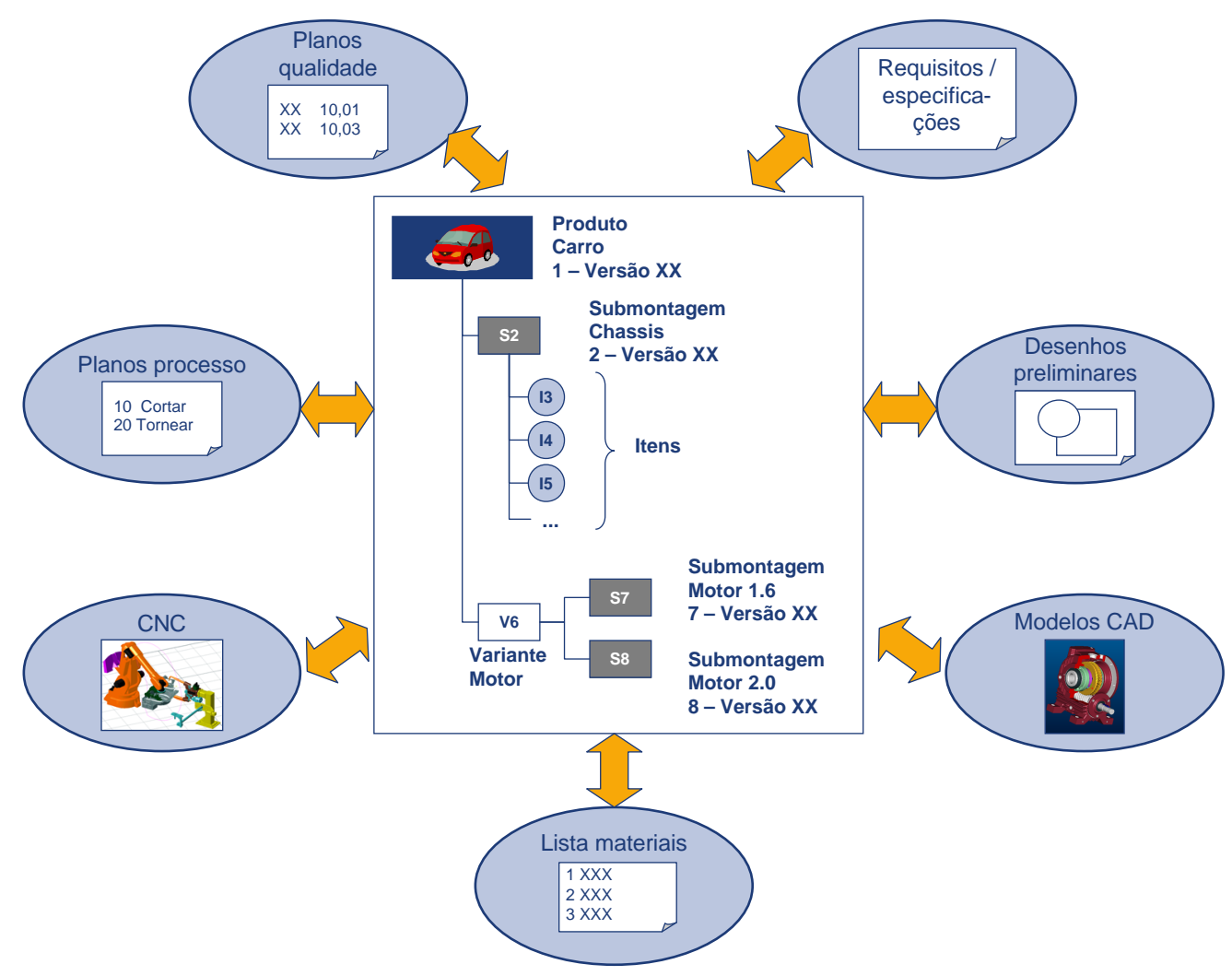

Figura 21. Papel da estrutura de produto na integração de informações no ciclo de vida

$\mathrm{Na}$ estruturação do produto, as funções definidas para atender aos requisitos do produto são combinadas em módulos físicos. Os módulos são detalhados em componentes individuais e as informações de produto são incorporadas à estrutura. Ao estabelecer a relação entre os itens de um produto e as suas informações, a estrutura de produto torna-se um dos elementos centrais para a gestão de dados de produto no ciclo de vida (SCHUH; ASSMUS; ZANCUL, 2006, p. 393-394). 


\section{Projeto integrado do produto e do processo}

A integração do desenvolvimento tanto do produto em si como do processo de produção, também conhecida como engenharia simultânea, é uma questão que as empresas estão tentando solucionar desde o início dos anos 90 (veja CARTER; BAKER, 1992; PRASSAD, 1996). A fim de antecipar decisões tomadas de forma consensual e reduzir o tempo de desenvolvimento, muitas empresas adotam uma estrutura com equipes multifuncionais (CLARK; WHEELWRIGHT, 1993, p. 457-470) e incentivam a participação dos fornecedores desde o início dos projetos de desenvolvimento (NISHIGUCHI, 1994). Considerando a perspectiva da gestão do ciclo de vida, o projeto integrado do produto e do processo significa expandir essas iniciativas para abranger também desde as áreas e atividades de especificação de requisitos - no início do ciclo de vida - até a manutenção, os serviços e a destinação final do produto - no término do ciclo de vida.

\section{Gestão da configuração}

A gestão da configuração é um dos processos de gestão do ciclo de vida de produtos discutidos no subitem 2.2.4. Por ser um elemento-chave para o PLM, a gestão da configuração é discutida mais detalhadamente.

Dois aspectos da gestão de configuração são encontrados na literatura. O primeiro é a gestão de versões e de mudanças no produto ao longo do tempo. O segundo aspecto envolve a configuração de produtos, a partir de regras predefinidas, para atender pedidos específicos de clientes (Figura 22).

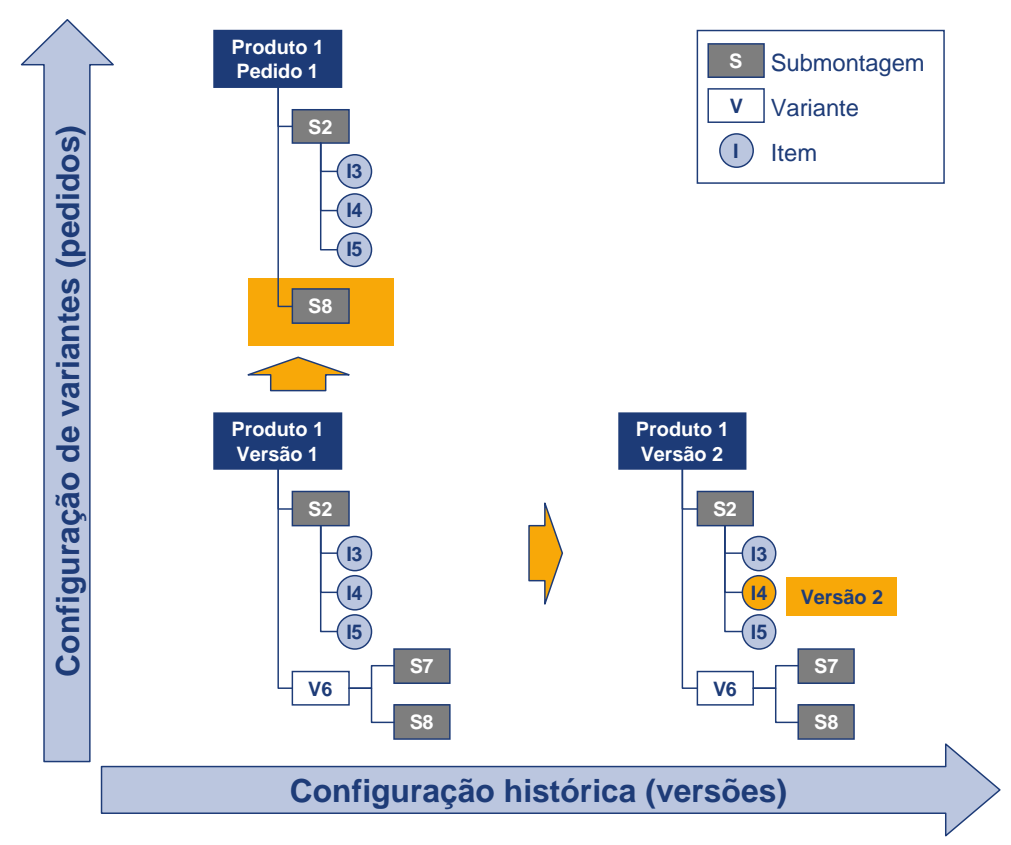

Figura 22. Aspectos da gestão de configuração (adaptado de ARNOLD et al., 2005, p. 74) 
Alguns autores, especialmente os de língua inglesa, enfocam a gestão das mudanças no produto ao longo do tempo - eixo horizontal da Figura 22 (LYON, 2000). Outros autores, notadamente os de língua alemã, tratam a configuração de produtos variantes no escopo da gestão de configuração - eixo vertical da Figura 22. De acordo com esses autores, a configuração abrange a definição das regras de combinação entre os itens variantes que compõem um produto e a definição de um produto para um cliente específico com base nessas regras (ARNOLD et al., 2005, p. 68-77; SCHUH, 2005, p. 240). No contexto do PLM, a gestão de configuração é composta por esses dois aspectos combinados, conforme ilustrado na Figura 22.

\section{Coleta sistematizada de dados de serviços para reutilização em novos desenvolvimentos}

A última prática importante para o PLM descrita aqui é o reaproveitamento das informações de uso dos produtos e de serviços para direcionar as atividades realizadas no início do ciclo de vida para desenvolver novos produtos.

As empresas geralmente não aproveitam os dados de campo da macrofase de uso dos produtos, principalmente porque esse tipo de informação é de difícil obtenção. Avanços recentes nas áreas de eletrônica e de software - como as tecnologias de transmissores RFID (Radio Frequency Identification), de comunicação móvel e de sistemas para diagnóstico à distância - permitem o desenvolvimento de soluções para a captura de dados dos produtos durante o seu uso, além do envio desses dados para o fabricante (KIRITSIS; BUFARDI; XIROUCHAKIS, 2003; JUN; KIRITSIS; XIROUCHAKIS, 2007; XU et al., 2007). A obtenção sistemática dos dados do uso dos produtos por meio de novas tecnologias possibilita fechar o loop de informações do fim para o início do ciclo de vida, garantindo o reaproveitamento de informações importantes para direcionar novos desenvolvimentos.

\subsection{Sistemas de informação para a gestão do ciclo de vida de produtos}

Neste item são apresentadas as principais características de sistemas de informação para apoiar o PLM. Inicialmente, discutem-se os elementos necessários e a abrangência envolvida na composição de uma solução de tecnologia da informação para apoiar o PLM (subitem 2.3.1). Um dos elementos centrais para a solução de PLM são os sistemas PDM / PLM. Tais sistemas, que podem ser classificados em tipos de acordo com sua origem (subitem 2.3.2), oferecem um amplo escopo de funcionalidades (subitem 2.3.3). Partindo do 
entendimento dos tipos de sistemas e de suas funcionalidades, são apresentadas algumas características dos principais sistemas PLM disponíveis hoje no mercado (subitem 2.3.4).

\subsubsection{Composição e abrangência de soluções para o PLM}

Ao longo do ciclo de vida, diversos sistemas de informação são empregados para gerar e para gerenciar dados de produtos. Na macrofase de desenvolvimento, a engenharia utiliza sistemas CAD e CAE (Computer Aided Engineering), CAPP (Computer Aided Process Planning), CAM (Computer Aided Manufacturing), entre outros, para criar as informações que definem os novos produtos. Os documentos de engenharia são gerenciados pelo sistema PDM/PLM, que também controla a estrutura de produto e as mudanças na configuração. Na produção, o sistema SCM (Supply Chain Management) calcula a necessidade de materiais e gerencia o uso dos recursos produtivos da empresa. O pessoal de serviços e de manutenção precisa acessar informações dos clientes, mantidas pelo CRM (Customer Relationship Management). Eles também precisam consultar e atualizar a configuração do produto, que pode estar armazenada no PDM/PLM (BOOS; ZANCUL, 2006, p. 789). Paralelamente, os dados de custeio dos produtos e da alocação de pessoal nas atividades relacionadas aos produtos são gerenciados, respectivamente, pelos módulos financeiro e de recursos humanos do ERP (Enterprise Resource Planning). A utilização de sistemas de informação ao longo das macrofases do ciclo de vida de produtos é ilustrada na Figura 23.

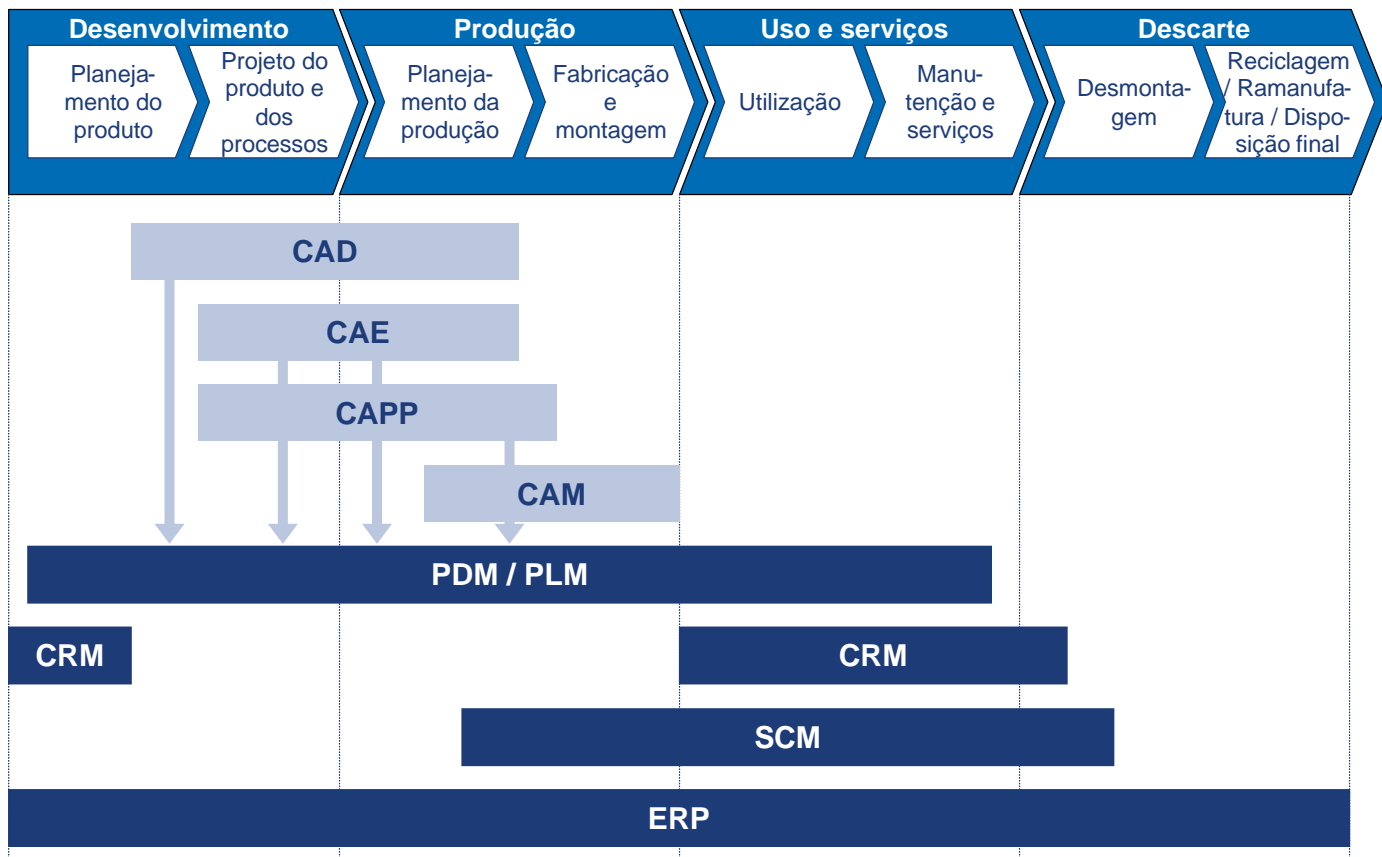

Figura 23. Utilização de sistemas de informação nas fases do ciclo de vida de produtos (adaptado de SCHUH, 2006, p. 10) 
Os sistemas listados na Figura 23 podem ser classificados em dois grupos. O primeiro grupo compreende as ferramentas típicas de engenharia, utilizadas na criação dos dados de produtos (CAD, CAE, CAPP e CAM). São ferramentas com foco de atuação bastante especializado, geralmente comercializadas por fornecedores com ênfase em engenharia. O uso nas empresas é muitas vezes restrito ao departamento responsável por gerar as informações correspondentes (modelos 3D, análises estruturais, planos de processo de fabricação e programas de comando numérico para máquinas, entre outras). O segundo grupo envolve quatro sistemas de uso mais amplo nas empresas (PDM/PLM, SCM, CRM e ERP). Atualmente, alguns fornecedores de TI organizam seus softwares de gestão empresarial nesses quatro grandes grupos de funcionalidades. O papel de cada um desses sistemas é resumido a seguir (ROZENFELD et al., 2006, p. 77-78):

CRM: armazena os dados de clientes e gerencia as informações sobre os contatos com os clientes - compreende as funcionalidades de automação de vendas, gerência de vendas, telemarketing, atendimento ao cliente, análise de informações gerenciais e comércio eletrônico, entre outras.

SCM: responsável por administrar o fluxo de produção na cadeia de suprimentos compreende as funcionalidades de gestão da demanda, vendas, compras, recebimento, gestão de estoques, planejamento da produção etc.

PDM/PLM: focado na criação e na gestão das informações dos produtos e dos projetos de desenvolvimento ao longo de todo o ciclo de vida.

ERP: envolve as funções centrais administrativas de gestão financeira, de contabilidade e de gestão de recursos humanos.

A intensidade do uso de cada um desses sistemas varia ao longo do ciclo de vida, conforme ilustrado na Figura 24. Durante o desenvolvimento, o principal sistema utilizado é o PDM/PLM. Na macrofase de produção, o SCM entra em primeiro plano, enquanto que o CRM ganha importância para gerenciar as vendas e os contatos com os clientes. Após a produção, na macrofase de uso e de serviços, o PDM/PLM volta a ter um papel mais importante por ser responsável pela constante gestão e atualização dos dados de produto (ROZENFELD et al., 2006, p. 78). 


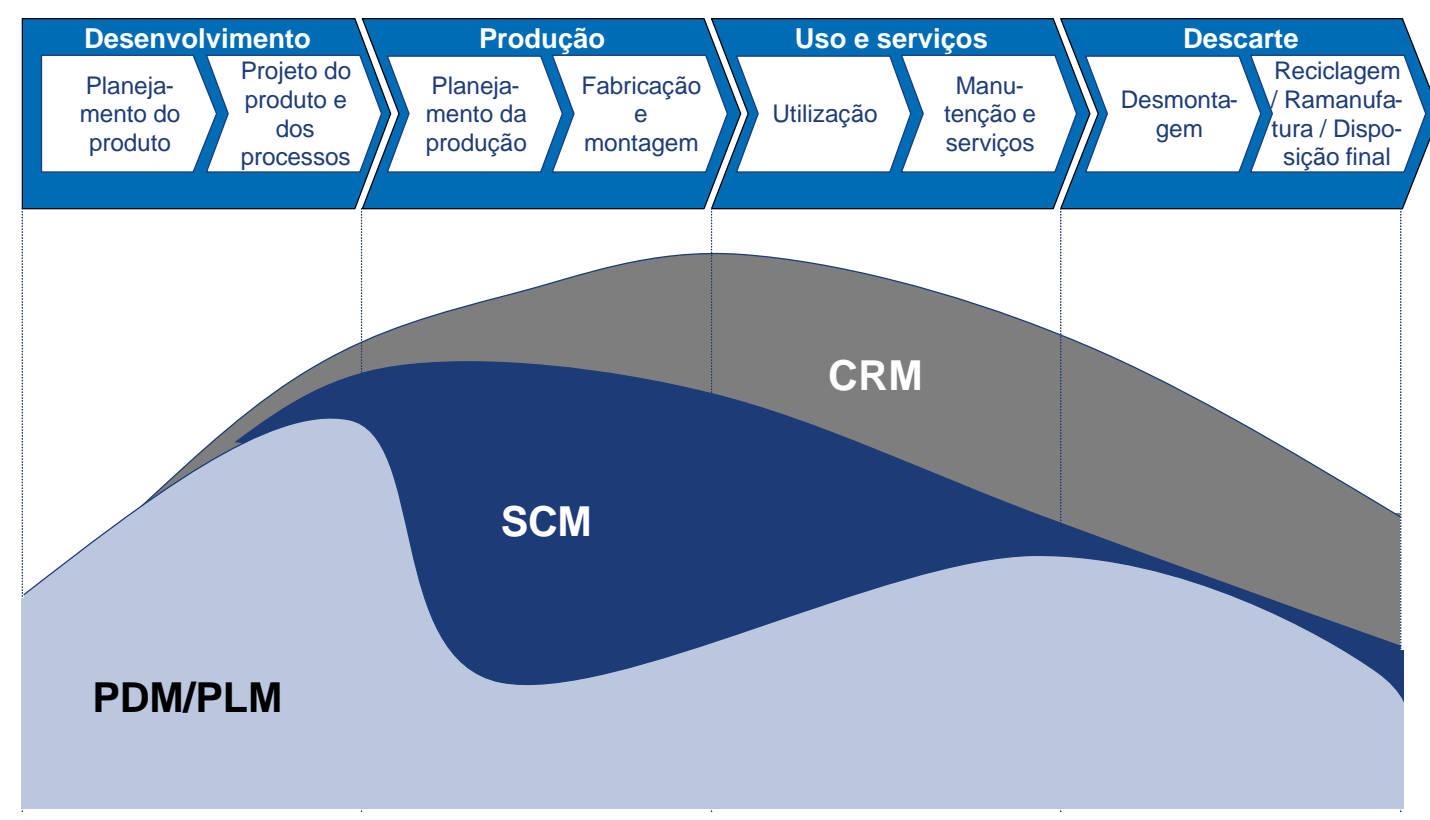

Figura 24. Nível de utilização dos sistemas PLM, CRM e SCM ao longo do ciclo de vida (adaptado de CIMDATA, 2001b, p. 14)

Nesse contexto, em que várias classes de sistemas de informação são empregadas para gerar e para gerenciar dados de produtos, pode ser necessário integrar os diversos sistemas envolvidos para compor a solução PLM capaz de atender a todos os requisitos da abordagem de gestão do ciclo de vida de produtos.

Na composição da solução PLM, os sistemas focados na gestão de dados de produto que podem ser chamados tanto de sistemas PDM, como de sistemas PLM - têm um papel fundamental. Durante a macrofase de desenvolvimento e eventualmente na produção, o PDM/PLM concentra a gestão da estrutura de produto, a gestão dos documentos e a gestão de mudanças no produto. Os recursos de integração de sistemas e as funções de coordenação do trabalho em equipe (e.g. workflow), permitem que os sistemas PDM/PLM integrem as ferramentas utilizadas pela engenharia (CAD, CAE, CAPP, CAM). Isso torna o sistema PDM/PLM o principal backbone de dados sobre os produtos (Figura 23). Após a liberação para produção, os sistemas PDM/PLM em muitas empresas dividem a responsabilidade pela gestão dos dados de produto com o SCM, o CRM e o ERP.

O papel do PDM/PLM na composição da solução completa de TI para apoiar a gestão do ciclo de vida de produtos depende do tipo de sistema utilizado. Esse assunto é discutido no subitem a seguir. 


\subsubsection{Tipos de sistemas PLM}

Atualmente existe uma ampla variedade de sistemas PDM/PLM. Os softwares disponíveis comercialmente podem ser diferenciados em relação à sua origem e em relação ao seu posicionamento de mercado.

Em relação à origem, os sistemas se dividem em três grupos. O primeiro grupo é formado por sistemas que se desenvolveram a partir de sistemas CAD. O segundo grupo é composto por soluções PDM/PLM que são parte de uma solução ERP mais ampla. O terceiro grupo engloba os sistemas de gestão de dados de produtos desenvolvidos originalmente para esse mercado e que se mantêm focados nesse escopo.

Em relação ao posicionamento, existem sistemas que mantêm o posicionamento mais tradicional do mercado de PDM. São soluções geralmente mais focadas na gestão de dados de engenharia. Outros fornecedores, que buscam diferenciação por oferecer um escopo maior de funcionalidades, adotam um posicionamento mais alinhado com PLM.

Uma pesquisa recente - executada no âmbito deste trabalho de doutorado - analisou os tipos de sistemas PLM disponíveis no mercado europeu (ASSMUS et al., 2006). Os resultados da pesquisa estão resumidos na Figura 25.

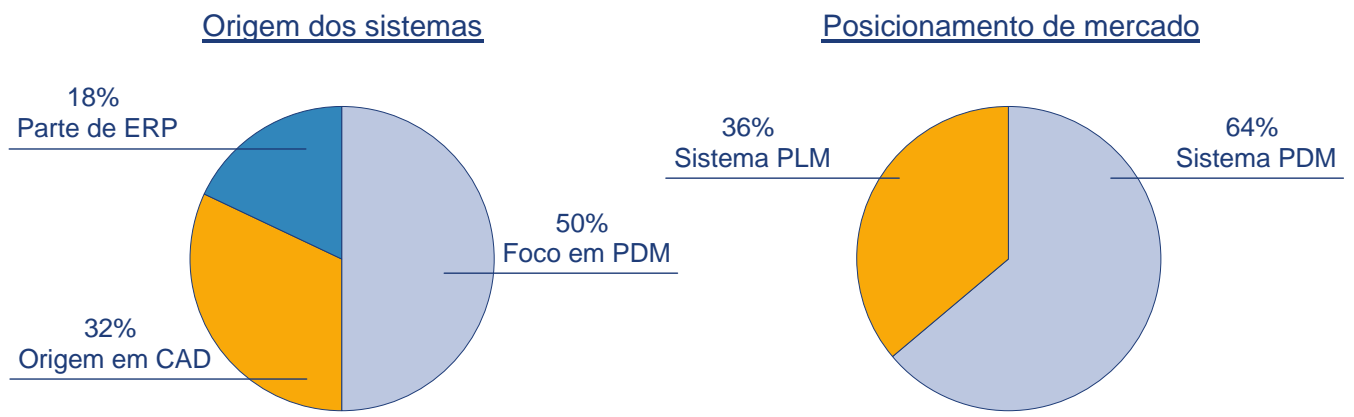

Figura 25. Origem dos sistemas existentes e posicionamento de mercado dos fornecedores (ASSMUS et al., 2006, p. 17)

A análise dos dados de mercado mostra que 32\% dos sistemas originaram-se de sistemas CAD, enquanto que 18\% são parte de uma suite ERP mais ampla. Os demais 50\%, são sistemas de fornecedores focados no mercado de gestão de dados de produto. Uma outra diferença é o posicionamento de mercado. Aproximadamente um terço das empresas posiciona-se como fornecedor de sistemas PLM, enquanto que cerca de dois terços apresentam-se como fornecedores de sistemas PDM (Figura 25). 


\subsubsection{Funcionalidades de sistemas PLM}

As funcionalidades de sistemas PLM podem variar muito de sistema para sistema. No entanto, é possível identificar um grupo de funcionalidades típicas de sistemas PLM. Esse grupo de funcionalidades abrange as funções que foram incorporadas nos primeiros sistemas PDM que surgiram no mercado, além de funções que estão presentes na maioria dos sistemas PLM existentes atualmente. Dentre essas funções, listadas na Figura 26, estão a gestão de documentos e a estruturação de produtos (CIMDATA, 2001a, p. 12; EIGNER, 2006, p. 22).

\begin{tabular}{|ll|}
\hline \multicolumn{2}{|c|}{$\begin{array}{c}\text { Funcionalidades típicas de } \\
\text { sistemas PLM }\end{array}$} \\
\hline 1. & Gestão de documentos \\
2. & Estruturação de produtos \\
3. & $\begin{array}{l}\text { Gestão de mudanças e } \\
\text { controle da configuração }\end{array}$ \\
4. & Colaboração \\
5. & Gestão de projetos \\
6. & $\begin{array}{l}\text { Suporte para integração de } \\
\text { sistemas }\end{array}$ \\
\hline
\end{tabular}

Figura 26. Funcionalidades típicas de sistemas PLM

As funcionalidades de PLM listadas na Figura 26 são descritas resumidamente a seguir (BOOS; ZANCUL, 2006, p. 792 - 795).

1. Gestão de documentos - os documentos são descritos por metadados e são armazenados em um "cofre” de dados, conhecido por vault. Cada documento pode ser relacionado a um ou mais objetos do sistema e pode ser visualizado. Além disso, as funções apóiam a publicação de documentos técnicos e o arquivamento de longo prazo de documentos, como desenhos de engenharia.

2. Estruturação de produtos - os dados mestres do produto são criados e gerenciados por esse grupo de funções. Os materiais e outros objetos no sistema são classificados de acordo com um sistema de classificação predefinido. Isso reduz o esforço necessário para procurar e reutilizar informações existentes. A estrutura de produto e as listas de materiais - Bill of Materials (BOM) - podem ser gerenciadas de acordo com várias perspectivas, também chamadas de "visões” (visão do desenvolvimento, visão da montagem etc.). 
3. Gestão de mudanças e controle da configuração - abrange a gestão de mudanças nas informações e nos documentos do produto e o controle da configuração do produto ao longo de todo o ciclo de vida.

4. Colaboração - engloba funções como workflow, videoconferência, compartilhamento de aplicativos e banco de dados de conhecimentos, que possibilitam a cooperação entre os membros dos times de projeto.

5. Gestão de projetos - além do planejamento e execução de projetos individuais, o planejamento integrado de múltiplos projetos também é apoiado por esse grupo de funções.

6. Suporte para a integração de sistemas - compreende os padrões e as interfaces necessárias para possibilitar a troca de dados entre as soluções de TI usadas na empresa.

Com base no entendimento dos tipos de PLM e de suas funcionalidades principais detalhadas anteriormente, os principais sistemas disponíveis atualmente no mercado são descritos no próximo subitem.

\subsubsection{Descrição de sistemas disponíveis comercialmente}

Atualmente, existe uma ampla oferta de sistemas de TI para apoiar a gestão do ciclo de vida de produtos. Neste item, são apresentadas as principais características dos sistemas dos cinco fornecedores apontados como líderes de mercado em um levantamento realizado pelo CIMData - SAP, Siemens PLM (antiga UGS), Dassault, PTC e Oracle/Agile (CIMDATA, 2008a, p. 4).

A Tabela 4 a seguir apresenta uma visão geral dos sistemas dos cinco fornecedores de sistemas PLM, incluindo: o nome do sistema, a classificação conforme a origem, a classificação de acordo com o posicionamento de mercado e a descrição de alguns características específicas, destacadas pelos fornecedores desses softwares como pontos fortes de seus sistemas ${ }^{20}$.

\footnotetext{
${ }^{20}$ Baseado em informações disponíveis no site dos fornecedores na Internet
} 
Tabela 4 - Visão geral de alguns sistemas PLM oferecidos no mercado brasileiro

\begin{tabular}{l|l|l|l|l}
\hline \multicolumn{1}{c|}{ Fornecedor } & \multicolumn{1}{|c|}{ Sistema } & $\begin{array}{c}\text { Classificação } \\
\text { origem }\end{array}$ & $\begin{array}{l}\text { Classificação } \\
\text { posicionamento }\end{array}$ & $\begin{array}{c}\text { Pontos forte informados pelos } \\
\text { fornecedores }\end{array}$ \\
\hline SAP & mySAP PLM & ERP & PLM & Gestão do portfólio de produtos \\
\hline $\begin{array}{l}\text { Siemens PLM } \\
\text { (anterior Unigraphics } \\
\text { Solutions) }\end{array}$ & Teamcenter & CAD & PLM & $\begin{array}{l}\text { Integração com CAD, } \\
\text { colaboração, planejamento da } \\
\text { fábrica e da produção }\end{array}$ \\
\hline $\begin{array}{l}\text { Dassault Systems e } \\
\text { IBM }\end{array}$ & Enovia & CAD & PLM & Integração com CAD, colaboração \\
\hline $\begin{array}{l}\text { PTC Parametric } \\
\text { Technology }\end{array}$ & Windchill & CAD & PLM & $\begin{array}{l}\text { Gestão de mudanças e de } \\
\text { configuração, workflow, } \\
\text { integração com CAD }\end{array}$ \\
\hline Oracle / Agile & Agile 9 & PDM & PLM & $\begin{array}{l}\text { Gestão de mudanças, gestão do } \\
\text { portfólio, eSourcing }\end{array}$ \\
\hline
\end{tabular}

Observa-se que dentre os cinco fornecedores líderes, estão representados sistemas com diferentes origens (CAD, PDM ou ERP), mas todos eles estão posicionados como fornecedores de soluções PLM. Já os pontos fortes destacados pelos fornecedores de cada sistema variam bastante. Nota-se que os três fornecedores originados de soluções CAD citam a integração do PLM com o CAD como sendo um diferencial de sua solução, enquanto que os outros dois sistemas ressaltam a importância de funcionalidades estendidas de PLM, como a gestão do portfólio.

Dentre os sistemas listados, apenas o SAP inclui uma representação detalhada dos processos que são apoiados pelo sistema em um modelo de referência. Tal modelo indica as funcionalidades do sistema que são utilizadas em cada atividade. Um modelo de referência amplo e genérico das funcionalidades típicas de sistemas PLM não é encontrado na revisão bibliográfica nem na pesquisa dos sistemas.

\subsection{Benefícios da gestão do ciclo de vida de produtos}

O PLM resulta em importantes benefícios para as empresas. Tais benefícios são relatados por estudos empíricos (ABRAMOVICI et al., 2004, p. 57-70), por estudos de caso (SCHEER et al., 2006, p. 147-256) e pela literatura especializada da área (STARK, 2005, p. 12-13 e 432-433; VDMA, 2005, p. 20; ASSMUS et al., 2006, p. 39). Alguns dos benefícios mais citados na literatura são listados a seguir:

Padronização dos processos;

Automatização de procedimentos repetitivos;

Melhoria do fluxo de informações; 
Aumento da intensidade de comunicação e do nível de cooperação;

Redução do tempo despendido em atividades que não agregam valor;

Maior facilidade de acesso às informações atualizadas dos produtos / processos;

Diminuição de erros e de retrabalho;

Redução da quantidade de mudanças realizadas nos produtos - principalmente nas etapas mais avançadas do desenvolvimento

Aumento da reutilização de itens e de documentos existentes;

Maior grau de preenchimento dos requisitos dos grupos de pessoas envolvidos;

Aumento da variedade de produtos para clientes;

Redução da complexidade;

Melhor aproveitamento do conhecimento gerado e disponível na empresa;

Maior disponibilidade de indicadores confiáveis.

Observa-se que a lista de benefícios atribuídos ao PLM é ampla, mas que a falta de uma estruturação desses benefícios dificulta o entendimento do seu impacto nas empresas. É necessário agrupar os benefícios em categorias. Além disso, é preciso entender a relação de causa e efeito entre as práticas de PLM e os benefícios esperados.

Uma possibilidade de categorização dos benefícios do PLM é apresentada por Schuh et al. (2008b, p. 21). De acordo com os autores, os benefícios do PLM podem ser agrupados em três categorias: eficiência, efetividade e gestão do processo. Considerando essas três categorias, é possível classificar a lista de benefícios apresentada anteriormente. Também é possível relacionar as práticas de PLM (apresentadas em 2.2.5) com as categorias de benefícios, de acordo com a relação de causa e efeito existente (Figura 27). 


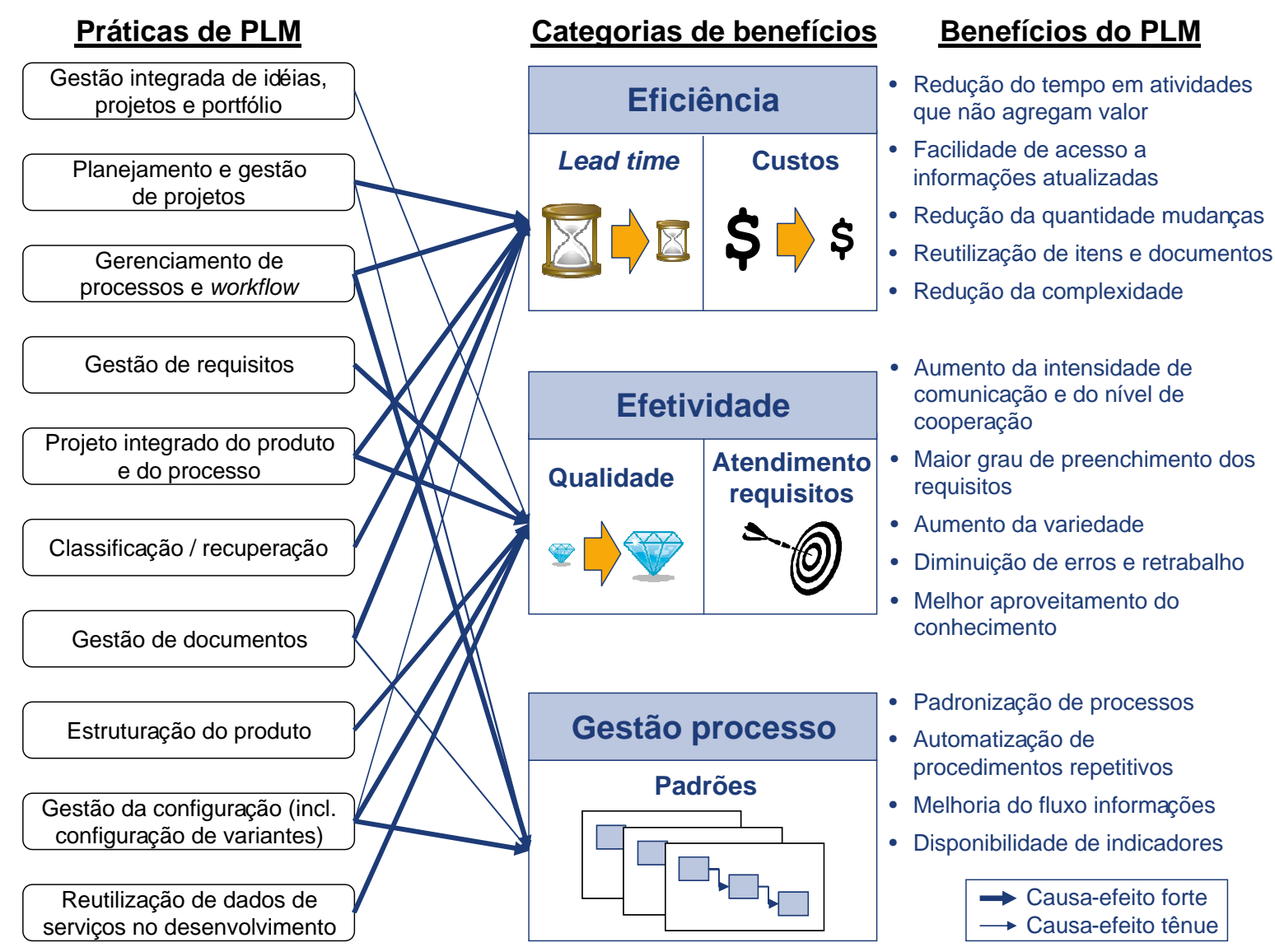

Figura 27. Relação entre as práticas e os benefícios de PLM

As práticas de PLM são apresentadas do lado esquerdo da Figura 27. A aplicação dessas práticas pode resultar em benefícios organizados nas três categorias apresentadas na parte central da Figura 27. Cada uma das práticas está ligada aos seus respectivos benefícios por linhas que indicam uma relação de causa e efeito. A largura das linhas indica a intensidade desse relacionamento. Linhas mais largas indicam uma relação de forte intensidade entre as práticas e os benefícios ligados a elas. Linhas mais finas representam ligações tênues entre as práticas e os seus benefícios. Ao lado direito da Figura 27 estão listados os benefícios detalhados, agrupados de acordo com a sua categoria. Essa sistematização facilita a compreensão dos benefícios que podem ser esperados na implantação da gestão do ciclo de vida de produtos e permite focar a implantação nas práticas que podem resultar nos benefícios mais importantes para a empresa específica.

O impacto dos benefícios do PLM no fluxo de caixa de um produto é ilustrado de forma conceitual na Figura 28. 


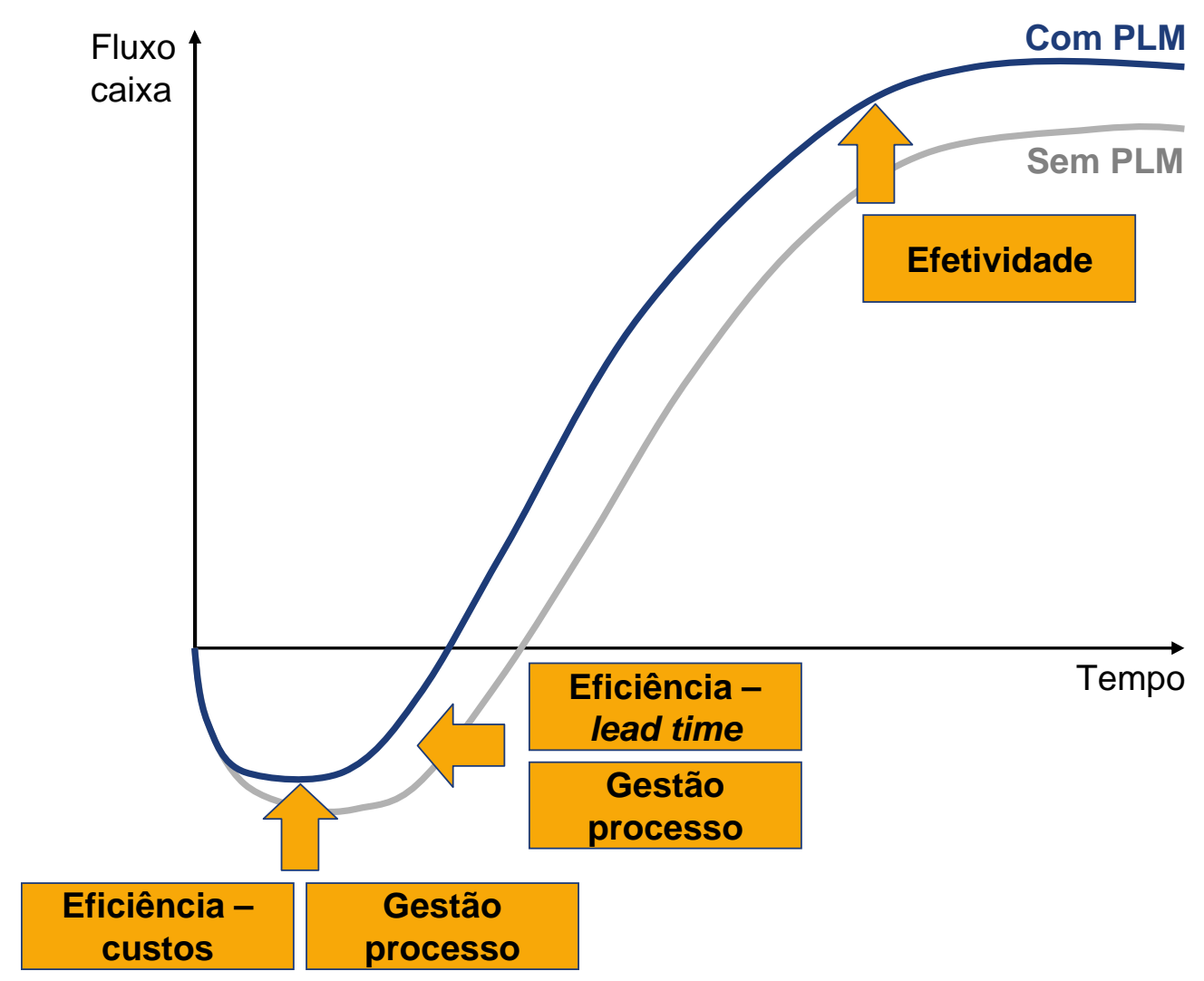

Figura 28. Impacto do PLM no fluxo de caixa de um produto - conceitual (adaptado de ABRAMOVICI et al., 2004, p. 64)

A gestão do ciclo de vida de produtos contribui para melhorar o fluxo de caixa dos produtos. O período de fluxo de caixa negativo no início do desenvolvimento é reduzido. Os custos de desenvolvimento são menores, devido ao maior controle do processo e aos ganhos de eficiência que reduzem despesas. O tempo necessário para lançar os produtos no mercado também é reduzido. Com o lançamento mais rápido em relação aos concorrentes, o produto pode atingir uma maior participação de mercado. Os ganhos de efetividade - maior qualidade e alto grau de atendimento dos requisitos - também contribuem para aumentar as chances de sucesso do produto no mercado (Figura 28). Esses fatores combinados resultam em aumento do retorno dos investimentos em desenvolvimento de produtos. 


\section{CONCEITOS DE MODELAGEM DE EMPRESAS}

Este capítulo trata de conceitos de modelagem de empresas. A Figura 29 apresenta a localização do capítulo 3 na estrutura da síntese da bibliografia fundamental, destacando o seu conteúdo e o seu relacionamento com o capítulo 2.

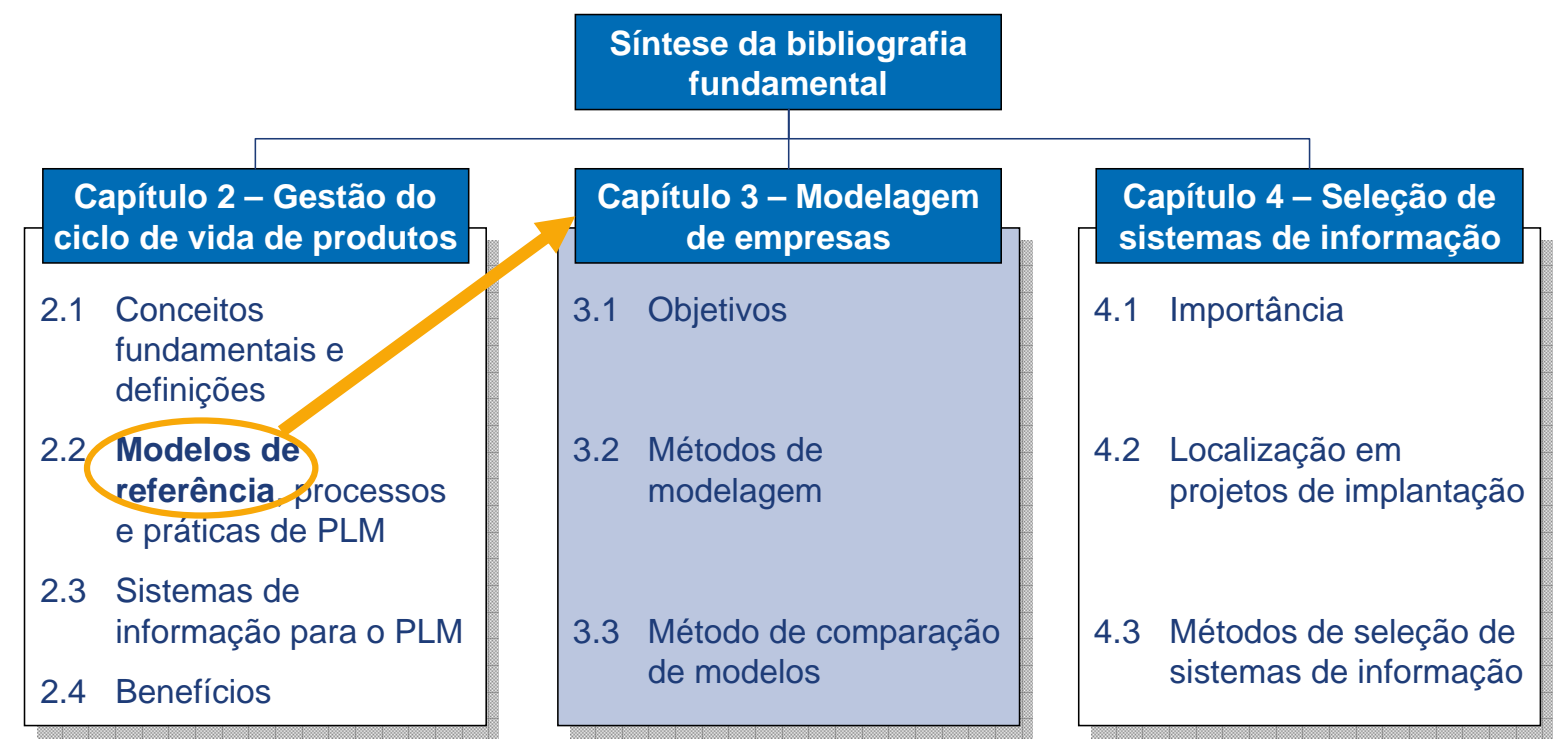

Figura 29. Conteúdo do capítulo 3

No capítulo 2, é discutida a definição de modelos de referência (subitem 2.2.2) como base para a apresentação dos modelos de referência existentes para apoiar a gestão do ciclo de vida de produtos (subitem 2.2.3). O enfoque do capítulo 2 é o conteúdo dos modelos de referência.

A partir da definição apresentada, neste capítulo são discutidos os aspectos técnicos da construção e da utilização de modelos de referência. A discussão realizada limita-se aos conceitos essenciais para a fundamentação teórica deste trabalho.

Assim, inicialmente são discutidos os objetivos da modelagem de empresas (item 3.1). Em seguida, são apresentados os métodos de modelagem relacionados com o escopo do trabalho (item 3.2). Por fim, apresenta-se um método de comparação de modelos voltado para a comparação entre modelos de processos de negócio e modelos de sistemas de informação (item 3.3).

\subsection{Os objetivos da modelagem de empresas}

A modelagem de empresas é a atividade de construção de modelos que representam parte de uma empresa ou de um grupo de empresas. Os aspectos da empresa a serem modelados são definidos de acordo com as necessidades dos usuários, podendo envolver, 
processos de negócio, dados, estrutura organizacional, recursos, entre outros (VERNADAT, 1996, p. 18-25; 2002, p. 4309).

Na modelagem, o conhecimento sobre a estrutura e a operação da empresa é formalizado para que possa ser compartilhado, analisado e otimizado. Um dos propósitos da modelagem é possibilitar a análise do desempenho da empresa, visando a otimização, como nos projetos de reengenharia de processos de negócio. Os modelos de empresa também são empregados para documentar processos de negócio, possibilitar a simulação baseada em computador e apoiar a implementação de sistemas de informação (VERNADAT, 1996, p. 1825; BARBALHO; ROZENFELD, 2002, p. 5).

Na implementação de sistemas de informação, a modelagem de empresas é geralmente empregada no mapeamento dos processos de negócio considerados no escopo do projeto de implementação. Os modelos de empresa também são usados na identificação dos requisitos funcionais e na especificação técnica da estrutura de dados do sistema de informação. Além disso, pesquisas recentes tratam do relacionamento entre modelos de processos de negócio com modelos de sistemas de informação para direcionar a implementação dos sistemas de TI a partir da definição dos processos (ODEH; KAMM, 2003; LANKHORST, 2004).

Considerando a definição de modelagem de empresas e a discussão dos seus objetivos, no próximo subitem são apresentados alguns métodos de modelagem.

\subsection{Métodos de modelagem}

Atualmente, os modelos de empresa podem ser representados por diversos métodos de modelagem disponíveis. Neste item, apresenta-se um resumo dos métodos de modelagem relevantes no contexto deste trabalho.

Nesse sentido, são descritos os métodos empregados nos modelos de referência dos processos de gestão do ciclo de vida de produtos analisados no capítulo anterior (subitem 2.2.3): Event-Driven Process Chain (EPC), Business Process Modeling Notation (BPMN) e a representação tabular como forma alternativa simplificada de modelagem. Também é apresentado o Modelo de Entidade-Relacionamento (MER), dada a sua importância para embasar o desenvolvimento do framework conceitual de elementos do PLM proposto neste trabalho (ver capítulo 6).

Cada um dos métodos listados anteriormente é apresentado sucintamente a seguir. Detalhes sobre esses e outros métodos de modelagem estão disponíveis nas referências citadas 
ao fim de cada seção e em obras de referência (VERNADAT, 1996; AGUILAR-SAVEN, 2004; BECKER; KUGELER; ROSEMANN, 2005; MERTINS; JOCHEM, 2005).

\section{EPC}

O método EPC é próprio para a modelagem de atividades, dados, eventos e organização. Esse método permite a descrição de processos de negócio por meio do fluxo seqüencial de eventos e de atividades. O EPC sempre começa e termina com um evento que descreve um estado que causa uma conseqüência. Os eventos são ligados às funções que representam a transformação realizada desde o estado inicial até o estado final. Se necessário, operadores lógicos podem ser utilizados nas ligações entre os eventos e as funções. A cada função podem ser associados elementos organizacionais responsáveis e informações de entrada e saída (BECKER; KUGELER; ROSEMANN, 2005, p. 68-90).

\section{BPMN}

O método BPMN foi desenvolvido pela Business Process Management Initiative (BPMI), com o objetivo de criar uma representação de fácil compreensão e, ao mesmo tempo, capaz de representar processos de negócio de forma adequada e abrangente, capturando todos os seus aspectos relevantes. Desde o início de sua concepção, o BPMN visa à descrição de processos de negócio.

Um modelo BPMN utiliza quatro categorias básicas de elementos: objetos de fluxo (eventos, atividades e decisões), objetos de conexão (representam a seqüência lógica do modelo), swimlanes ou "raias de piscina" (delimitam o papel das áreas organizacionais no modelo) e artefatos (permitem a inclusão de comentários e de outros dados que descrevem o contexto do modelo). O BPMN foi reconhecido como um padrão pelo Object Management Group (OMG) e continua sendo desenvolvido por essa organização (WHITE, 2004; OMG, 2006).

\section{Representação tabular}

Na prática, a representação tabular é freqüentemente aplicada em empresas como forma alternativa e simplificada de modelagem. Na tabela, geralmente, as colunas são utilizadas para designar os diferentes objetos do modelo (e.g. atividades, recursos, informações), enquanto as linhas são empregadas para a entrada dos dados. Os registros podem ser identificados por meio de uma numeração hierárquica estruturada, definindo assim os níveis de detalhamento do modelo. 
Essa forma de representação é de fácil utilização, uma vez que ela não exige conhecimento prévio sobre nenhum formalismo de modelagem específico. Além disso, a representação tabular é flexível, pois permite a realização de adaptações de acordo com as necessidades dos usuários. Por fim, a modelagem em tabelas dispensa o uso de ferramentas (softwares) de modelagem, já que o modelo é construído com uso de planilhas eletrônicas.

\section{MER}

O Modelo de Entidade-Relacionamento foi desenvolvido para auxiliar a especificação de bancos de dados. Esse modelo baseia-se na percepção do universo constituído por entidades, relacionamentos e atributos.

As entidades representam objetos reais, concretos ou abstratos descritos por um conjunto de atributos. Os atributos são características ou propriedades de uma entidade ou um relacionamento. Os relacionamentos determinam as ligações entre as entidades. A cardinalidade de um relacionamento entre um par de entidades pode ser definido como 1:1 (ou seja, cada ocorrência de uma entidade é ligada a somente uma ocorrência da outra entidade), 1:n (cada ocorrência de uma entidade pode ser ligada a mais de uma ocorrência da outra entidade), n:1 (simétrico a 1:n) e m:n (produto cartesiano entre as ocorrências de ambas as entidades).

Graficamente, as entidades são representadas por retângulos, os relacionamentos, por losangos e os atributos, por elipses. (VERNADAT, 1996, p. 202-206).

\subsection{Método de comparação de modelos}

A comparação de modelos tem como objetivo identificar as similaridades entre dois ou mais modelos distintos. Essa abordagem é útil para diversos tipos de iniciativas nas empresas. Por exemplo, pode-se comparar processos semelhantes realizados em unidades diferentes da empresa com o intuito de padronizar ou centralizar a operação. Os modelos de sistemas de informação podem ser comparados com modelos de processos negócio para que se verifique o grau de aderência do sistema ao processo (VAN DONGEN; DIJKMAN; MENDLING, 2007, p. 450-451).

No contexto deste trabalho, o interesse principal é a comparação entre modelos de sistemas de informação com modelos de processos de negócio. Segundo Kirchmer (1998, p. 112), esse tipo de comparação pode ser utilizado como ferramenta para apoiar a seleção do sistema de informação mais adequado aos requisitos dos processos de negócio modelados. Outra aplicação possível é na delimitação do escopo de implementação de um sistema de 
informação já selecionado, ou seja, na definição das atividades de uma empresa que podem ser apoiadas por funcionalidades de um sistema de informação.

Nesse sentido, os modelos que representam os processos de negócio da empresa e as funcionalidades do sistema de informação são comparados e as similaridades são determinadas. Nos casos em que modelos de referência já estão disponíveis para o sistema de informação, eles devem ser utilizados. Se esse não for o caso, o modelo de referência do sistema de informação precisa ser construído a partir das informações técnicas sobre o sistema.

De acordo com Kirchmer (1998, p. 112-116), a comparação entre os modelos é dificultada pelo emprego de terminologias distintas e pelo diferente grau de detalhamento encontrado em cada um dos modelos. Para contornar esses obstáculos, a comparação deve ser realizada com base em uma definição comum da terminologia empregada. Também, deve-se permitir que nenhum, um ou mais de um elemento do modelo do sistema sejam relacionados com cada um dos elementos do modelo do processo de negócio. O resultado da comparação é a indicação da adequação do software (sistema de informação) para apoiar os processos de negócio. A Figura 30 apresenta a visão geral do método de comparação de modelos.

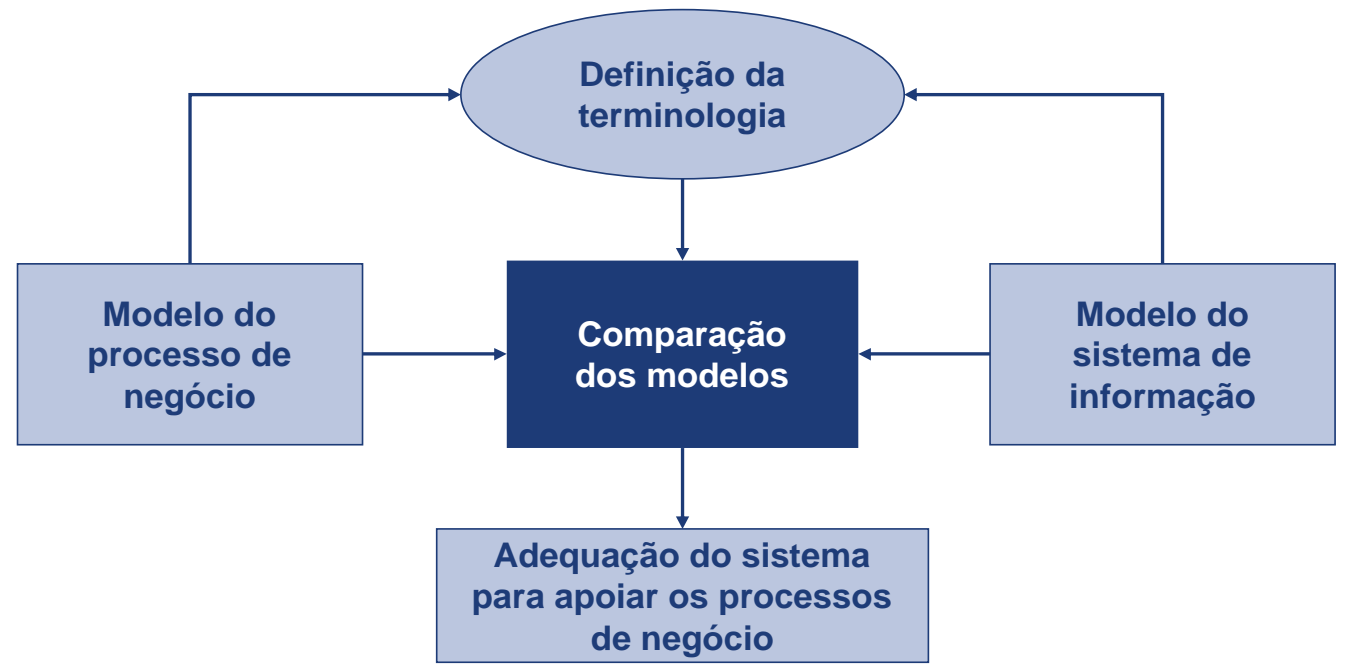

Figura 30. Método de comparação de modelos (KIRCHMER, 1998, p. 114)

O método de comparação de modelos proposto por Kirchmer (1998) define os aspectos conceituais da comparação. A validação do método em uma aplicação detalhada é apresentada por Zancul (2000, p. 82-84). Pesquisas avançadas nessa área tratam da automação da comparação de modelos, inclusive considerando as diferenças semânticas, mas a aplicação dessa tecnologia ainda é restrita (VAN DONGEN; DIJKMAN; MENDLING, 2008).

Dada a discussão sobre conceitos de modelagem, o próximo capítulo aborda tópicos sobre a seleção de sistemas de informação relevantes no contexto deste trabalho. 


\section{TÓPICOS SOBRE A SELEÇÃO DE SISTEMAS DE INFORMAÇÃO}

Este capítulo trata da seleção de sistemas de informação. O conteúdo do capítulo está em destaque na Figura 31.

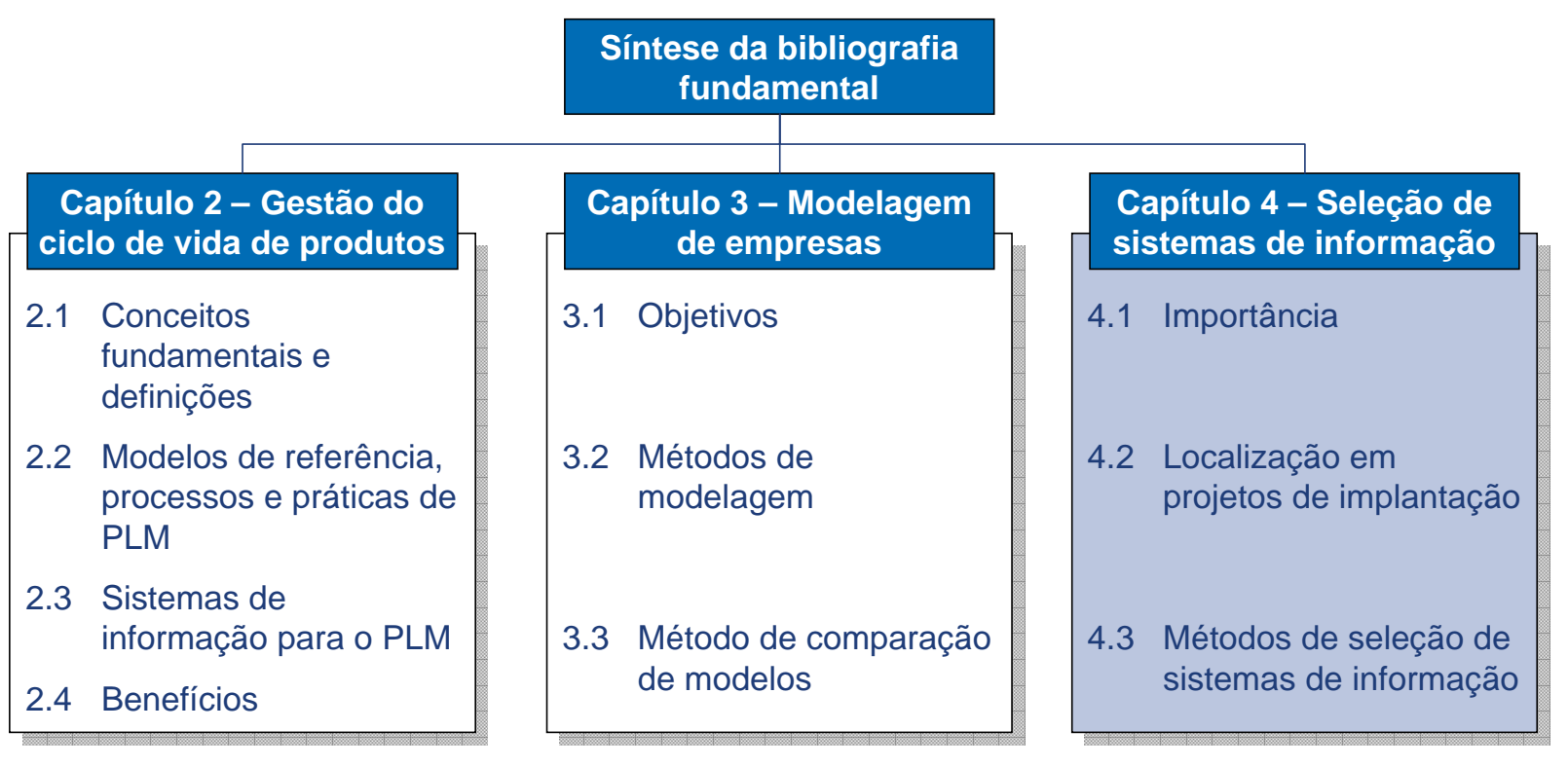

Figura 31. Conteúdo do capítulo 4

O capítulo é iniciado com a discussão da importância da fase de seleção de sistemas de informação em projetos de implantação de softwares (item 4.1). Em seguida, analisa-se a localização dessa fase nos projetos de implantação (item 4.2). Por fim, os métodos de seleção de sistemas de informação levantados na pesquisa bibliográfica são analisados e comparados (item 4.3).

\subsection{Importância da seleção de sistemas}

O processo de seleção de sistemas de informação pode ser definido como uma seqüência de passos por meio dos quais as empresas, partindo de uma lista de alternativas, selecionam um software para ser implantado (COLOMBO; FRANCALANCI, 2004, p. 187).

A escolha de um software adequado para atender às necessidades da empresa é fundamental para o sucesso do projeto de implantação. De acordo com Umble et al. (2003, p. 247), fracassos na implantação de sistemas de informação são comuns quando os recursos da nova tecnologia não atendem aos requisitos dos processos de negócio.

Em se tratando de sistemas PLM, os problemas resultantes de um processo de seleção falho são relatados em um estudo de caso realizado em uma empresa de autopeças (ZANCUL, 2008). Na implantação do PLM nessa empresa, houve um grande atraso em relação ao cronograma definido no início do projeto. A implantação prevista para ocorrer em 22 meses já 
estava, no momento do estudo de caso, 17 meses atrasada em relação ao plano original, ainda sem previsão de conclusão.

No estudo de caso, foram identificadas quatro causas principais para o atraso na implantação do PLM. Uma dessas causas foi a seleção do sistema com base em requisitos pouco detalhados, que não refletiam todas as necessidades específicas dos processos de negócio da empresa.

Os requisitos para a seleção do sistema PLM foram agrupados em dez categorias de critérios funcionais, técnicos e de custos. Foi atribuído maior peso aos critérios funcionais (63\%) que aos critérios técnicos (32\%) e aos critérios de custos (5\%). Em cada uma das categorias, foram especificados requisitos descritos de maneira abrangente (e.g. gerenciamento da estrutura de produtos). Tal descrição não representa as características mais específicas dos processos de negócio da empresa (e.g. tipo de estruturas de produto utilizadas). Além disso, requisitos importantes foram negligenciados. Por fim, os sistemas mais bem avaliados com base nos critérios de análise não foram testados de forma exaustiva para comprovar a capacidade de execução declarada pelos fornecedores, resultando em uma análise superficial (ZANCUL, 2008).

Falhas como as relatadas no estudo de caso acima decorrem da complexidade da seleção de sistemas de informação. São vários os fatores que dificultam a escolha de um software adequado para atender às necessidades de uma empresa. Primeiramente, é preciso definir a lista de sistemas relevantes para a comparação. No entanto, as fronteiras que definem cada classe de sistemas no mercado não são delimitadas claramente. Partindo da lista para a comparação, é difícil obter um entendimento profundo das capacitações oferecidas pelos sistemas disponíveis, pois os sistemas são abrangentes, sofisticados em termos de tecnologia e estão em constante evolução com o lançamento de novas versões. A compreensão dos softwares também é prejudicada pelo acesso limitado às especificações técnicas detalhadas dos sistemas. Por fim, a seleção de sistemas de informação é uma atividade realizada, geralmente, com restrições de tempo e de recursos (CARNEY; WALLNAU, 1998, p. 851852). Isso ocorre, pois em muitos casos existe pressão interna na empresa para que as atividades práticas de implantação do sistema sejam iniciadas rapidamente. Visando cumprir os prazos acordados para o projeto de implantação como um todo, é comum que a fase de seleção do sistema seja demasiadamente simplificada. 


\subsection{Localização da fase de seleção da solução em projetos de implementação de sistemas de informação}

Basicamente, a seleção de sistemas de informação pode ser realizada em dois momentos distintos no escopo de um projeto completo de implantação de software - no início do projeto, antes mesmo do mapeamento detalhado do processo atual (as-is), ou ao longo do projeto, em conjunto ou após a especificação dos novos processos (to-be). A distinção entre as duas alternativas é dada pela posição da seleção do sistema em relação ao redesenho dos processos de negócio. Cada uma das alternativas é discutida a seguir.

Hansmann e Neumann (2002, p. 336-352) apresentam uma abordagem para a implantação de sistemas ERP composta por sete fases: (1) seleção do sistema; (2) estudo preliminar; (3) análise da situação inicial (as-is); (4) definição do conceito futuro (to-be); (5) implementação técnica (customização, programação); (6) instalação; (7) operação. Observase, nessa seqüência, que o projeto é iniciado pela seleção do sistema.

Na abordagem de Hansmann e Neumann (2002, p. 336-352), a fase de seleção do sistema, por sua vez, compreende seis etapas: (1) definição dos objetivos; (2) especificação dos requisitos e atribuição do peso de cada requisito; (3) mapeamento do mercado; (4) análise e seleção de um grupo de sistemas favoritos; (5) testes dos sistemas favoritos; (6) seleção final.

Segundo os autores, a especificação dos requisitos (etapa 2) pode ser derivada da definição dos objetivos da implantação bem como da documentação já existente dos processos de negócio. Caso a documentação dos processos não esteja disponível, os autores sugerem a realização de uma modelagem macro (top-down) dos processos, com a documentação das deficiências atuais, para apoiar a definição dos requisitos (HANSMANN; NEUMANN, 2002).

Nessa abordagem, os processos podem ser considerados como uma das fontes de informação para a definição de requisitos, mas a ênfase é colocada na visão de requisitos individuais e dissociados do processo. Ou seja, a visão dos processos pode ser perdida na construção do caderno de requisitos. Na abordagem de Hansmann e Neumann (2002, p. 336352), após a fase de seleção do sistema é que ocorre a análise mais detalhada os processos atuais e a posterior definição do processo futuro.

Na segunda alternativa, Kirchmer (1998, p. 75-125) apresenta uma abordagem de implantação de sistemas corporativos baseada em processos de negócio. Tal abordagem é composta por seis etapas, iniciadas após o mapeamento dos processos atuais (as-is): 
1. Definição das metas de negócio;

2. Definição dos processos de negócio considerados no escopo da implantação;

3. Detalhamento dos requisitos específicos da empresa (modelagem detalhada);

4. Detalhamento dos processos considerados no escopo do projeto;

5. Definição do escopo da implantação do sistema (seleção do sistema);

6. Definição da estratégia de implantação.

Nessa abordagem, a seleção do sistema, realizada na quinta etapa, ocorre simultaneamente com ou após o desenho detalhado dos novos processos. O procedimento sugerido por Kirchmer (1998, p. 112-116) para a seleção do sistema é a comparação entre o modelo dos processos de negócio com o modelo dos sistemas de informação (conforme o método de comparação de modelos apresentado no item 3.3). Dessa forma, procura-se garantir que as necessidades dos processos sejam consideradas na seleção do sistema.

As duas alternativas discutidas anteriormente são fundamentalmente distintas. A comparação das duas possibilidades é apresentada na Figura 32 (adaptado de KIRCHMER, 1998, p. 75; HANSMANN; NEUMANN, 2002, p. 337).
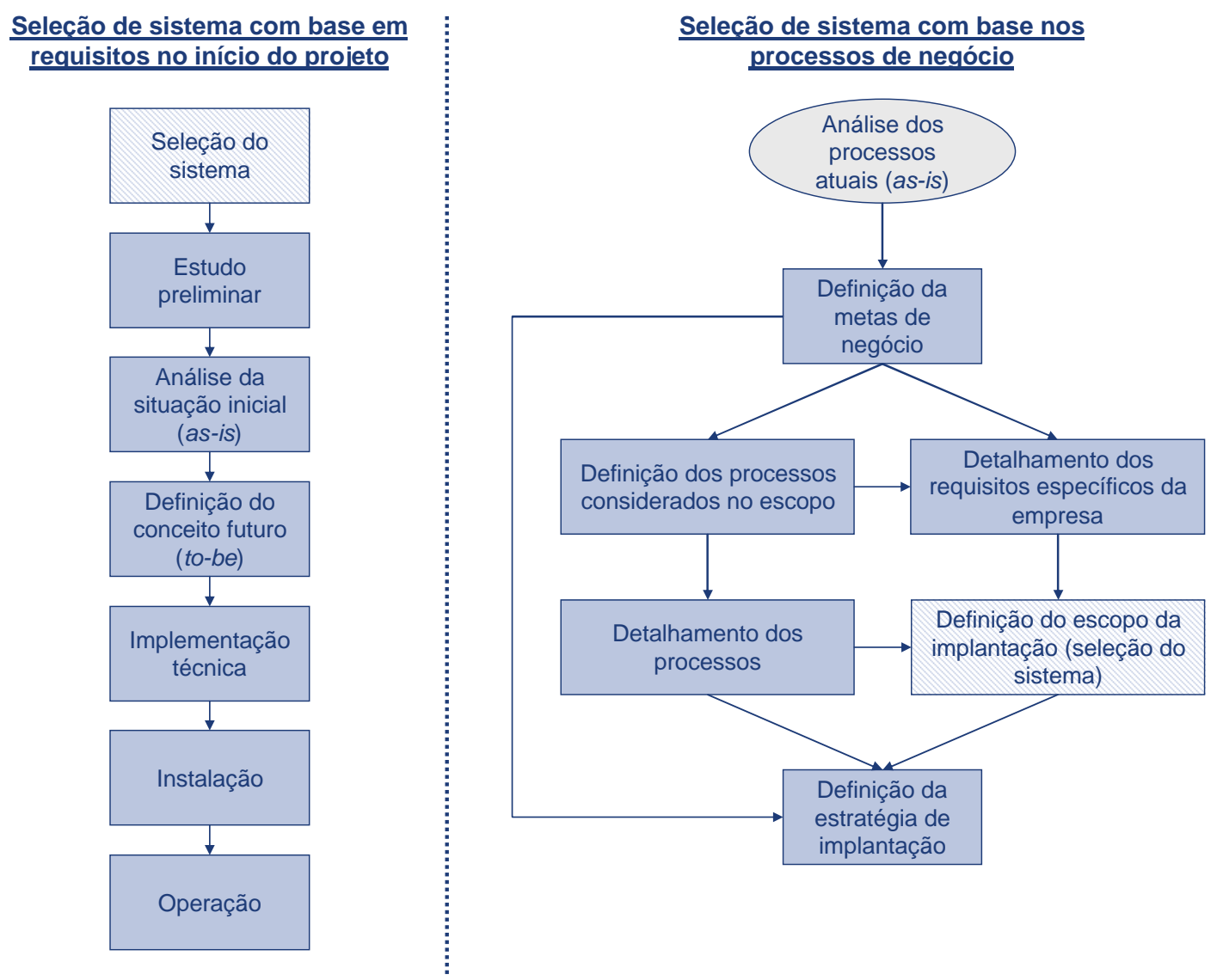

Figura 32. Comparação entre as alternativas de posicionamento da seleção de sistemas de informação no escopo de projetos de implantação de software 
Considerando a importância da seleção de sistemas e a sua localização nos projetos de implantação, no próximo item são avaliados os métodos de seleção de sistemas de informação.

\subsection{Métodos de seleção de sistemas de informação}

A seleção de sistemas de informação é realizada segundo métodos de trabalho estruturados para resultar na escolha de uma ferramenta adequada para atender aos requisitos de uma empresa. Neste item, os métodos de seleção de sistemas de informação levantados na pesquisa bibliográfica são analisados e comparados.

Segundo Colombo e Francalanci (2004, p. 187), existe praticamente um consenso na literatura sobre a subdivisão dos métodos de seleção de sistemas de informação em três fases, da intenção inicial de adotar um software até a decisão final e o início da implantação. As três fases citadas por Colombo e Francalanci (2004, p. 187) são descritas abaixo:

1. Pré-seleção - tem como objetivo reduzir o número de alternativas consideradas no processo de seleção;

2. Análise - visa possibilitar a obtenção de um entendimento detalhado das características funcionais e tecnológicas dos sistemas pré-selecionados, a fim de avaliar a sua adequação ao contexto em questão;

3. Negociação - objetiva avaliar a capacidade de fornecedores proverem serviços de pós-vendas (suporte) e avaliar a proposta comercial, para resultar na seleção final do fornecedor e do sistema a ser implantado.

Essas três fases podem ser utilizadas para estruturar a comparação entre os métodos de seleção de sistemas específicos.

Maiden e Ncube (1998) apresentam um método de seleção de sistemas, denominado PORE (Procurement-Oriented Requirements Engineering), estruturado em cinco etapas:

1. Levantamento de requisitos por meio de análise de documentos e de entrevistas;

2. Identificação de possíveis candidatos;

3. Pré-seleção dos candidatos com base nos requisitos macro ${ }^{21}$;

4. Análise detalhada em demonstrações de casos de uso construídos com base nos requisitos - análise quantitativa e qualitativa;

5. Avaliação detalhada em aplicações de teste.

\footnotetext{
${ }^{21}$ Em um caso prático relatado pelos autores, seis sistemas foram escolhidos na pré-seleção.
} 
No PORE, os autores enfatizam as etapas de obtenção dos requisitos e de avaliação da solução; por outro lado, as etapas relacionadas com a negociação não são exploradas.

Umble et al. (2003, p.247-249), por sua vez, apresentam uma abordagem mais ampla de seleção, voltada para sistemas ERP. Tal abordagem é estruturada em treze etapas:

1. Definição da visão;

2. Criação de uma lista de funcionalidades;

3. Obtenção de uma lista de sistemas candidatos;

4. Pré-seleção de quatro a seis candidatos principais;

5. Elaboração de um request for proposal (RFP);

6. Revisão das propostas;

7. Seleção de dois ou três finalistas;

8. Demonstração dos sistemas pelos finalistas;

9. Seleção do sistema mais adequado;

10. Avaliação dos benefícios e do retorno do investimento;

11. Negociação do contrato;

12. Teste de uma solução piloto;

13. Validação da decisão de implantação.

Nessa abordagem, as fases de pré-seleção, análise e negociação, citadas por Colombo e Francalanci (2004, p. 187), estão bem caracterizadas. Em comparação com o método PORE, observa-se que Umble et al. (2003, p.247-249) consideram testes na solução somente após a seleção final, enquanto que no método PORE os testes são realizados para apoiar a escolha.

Um terceiro método de seleção de sistemas de informação é o método desenvolvido e aplicado pela Trovarit AG, que é uma prestadora de serviços de apoio para a seleção de sistemas de informação para empresas de médio porte na Alemanha.

O método utilizado pela Trovarit se diferencia por utilizar uma lista padronizada de requisitos e uma base de dados do perfil de soluções comerciais em relação a esses requisitos. Para construir essa base de dados, a Trovarit realiza parcerias com provedores de conteúdo, que desenvolvem listas de requisitos específicas para cada classe de software (e.g. ERP, CRM). Em seguida, fornecedores de software são convidados a informar as capacitações de seus sistemas em relação aos requisitos padronizados. Essas informações ficam armazenadas em uma base de dados e são utilizadas nos projetos de seleção de sistemas (TROVARIT, 2005).

O método de seleção de sistemas da Trovarit é organizado em cinco etapas principais (TROVARIT, 2005): 
1. Preparação do projeto de seleção;

2. Análise macro e preparação do caderno de requisitos da empresa;

3. Análise do mercado e pré-seleção;

4. Análise detalhada de sistemas pré-selecionados (tipicamente 3 a 5 sistemas), avaliação dos custos e seleção final;

5. Negociação do contrato.

Nesse método, a base de dados de capacitações dos sistemas comerciais é utilizada na terceira etapa, para apoiar a pré-seleção dos sistemas com maior adequação às necessidades especificadas no caderno de requisitos.

Os três métodos discutidos anteriormente são apresentados na Tabela 5 organizados de acordo com as fases típicas da seleção dos sistemas de informação.

Tabela 5 - Comparação dos métodos de seleção de sistemas de informação

\begin{tabular}{|c|c|c|c|}
\hline \multirow{2}{*}{ Fases } & \multicolumn{3}{|c|}{ Métodos de seleção de sistemas de informação } \\
\hline & PORE & Umble et al. (2003) & Trovarit \\
\hline Pré-seleção & $\begin{array}{l}\text { 1. Levantamento de } \\
\text { requisitos } \\
\text { 2. Identificação de } \\
\text { possíveis candidatos } \\
\text { 3. Pré-seleção dos } \\
\text { candidatos com base nos } \\
\text { requisitos macro }\end{array}$ & $\begin{array}{l}\text { 1. Definição da visão } \\
\text { 2. Criação de uma lista de } \\
\text { funcionalidades } \\
\text { 3. Obtenção de uma lista } \\
\text { de sistemas candidatos } \\
\text { 4. Pré-seleção de quatro a } \\
\text { seis candidatos } \\
\text { principais }\end{array}$ & $\begin{array}{l}\text { 1. Preparação do projeto de } \\
\text { seleção } \\
\text { 2. Análise macro e } \\
\text { preparação do caderno de } \\
\text { requisitos da empresa } \\
\text { 3. Análise do mercado e } \\
\text { pré-seleção }\end{array}$ \\
\hline Análise & $\begin{array}{l}\text { 4. Análise detalhada em } \\
\text { demonstrações de casos } \\
\text { de uso construídos com } \\
\text { base nos requisitos } \\
\text { 5. Avaliação detalhada em } \\
\text { aplicações de teste }\end{array}$ & $\begin{array}{l}\text { 6. } \begin{array}{l}\text { Elaboração de um } \\
\text { request for proposal } \\
\text { (RFP) }\end{array} \\
\text { 7. Revisão das propostas } \\
\text { 8. Seleção de dois ou três } \\
\text { finalistas } \\
\text { 9. Demonstração dos } \\
\text { sistemas pelos finalistas } \\
\text { 10. Seleção do sistema mais } \\
\text { adequado }\end{array}$ & $\begin{array}{l}\text { 4. Análise detalhada de } \\
\text { sistemas pré-selecionados } \\
\text { (tipicamente } 3 \text { a } 5 \\
\text { sistemas), avaliação dos } \\
\text { custos e seleção final; }\end{array}$ \\
\hline Negociação & & $\begin{array}{l}\text { 11. Avaliação dos } \\
\text { benefícios e do retorno } \\
\text { do investimento } \\
\text { 12. Negociação do contrato } \\
\text { 13. Teste de uma solução } \\
\text { piloto } \\
\text { 14. Validação da decisão de } \\
\text { implantação }\end{array}$ & 5. Negociação do contrato \\
\hline
\end{tabular}

Na Tabela 5, observa-se que, com exceção da ausência da fase de negociação no método PORE, os métodos apresentam características bastantes semelhantes. De forma geral, 
a seleção de sistemas de informação parte de uma lista ampla de sistemas pesquisados no mercado. Com base em requisitos da empresa, é realizada uma pré-seleção que resulta tipicamente em três a seis sistemas candidatos. Esses sistemas são avaliados de forma mais detalhada em demonstrações ou em aplicações de teste. Paralelamente são solicitadas propostas comerciais que, em conjunto com a avaliação técnica, resultam na escolha do sistema mais adequado para a empresa.

Essa discussão sobre a seleção de sistemas de informação neste capitulo conclui a síntese da bibliografia fundamental. No próximo capítulo, são discutidos os procedimentos metodológicos considerados na realização do trabalho. 


\section{PROCEDIMENTOS METODOLÓGICOS}

Neste capítulo, são discutidos os aspectos metodológicos considerados na realização deste trabalho. O ponto de partida é a discussão do método que direciona a execução do trabalho visando responder às questões de pesquisa e atingir os objetivos estabelecidos (item 5.1). Considerando o método, são detalhadas as fases da pesquisa e especificados os procedimentos técnicos de coleta e de análise de dados empregados em cada uma das fases (item 5.2).

\subsection{Método}

O problema prático que motiva a realização deste trabalho é a dificuldade enfrentada pelas empresas hoje para avaliar os sistemas PLM existentes e para selecionar a alternativa mais adequada aos seus processos de negócio. Atualmente, faltam métodos e instrumentos para apoiar a seleção de sistemas PLM (item 1.2). Esse problema tem duas causas principais, discutidas nos parágrafos seguintes.

A primeira causa é a falta de uma referência genérica que descreva as funcionalidades típicas de sistemas PLM e que possibilite uma comparação entre os sistemas disponíveis comercialmente, considerando uma base comum. A pesquisa da bibliografia na área indica que existem descrições de sistemas específicos, mas representações genéricas de sistemas PLM não são encontradas (item 2.3).

A segunda causa do problema é a falta de um método de seleção de sistemas PLM que seja fundamentalmente baseado nos modelos de referência dos processos de negócio e dos sistemas de informação. Os métodos existentes para a seleção de softwares consideram os requisitos dos processos de negócio para a definição de critérios. Entretanto, nenhum método combina a utilização de modelos de referência do processo e do sistema para avaliar a adequação de funcionalidades do sistema às atividades do processo (capítulo 4).

A fim de propor uma solução para o problema identificado, o trabalho visa definir um modelo de referência de sistemas PLM, que represente de forma genérica as funcionalidades que caracterizam esse tipo de sistema. O trabalho também visa desenvolver um método para a seleção de sistemas PLM baseado em modelos de referência (ver perguntas de pesquisa e objetivos do trabalho no item 1.3).

A escolha do método utilizado para atingir esses objetivos depende da avaliação do conhecimento já acumulado na área de pesquisa. Conforme discutido na justificativa do trabalho (item 1.2) e na síntese da bibliografia fundamental (item 2.3), atualmente, diversos 
sistemas PLM estão disponíveis comercialmente. A construção de um modelo de referência para esses sistemas passa por um processo de generalização, partindo de vários casos específicos para o modelo genérico.

As funcionalidades representadas no modelo de referência de sistemas PLM obtido neste trabalho podem, então, ser relacionadas com as atividades dos processos de negócio de gestão do ciclo de vida de produtos. Uma solução semelhante já é empregada pela SAP na documentação de seus sistemas. A SAP fornece para seus clientes modelos de referência dos processos de negócio que são apoiados por seus softwares. Nesses modelos, em cada atividade do processo é indicada a funcionalidade correspondente no sistema SAP (ZANCUL, 2000, p. 81). Nesse caso, o relacionamento é entre modelo do processo e as funcionalidades de um sistema específico, enquanto que a proposta deste trabalho é generalizar esse relacionamento, interligando modelos de referência genéricos tanto para o processo como para o sistema.

O modelo resultante interligando o processo a uma representação genérica de sistemas PLM é o elemento inovador do método de seleção de sistemas PLM proposto neste trabalho. Hoje, já existem várias abordagens para apoiar a seleção de softwares (capítulo 4). A maior parte dessas abordagens segue uma seqüência lógica semelhante. Partindo da análise dos processos de negócio, definem-se critérios que são então utilizados para avaliar os sistemas específicos. Esse procedimento, realizado individualmente para cada empresa que avalia um sistema de informação, apresenta deficiências ${ }^{22}$. É difícil calibrar o nível de detalhamento dos critérios de avaliação. Ou seja, alguns critérios podem ser muito abrangentes, sem capacidade de diferenciação entre os sistemas, enquanto outros podem ser tão específicos, que não são atendidos por nenhum dos softwares avaliados.

Assim, definidos os critérios, o problema passa a ser como avaliar uma ampla gama de sistemas distintos, que podem possuir foco de atuação diferenciado e utilizar nomenclaturas diferentes para designar funcionalidades semelhantes. O esforço demandado cresce com o número de sistemas comparados. Com isso, muitas empresas limitam o número de softwares que participam da avaliação (tipicamente de 3 a 7 sistemas).

22 Informação baseada em dados coletados em cinco estudos de caso conduzidos pelo pesquisador durante o seu estágio de pesquisa de dois anos no WZL da RWTH Aachen. Ver ZANCUL, E. Estudos de caso sobre a implantação da gestão do ciclo de vida de produtos em empresas de manufatura. In: XV SIMPEP. 2008, Bauru. Anais, 2008, 1-12. 
As deficiências citadas podem ser minimizadas com a utilização do modelo de referência resultante deste trabalho. Mesmo com a utilização deste novo instrumento, a seqüência lógica tradicionalmente utilizada para avaliar softwares continua válida.

Desse modo, o desafio desta pesquisa é avaliar as diversas metodologias de seleção de software disponíveis e adaptá-las, introduzindo o modelo de referência como elemento para padronizar a avaliação.

Observa-se que para atingir os objetivos desta pesquisa, é necessário generalizar o conhecimento existente em casos específicos. Nessa situação, é empregado o método indutivo, como abordagem científica mais ampla para direcionar a realização deste trabalho.

Segundo Gil (2008, p. 10-11) e Markoni e Lakatos (2008, p. 53), no método indutivo, parte-se do exame de casos particulares para derivar generalizações, baseadas nas relações verificadas entre fatos ou fenômenos. Assim, o método indutivo é adequado para nortear a realização desta pesquisa, pois o que se pretende com este trabalho, é dar uma passo na construção do conhecimento, no sentido de generalizar representações de sistemas e métodos de seleção de softwares já existentes (casos particulares) para possibilitar aplicação mais ampla na indústria. Todo o encadeamento lógico discutido nos parágrafos anteriores, do problema prático ao método, é apresentado na Figura 33.

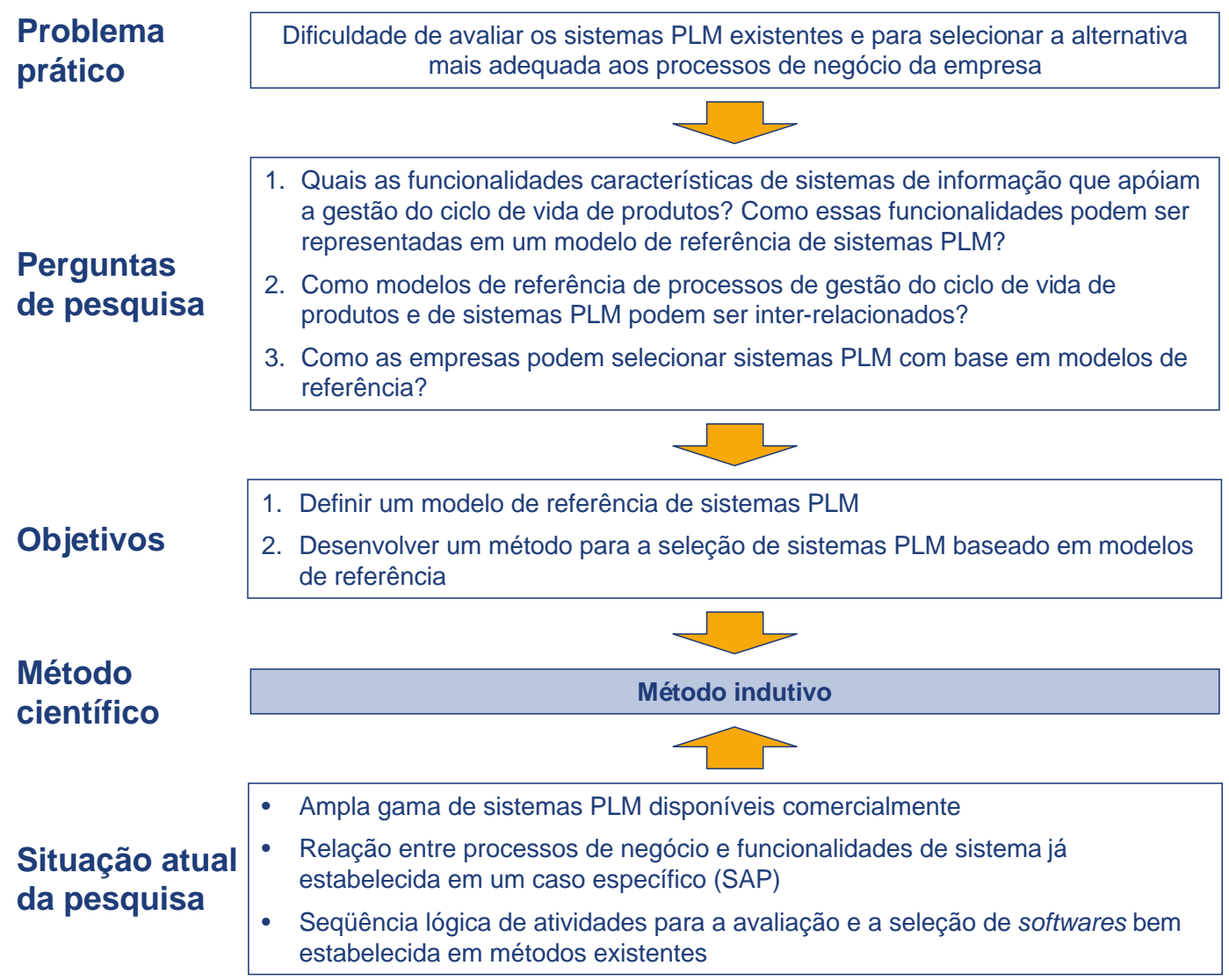

Figura 33. Problema prático, perguntas de pesquisa, objetivo do trabalho e método científico 
Definido o método, no próximo item são discutidas as fases do trabalho e os procedimentos técnicos aplicados na coleta e na análise dos dados.

\subsection{Fases do trabalho e procedimentos técnicos de pesquisa}

O trabalho é estruturado em sete fases que estão ilustradas na Figura 34.

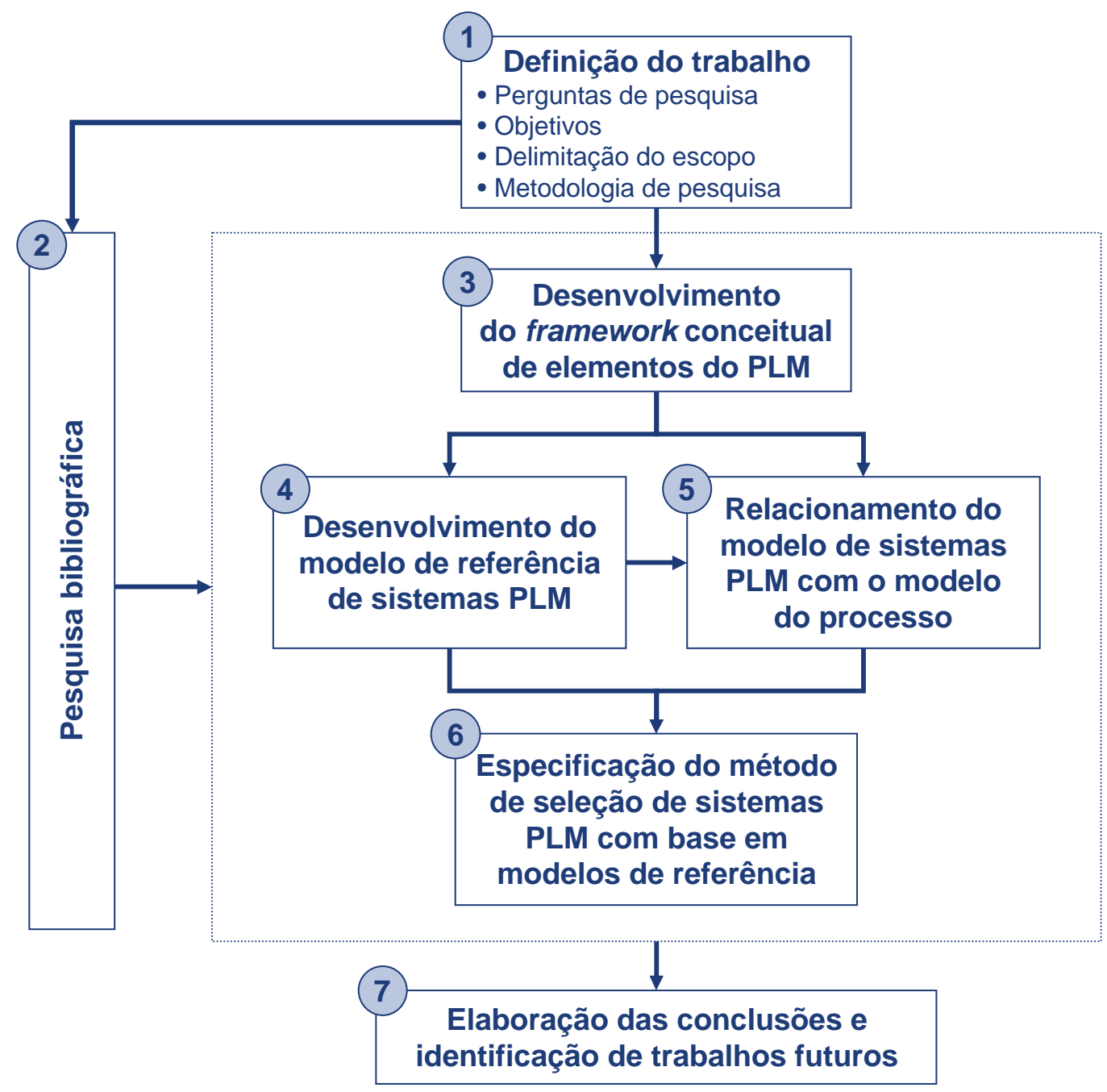

Figura 34. Fases da pesquisa

Cada uma das fases da pesquisa é discutida detalhadamente a seguir.

\section{Fase 1: Definição do trabalho}

A definição do trabalho compreende a determinação das perguntas de pesquisa e o estabelecimento dos objetivos a serem atingidos (item 1.3). Nessa fase também são delimitados os setores da indústria considerados no escopo do trabalho (item 1.4). Por fim, a metodologia da pesquisa é definida (capítulo 5). 


\section{Fase 2: Pesquisa bibliográfica}

A fase de pesquisa bibliográfica tem como objetivos fornecer a fundamentação teórica necessária tanto para o desenvolvimento desta pesquisa como para a determinação de sua contribuição para a área de conhecimentos (CERVO; BERVIAN, 1983; DANE, 1990). A revisão bibliográfica está organizada em três partes. A primeira parte trata de conceitos de gestão do ciclo de vida de produtos, tema principal do trabalho (capítulo 2). A segunda parte discute as abordagens e os métodos de modelagem e de integração de empresas (capítulo 3). A terceira parte analisa os métodos existentes atualmente para a seleção de sistemas de informação (capítulo 4).

\section{Fase 3: Desenvolvimento do framework conceitual de elementos do PLM}

A fase 3 da pesquisa compreende a definição de um framework conceitual abrangendo os principais elementos envolvidos na implantação da gestão do ciclo de vida de produtos em empresas.

Assim, é definido o papel de cada elemento do framework (modelo de referência dos processos, modelo de referência de sistemas PLM, base de conhecimentos, entre outros) e são explicitadas as inter-relações entre cada um desses elementos. Especificamente, discute-se detalhadamente a inter-relação entre as atividades do modelo de referência do processo e as funcionalidades do modelo de referência de sistemas PLM. A definição conceitual dessa interrelação serve de base para a realização das fases 5 e 6 da pesquisa.

A avaliação do framework conceitual é realizada com a publicação de um artigo em um periódico internacional, com revisão por pares, considerado relevante na área de pesquisa.

\section{Fase 4: Desenvolvimento do modelo de referência de sistemas PLM}

Atualmente, a abrangência das funções oferecidas pelos sistemas PLM disponíveis no mercado varia muito. A fim de facilitar a comparação entre os diversos sistemas existentes e apoiar o desenvolvimento de novos aplicativos na área, um dos objetivos desse trabalho é especificar um modelo de referência de sistemas PLM.

O ponto de partida para o desenvolvimento do modelo de referência de sistemas PLM é o levantamento das funcionalidades oferecidas pelos fornecedores líderes de mercado. Esse levantamento é feito por meio do emprego de cinco procedimentos técnicos:

Pesquisa bibliográfica em livros e publicações que descrevem os sistemas;

Pesquisa documental em brochuras e no material de marketing dos sistemas;

Participação do pesquisador em treinamentos sobre sistemas específicos; 
Manipulação de sistemas específicos pelo pesquisador;

Visita a feiras, com objetivo de discutir as funcionalidades dos sistemas com funcionários das empresas fornecedoras.

As funcionalidades identificadas no levantamento são sintetizadas em uma lista única. A lista, que representa o conjunto união das funcionalidades encontradas em todos os sistemas pesquisados, é organizada de maneira hierárquica em quatro níveis ${ }^{23}$ : módulos, grupos de funcionalidades, funcionalidades e transações. Todos os itens da lista são descritos de maneira genérica, utilizando uma nomenclatura técnica que não se refere a nenhuma solução comercial específica.

O passo seguinte é a realização de uma survey para validar a lista hierárquica como uma representação de um conjunto amplo, consistente e representativo de sistemas PLM, ou seja, um modelo de referência de sistemas PLM.

Nesse sentido, a partir da lista hierárquica de funcionalidades é derivado um questionário. Cada funcionalidade é reescrita no formato de pergunta, enquanto as transações da lista são transformadas em possibilidades de resposta do tipo múltipla escolha. Módulos e grupos de funcionalidades complementam a estrutura do questionário.

Com os resultados da survey, a lista inicial de funcionalidades é ajustada. As funcionalidades e as transações não disponíveis em nenhum dos sistemas pesquisados são excluídas. Essa situação é possível devido à metodologia de levantamento de dados empregada, que inclui a identificação de funcionalidades e de transações por meio da análise do material de marketing dos sistemas e de discussões com representantes de empresas fornecedoras. Por outro lado, funcionalidades encontradas na survey, em pelo menos um sistema, são consideradas validadas.

As atividades realizadas nessa fase 4 da pesquisa são ilustradas na Figura 35, que também descreve o fluxo de atividades da fase 5.

${ }^{23}$ Conforme níveis de detalhamento do modelo de referência de sistemas, na definição do framework conceitual de elementos do PLM (capítulo 6). 


\section{Fase 4}

$\left.\begin{array}{c}\text { Levantamento } \\ \text { de dados }\end{array}\right\rangle$ Síntese $\quad$ Survey $\quad \begin{aligned} & \text { Validação } \\ & \text { e ajustes }\end{aligned}$
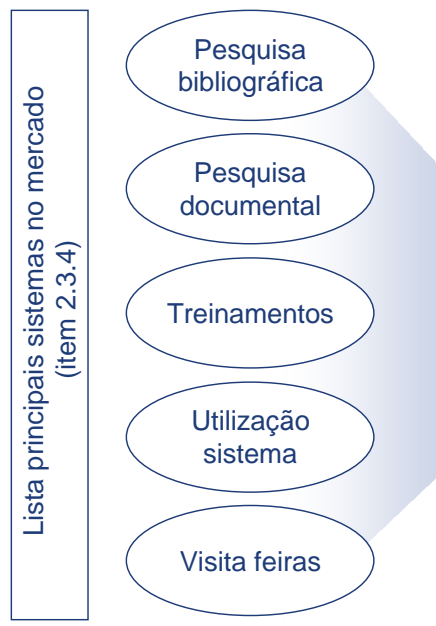

Lista de
funcionalidades

Modelo referência

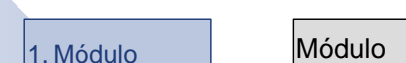

1.1.1 Func. A

- Transação A

Transação B

1.2.

- Estrutura

hierárquica

- Módulos, grupo

funcionalidades

funcionalidades,

transações sistemas PLM

\section{Fase 5}

Modelo Unificado PDP
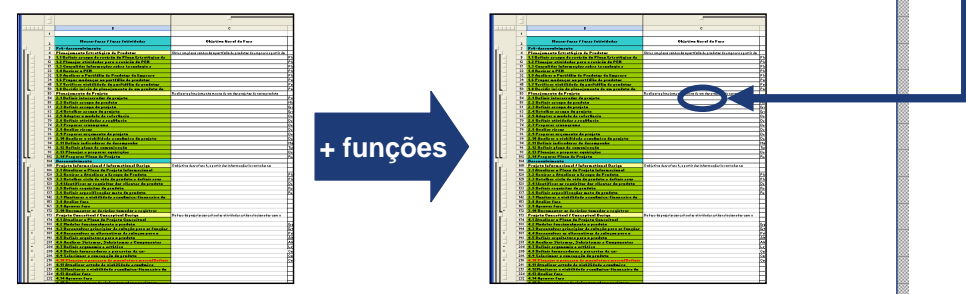

- Lista hierárquica

Revisão bibliográfica / pesquisa documental

Relacionamento entre

sistema e processo

Figura 35. Fases 4 e 5 da pesquisa

O modelo de referência de sistemas PLM desenvolvido na fase 4 da pesquisa é relacionado com um modelo do processo na fase 5, descrita a seguir.

\section{Fase 5: Relacionamento do modelo de sistemas PLM com o modelo do processo}

A fase 5 da pesquisa é iniciada com a seleção de um modelo de referência dos processos de gestão do ciclo de vida de produtos para ser relacionado com o modelo de referência de sistemas PLM. 
A escolha do modelo de referência de processos de PLM é baseada em quatro critérios definidos previamente: escopo relacionado ao PLM; alto grau de detalhamento; acesso aberto; disponibilidade em português, que facilita seu uso por empresas instaladas no Brasil.

O passo seguinte é o relacionamento entre as funcionalidades do modelo de referência de sistemas PLM com as atividades do modelo do processo (Figura 35). Para isso, é utilizada a especificação desse relacionamento detalhada na fase 3 da pesquisa e o método de comparação de modelos existente (item 3.3).

O resultado é um modelo de referência dos processos de gestão do ciclo de vida de produtos que descreve as atividades do processo e que especifica, para cada atividade, qual a funcionalidade de sistemas PLM necessária. Esse modelo é utilizado como instrumento para apoiar a seleção de sistemas PLM, no contexto de um método de seleção desenvolvido na fase 6 da pesquisa.

\section{Fase 6: Especificação do método de seleção de sistemas PLM com base em modelos de referência}

A especificação de um método de seleção de sistemas PLM com base em modelos de referência parte da análise dos métodos existentes para selecionar softwares (capítulo 4). A partir dos métodos existentes, é derivado um novo método de seleção de sistemas PLM, que utiliza como elemento central o modelo de referência desenvolvido na fase 5 desta pesquisa. A utilização desse modelo de referência, interligando processo e sistema PLM para apoiar a seleção de PLM, é uma das inovações deste trabalho.

O método proposto é validado por meio de entrevistas com especialistas na área. A validação por entrevistas é necessária, pois a aplicação do método completo em um caso real demandaria um tempo muito superior ao prazo disponível para a conclusão desta pesquisa.

A realização das entrevistas envolve a definição de critérios para a seleção dos especialistas a serem entrevistados, a escolha dos especialistas, a elaboração prévia de um roteiro de entrevistas, a realização das entrevistas e a sistematização dos resultados obtidos.

São definidos dois critérios para a seleção dos especialistas para as entrevistas. Definiu-se que os especialistas devem ter experiência profissional na seleção e na implantação de pacotes de sistemas de informação. Ao mesmo tempo, os especialistas selecionados não podem atuar em nenhuma empresa fornecedora de softwares. Candidatos típicos para participar da validação são, portanto, funcionários de empresas usuárias de PLM, consultores e acadêmicos na área. 
Optou-se por realizar duas entrevistas para possibilitar a coleta de opiniões distintas. Cada entrevista é estruturada de forma que o entrevistado possa percorrer as etapas do método de seleção e manipular o modelo de referência. Ao longo da entrevista, o método proposto neste trabalho é comparado com os métodos tradicionais e as vantagens e limitações da nova proposta são discutidas. O intuito é validar a aplicabilidade da abordagem proposta, em comparação com as práticas adotadas atualmente nas empresas.

\section{Fase 7: Elaboração das conclusões e identificação de trabalhos futuros}

Por fim, a última parte deste trabalho envolve a elaboração de conclusões sobre os instrumentos e o método desenvolvido nas demais fases do trabalho. Além disso, esta fase abrange a análise das contribuições desta pesquisa para o campo de conhecimento e a discussão de trabalhos futuros que podem ser desenvolvidos a partir do conhecimento gerado aqui. 


\section{FRAMEWORK CONCEITUAL DE ELEMENTOS DO PLM}

Este capítulo está organizado em dois itens. Inicialmente, apresenta-se a estrutura do framework conceitual de elementos do PLM (item 6.1). Em seguida, discute-se em detalhe a inter-relação entre dois dos elementos do framework - atividades do modelo de referência do processo e funcionalidades do modelo de referência de sistemas PLM (item 6.2).

\subsection{Estrutura do framework conceitual de elementos do PLM}

O framework conceitual de elementos do PLM visa organizar o conhecimento existente sobre PLM de forma estruturada, para que ele possa servir de referência em projetos de implantação da gestão do ciclo de vida de produtos em empresas. Nesse sentido, o framework deve abranger os principais elementos envolvidos na implantação da gestão do ciclo de vida de produtos. Mais ainda, as inter-relações lógicas entre os elementos do framework devem ser explicitadas.

Os elementos necessários para compor o framework são derivados da análise da bibliografia (capítulo 2). O ponto de partida para qualquer projeto de implantação da gestão do ciclo de vida de produtos deve ser o entendimento da visão e do significado do conceito de PLM (subitens 2.1 .2 e 2.1.3). A definição de PLM e as suas implicações para a empresa devem ser discutidas com toda a equipe de projeto, para que os aspectos conceituais sejam bem disseminados entre todos os envolvidos na implantação. Daí surge o primeiro elemento do framework - a definição de PLM.

Após adotar uma definição de PLM, a discussão passa a ser sobre o escopo da gestão do ciclo de vida de produtos. Devem ser identificadas as áreas organizacionais da empresa e as atividades envolvidas. A delimitação do escopo da gestão do ciclo de vida de produtos, em termos de atividades e de áreas organizacionais, é dada pelo modelo de referência dos processos de negócio de PLM (subitens 2.2.3 e 2.2.4), que compõe o segundo elemento do framework.

Em relação ao conteúdo dos processos de negócio, as atividades de estruturação dos produtos desempenham um papel fundamental para o sucesso da implantação do PLM. A estrutura de produto é um componente central para a gestão de dados de produto no ciclo de vida, pois estabelece a relação entre os itens de um produto e as suas informações (subitem 2.2.5 - estruturação do produto). O PLM requer a utilização de estruturas de produto robustas, com possibilidade de relacionamento entre os itens do produto e as múltiplas informações de fontes e de formatos distintos, incluindo tanto documentos (e.g. desenhos, relatórios de 
experimentos) como informações armazenadas em bases de dados (e.g. lista de materiais, planos de processo de fabricação). Ao mesmo tempo, para garantir a integridade da estrutura de produto ao longo de todo o ciclo de vida, é necessário que as atividades de estruturação do produto sejam controladas por mecanismos eficazes de gestão da configuração. A estrutura de produto como fundamento conceitual para a prática do PLM é o terceiro elemento do framework.

Nas atividades dos processos de negócio são utilizados sistemas de informação, que também podem ser representados por modelos de referência que descrevem as suas funcionalidades (subitem 2.2.2). Assim, o quarto elemento do framework é o modelo de referência de sistemas PLM. Além da representação genérica dada pelo modelo de referência, é preciso considerar, no framework, a descrição dos sistemas existentes atualmente (subitem 2.3.4). Essa descrição é útil para auxiliar as empresas na análise dos sistemas oferecidos no mercado. Assim, a descrição do perfil de sistemas PLM disponíveis comercialmente é o quinto elemento do framework.

A fim de executar as atividades, as pessoas envolvidas nos processos precisam ter conhecimentos técnicos sobre as práticas associadas à gestão do ciclo de vida de produtos, como, por exemplo, a gestão de requisitos, a gestão da configuração, entre outras (subitem 2.2.5). Uma base de conhecimentos estruturada com esse conteúdo é capaz de prover o material necessário para os treinamentos sobre PLM nas empresas. Deve-se ressaltar que a ênfase aqui incide sobre os conhecimentos necessários para que as pessoas estejam habilitadas a executar as atividades dos processos, e não sobre conhecimentos sobre os produtos. A base de conhecimentos é o sexto elemento que compõe o framework.

Por fim, a gestão do ciclo de vida de produtos é implantada para que as empresas obtenham ganhos de eficiência (redução de lead time e redução de custos), melhora da eficácia (aumento dos níveis de qualidade e maior nível de atendimento dos requisitos do produto) e melhora do controle do processo por meio de padrões (item 2.4). A obtenção desses benefícios está vinculada à revisão dos processos, à adoção de práticas de trabalho e à implantação de sistemas de informação. O estabelecimento, a priori, dos benefícios mais relevantes esperados pela empresa, com a adoção da gestão do ciclo de vida de produtos, possibilita direcionar a implantação para resolver os problemas mais críticos e para obter os benefícios mais expressivos. Assim, o sétimo e último elemento do framework é a relação estruturada de benefícios do PLM. 
A Tabela 6 apresenta um resumo sobre os sete elementos do framework conceitual de PLM $^{24}$.

Tabela 6 - Elementos do framework conceitual de PLM

\begin{tabular}{l|l}
\hline \multicolumn{1}{c|}{$\begin{array}{c}\text { Elementos } \\
\text { do framework }\end{array}$} & \multicolumn{1}{c}{ Descrição } \\
\hline 1. Definição de PLM & $\begin{array}{l}\text { Especificação da visão de gestão do ciclo de vida de produtos } \\
\text { Direcionamento macro da abordagem de PLM }\end{array}$ \\
\hline 2. Fundamento conceitual & $\begin{array}{l}\text { Práticas (atividades) de estruturação dos produtos } \\
\text { Estrutura de produto }\end{array}$ \\
\hline $\begin{array}{l}\text { 3. Modelo de referência dos } \\
\text { processos de negócio de } \\
\text { PLM }\end{array}$ & $\begin{array}{l}\text { Processos de negócio e atividades de PLM } \\
\text { Áreas organizacionais responsáveis por executar as atividades }\end{array}$ \\
\hline $\begin{array}{l}\text { 4. Modelo de referência de } \\
\text { sistemas PLM }\end{array}$ & Funcionalidades de sistemas PLM representadas de forma genérica \\
\hline $\begin{array}{l}\text { 5. Descrição do perfil de } \\
\text { sistemas PLM disponíveis } \\
\text { comercialmente }\end{array}$ & $\begin{array}{l}\text { Lista de sistemas disponíveis no mercado } \\
\text { Perfil dos sistemas em relação ao modelo de referência de sistemas PLM }\end{array}$ \\
\hline $\begin{array}{l}\text { 6. Base de conhecimentos } \\
\text { 7. Benefícios do PLM }\end{array}$ & $\begin{array}{l}\text { Conhecimentos técnicos necessários para executar as atividades } \\
\text { relacionadas ao PLM }\end{array}$ \\
\hline
\end{tabular}

Definidos os elementos do framework, o passo seguinte é a especificação das interrelações existentes entre eles. Nesse sentido, cada elemento é analisado individualmente. A existência de uma inter-relação é identificada em duas situações. Na primeira situação, considerando um elemento específico, haverá uma inter-relação quando uma modificação no conteúdo desse elemento levar a mudanças no conteúdo de outro elemento. Por exemplo, a alteração na definição de PLM pode resultar em uma revisão do escopo considerado para os processos de negócios de gestão do ciclo de vida de produtos. Na segunda situação, existe uma inter-relação quando um elemento requer a utilização de outro elemento para a sua execução. É o caso, por exemplo, da utilização de sistemas de informação nas atividades dos processos de negócio. O resultado dessa análise é discutido nos parágrafos seguintes e resumidos na Tabela 7.

${ }^{24}$ Na tabela, a posição dos elementos - fundamento conceitual e modelo de referência - está invertida em comparação com a do texto explicativo. Optou-se por essa modificação, pois, no texto, a seqüência adotada facilita a compreensão dos elementos, enquanto, na tabela resumo, a seqüência escolhida vai dos elementos mais abrangentes para os mais específicos. 
A definição de PLM tem relação com todos os demais elementos do framework. Por especificar a visão de gestão do ciclo de vida e definir o direcionamento conceitual macro, qualquer mudança nesse elemento resulta na necessidade de alterar os outros elementos.

O fundamento conceitual, que contempla essencialmente a estruturação de produtos, tem relação com outros três elementos do framework. A estruturação de produto envolve atividades que estão contidas no modelo de referência dos processos, demanda habilidades técnicas específicas da base de conhecimentos e tem impacto direto nos benefícios relacionados com ganhos de eficácia (qualidade e atendimento dos requisitos do produto).

A execução das atividades do modelo de referência dos processos exige outros dois elementos do framework: as funcionalidades de TI, especificadas no modelo de referência de sistemas, e os conhecimentos contidos na base de conhecimentos. Além disso, existe uma relação direta entre as atividades do processo e os benefícios obtidos com a implantação do PLM.

O modelo de referência de sistemas PLM estabelece o padrão utilizado para a descrição do perfil de sistemas PLM disponíveis comercialmente. A utilização das funcionalidades de PLM listadas no modelo de referência demanda habilidades técnicas da base de conhecimentos. Ao mesmo tempo, a introdução de funcionalidades que resultem, por exemplo, em maior grau de automação, gera benefícios para a empresa.

A Tabela 7 resume as inter-relações entre os elementos do framework. Os elementos são listados nas linhas e nas colunas da tabela. Um “ X” na interseção entre uma linha e uma coluna indica que existe um inter-relacionamento entre os dois elementos.

Tabela 7 - Inter-relações entre os elementos do framework conceitual de PLM

\begin{tabular}{|c|c|c|c|c|c|c|c|}
\hline $\begin{array}{l}\text { Elementos } \\
\text { do framework }\end{array}$ & 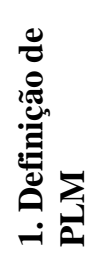 & 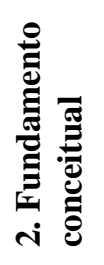 & 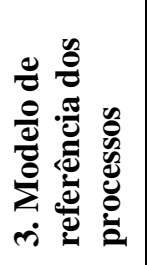 & 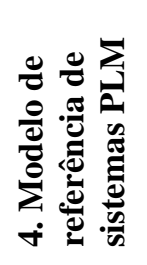 & 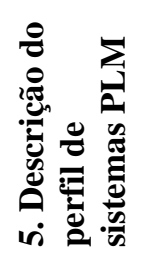 & 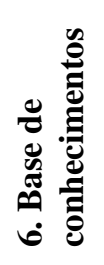 & 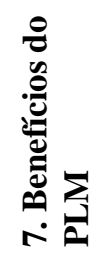 \\
\hline 1. Definição de PLM & & $\mathrm{X}$ & $\mathrm{X}$ & $\mathrm{X}$ & $\mathrm{X}$ & $\mathrm{X}$ & $\mathrm{X}$ \\
\hline 2. Fundamento conceitual & & & $\mathrm{X}$ & & & $\bar{X}$ & $\mathrm{X}$ \\
\hline $\begin{array}{l}\text { 3. Modelo de referência dos } \\
\text { processos de negócio }\end{array}$ & & & & $\mathrm{X}$ & & $\mathrm{X}$ & $\mathrm{X}$ \\
\hline $\begin{array}{l}\text { 4. Modelo de referência de } \\
\text { sistemas PLM }\end{array}$ & & & & & $\mathrm{X}$ & $\mathrm{X}$ & $\mathrm{X}$ \\
\hline \multicolumn{8}{|l|}{$\begin{array}{l}\text { 5. Descrição do perfil de } \\
\text { sistemas PLM }\end{array}$} \\
\hline \multicolumn{8}{|l|}{ 6. Base de conhecimentos } \\
\hline 7. Benefícios do PLM & & & & & & & \\
\hline
\end{tabular}


Os elementos discutidos anteriormente e as suas inter-relações são ilustrados na Figura 36, que representa o framework conceitual de elementos do PLM.
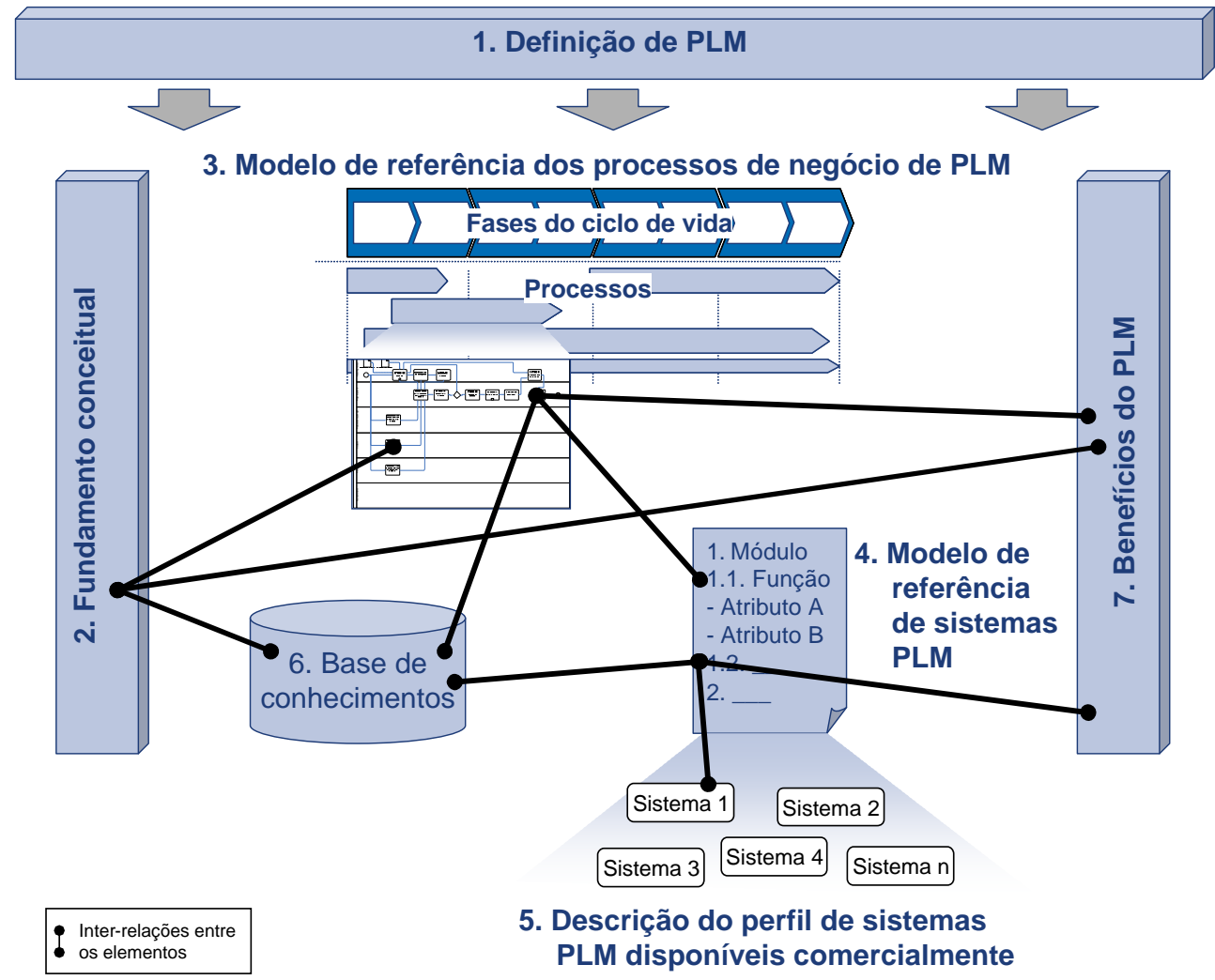

Figura 36. Framework conceitual de elementos do PLM

A definição de PLM provê a visão e a delimitação escolhida, ou seja, o escopo, de acordo com o qual o modelo de referência dos processos e os demais elementos do framework são detalhados. Partindo da definição de PLM, o pré-requisito necessário para a sua implantação é dado pelo fundamento conceitual.

O modelo de referência dos processos de negócio de PLM está localizado em uma posição central do framework, integrando os demais elementos (a relação com a descrição do perfil de sistemas PLM é indireta). O modelo abrange os processos de gestão do ciclo de vida de produtos (e.g. desenvolvimento de produtos) e inclui as práticas-chave de PLM (e.g. gestão de requisitos).

O modelo de referência de sistemas PLM, por sua vez, consiste em uma relação estruturada das funcionalidades de TI que caracterizam sistemas PLM. Tal modelo serve como base para a descrição do perfil de sistemas PLM disponíveis comercialmente.

Finalmente, a base de conhecimentos contém o conteúdo necessário para apoiar os treinamentos na área de PLM. Completando o framework, os benefícios do PLM ilustram as 
vantagens competitivas relacionadas com a adoção dos demais elementos do framework (e.g. processos, sistemas).

Definido o framework, optou-se por uma forma de avaliação que envolvesse a revisão por pares da academia. Assim, a forma escolhida para a avaliação foi a submissão de um artigo para publicação em um periódico internacional relevante na área de pesquisa. O periódico escolhido foi o Computers in Industry, classificado pela CAPES no nível A1/A2 ${ }^{25}$. Além disso, o tema do trabalho é diretamente relacionado com o foco da Computers in Industry, cujo escopo principal envolve pesquisas na integração de ferramentas de TI para apoiar processos de negócio em empresas industriais.

O artigo sobre o framework foi submetido em maio de 2006, aceito em agosto de 2007 e publicado em março de $2008^{26}$.

Deve-se observar que a versão do framework apresentada neste texto é uma revisão aprimorada da versão publicada originalmente. Entretanto, as melhorias realizadas não alteram a essência do framework (quantidade e conteúdo de seus elementos), de forma que a avaliação realizada continua válida.

Determinado o framework, o próximo item aborda o detalhamento do relacionamento entre as atividades do modelo de referência do processo e as funcionalidades do modelo de referência de sistemas PLM.

\subsection{Relacionamento entre as atividades do processo e as funcionalidades de sistemas PLM}

O detalhamento da relação entre as atividades do modelo de referência do processo e as funcionalidades do modelo de referência de sistemas é essencial para que os objetivos desta pesquisa possam ser atingidos. Tal relacionamento é utilizado, neste trabalho, para integrar o modelo de referência dos processos de gestão do ciclo de vida com o modelo de referência de sistemas PLM (capítulo 8). O modelo integrado processo-sistemas PLM é, por sua vez, utilizado no método de seleção de sistemas PLM aqui proposto (capítulo 9).

${ }^{25}$ A classificação A1 é o nível mais alto de avaliação de periódicos da CAPES. A Computers in Industry é classificada no nível A1 na área de Administração e no nível A2 na área de Engenharia (área Engenharias III da CAPES).

${ }^{26}$ SCHUH, G.; ROZENFELD, H.; ASSMUS, D.; ZANCUL, E. Process oriented framework to support PLM implementation. Computers in Industry, Março 2008, 59, 2-3, 210-218, 2008a. 
A localização do relacionamento entre o modelo de referência dos processos de negócio de PLM (elemento 3 do framework) e o modelo de referência de sistemas PLM (elemento 4) é ilustrada na Figura 37.

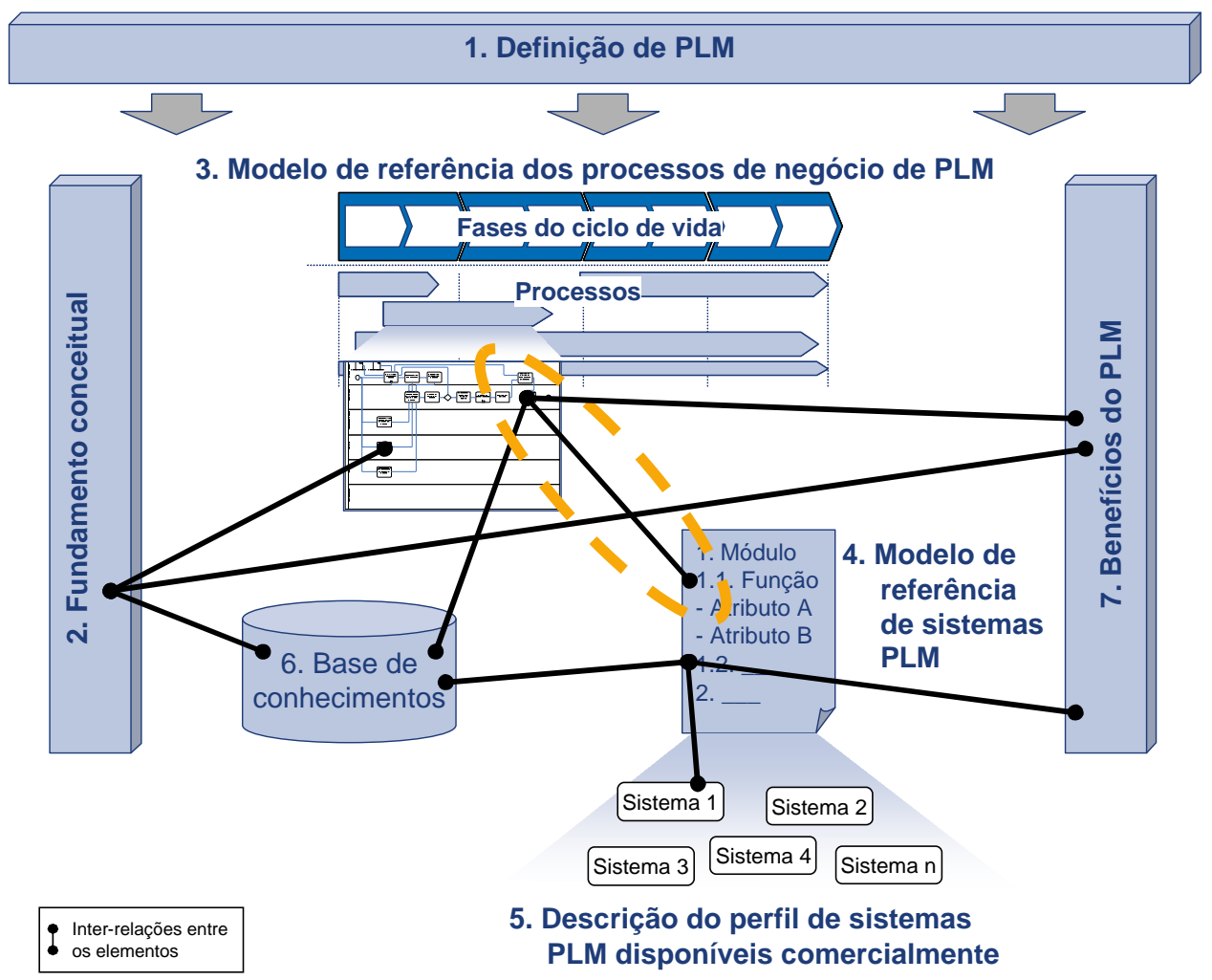

Figura 37. Localização do relacionamento entre o modelo do processo e o modelo de sistemas PLM no framework conceitual de elementos do PLM

A fim de relacionar as atividades do modelo de processos com as funcionalidades do modelo de sistemas é necessário especificar dois aspectos do relacionamento. O primeiro aspecto é o nível de detalhamento em que ocorre o relacionamento, tanto do lado do modelo de processos como do lado do modelo de sistemas. O segundo aspecto é a cardinalidade do relacionamento, que define a quantidade de relacionamentos que um objeto (do processo ou do sistema) pode ter.

O nível em que ocorre o relacionamento depende do grau de abstração utilizado nos modelos considerados. A quantidade de níveis e o grau de detalhamento em cada nível podem variar bastante de acordo com o modelo específico. Entretanto, é possível definir um direcionamento macro baseado na análise de modelos existentes. Nesse sentido, inicialmente 
são analisados os modelos de processos. A Tabela 8 descreve os níveis de detalhamento empregados em três modelos de referência de gestão do ciclo de vida de produtos ${ }^{27}$.

Tabela 8 - Níveis de detalhamento dos modelos de referência de PLM

\begin{tabular}{c|c|l|l}
\hline \multirow{2}{*}{$\begin{array}{c}\text { Nível de } \\
\text { detalha- } \\
\text { mento }\end{array}$} & \multicolumn{1}{|c}{$\begin{array}{c}\text { Modelo Unificado } \\
\text { do PDP }\end{array}$} & \multicolumn{1}{|c}{$\begin{array}{c}\text { CMMI } \\
\text { desenvolvimento }\end{array}$} & \multicolumn{1}{c}{ TFB-57 } \\
\cline { 2 - 4 } Nível 1 & Macrofase (desenvolvimento) & $\begin{array}{l}\text { Área de processo (gestão da } \\
\text { configuração) }\end{array}$ & Processo (gestão de mudanças) \\
\hline Nível 2 & Fase (projeto conceitual) & $\begin{array}{l}\text { Meta (monitorar e controlar } \\
\text { mudanças) }\end{array}$ & $\begin{array}{l}\text { Fase (planejamento de } \\
\text { mudanças) }\end{array}$ \\
\hline Nível 3 & $\begin{array}{l}\text { Atividade (modelar } \\
\text { funcionalmente o produto) }\end{array}$ & $\begin{array}{l}\text { Prática (monitorar solicitações } \\
\text { de mudanças) }\end{array}$ & $\begin{array}{l}\text { Atividade (consolidação de } \\
\text { várias mudanças em um pacote } \\
\text { de mudanças) }\end{array}$ \\
\hline Nível 4 & $\begin{array}{l}\text { Tarefa (estabelecer estruturas } \\
\text { funcionais alternativas) }\end{array}$ & $\begin{array}{l}\text { Subprática (criar e gravar } \\
\text { solicitação de mudança na } \\
\text { base de dados) }\end{array}$ & Não disponível \\
\hline
\end{tabular}

Pode-se observar, nos modelos analisados, que os dois primeiros níveis de detalhamento (1 e 2) representam fases amplas (Tabela 8). Uma evidência adicional da abrangência considerada nesse nível, identificada pela análise detalhada dos modelos, é a quantidade restrita de subdivisões utilizadas em cada nível. Por exemplo, o Modelo Unificado do PDP é organizado em quatro macrofases (nível 1) e onze fases (nível 2). Esse grau de detalhamento não é compatível com a representação de funcionalidades de softwares, que são mais específicas.

O terceiro e o quarto níveis de detalhamento representam, respectivamente, atividades e tarefas (procedimentos). O relacionamento com as funcionalidades de sistemas de informação deve ocorrer em um desses níveis. A escolha entre o nível 3 ou 4 depende do modelo utilizado e também do grau de abstração empregado no modelo correspondente do sistema de informação.

Nos modelos apresentados na Tabela 8, o nível 4 representa procedimentos muito fragmentados. Nesse nível, a quantidade de procedimentos pode ser muito grande - por exemplo, no Modelo Unificado do PDP são definidos 472 procedimentos distintos. A complexidade gerada pelo elevado grau de detalhamento pode inviabilizar o relacionamento com as funcionalidades de sistemas. Nos casos em que o nível 4 é representado em um nível muito específico, o nível 3 é o mais apropriado para o relacionamento com as

${ }^{27}$ Os três modelos descritos na Tabela 8 são aqueles com maior nível de detalhamento disponível dentre os cinco modelos analisados na revisão bibliográfica (subitem 2.2.3). 
funcionalidades. A decisão final sobre o nível de detalhamento a ser considerado depende, entretanto, do grau de abstração do modelo do sistema.

Apesar de não ser possível definir uma regra única, a análise dos modelos apresentados na Tabela 8 permite a definição de um direcionamento macro para o relacionamento entre modelos de processo e de sistemas. Generalizando os níveis de detalhamento analisados na Tabela 8 e adotando uma nomenclatura neutra e genérica, são definidos quatro níveis de detalhamento para o modelo de processos: (1) processo; (2) subprocesso; (3) atividade; (4) procedimento. Nessa estrutura, em geral, a representação de atividades (nível 3) apresenta o grau de detalhamento mais adequado para o relacionamento com o modelo de sistemas de informação.

Em relação aos sistemas de informação, é possível definir uma organização estruturada em quatro níveis de detalhamento, comparáveis com os níveis utilizados para os processos de negócio. Por exemplo, a SAP descreve as funcionalidades de seus sistemas em modelos de referência chamados de solution maps. Os solution maps representam três níveis de detalhamento, denominados processo principal, processo e detalhamento (SAP, 2005, p. 30; 2008b). Um exemplo de solution map é apresentado na Figura 38.

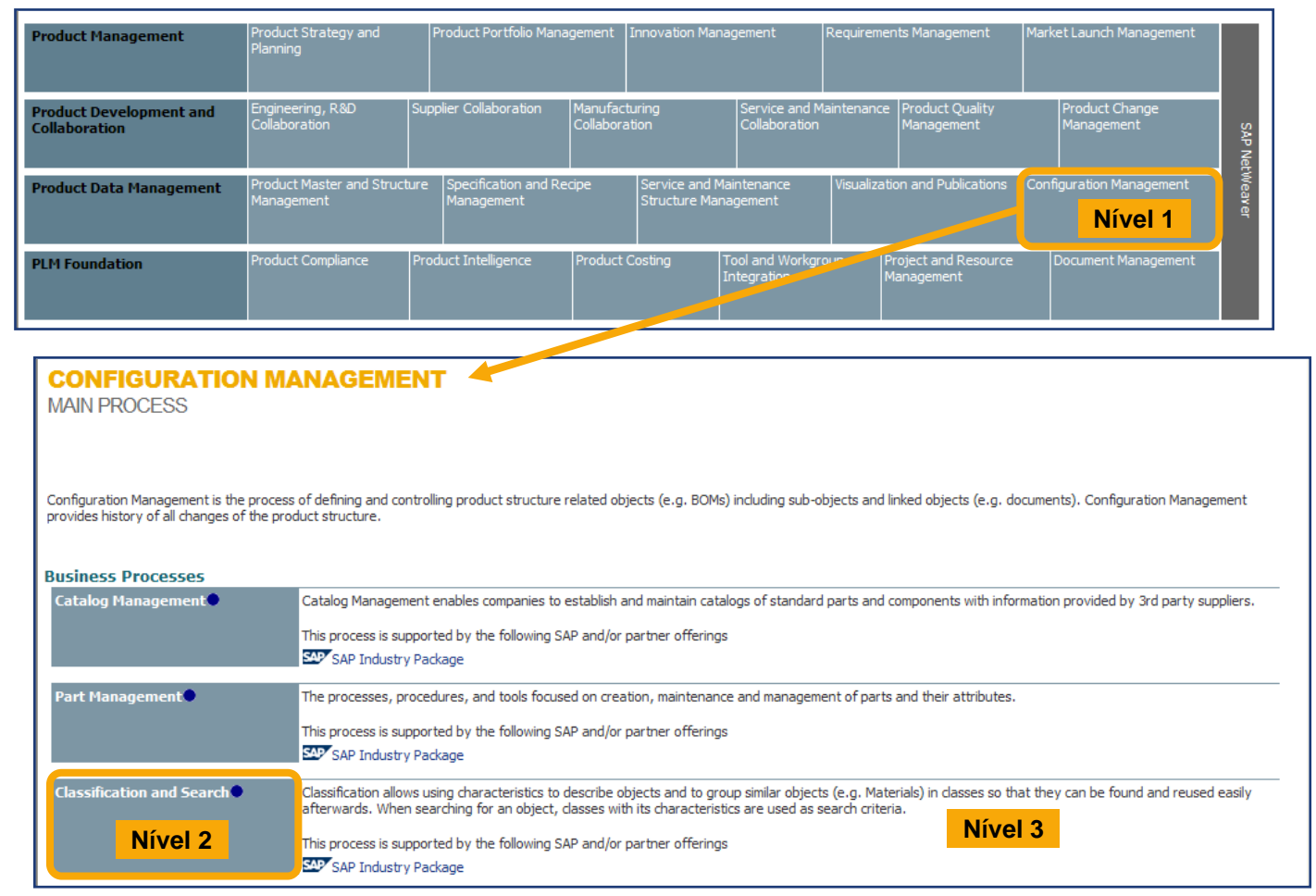

Figura 38. Níveis de detalhamento do solution map da SAP (SAP, 2008b)

Além do solution map, a SAP fornece, em conjunto com os sistemas, modelos detalhados das funcionalidades das soluções. Tais modelos, representados utilizando o formalismo EPC, são descritos em quatro níveis. Os dois primeiros níveis são semelhantes ao 
solution map. O nível 3 é compatível com o terceiro nível do solution map, mas é descrito de forma mais detalhada, representando funcionalidades por meio de EPCs. O nível 4, por sua vez, representa transações do sistema. Utilizando a busca e classificação como exemplo para o nível 2 (Figura 38), um exemplo de funcionalidade do nível 3 é editar classes. Para essa funcionalidade, as transações disponíveis no nível 4 são: criar classe, modificar classe, apresentar classe, apagar classe; tipos de classes (ZANCUL, 2000, p. 81).

Considerando o significado dos objetos que são representados em cada nível de detalhamento do modelo descrito anteriormente e generalizando a nomenclatura utilizada pela SAP, definem-se quatro níveis de detalhamento para o modelo de sistemas: (1) módulo; (2) grupo de funcionalidade; (3) funcionalidade; (4) transação.

Nessa estrutura, a representação de funcionalidades (nível 3) apresenta, em geral, um grau de detalhamento semelhante ao nível de abstração utilizado para as atividades (nível 3) do modelo de referência de processos. Portanto, o relacionamento que se procura especificar aqui pode ser realizado entre as atividades e as funcionalidades.

Dado o nível em que ocorre o relacionamento, é necessário especificar a sua cardinalidade. Conforme a definição utilizada no modelo entidade-relacionamento (item 3.2), a cardinalidade do relacionamento pode ser de quatro tipos: um-para-um, um-para-muitos, muitos-para-um, muitos-para-muitos.

No caso do relacionamento entre as atividades e as funcionalidades, considera-se que uma mesma funcionalidade pode ser utilizada para atender aos requisitos de múltiplas atividades. Ao mesmo tempo, as atividades podem exigir o uso de várias funcionalidades para a sua execução. A possibilidade de relacionamento é, portanto, de muitos-para-muitos.

A Figura 39 resume a especificação do relacionamento entre as atividades do modelo de processos e as funcionalidades do modelo de sistemas. 


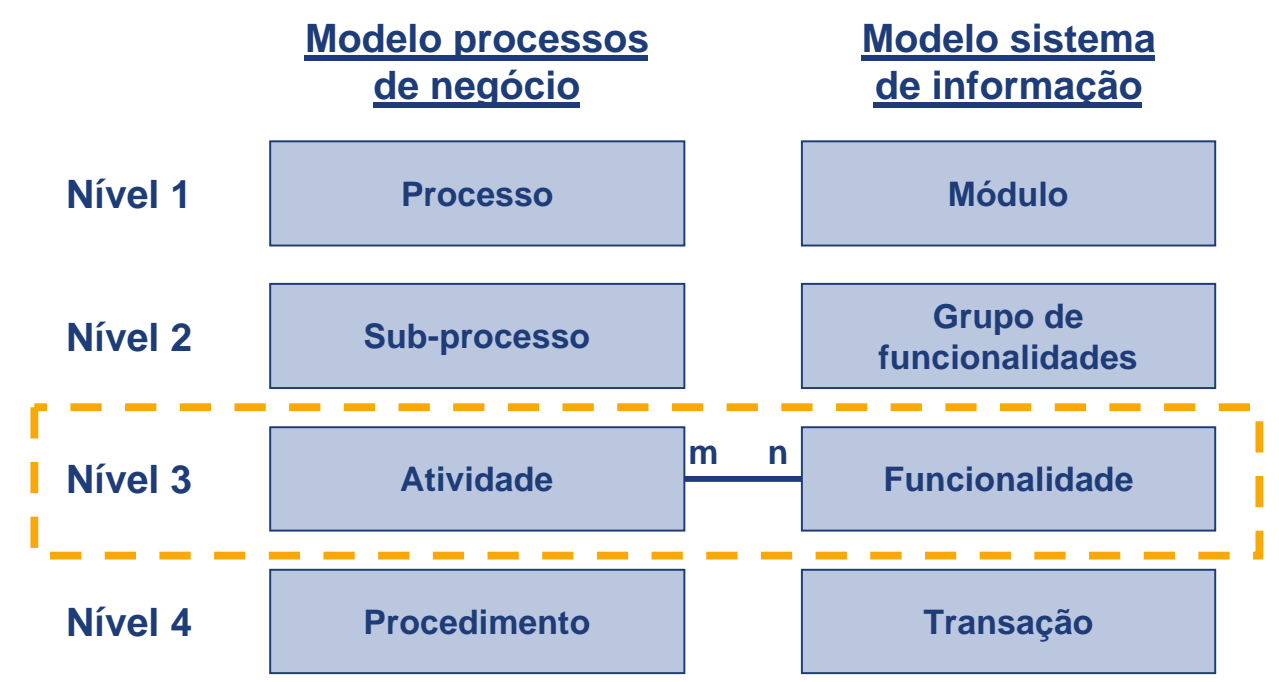

Figura 39. Especificação do relacionamento entre atividades do modelo de processo e funcionalidades do modelo de sistemas

A partir da definição do framework conceitual de elementos do PLM neste capítulo, o modelo de referência de sistemas PLM é detalhado no capítulo a seguir. 


\section{MODELO DE REFERÊNCIA DE SISTEMAS PLM}

Este capítulo apresenta o modelo de referência de sistemas PLM. Inicialmente, discute-se os passos empregados na construção do modelo (item 7.1). Em seguida, apresentase uma visão geral do modelo de referência de sistemas PLM. O conteúdo de cada um dos módulos do modelo é descrito de forma resumida (item 7.2). Apresenta-se, então, a análise dos principais resultados quantitativos da survey sobre sistemas PLM. A análise indica o atual estágio de desenvolvimento dos sistemas disponíveis no mercado (item 7.3). Por fim, são discutidas as tendências de evolução de sistemas PLM (item 7.4).

\subsection{Desenvolvimento do modelo de referência de sistemas PLM}

O desenvolvimento do modelo de referência de sistemas PLM foi iniciado com o levantamento das funcionalidades oferecidas pelos cinco fornecedores líderes de mercado SAP, Siemens PLM (antiga UGS), Dassault, PTC e Oracle/Agile (ver subitem 2.3.4). No levantamento, foram aplicados cinco procedimentos técnicos de coleta de dados:

Pesquisa bibliográfica em livros e publicações que descrevem os sistemas;

Pesquisa documental em brochuras e no material de marketing dos sistemas;

Participação do pesquisador em um treinamento sobre o sistema Windchill da PTC $^{28}$;

Manipulação do sistema Windchill da PTC pelo pesquisador ${ }^{29}$;

Visita à feira CAT.PRO em 2005 (principal feira na área de PLM na Alemanha) e

a CEBIT em 2006, com o objetivo de discutir as funcionalidades dos sistemas com funcionários das empresas fornecedoras.

As funcionalidades identificadas no levantamento foram sintetizadas em uma lista única, organizada de maneira hierárquica em quatro níveis: módulos, grupos de funcionalidades, funcionalidades e transações.

O passo seguinte foi a realização de uma survey para validar a lista hierárquica como uma representação de um conjunto amplo, consistente e representativo de sistemas PLM. Essa atividade do trabalho foi realizada pelo autor no escopo de um projeto de pesquisa do WZL, em conjunto com a empresa Trovarit AG. Na divisão de responsabilidades desse projeto

28 Treinamento de 24 horas realizado pela PTC em 2005 no IKT (Institut für Allgemeine Konstruktionstechnik des Maschinenbaus), da Universidade de Aachen, na Alemanha.

${ }^{29}$ O sistema Windchill estava disponível para ser utilizado em pesquisas no WZL, onde o autor trabalhou como pesquisador assistente entre 2005 e 2007. 
conjunto, o pesquisador foi responsável pelo desenvolvimento do conteúdo técnico da survey, incluindo a elaboração do questionário e a análise dos dados. A Trovait AG foi responsável pela condução do processo de coleta de dados, envolvendo a formatação do questionário, o envio do questionário para fornecedores de software e o posterior recebimento de questionários respondidos.

A partir da lista hierárquica de funcionalidades foi derivado um questionário. Cada funcionalidade foi reescrita no formato de pergunta, enquanto as transações da lista foram transformados em possibilidades de resposta do tipo múltipla escolha. Módulos e grupos de funcionalidades complementam a estrutura do questionário. O questionário resultante contém 1592 itens, organizados em quatro níveis de detalhamento:

Módulos: 13;

Grupos de funcionalidades: 49;

Funcionalidades (perguntas): 296;

Transações (respostas múltipla escolha): 1234.

Para ilustrar o formato final do questionário, pode-se citar um exemplo de pergunta relacionada com a funcionalidade de gestão de produtos variantes. Nesse caso, a pergunta seria formulada da seguinte forma: Como produtos variantes são gerenciados no sistema? Para essa pergunta, as respostas possíveis incluem, por exemplo: o sistema possibilita a criação de estruturas de produto independentes de uma ordem de produção; os dados mestres de materiais não precisam ser gerados para cada possível variante.

O questionário foi formatado em uma planilha eletrônica (MS Excel). As questões mais complexas são complementadas com uma explicação, descrevendo em maior detalhe o conteúdo técnico da pergunta. Além das respostas em múltipla escolha, em cada pergunta existe a possibilidade de complemento da resposta por meio de um comentário escrito em um campo de texto livre. Com isso, o objetivo foi possibilitar a obtenção de informações adicionais sobre as funcionalidades.

Na survey, foram contatados 57 fornecedores de PLM, com escritório nos países europeus de língua alemã (Alemanha, Áustria e Suíça). Dentre os fornecedores convidados a participar da pesquisa, 17 responderam o questionário. O estímulo que os fornecedores tinham para participar da pesquisa era a publicação do perfil de seus sistemas em um relatório de mercado publicado na Alemanha (ASSMUS et al., 2006). A lista de todos os fornecedores contatados é apresentada no Apêndice A. Os fornecedores que participaram da pesquisa estão 
em destaque na lista. Na Tabela 9 é apresentada a classificação dos 17 sistemas que participaram da survey em relação à sua origem e ao seu posicionamento de mercado.

Tabela 9 - Classificação dos sistemas participantes da survey (conforme tipos definidos no subitem 2.3.2)

\begin{tabular}{l|c|c}
\hline \multirow{2}{*}{$\begin{array}{c}\text { Classificação conforme } \\
\text { origem dos sistemas }\end{array}$} & \multicolumn{2}{|c}{ Classificação segundo posicionamento de mercado } \\
\cline { 2 - 3 } & PDM & PLM \\
\hline ERP & - & 2 \\
\hline PDM & 9 & 1 \\
\hline CAD & 2 & 3 \\
\hline
\end{tabular}

A coleta de dados foi realizada entre janeiro e maio de 2006, na Alemanha. Durante o período de coleta de dados, o contato de fornecedores com o pesquisador para discutir dúvidas técnicas do questionário foram freqüentes. Na resposta do questionário, os fornecedores indicaram se ofereciam ou não cada uma das transações relacionadas com as funcionalidades.

Com os resultados da survey, a lista inicial de funcionalidades foi ajustada. As funcionalidades e as transações não disponíveis em nenhum dos sistemas pesquisados foram excluídas. Essa situação é possível devido à metodologia de levantamento de dados empregada, que incluía a identificação de funcionalidades e de transações por meio da análise do material de marketing dos sistemas e de discussões com representantes de empresas fornecedoras. Das 1234 transações do questionário, 19 (1,5\%) não foram posteriormente confirmadas na survey. Por outro lado, funcionalidades encontradas na survey, em pelo menos um sistema, foram consideradas validadas. O resultado da validação e ajuste é o modelo de referência de sistemas PLM, descrito no item 7.2 a seguir e apresentado na integra no Apêndice B.

Além da obtenção das respostas, o contato freqüente com fornecedores na fase de coleta de dados da survey permitiu a identificação de tendências de evolução de sistemas PLM, que também foram compiladas de forma estruturada (item 7.4).

\subsection{Visão geral do modelo de referência de sistemas PLM}

O modelo de referência de sistemas PLM proposto neste trabalho visa, principalmente, estabelecer uma base comum para a comparação entre os diversos sistemas PLM disponíveis comercialmente. A possibilidade de comparação dos sistemas em relação a uma base comum contribui para que as empresas possam selecionar o software mais adequado para atender aos requisitos de seus processos de negócio. 
A fim de atingir esse objetivo, o modelo de referência de sistemas PLM deve contemplar as funcionalidades utilizadas para apoiar os processos de negócio das empresas. Trata-se, portanto, de um modelo de referência de funcionalidades. Outros aspectos dos sistemas PLM, como características do fornecedor (e.g. porte, tempo de atuação no mercado, presença geográfica) ou da tecnologia empregada (e.g. sistema operacional, banco de dados), não são considerados. A exceção são os padrões de integração disponíveis no sistema, uma vez que a capacidade de integração com outras ferramentas (e.g. CAD) tem impacto direto no suporte às atividades dos processos de negócio.

Ao especificar um conjunto amplo e genérico de funcionalidades de sistemas PLM, o modelo de referência também pode ser utilizado como base para guiar o desenvolvimento de softwares nessa área. Trata-se de uma possibilidade adicional de aplicação do modelo desenvolvido no presente trabalho.

Em relação à sua estrutura, o modelo de referência de sistemas PLM está organizado em quatro níveis de detalhamento: módulos, grupos de funcionalidades, funcionalidades e transações. Essa estrutura segue a especificação definida no framework conceitual de elementos do PLM (item 6.2).

Os quatro níveis de detalhamento são apresentados em três visões distintas do modelo. A primeira, uma macro-visão, ilustra apenas os módulos de sistemas PLM. A segunda apresenta os módulos e os grupos de funcionalidades. Por fim, a terceira visão do modelo, em formato tabular, contempla os quatro níveis de detalhamento (Figura 40).

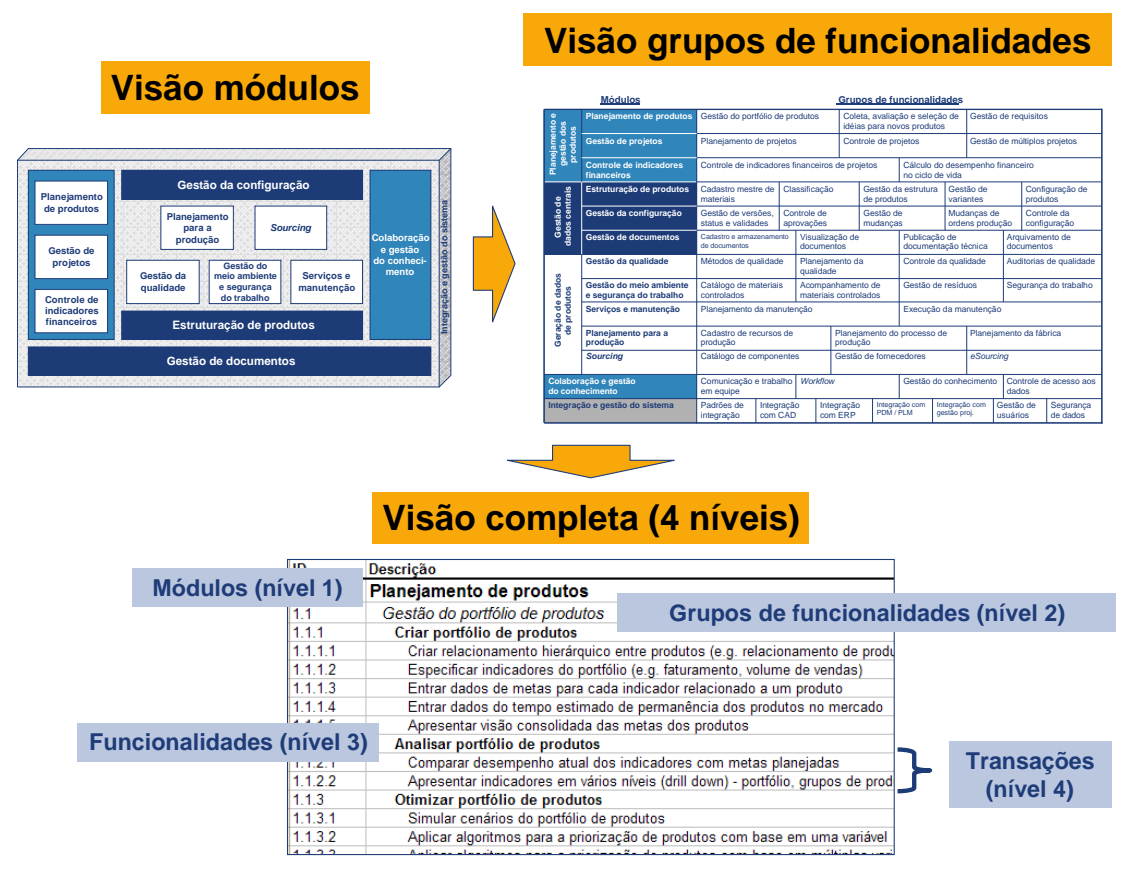

Figura 40. Estrutura do modelo de referência de sistemas PLM 
Dada a estrutura do modelo de referência, as duas visões mais abrangentes - módulos e grupos de funcionalidades - são detalhadas a seguir. Já a visão completa do modelo está disponível para consulta no Apêndice B. No primeiro nível de detalhamento, o modelo é composto por 13 módulos, ilustrados na Figura 41.

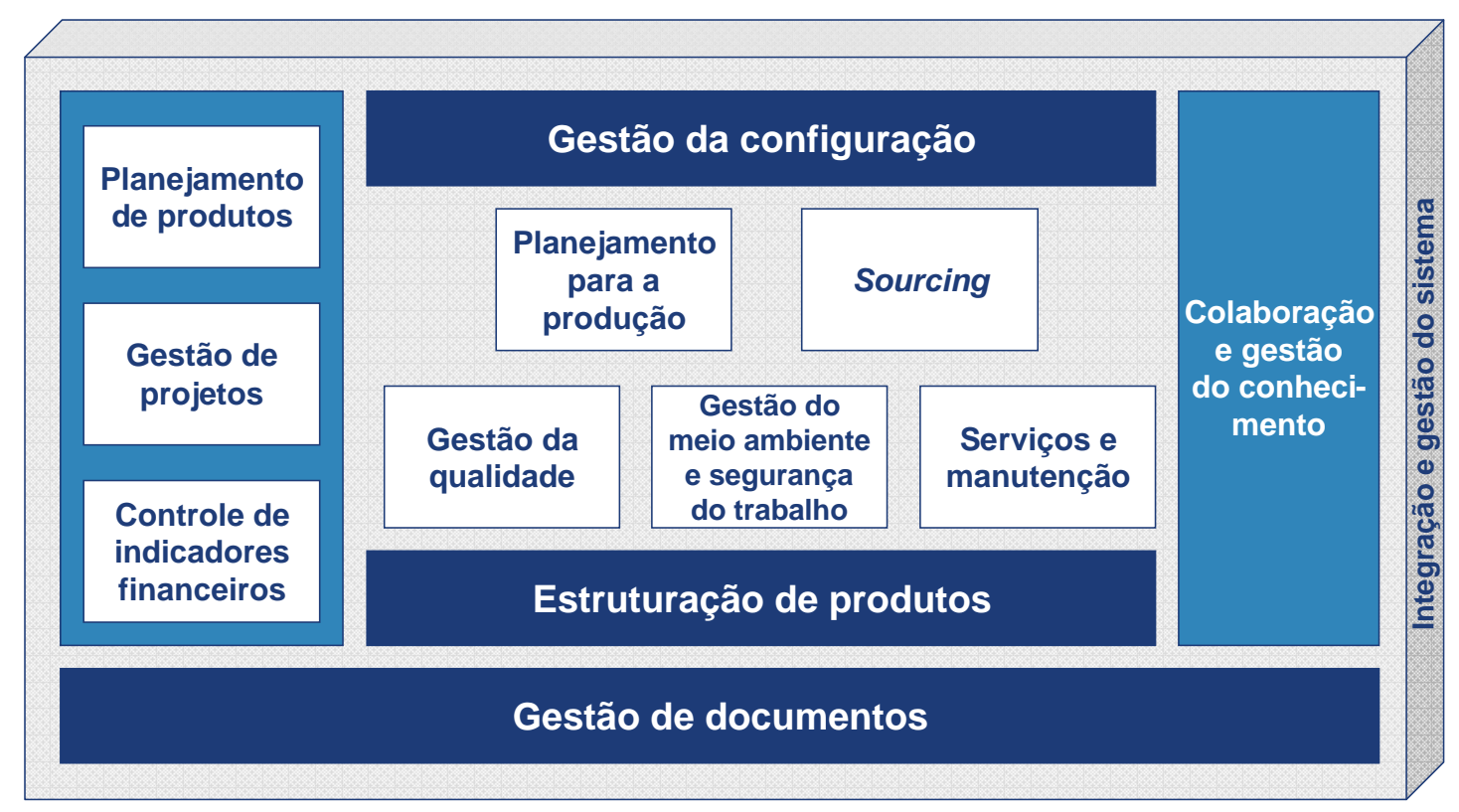

Figura 41. Módulos do modelo de referência de sistemas PLM

Na Figura 41, a disposição dos módulos ilustra o seu papel no sistema PLM. Do lado esquerdo da figura estão agrupados três módulos relacionados com o planejamento e a gestão dos produtos no ciclo de vida - planejamento de produtos, gestão de projetos, controle de indicadores financeiros.

Na parte superior e inferior da Figura 41, em azul escuro, estão destacados os três módulos de gestão de dados centrais do modelo de referência de sistemas PLM estruturação de produtos, gestão da configuração e gestão de documentos. São os móduloschave para a gestão de dados de produtos no ciclo de vida.

No centro da Figura 41, na cor branca, são apresentados os módulos de geração de dados de produtos. São módulos com funcionalidades focadas, essencialmente, no detalhamento da especificação dos produtos - gestão da qualidade, gestão do meio ambiente e segurança do trabalho, serviços e manutenção, planejamento para a produção, sourcing.

Do lado direito da Figura 41 está posicionado o módulo de colaboração e de gestão do conhecimento, que engloba as funções que apóiam o trabalho em equipe, tanto internamente na empresa como também com parceiros na cadeia de suprimentos. 
Por fim, ao fundo da Figura 41, o módulo de integração e de gestão do sistema compreende os padrões e as interfaces necessárias para possibilitar a troca de dados entre o PLM e outros sistemas de informação.

Os 13 módulos do modelo de referência de sistemas PLM estão, por sua vez, detalhados em 49 grupos de funcionalidades. A visão do modelo de referência por grupos de funcionalidades é apresentada na Figura 42. Nessa visão, a forma de representação adotada é baseada na representação utilizada pela SAP em seu solution map (item 6.2). Os módulos do modelo de referência estão posicionados na segunda coluna à esquerda da Figura 42. Do lado direito de cada módulo estão detalhados os grupos de funcionalidades correspondentes. 
Módulos

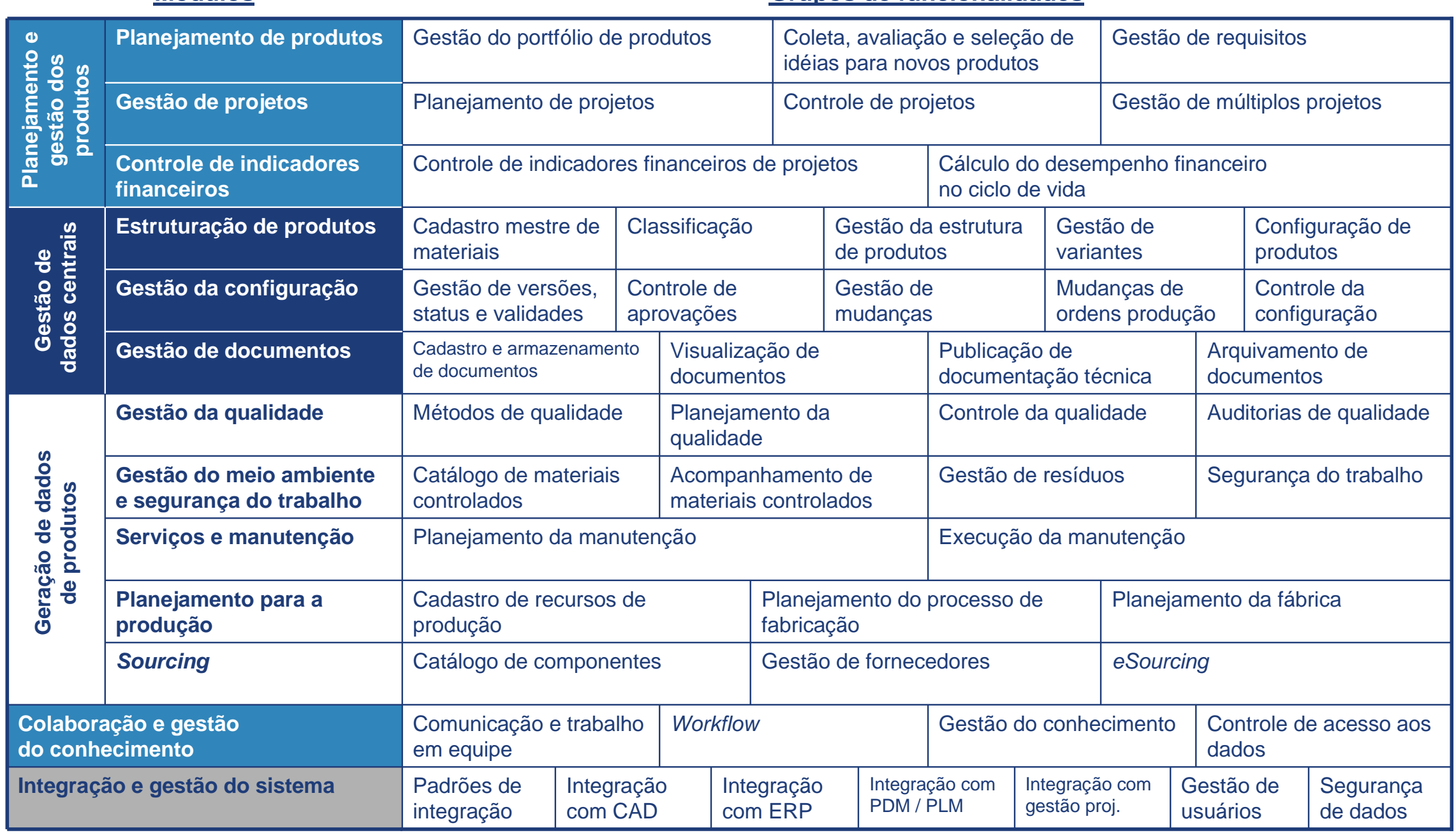

Figura 42. Grupos de funcionalidades do modelo de referência de sistemas PLM 
Cada um dos 13 módulos do modelo de referência é descrito resumidamente a seguir. A seqüência de apresentação dos módulos está organizada conforme o agrupamento deles no modelo de referência:

Planejamento e gestão dos produtos: planejamento de produtos, gestão de projetos, controle de indicadores financeiros;

Gestão de dados centrais: estruturação de produtos, gestão da configuração e gestão de documentos;

Geração de dados de produtos: gestão da qualidade, gestão do meio ambiente e segurança do trabalho, serviços e manutenção, planejamento para a produção, sourcing;

Colaboração e gestão do conhecimento;

Integração e gestão do sistema.

O objetivo aqui é ilustrar as principais atribuições dos módulos nos sistemas PLM. Os detalhes de cada um dos módulos são apresentados no modelo de referência completo (Apêndice B).

\section{Módulos de planejamento e gestão dos produtos}

\section{Planejamento de produtos}

O planejamento de produtos envolve os grupos de funções de gestão do portfólio de produtos, de coleta, avaliação e seleção de idéias para novos produtos e de gestão de requisitos.

A gestão do portfólio compreende funcionalidades para o planejamento do portfólio de produtos da empresa. Nesse sentido, são definidos os relacionamentos entre produtos e grupos de produtos. As metas de cada produto em relação a indicadores configurados previamente (e.g. faturamento, volume de vendas, tempo estimado de permanência no mercado) são armazenadas no sistema. Essas metas do portfólio planejado podem ser comparadas com dados reais do desempenho realizado. Funções de simulação e de otimização apóiam a análise de cenários e a tomada de decisão sobre alterações no portfólio.

A coleta, avaliação e seleção de idéias para novos produtos abrange todo o ciclo de avaliação de idéias. As idéias são coletadas em um banco de dados disponível para ser acessado por várias áreas da empresa. A configuração desse banco de dados no PLM possibilita uma descrição abrangente das idéias bem como a inclusão de documentos, como, por exemplo, relatórios ou desenhos. As idéias cadastradas podem ser classificadas com base 
em categorias predefinidas no sistema PLM. Uma funcionalidade de pesquisa permite a busca por idéias cadastradas na base de dados.

As idéias coletadas entram no processo de avaliação. Esse processo pode ser apoiado pelo workflow do PLM (módulo colaboração e gestão do conhecimento), que coordena a distribuição das tarefas para os responsáveis pela sua execução. Os critérios de avaliação e os respectivos pesos são especificados no sistema. Os resultados da avaliação são documentados e o status da idéia (e.g. aprovada, rejeitada) no sistema PLM é atualizado. As idéias avaliadas podem ser comparadas graficamente e visualizadas em um ranking de idéias.

Por fim, a gestão de requisitos é iniciada com a coleta, a classificação e a avaliação de requisitos de produtos. Os requisitos de produtos podem ser relacionados com outros objetos no sistema PLM (e.g. projetos, produtos, itens da estrutura de produtos). O conjunto final de requisitos de um produto resulta na confecção de um caderno de especificações. Funcionalidades específicas do sistema PLM registram a evolução dos requisitos ao longo do ciclo de vida em comparação com um baseline definido inicialmente.

\section{Gestão de projetos}

A gestão de projetos abrange os grupos de funcionalidades de planejamento de projetos, de controle de projetos e de gestão de múltiplos projetos.

O planejamento de projetos tem como pré-requisito a definição de um banco de dados de recursos (e.g. pessoas, equipamentos) para a execução de projetos. Dada a base de recursos, o planejamento de um projeto envolve a criação da Estrutura Analítica de Projeto (EAP), o desenvolvimento da rede de atividades e a definição do cronograma do projeto. A programação do projeto é realizada aplicando métodos específicos de gestão de projetos. Definido o plano de projeto, é possível analisar o nível de utilização dos recursos. Quando necessário, funcionalidades de simulação apóiam a otimização do planejamento realizado.

Após o início de um projeto, as funcionalidades de controle de projetos passam a ser utilizadas para registrar os avanços realizados nas atividades, para visualizar os indicadores do projeto (e.g. prazos) e para gerar relatórios periódicos de acompanhamento.

Nos casos em que vários projetos relacionados são executados simultaneamente, a gestão de múltiplos projetos apóia a especificação do inter-relacionamento entre os projetos, o planejamento agregado considerando a necessidade global de recursos e a geração de relatórios agregados do desempenho de projetos relacionados. 


\section{Controle de indicadores financeiros}

O controle de indicadores financeiros é subdividido em dois grupos de funcionalidades: controle de indicadores financeiros de projetos e cálculo do desempenho financeiro no ciclo de vida.

O controle de indicadores financeiros de projetos dá suporte ao cálculo do investimento necessário no projeto, com base nos dados de alocação de recursos, consumo de materiais, utilização de serviços externos, entre outros. Considerando a estimativa de custos, o orçamento do projeto é definido e a sua execução é controlada pelo sistema PLM.

Paralelamente, as funções de cálculo do desempenho financeiro no ciclo de vida tratam do desempenho financeiro de produtos. As receitas e as despesas de um produto, que incorrem ao longo de todo o ciclo de vida, são contabilizadas. Considerando esses dados, o sistema calcula e apresenta o fluxo de caixa do produto no ciclo de vida.

\section{Módulos de gestão de dados centrais}

\section{Estruturação de produtos}

A estruturação de produtos abrange cinco grupos de funcionalidades que têm papel central para a gestão de dados de produtos no ciclo de vida: o cadastro mestre de materiais, a classificação, a gestão da estrutura de produtos, a gestão de variantes e a configuração de produtos.

O cadastro mestre de materiais contém as funcionalidades para a inclusão de novos materiais (itens) no sistema PLM. Os novos materiais recebem uma identificação e os dados que caracterizam o material são cadastrados no sistema PLM.

A classificação envolve, inicialmente, a construção do sistema de classificação da empresa. São definidas as características (e.g. diâmetro) e as classes (e.g. eixo dianteiro) necessárias. As classes podem ser organizadas em uma hierarquia. A partir dessa estrutura, os materiais e os demais objetos do PLM podem ser classificados. As funcionalidades de pesquisa apóiam a realização de buscas por meio de características ou da estrutura de classes. Nos casos em que o PLM atua de forma integrada com um CAD, é possível gerar modelos parametrizados no CAD a partir das características de um produto definidas no sistema PLM.

Na gestão da estrutura de produtos, os materiais são relacionados entre si dando origem a estruturas de produtos. Um “navegador” gráfico, chamado de browser da estrutura de produto, possibilita a visualização gráfica das estruturas de produto e dos relacionamentos entre materiais e dos materiais com outros objetos do sistema (e.g. modelos 3D). O sistema 
PLM dá suporte a diversos tipos e visões da estrutura de produto (e.g. visão de engenharia, visão de manufatura). Relatórios gerenciais possibilitam a comparação entre as estruturas de produto e a identificação de todas as estruturas nas quais um objeto específico é utilizado ${ }^{30}$.

A gestão de variantes apóia a criação de estruturas de produto modulares, que possibilitam a definição de produtos finais diferenciados a partir de uma estrutura base e de uma lógica de configuração especificada no sistema PLM. A lógica de configuração envolve, por exemplo, a definição de itens obrigatórios, opcionais ou alternativos.

Considerando a lógica de configuração, o configurador de produtos contempla funcionalidades de apoio à geração de produtos específicos. Ao final do processo de configuração, as características do produto final são apresentadas.

\section{Gestão da configuração}

A gestão da configuração também abrange cinco grupos de funcionalidades: a gestão de versões, status e validades, o controle de aprovações, a gestão de mudanças, as mudanças de ordens de produção e o controle da configuração.

A gestão de versões, status e validades define a forma como a evolução dos objetos ao longo do ciclo de vida é gerenciada pelo sistema PLM. Versões indicam revisões (alterações) realizadas nos objetos. No PLM, uma nova versão pode ser armazenada automaticamente, a cada mudança realizada, ou pode ser definida manualmente pelo usuário. Já o status especifica a situação dos objetos (e.g. preliminar, em validação, liberado) e com isso define as ações que cada objeto pode ter no sistema. Por fim, a validade dos objetos indica em quais situações eles podem ser empregados (e.g. datas, clientes, regiões geográficas).

O controle de aprovações gerencia os processos de análise e de aprovação dos objetos no sistema PLM. A aprovação - feita individualmente ou para um grupo de objetos - pode desencadear uma série de ações automáticas no sistema, como o congelamento dos objetos para evitar alterações, o envio de dados para outros sistemas e a notificação das pessoas envolvidas.

A gestão de mudanças apóia a geração dos pedidos de mudança de engenharia Engineering Change Request (ECR). No sistema, os pedidos de mudança permitem a inclusão de informações que descrevem o problema encontrado. A partir da geração de um ECR, o sistema controla o processo de avaliação até a aprovação ou rejeição das mudanças pretendidas. A aprovação de um ECR resulta em uma ordem de mudança - Engineering

\footnotetext{
${ }^{30}$ Funcionalidade conhecida pelo termo where-used.
} 
Change Order (ECO), que autoriza a execução das alterações necessárias nos produtos. No caso das mudanças afetarem ordens de produção em execução, são utilizadas funcionalidades do grupo de mudanças de ordens de produção para avaliar o impacto das alterações na produção em andamento.

Completando este módulo, as funcionalidades de controle da configuração possibilitam o acompanhamento de toda a evolução da configuração de um produto ao longo do ciclo de vida. No sistema, são indicados os objetos cuja configuração deve ser gerenciada. Além disso, são definidos os eventos nos quais a configuração do produto é congelada para possibilitar que as informações sejam rastreadas. Dessa forma, o sistema possibilita a verificação da configuração de um produto a qualquer instante.

\section{Gestão de documentos}

A gestão de documentos é organizada em quatro grupos de funcionalidades: o cadastro e armazenamento de documentos, a visualização de documentos, a publicação de documentação técnica e, por fim, o arquivamento de documentos.

No cadastro e armazenamento de documentos, para cada documento é criado um registro que contém informações sobre a identificação (e.g. número de identificação, versão, nome do arquivo eletrônico) e sobre as características do documento (e.g. descrição do conteúdo). O documento é armazenado em um “cofre de dados” (vault) e o acesso ao arquivo eletrônico passa a ser gerenciado pelo PLM. As funcionalidades de controle de acesso (checkin e check-out) garantem que o documento não seja alterado indevidamente por mais de uma pessoa simultaneamente. Os documentos cadastrados no PLM podem ser relacionados com outros objetos do sistema, tais como os materiais.

A fim de facilitar o acesso aos documentos no ciclo de vida, as funcionalidades de visualização de documentos permitem a visualização de arquivos de formatos distintos, sem que o respectivo software esteja, necessariamente, instalado no computador. Além da própria visualização, as funcionalidades permitem a inserção de comentários sobre as imagens, sem alterar o conteúdo do documento, facilitando a troca de informações entre as pessoas.

Além de gerenciar os documentos de especificação do produto, este módulo do PLM contempla funcionalidades que apóiam a publicação de documentação técnica, tais como catálogos e manuais. Adicionalmente, o módulo abrange as funcionalidades de arquivamento de documentos, que enfocam o armazenamento de longo prazo de grandes quantidades de dados. Os documentos são convertidos para formatos apropriados para o arquivamento e são armazenados em meios designados especificamente para esse fim. 


\section{Módulos de geração de dados de produtos}

\section{Gestão da qualidade}

O módulo de gestão da qualidade está estruturado em quatro grupos de funcionalidades. O grupo métodos de qualidade contempla as funções que apóiam a aplicação de métodos específicos de qualidade, como a documentação do Production Part Approval Process (PAPP). O planejamento da qualidade permite a geração de planos de controle e a gestão dos meios de medição. No controle da qualidade são armazenados os resultados de inspeções realizadas. Por fim, o módulo de auditorias de qualidade apóia o planejamento das auditorias e a documentação dos resultados dessas auditorias, incluindo a definição das ações corretivas.

\section{Gestão do meio ambiente e segurança do trabalho}

O módulo de gestão do meio ambiente e segurança do trabalho também está estruturado em quatro grupos de funcionalidades. O catálogo de materiais controlados contém as informações descritivas e os procedimentos de trabalho (e.g. transporte, armazenamento, descarte) específicos para cada um dos materiais perigosos que exigem controle. O acompanhamento de materiais controlados possibilita a geração da documentação necessária para a utilização desses materiais. Na gestão de resíduos calcula-se o volume de resíduo gerado e preparam-se os documentos necessários para o descarte. Por fim, o módulo de segurança do trabalho apóia a definição de procedimentos de trabalho e o armazenamento dos resultados dos controles de segurança do trabalho aplicados pela empresa.

\section{Serviços e manutenção}

O módulo de serviços e manutenção contempla dois grupos de funcionalidades. $\mathrm{O}$ planejamento da manutenção permite a geração da documentação técnica sobre a manutenção dos produtos. O sistema também apóia a geração de ordens de trabalho para a manutenção, nos casos em que a própria empresa realiza esse serviço. Na execução da manutenção, os prestadores de serviço podem acessar os dados necessários para executar os procedimentos técnicos, como o plano de manutenção e o catálogo de peças de reposição. Os resultados da manutenção são registrados no sistema PLM e a configuração do produto é atualizada.

\section{Planejamento para a produção}

O planejamento para a produção envolve as funcionalidades relacionadas com o projeto dos processos de produção. Este módulo está subdividido em três grupos de 
funcionalidades. O cadastro de recursos de produção apóia a construção de um banco de dados sobre máquinas, equipamentos e demais recursos de manufatura. Esse banco de dados é empregado no planejamento do processo de fabricação para gerar os planos de processo de produção. Adicionalmente, as funcionalidades de planejamento da fábrica apóiam a análise do layout de chão de fábrica.

\section{Sourcing}

O módulo de sourcing contempla funcionalidades que dão suporte à busca de fornecedores e à realização de cotações de compras. As funções do catálogo de componentes apóiam a criação de catálogos eletrônicos de componentes padronizados no PLM. Para compor o catálogo, o PLM pode obter os dados descritivos de componentes por meio de fontes eletrônicas (CD ou Internet) disponibilizadas pelos fornecedores. As funcionalidades de gestão de fornecedores contemplam a construção de um banco de dados de fornecedores que inclui informações sobre o desempenho dos fornecedores de acordo com critérios de avaliação. A partir das bases de dados de fornecedores e de componentes, as funcionalidades chamadas de eSourcing apóiam a elaboração e o acompanhamento eletrônico de requisições de compras - Requests for Quotations (RFQs).

\section{Colaboração e gestão do conhecimento}

O módulo de colaboração e de gestão do conhecimento está organizado em quatro grupos de funcionalidades. O grupo de comunicação e de trabalho em equipe contempla as funcionalidades de groupware - calendário, banco de dados de contatos, grupos de discussão, sistema de notificação automática e funções de colaboração em tempo real com o compartilhamento de aplicativos.

O workflow permite a definição de rotinas de trabalho padronizadas. Com o workflow, após a conclusão de uma tarefa, o trabalho a ser executado é automaticamente transferido pelo sistema PLM para o responsável pela próxima atividade.

A gestão do conhecimento envolve as funcionalidades que apóiam o armazenamento estruturado e a recuperação de conhecimentos na empresa. A ênfase neste módulo é em conhecimentos não necessariamente relacionados diretamente com os produtos, uma vez que tais conhecimentos são gerenciados pelos outros módulos do sistema PLM. É o caso, por exemplo, de normas, padrões e apresentações externas. Além disso, esse grupo de funções também possibilita o gerenciamento de conhecimentos estruturados como melhores práticas e 
como lições aprendidas. Um banco de dados de competências das pessoas da empresa possibilita a busca por profissionais com conhecimentos especializados.

Por fim, as funções de controle do acesso aos dados possibilitam que parceiros externos acessem dados de projetos da empresa.

\section{Integração e gestão do sistema}

O último módulo a ser descrito aqui é o que contempla as funcionalidades de integração e gestão do sistema. O módulo está organizado em sete grupos de funcionalidades.

Desses sete grupos, cinco tratam da integração de dados do PLM com outros sistemas - padrões de integração, integração com CAD, integração com ERP, integração com outros PDM/PLM e integração com sistemas de gestão de projetos. Tais grupos de funcionalidades especificam os padrões de integração apoiados pelo sistema (e.g. IGES, STEP, XML), os tipos de integração possíveis (e.g. API) e a relação de dados que podem ser exportados do PLM para outros sistemas e importados de outros softwares para o sistema PLM. Também é especificada a lista de sistemas complementares (CAD, ERP, gestão de projetos, outros PDM/PLM) com os quais uma interface direta está disponível na versão comercial básica do sistema PLM.

Os outros dois grupos de funcionalidades desse módulo - gestão de usuários e segurança de dados - tratam das regras e das tecnologias disponíveis para garantir a integridade dos dados da empresa armazenados no sistema PLM. De acordo com o perfil de cada usuário, são determinadas as permissões e as restrições de acesso aos dados do PLM. Tecnologias de segurança de dados evitam o acesso não autorizado às informações.

\subsection{Status atual do desenvolvimento de sistemas PLM}

O modelo de referência de sistemas PLM descrito no item anterior é o principal resultado da survey que foi realizada para validar o conteúdo do referido modelo. Na survey, fornecedores de software indicaram as funcionalidades do modelo de referência que estão disponíveis nos seus sistemas PLM. Esses dados foram coletados com o intuito principal de validar o conteúdo do modelo de referência.

Os mesmos dados coletados na survey são utilizados, também, para a análise do perfil dos sistemas PLM oferecidos no mercado. O propósito dessa análise é avaliar e comparar o estágio de evolução dos diferentes módulos dos sistemas PLM definidos no modelo de referência. 
Nesse sentido, analisou-se, por módulo, o percentual de transações do modelo de referência oferecidas pelos sistemas PLM pesquisados ${ }^{31}$. Os resultados da análise são apresentados na Figura 43.

Transações disponíveis nos sistemas pesquisados vs. total de transações do modelo de referência (\%)

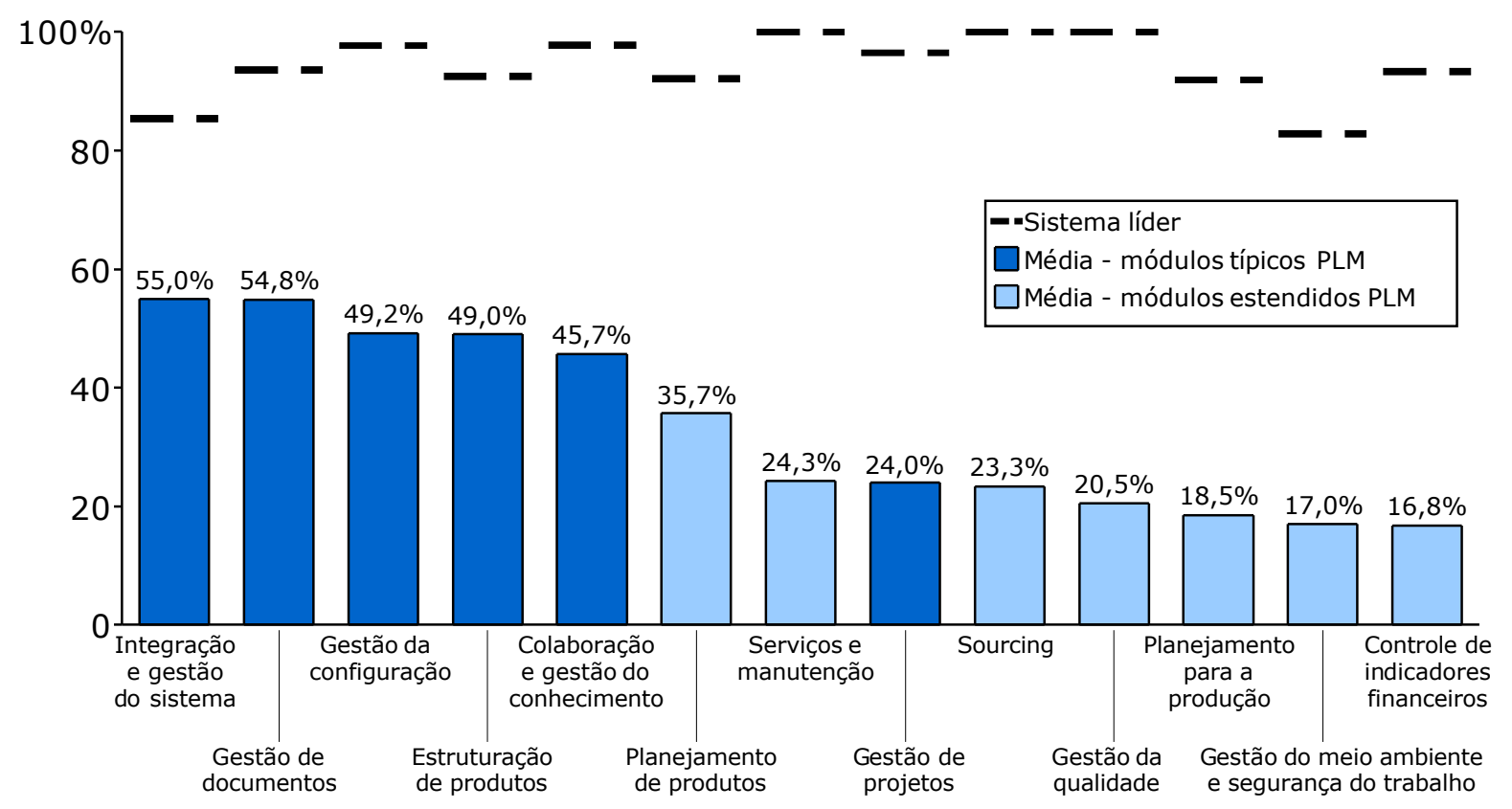

Figura 43. Comparação do status atual do desenvolvimento dos módulos de sistemas PLM

A Figura 43 apresenta, para cada módulo do modelo de referência, o percentual de transações listadas no modelo que são oferecidas, na média, pelos 17 sistemas pesquisados (colunas). A figura também ilustra o percentual de transações oferecidas pelo sistema líder em cada módulo (linha tracejada acima das colunas).

Os módulos estão classificados em duas categorias: módulos típicos de PLM e módulos com funcionalidades estendidas de PLM. A primeira categoria abrange os módulos que são, há anos, considerados atributos típicos de PLM (conforme definido no subitem 2.3.3). A segunda categoria abrange os módulos que foram incluídos recentemente no escopo de PLM, como o planejamento de produtos.

A análise dos dados indica que o grau de preenchimento dos requisitos do modelo de referência é mais alto para os módulos típicos de PLM, com exceção da gestão de projetos. O nível mais baixo do módulo de gestão de projetos pode ser explicado pelo uso disseminado de soluções stand-alone (e.g. MS Project), integradas com os módulos de gestão de projetos de

${ }^{31}$ A metodologia utilizada na survey e a classificação dos sistemas participantes da pesquisa constam do no item 5.2. 
sistemas ERP. A existência de uma solução alternativa consolidada não incentiva a evolução dos sistemas PLM nessa área.

No caso das funções estendidas de PLM, a interpretação dos resultados é distinta para cada um dos módulos. Em relação aos módulos de planejamento do produto e de serviços e manutenção, o nível médio de atendimento dos requisitos pode ser considerado baixo (35,7\% e 24,3\%, respectivamente). No entanto, os três sistemas líderes em cada um desses grupos cobrem mais de $70 \%$ dos requisitos. Isso indica que pode haver uma tendência de ampliar a cobertura dos requisitos desses dois módulos. Dados qualitativos obtidos no contato com os fornecedores confirmam essa tendência (ver item 7.4).

Sourcing e planejamento para a produção são apenas em parte apoiados pelo PLM, uma vez que tais funções são tipicamente suportadas pelo ERP. Finalmente, o nível de atendimento dos requisitos de gestão da qualidade, de gestão do meio ambiente e segurança do trabalho e do controle de indicadores financeiros é baixo. Isso significa que a maior parte das empresas continuará dependendo de soluções complementares de TI para executar essas funções.

A partir do entendimento da situação atual de desenvolvimento dos sistemas PLM, no próximo item são discutidas as tendências de evolução nesse mercado.

\subsection{Tendências de evolução de sistemas PLM}

Durante a realização da survey, além da coleta dos dados quantitativos, o contato freqüente do pesquisador com os fornecedores permitiu a identificação de algumas tendências de desenvolvimento dos sistemas PLM para os próximos anos.

As tendências identificadas foram citadas pelos fornecedores em contatos informais com o pesquisador. Não se trata, portanto, de uma relação exaustiva, mas apenas de uma compilação das citações dos fornecedores, como um subproduto da survey.

As tendências citadas por fornecedores incluem projetos de desenvolvimento em andamento nas software houses ou planos para desenvolvimento futuro. As tendências identificadas são listadas a seguir:

Aumento da importância das funcionalidades no início e no fim do ciclo de vida, como o planejamento de produtos e o apoio aos serviços e à manutenção.

Aprimoramento do grupo de funcionalidades de gestão de requisitos do produto (módulo planejamento de produtos), com a inclusão de funções para acompanhar a evolução dos requisitos ao longo do tempo. 
Desenvolvimento das funcionalidades que apóiam a definição de produtos variantes (módulo estruturação de produtos, grupo gestão de variantes), com recursos para a criação de produtos derivados e para o controle da configuração de variantes ao longo de todo o ciclo de vida.

Melhoria das funcionalidades para apoiar a colaboração entre pessoas trabalhando em equipes virtuais (módulo colaboração e gestão do conhecimento).

Integração crescente entre os ambientes de desenvolvimento de produtos (engenharia) e de produção (módulo integração e gestão do sistema, grupo integração com ERP).

O modelo de referência apresentado neste capítulo é relacionado, no capítulo 8, com um modelo de referência dos processos de PLM, gerando um modelo integrado processossistema PLM. 


\section{MODELO DE REFERÊNCIA INTEGRADO PROCESSO-SISTEMAS PLM}

Neste capítulo, o modelo de referência de sistemas PLM desenvolvido no capítulo anterior é integrado com um modelo de referência de processos de gestão do ciclo de vida de produtos. O modelo integrado resultante é complementado com dados sobre a capacitação de sistemas PLM disponíveis comercialmente. O escopo do modelo integrado processo-sistemas PLM, incluindo a capacitação de sistemas existentes no mercado, é delimitado pela linha tracejada no framework de elementos do PLM (Figura 44).
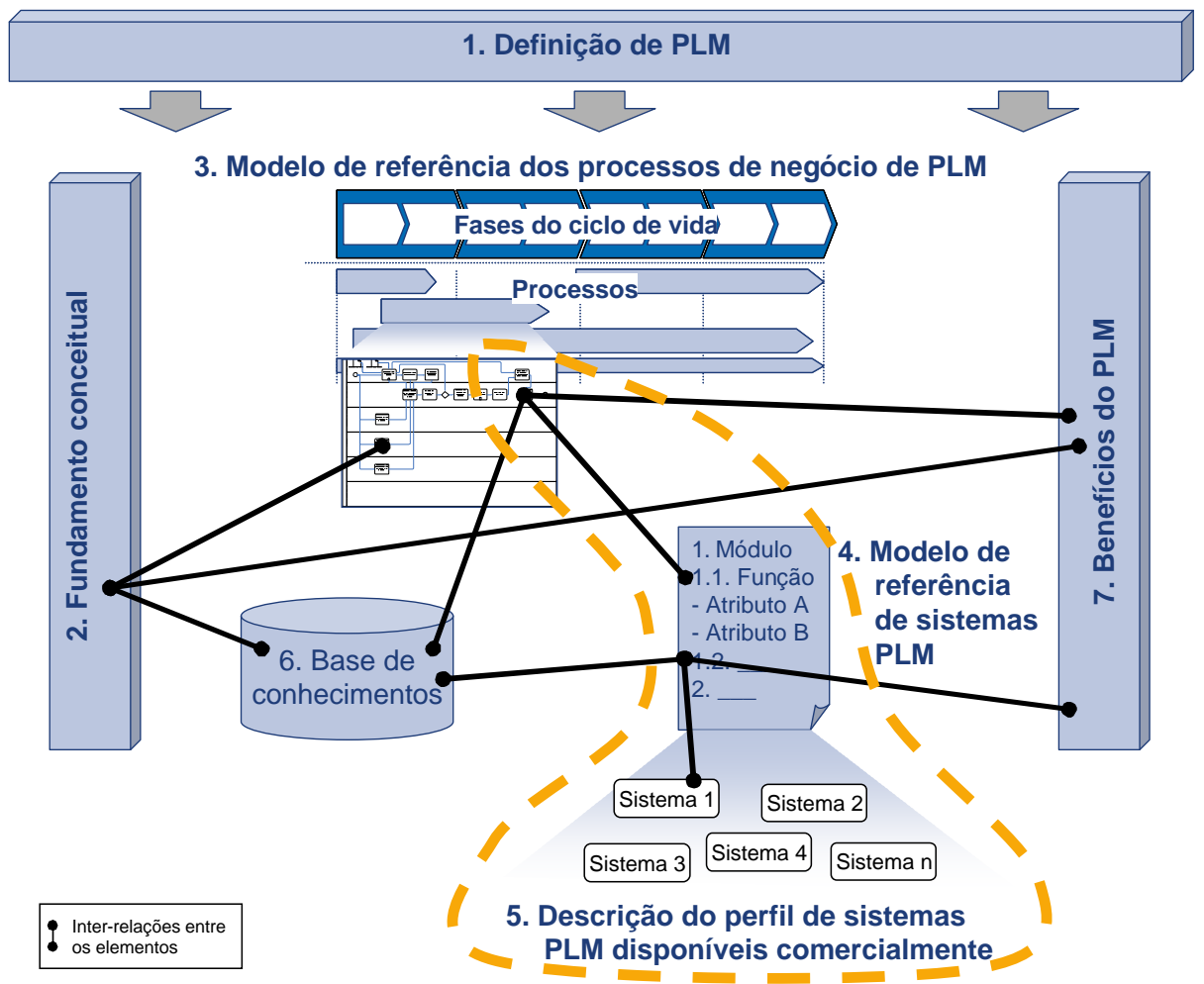

Figura 44. Escopo do modelo integrado processo-sistemas PLM complementado com a descrição do perfil de sistemas PLM disponíveis comercialmente

De forma mais detalhada, no modelo de processos, são identificadas as atividades que podem ser apoiadas por funcionalidades de sistemas PLM. Tais funcionalidades são representadas de forma genérica pelo modelo de referência de sistemas PLM. O modelo de sistemas é, por sua vez, relacionado com a base de dados de capacitações de sistemas comerciais específicos, obtida na survey de sistemas PLM (item 7.3). Esse relacionamento é realizado no nível de transações - o nível mais detalhado do modelo de referência de sistemas - pois é nesse nível que são avaliadas, na survey, as capacitações dos sistemas disponíveis no mercado. 
Ou seja, por meio dos relacionamentos, é possível criar uma ligação entre as atividades do modelo de referência de processos, as funcionalidades do modelo de referência de sistemas e as capacitações de sistemas específicos (transações). Todo esse conteúdo é organizado e publicado em uma ferramenta estruturada para auxiliar as empresas na seleção de sistemas de informação para a gestão do ciclo de vida de produtos. A Figura 45 ilustra, de forma conceitual, a cadeia de relacionamentos e o conteúdo da ferramenta construída para possibilitar a utilização do modelo integrado.

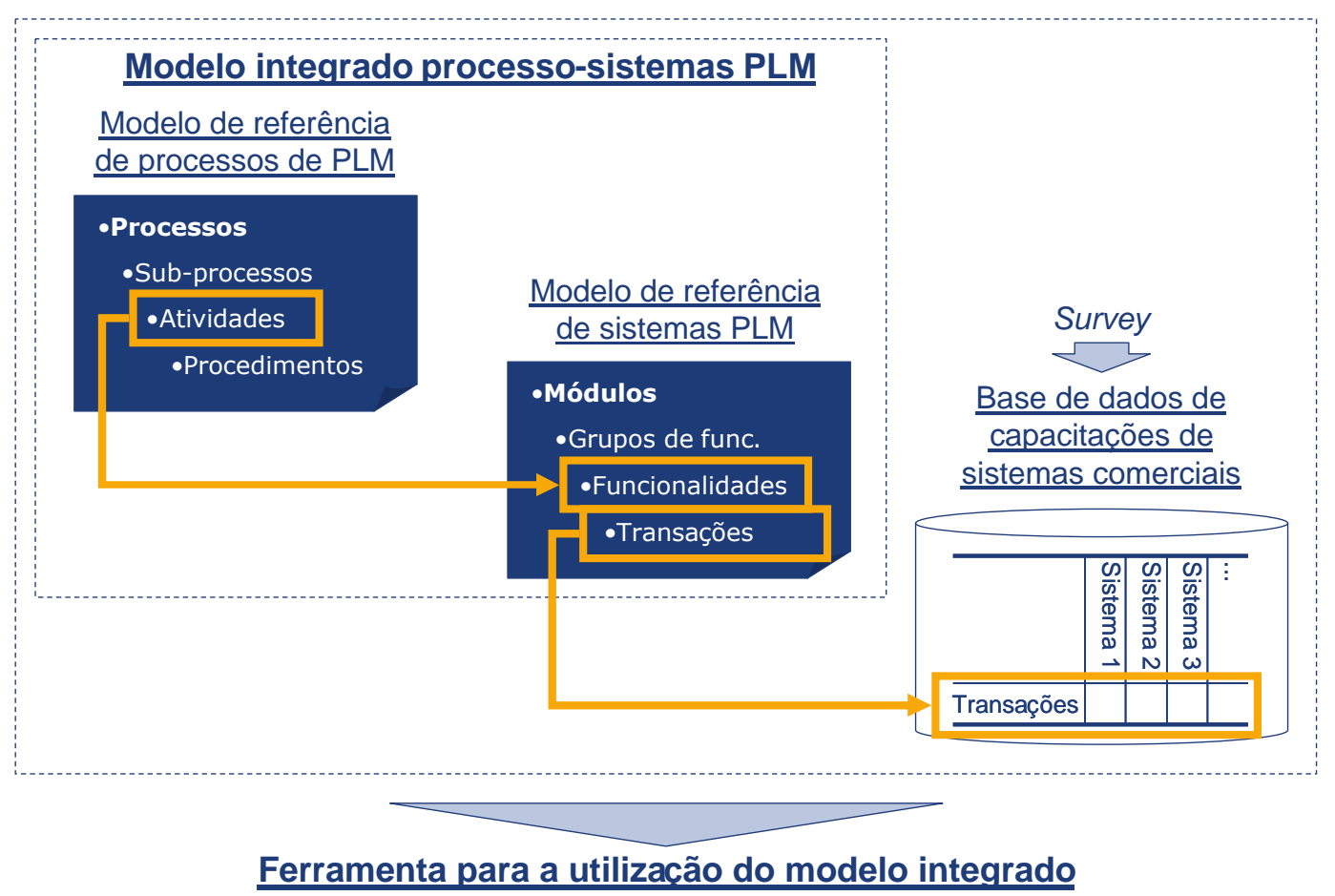

Figura 45. Estrutura de relacionamento entre os modelos de processos e de sistemas PLM e a base de dados de capacitações de sistemas comerciais (conceitual)

O capítulo está organizado em dois itens. Inicialmente, discute-se o método empregado para relacionar o modelo de processos com o modelo de sistemas e apresenta-se o modelo integrado resultante (item 8.1). Em seguida, é apresentada a ferramenta para a utilização do modelo integrado processo-sistemas PLM, incluindo o inter-relacionamento do modelo integrado com a base de dados de capacitações de sistemas PLM (item 8.2).

\subsection{Relacionamento entre os modelos de referência dos processos e de sistemas PLM \\ O desenvolvimento do modelo integrado processo-sistemas PLM seguiu três etapas} principais: (1) seleção, obtenção e tratamento dos modelos para a integração; (2) classificação 
e diferenciação dos tipos de funcionalidades do modelo de sistemas; (3) relacionamento entre os modelos de processos e de sistemas. Cada uma dessas etapas é discutida a seguir.

\section{Seleção, obtenção e tratamento dos modelos para a integração}

O modelo de referência de processos selecionado para a integração é o Modelo Unificado do PDP (descrito no subitem 2.2.3). Os critérios que levaram a essa escolha são discutidos nos procedimentos metodológicos (item 5.2).

O Modelo Unificado do PDP foi obtido do portal da Comunidade de Prática em Desenvolvimento de Produtos ${ }^{32}$. Nesse portal, o modelo está disponível no formato tabular e EPC. Optou-se por obter e empregar a notação tabular devido à facilidade de uso e de interpretação para posterior aplicação na indústria.

O modelo obtido foi, então, tratado para ser integrado ao modelo de sistemas. A estrutura em níveis de detalhamento dos processos foi ajustada para que o modelo refletisse, no primeiro nível, de forma precisa, os cinco processos de gestão do ciclo de vida de produtos definidos na síntese da bibliografia (subitem 2.2.4): planejamento estratégico de produtos e planejamento do projeto; desenvolvimento de produtos; acompanhamento e retirada de produtos; gestão da configuração e melhoria dos processos. Além disso, os quatro níveis de detalhamento do modelo foram classificados utilizando a nomenclatura definida no framework de elementos do PLM: processo, sub-processo, atividade e procedimento.

Com exceção do ajuste no nível de detalhamento dos processos, todo o conteúdo do modelo (e.g. atividades, informações de entrada e de saída, ferramentas) foi mantido inalterado. Como as alterações realizadas na estrutura, o modelo resultante é organizado em 5 processos, 12 sub-processos, 118 atividades e 535 procedimentos.

O modelo de referência de sistemas PLM utilizado no relacionamento é o modelo resultante deste trabalho (apêndice B). Tal modelo está organizado em 13 módulos, 49 grupos de funcionalidades, 296 funcionalidades e 1215 transações. Não foi necessário realizar nenhum ajuste no modelo de sistemas para o seu relacionamento com o modelo de processos.

\section{Classificação e diferenciação dos tipos de funcionalidades do modelo de sistemas}

No modelo de sistemas PLM, é possível diferenciar dois tipos de funcionalidades. O primeiro tipo é composto por funcionalidades gerais, como as funcionalidades de apoio ao

\footnotetext{
${ }^{32}$ www.pdp.org.br
} 
trabalho em equipe (e.g. workflow), que podem ser utilizadas para dar suporte a várias das atividades dos processos. O segundo tipo é composto por funcionalidades específicas, que focam a execução de tarefas bem delimitadas (e.g. cadastro de materiais).

Com base nessa distinção, podem ser consideradas funcionalidades gerais as funcionalidades dos seguintes módulos e grupos de funcionalidades do modelo de referência de sistemas PLM: módulo de gestão de documentos $(6)^{33}$ - grupo de cadastro e armazenamento de documentos (6.1), grupo de visualização de documentos (6.2) e grupo de arquivamento de documentos (6.4) - ; módulo de colaboração e gestão do conhecimento (12); módulo de integração e gestão do sistema (13). As funcionalidades desses módulos e grupos são empregadas de forma ampla ao longo dos processos de gestão do ciclo de vida de produtos.

Considerando que as funcionalidades gerais são utilizadas em muitas das atividades dos processos, optou-se por diferenciar o tratamento dado aos dois tipos de funcionalidades no relacionamento com o modelo de processos. Definiu-se que funcionalidades gerais são analisadas separadamente, de acordo com sua necessidade para apoiar os processos de PLM como um todo. Por outro lado, cada funcionalidade específica pode ser relacionada diretamente com atividades individuais do modelo de processos. O procedimento utilizado no relacionamento é detalhado na próxima seção.

\section{Relacionamento entre os modelos de processos e de sistemas}

Após serem obtidos e receberem tratamento, os modelos de referência dos processos e de sistemas PLM foram inter-relacionados.

A base conceitual para o relacionamento entre os modelos é dada pela especificação definida no framework de elementos do PLM (capítulo 6). Assim, optou-se por interligar o terceiro nível de detalhamento de cada um dos modelos, identificando as funcionalidades de sistemas que podem ser utilizadas para apoiar as atividades dos processos. A possibilidade de relacionamento é de muitos-para-muitos (conforme discutido no item 6.2).

Partindo dessa referência conceitual, na prática, o relacionamento entre os modelos foi realizado por meio da comparação de modelos. Nesse sentido, empregou-se o método de comparação de modelos proposto originalmente por Kirchmer (1998) e detalhado por Zancul (2000, p. 82-84).

${ }^{33}$ Os números entre parênteses indicam o código hierárquico de identificação do módulo / grupo de funcionalidade no modelo de referência de sistemas PLM apresentado no apêndice B. 
Inicialmente, foi construída uma matriz de comparação, na qual as linhas descrevem o modelo detalhado de processos e as colunas representam o modelo de sistemas, limitado às funcionalidades do tipo específico (conforme definido na seção anterior). Para cada relação existente entre uma atividade dos processos e uma funcionalidade de sistemas foi feita a seguinte pergunta: “A atividade pode ser apoiada pela funcionalidade de sistemas PLM?”. Em caso afirmativo, assinalou-se a intersecção entre a linha da atividade e a coluna da funcionalidade. Esse procedimento foi repetido para todas as relações da matriz.

Em seguida, considerando as relações assinaladas na matriz, o modelo de referência integrado processo-sistemas PLM foi detalhado. Na construção do modelo integrado, foram adicionadas duas colunas ao modelo de referência dos processos: uma contendo o código hierárquico de identificação das funcionalidades de sistemas PLM e a segunda contemplando a descrição dessas funcionalidades. Para cada atividade do processo, foram completadas as funcionalidades correspondentes, dadas pela matriz de comparação.

Deve-se ressaltar que o modelo integrado não especifica a alocação de funcionalidades do tipo geral para atividades específicas, pois essas funcionalidades são, geralmente, utilizadas em muitas das atividades dos processos de gestão do ciclo de vida de produtos.

Uma visão simplificada do modelo integrado resultante, ilustrando as colunas que apresentam as atividades dos processos e as respectivas funcionalidades de sistemas PLM, é apresentada na Figura 46.

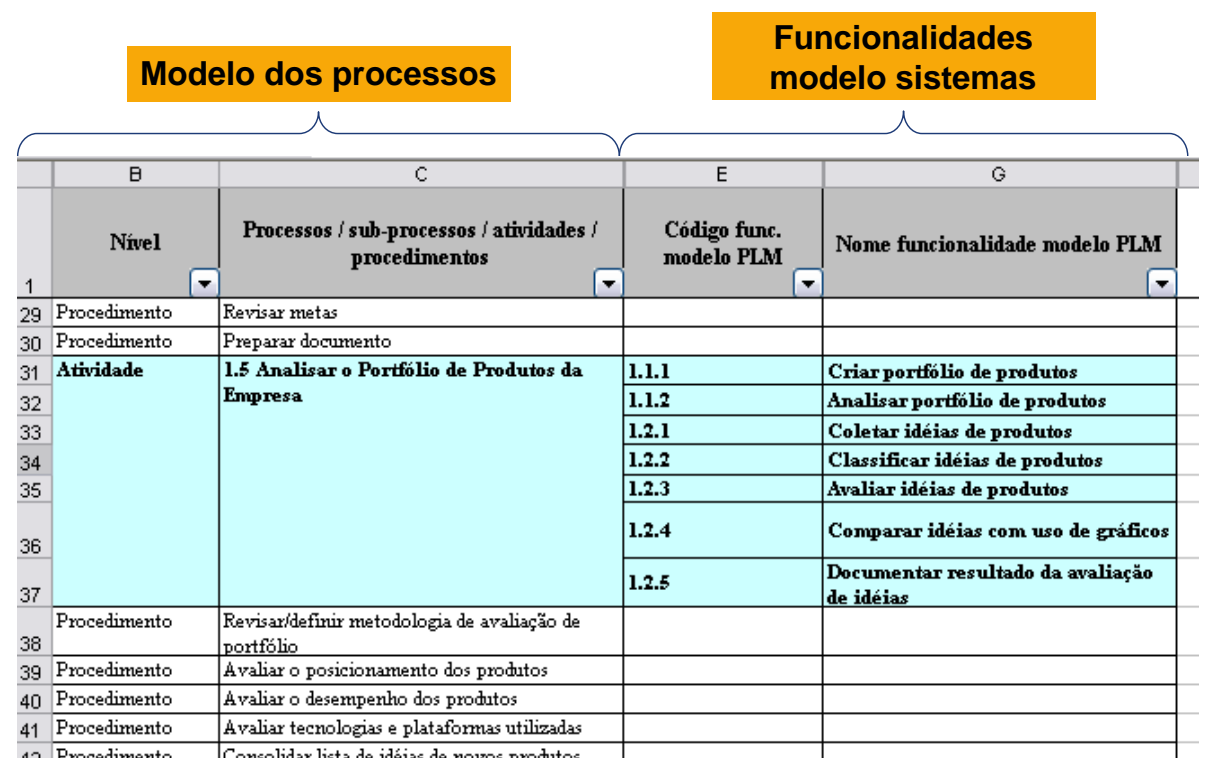

Figura 46. Modelo de referência integrado processo-sistemas PLM

O modelo de referência integrado processo-sistemas PLM está disponível para consulta no Apêndice C. 


\subsection{Ferramenta de utilização do modelo de referência integrado processo- sistemas PLM}

Visando estabelecer o vínculo completo entre os processos de gestão do ciclo de vida de produtos, as funcionalidades de sistemas PLM e as características de sistemas comerciais específicos, construiu-se uma ferramenta para a utilização do modelo integrado processosistemas PLM. O objetivo dessa ferramenta é apoiar as empresas na identificação dos sistemas mais adequados a suas necessidades, a partir da configuração dos processos de negócio e da delimitação das funcionalidades de sistemas que são requeridas pelos processos.

A ferramenta foi desenvolvida em MS Excel. A opção pelo Excel deve-se a três fatores. O primeiro é a facilidade de construção da ferramenta nesse software, sem a necessidade de programação. O segundo fator é a flexibilidade, que é fundamental para possibilitar o cruzamento entre as tabelas que representam o modelo de processos, o modelo de sistemas e as capacitações de sistemas comerciais. O terceiro fator é a facilidade de uso e a ampla disseminação do MS Excel na indústria, características importantes para facilitar e incentivar a adoção da ferramenta em empresas.

A ferramenta está organizada em quatro partes, detalhadas a seguir:

1. Modelo de referência integrado processo-sistemas PLM - contempla o modelo dos processos com a indicação das funcionalidades de PLM necessárias para apoiar cada atividade (resultado do item 8.1 - apêndice C).

2. Modelo de referência de sistemas PLM - detalha as transações para cada funcionalidade de sistemas PLM (resultado do capítulo 7 - apêndice B).

3. Perfil dos sistemas comerciais - indica as capacitações dos sistemas comerciais que participaram da survey em relação às transações do modelo de referência de sistemas PLM.

4. Resultados - apresenta o nível de cobertura de cada um dos sistemas comerciais em relação às transações de sistemas PLM requeridas.

A ferramenta está estruturada para possibilitar a adaptação do modelo de processos de acordo com as características de uma determinada empresa. Nessa adaptação, são identificados os processos, sub-processos e atividades relevantes para o projeto de gestão do ciclo de vida da empresa. Com a seleção das atividades relevantes, é definida a lista correspondente de funcionalidades necessárias no modelo de referência de sistemas PLM. Partindo dessas funcionalidades necessárias, o passo seguinte é a delimitação das transações requeridas. Definidas as transações requeridas, é possível verificar a relação dos sistemas 
comerciais mais adequados para atender aos requisitos da empresa. O conteúdo de cada uma das quatro partes da ferramenta é apresentado a seguir, juntamente com a descrição da forma de utilização da ferramenta.

\section{Parte 1 - modelo de referência integrado processo-sistemas PLM}

A primeira parte da ferramenta contempla o modelo de referência integrado processosistemas PLM. Esse modelo indica, para cada atividade do processo, quais as funcionalidades de PLM envolvidas (Figura 47). Nas colunas B, C, E e G da Figura 47, são listadas as informações do modelo integrado processo-sistemas PLM. As colunas D e H da Figura 47 não pertencem ao modelo original e são incluídas na ferramenta.

Nessa parte da ferramenta, é delimitado o escopo do projeto de gestão do ciclo de vida de uma empresa em termos de atividades do processo e de funcionalidades de sistemas. Nesse sentido, inicialmente, são indicadas as atividades dos processos que são relevantes para a empresa (Figura 47, coluna D). A marcação de uma atividade resulta, a princípio, na inclusão de todas as funcionalidades correspondentes no escopo de funcionalidades relevantes (Figura 47, coluna $\mathrm{H})$.

O passo seguinte é a verificação da efetiva necessidade, para a empresa, das funcionalidades assinaladas como relevantes, em decorrência da seleção das atividades dos processos. Para isso, é preciso verificar cada funcionalidade marcada com relevante e desmarcar aquelas que não são necessárias para a empresa (Figura 47, coluna H). Dessa forma, é gerada uma lista de funcionalidades relevantes, em decorrência da análise do processo de negócio.

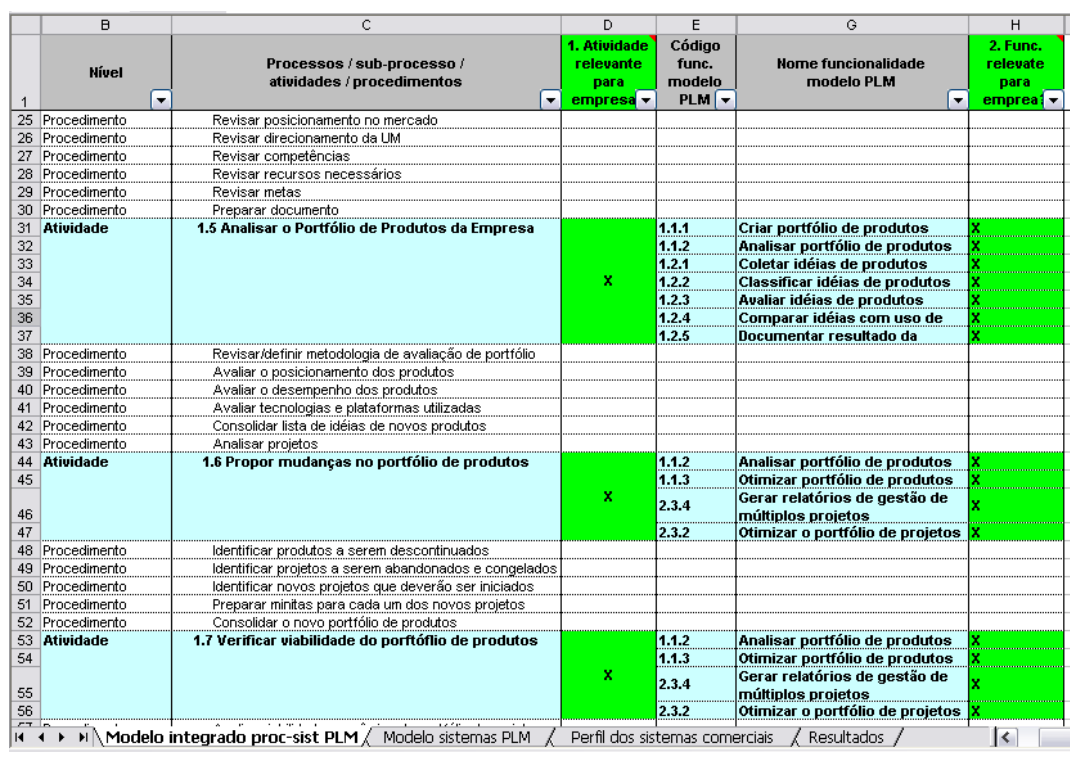

Figura 47. Delimitação do escopo em termos de atividades do processo e funcionalidades de sistemas PLM 
A lista de funcionalidades relevantes selecionada no modelo integrado processosistemas PLM é utilizada na segunda parte da ferramenta, descrita abaixo.

\section{Parte 2 - modelo de referência de sistemas PLM}

Na segunda parte da ferramenta, são detalhadas, no modelo de referência de sistemas PLM, as transações necessárias para a empresa (Figura 48).

O ponto de partida são as funcionalidades selecionadas na primeira parte da ferramenta (modelo integrado). Caso uma funcionalidade tenha sido marcada como relevante no modelo integrado, todas as suas transações são inicialmente indicadas como relevantes. Por outro lado, caso uma funcionalidade não tenha sido incluída no conjunto de requisitos no modelo integrado, as suas respectivas transações são primeiramente desconsideradas do grupo de transação relevantes (Figura 48, coluna $\mathrm{H}$ ).

Dada a lista inicial de transações relevantes, deve-se verificar cada transação e analisar se ela é efetivamente necessária para atender aos requisitos dos processos de negócio de gestão do ciclo de vida da empresa. Os ajustes necessários são realizados na tabela, incluindo ou excluindo transações relevantes (Figura 48, coluna H).

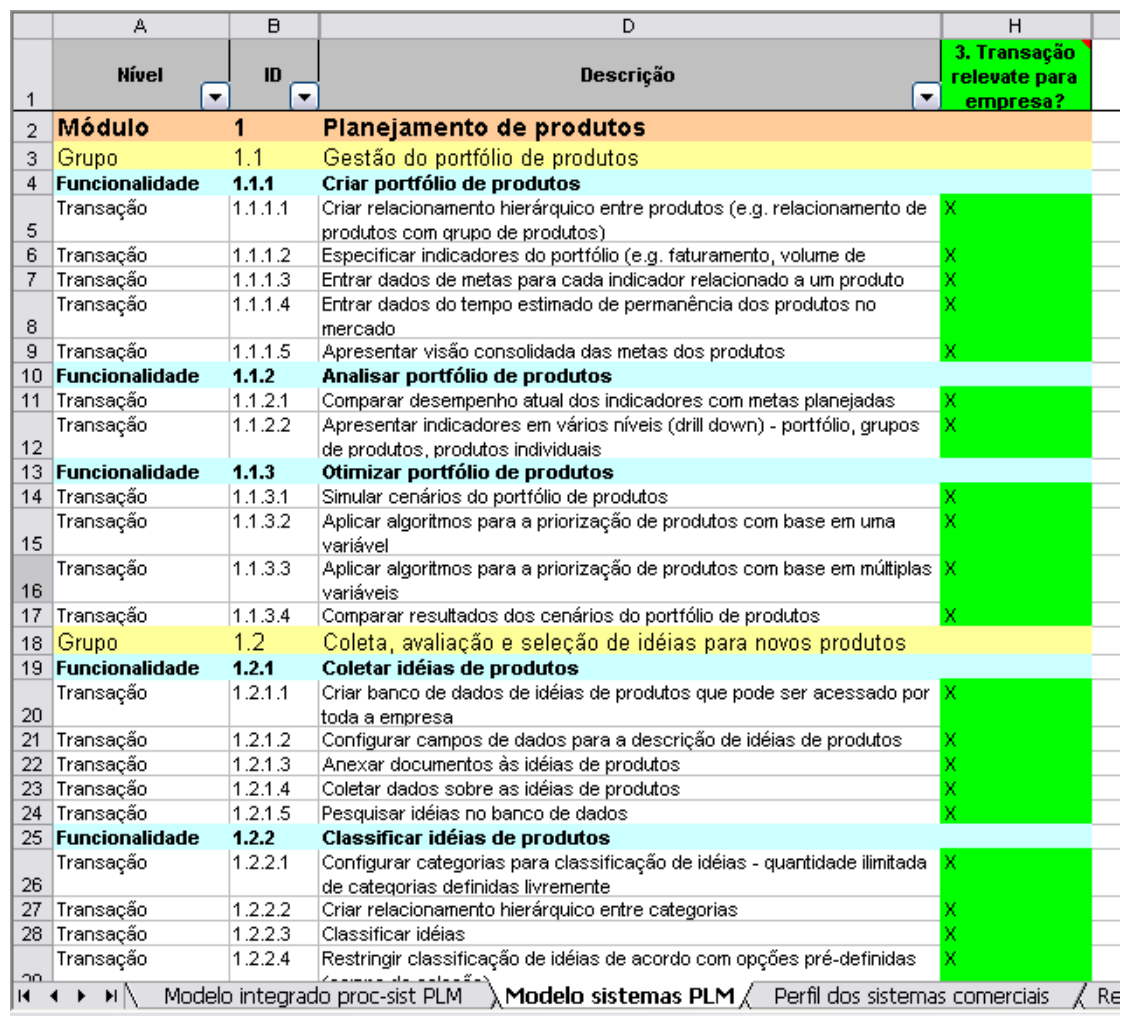

Figura 48. Detalhamento das transações necessárias

O resultado dessa parte da ferramenta é um conjunto de requisitos detalhados para a seleção do sistema PLM. 


\section{Parte 3 - perfil de sistemas comerciais}

A terceira parte da ferramenta contempla a base de dados de capacitações dos sistemas PLM disponíveis comercialmente em relação ao modelo de referência de sistemas PLM. Essa parte da ferramenta contém dados coletados previamente e não é manipulada por usuários na utilização da ferramenta.

A base de dados de capacitações de sistemas PLM é apresentada na Figura 49. Cada linha da tabela ilustrada na Figura 49 representa uma das 1215 transações do modelo de referência de sistemas PLM. As colunas S1 a S17 representam cada um dos 17 sistemas pesquisados na survey. Na matriz, o número 1 indica transações oferecidas pelos sistemas, enquanto o número 0 indica transações não disponíveis nos sistemas.

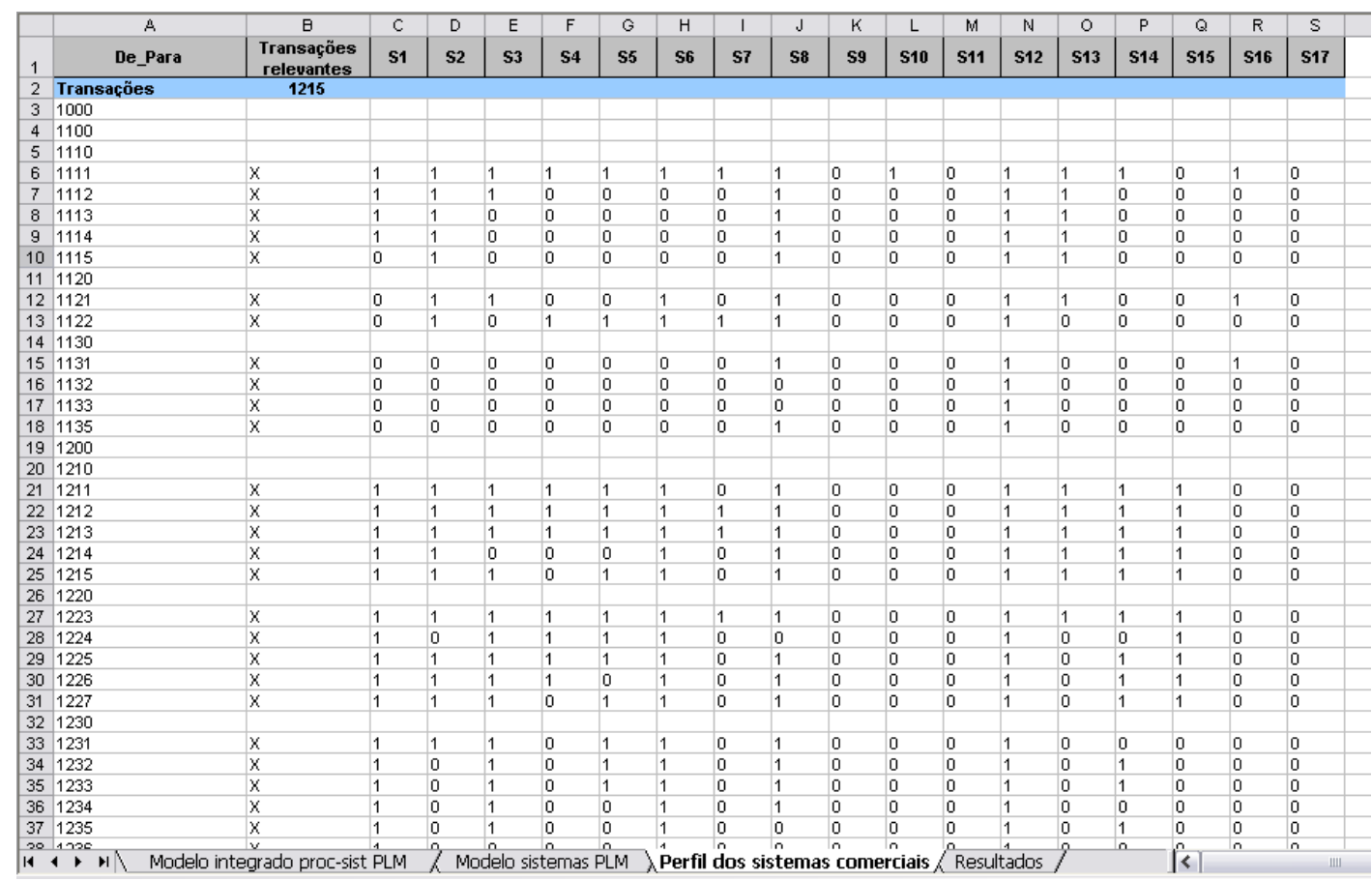

Figura 49. Base de dados de capacitações dos sistemas PLM disponíveis comercialmente

Nessa primeira versão da ferramenta desenvolvida por esta pesquisa, a base de dados de capacitações dos sistemas PLM foi constituída a partir da survey com os fornecedores de sistemas. Deve-se ressaltar que essa base de dados deve ser atualizada periodicamente para que a ferramenta reflita o desempenho real dos sistemas comerciais.

\section{Parte 4 - resultados}

Considerando o conjunto de transações requeridas pela empresa, definido a partir do modelo integrado processo-sistemas PLM e detalhado no modelo de referência de PLM, e considerando o perfil das soluções comerciais, a ferramenta indica o grau de cobertura dos requisitos da empresa por cada um dos sistemas comerciais (Figura 50). 


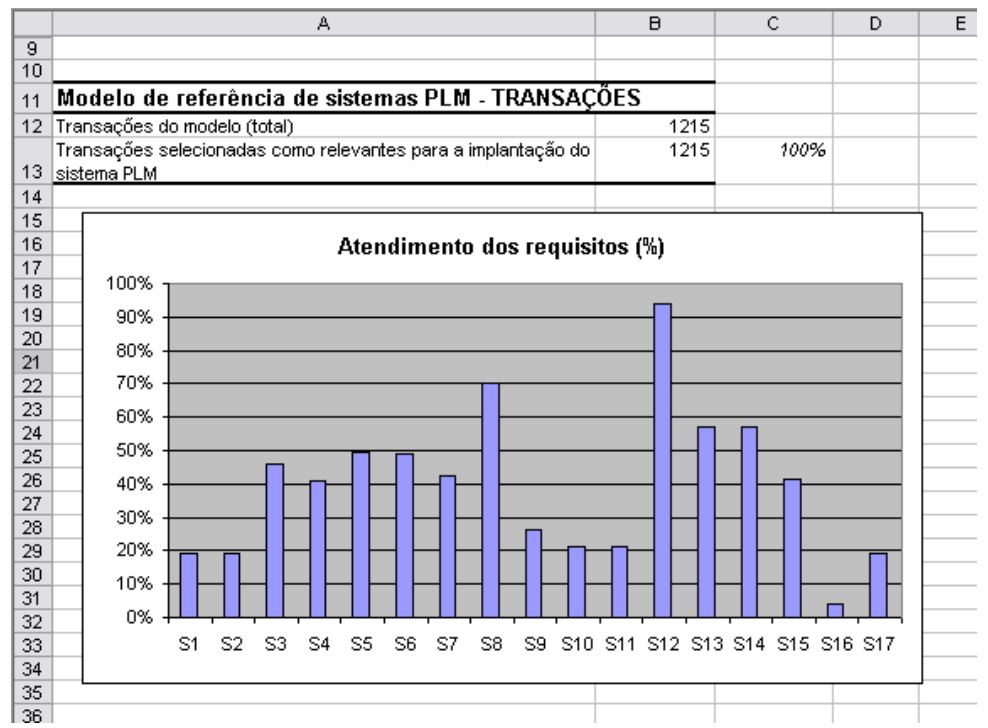

Figura 50. Resultados da análise da adequação dos sistemas comerciais aos requisitos

Nos resultados, é possível identificar os sistemas com maior grau de cobertura dos requisitos da empresa. Tais sistemas são candidatos a uma análise mais detalhada de seu desempenho em demonstrações e em testes de cenários.

A ferramenta descrita neste item é aplicada ao contexto de um método de seleção de sistemas PLM apresentado no próximo capítulo. 


\section{MÉTODO DE SELEÇÃO DE SISTEMAS PLM}

Este capítulo apresenta o método proposto neste trabalho para a seleção de sistemas PLM com base em modelos de referência. O novo método emprega o modelo de referência integrado processo-sistemas PLM e a ferramenta de aplicação desse modelo, ambos descritos no capítulo 8.

O capítulo está organizado em dois itens. No primeiro item, são apresentadas as fases e as etapas do método de seleção de sistemas PLM (item 9.1). No segundo, é discutida a avaliação do método proposto (item 9.2).

\subsection{Fases e etapas do método de seleção de sistemas PLM}

O método de seleção de sistemas PLM desenvolvido neste trabalho tem como principal premissa a utilização de modelos de referência para apoiar a escolha de um software que atenda aos requisitos dos processos de negócio de gestão do ciclo de vida de produtos de uma determinada empresa.

O novo método é derivado da análise dos métodos existentes para selecionar softwares, avaliados na síntese da bibliografia fundamental (capítulo 4). Na análise da bibliografia, são identificados três aspectos-chave dos métodos de seleção de sistemas de informação: a abordagem empregada, as fases seguidas no processo de seleção e as etapas realizadas em cada fase.

A abordagem indica o direcionamento conceitual empregado na seleção do sistema. Duas abordagens principais de seleção de sistemas são citadas na literatura. Na primeira abordagem, a seleção do software é uma das primeiras atividades realizadas em projetos de implantação de sistemas como um todo. Nessa abordagem, a seleção do sistema de informação é realizada com base em um conjunto de requisitos levantados na empresa. Na segunda abordagem, a seleção do software ocorre numa fase mais avançada do projeto de implantação de sistemas, com base no desenho dos processos de negócio futuros (to-be).

Em relação às fases da seleção de sistemas, observa-se na literatura que existe praticamente um consenso sobre a estruturação lógica de iniciativas de seleção de sistemas em três fases: pré-seleção, análise e negociação. Já as etapas detalhadas em cada fase podem variar de acordo com o autor considerado (capítulo 4).

Na definição do método proposto, os três aspectos-chave dos métodos de seleção de sistemas de informação, - abordagem, fases e etapas -, são definidos. 
Em relação à abordagem, a seleção de sistemas com base no desenho dos processos de negócio futuros (to-be) é a opção mais alinhada com a visão delineada para o método proposto. Nessa abordagem, o modelo integrado processo-sistemas PLM pode ser ajustado para refletir as atividades especificadas no desenho dos processos futuros da empresa. Caso a empresa ainda não tenha desenvolvido o seu modelo de processos futuros, ele pode ser derivado do modelo de referência integrado processo-sistemas PLM. A outra alternativa de abordagem, baseada em requisitos das empresas, não permitiria o estabelecimento desse paralelismo entre o modelo da empresa e o modelo de referência integrado.

Dada a abordagem, optou-se por empregar, no método proposto, a estrutura em três fases, típica de métodos de seleção de sistemas de informação: pré-seleção, análise e negociação. Essa estrutura também é adequada para a seleção de sistemas de informação com base em modelos de referência.

Na fase de pré-seleção, a utilização de modelos de referência pode contribuir tanto para facilitar a execução como para melhorar a assertividade dos resultados obtidos. Nessa fase, partindo de uma lista ampla de sistemas, são identificados aqueles sistemas mais adequados aos processos de negócio da empresa. Tipicamente, de três a seis sistemas são préselecionados. Na fase seguinte de análise, as funcionalidades dos sistemas pré-selecionados devem ser avaliadas detalhadamente por meio de testes. Por fim, na fase de negociação, são realizados estudos da viabilidade econômica do projeto com base nas condições comerciais definidas com os fornecedores. Dada a natureza do trabalho realizado em cada uma das fases, pode-se concluir que o maior impacto da utilização de modelos de referência para apoiar a seleção de sistemas de informação ocorre na fase de pré-seleção.

A visão geral do método proposto é ilustrada na Figura 51. A abordagem macro adotada, baseada no desenho dos processos de negócio, é refletida pela utilização do modelo dos novos processos (to-be) como informação de entrada para o início da primeira fase. O método está estruturado nas três fases de pré-seleção, de análise e de negociação, sendo concluído com a definição de um sistema a ser implantado na empresa.

A Figura 51 também apresenta o detalhamento das etapas da fase de pré-seleção, mais impactada pela utilização de modelos de referência. Além disso, é ilustrada a vinculação lógica entre o modelo de referência integrado processo-sistemas PLM, a ferramenta de utilização desses modelos e as fases do método de seleção proposto. 

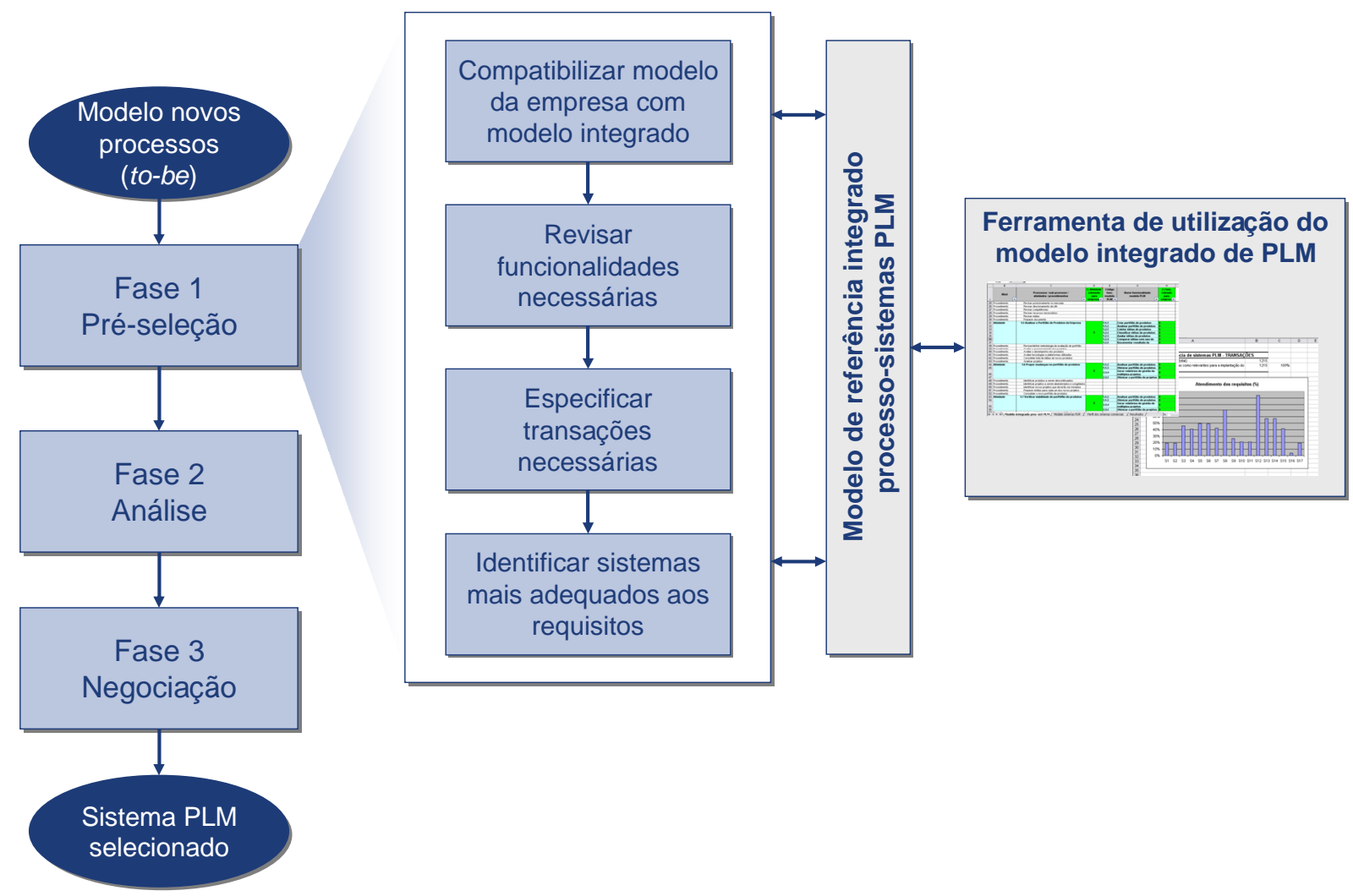

Figura 51. Visão geral do método de seleção de sistemas PLM com base em modelos de referência

Dada a visão geral do método, o conteúdo de cada uma das fases é discutido detalhadamente a seguir, com ênfase na fase de pré-seleção ${ }^{34}$.

\section{Pré-seleção}

A pré-seleção é a fase mais impactada pela utilização de modelos de referência. Com o emprego do modelo de referência integrado processo-sistemas PLM e de sua ferramenta de utilização, algumas etapas realizadas na pré-seleção em métodos tradicionais de seleção de sistemas deixam de ser necessárias. Isso ocorre, devido às informações geradas nessas etapas já estarem sistematizadas pelo trabalho prévio de construção do modelo integrado.

As etapas da fase de pré-seleção de métodos tradicionais de seleção de sistemas, analisados na síntese da bibliografia, são apresentadas na Tabela 10. As etapas marcadas em cinza na Tabela 10 são abrangidas pela construção prévia do modelo de referência integrado. Assim, o método de seleção de sistemas proposto pode ser simplificado com a eliminação de

${ }^{34} \mathrm{O}$ escopo do detalhamento do método proposto não aborda as questões organizacionais acerca da responsabilidade pela execução de cada uma das atividades, pois a estrutura organizacional necessária para realizar a seleção de sistemas pode variar muito dependendo das características de cada empresa. 
etapas como a análise do mercado, a identificação de possíveis candidatos e a criação de uma lista de funcionalidades, que já são contempladas no modelo de referência.

Tabela 10 - Etapas da fase de pré-seleção de métodos de seleção de sistemas de informação

\begin{tabular}{|c|c|c|c|}
\hline \multirow{2}{*}{ Fases } & \multicolumn{3}{|c|}{ Métodos de seleção de sistemas de informação } \\
\hline & PORE & Umble et AL. (2003) & Trovarit \\
\hline Pré-seleção & $\begin{array}{l}\text { Levantamento de } \\
\text { requisitos } \\
\text { Identificação de } \\
\text { possíveis candidatos } \\
\text { Pré-seleção dos } \\
\text { candidatos com base nos } \\
\text { requisitos macro }\end{array}$ & $\begin{array}{l}\text { Definição da visão } \\
\text { Criação de uma lista de } \\
\text { funcionalidades } \\
\text { Obtenção de uma lista de } \\
\text { sistemas candidatos } \\
\text { Pré-seleção de quatro a } \\
\text { seis candidatos } \\
\text { principais }\end{array}$ & $\begin{array}{l}\text { Preparação do projeto de } \\
\text { seleção } \\
\text { Análise macro e } \\
\text { preparação do caderno } \\
\text { de requisitos da empresa } \\
\text { Análise do mercado e } \\
\text { pré-seleção }\end{array}$ \\
\hline
\end{tabular}

Deve-se observar também, que outras etapas dos métodos tradicionais de seleção de sistemas são inadequadas para o novo contexto de utilização de modelos de referência. É o caso do levantamento de requisitos e da preparação do caderno de requisitos da empresa, que são substituídos pela configuração dos processos de negócio do modelo de referência. No método proposto, as necessidades em termos de funcionalidades e de transações são derivadas dos processos de negócio.

Portanto, visando empregar modelos de referência na seleção de sistemas, é necessário redefinir completamente a fase de pré-seleção. No método proposto, a pré-seleção é composta por quatro etapas, partindo do desenho dos processos de negócio da empresa: compatibilizar o modelo da empresa com o modelo integrado; revisar as funcionalidades necessárias; especificar as transações necessárias; identificar os sistemas mais adequados aos requisitos (Figura 51). Tais etapas são realizadas com o apoio da ferramenta de utilização do modelo de referência integrado processo-sistemas PLM. Cada uma das etapas é descrita a seguir, em conjunto com a indicação da forma de aplicação da ferramenta do modelo integrado ${ }^{35}$.

\section{Compatibilizar o modelo da empresa com o modelo integrado}

Nesta etapa, o modelo dos processos de negócio da empresa e o modelo de referência integrado processo-sistemas PLM são compatibilizados para que representem o mesmo conteúdo. Nesse sentido, as atividades do modelo de referência integrado relevantes para os processos de PLM da empresa devem ser assinaladas. Essa etapa é realizada na parte 1 da ferramenta de utilização do modelo integrado (Figura 47, coluna D).

\footnotetext{
${ }^{35}$ Instruções mais detalhadas sobre a operação da ferramenta estão apresentadas no item 8.2.
} 
A indicação das atividades do processo relevantes para a empresa resulta em uma lista preliminar de funcionalidades necessárias, a ser validada na próxima etapa.

\section{Revisar as funcionalidades necessárias}

Nesta etapa, a lista preliminar de funcionalidades necessárias é revisada e uma lista definitiva de funcionalidades requeridas é gerada.

As funcionalidades de PLM estão vinculadas com as atividades dos processos de negócio no modelo integrado processo-sistemas PLM. Na etapa anterior, a indicação das atividades relevantes para os processo de PLM da empresa resulta na criação de uma lista preliminar de funcionalidades necessárias, contendo todas as funcionalidades correspondentes a cada uma das atividades selecionadas.

A lista preliminar de funcionalidades deve ser revisada, avaliando-se a efetiva necessidade de cada uma das funcionalidades para a empresa. Nesse sentido, as funcionalidades da lista preliminar devem ser verificadas uma a uma, e as funcionalidades desnecessárias devem ser desmarcadas no modelo integrado. Essa etapa também é realizada na parte 1 da ferramenta do modelo integrado (Figura 47, coluna $\mathrm{H}$ ).

O resultado da etapa é a lista definitiva de funcionalidades de PLM relevantes para os processo de gestão do ciclo de vida de produtos da empresa.

\section{Especificar as transações necessárias}

Nessa etapa, são especificadas as transações de sistemas PLM que são necessárias para apoiar os processos de negócio da empresa.

As funcionalidades confirmadas na lista definitiva gerada na etapa anterior estão vinculadas às transações no modelo de referência de sistemas PLM. Caso uma funcionalidade tenha sido incluída na lista definitiva, todas as suas respectivas transações são, inicialmente, consideradas como relevantes para a empresa.

A necessidade efetiva de cada uma das transações para os processos da empresa também deve ser revisada. Os ajustes necessários são realizados no modelo de sistemas PLM, marcando ou desmarcando transações relevantes. Essa etapa é executada na parte 2 da ferramenta do modelo integrado (Figura 48, coluna $\mathrm{H}$ ).

O resultado da etapa é a especificação das transações de sistemas PLM necessárias para apoiar os processos de gestão do ciclo de vida de produtos da empresa. 


\section{Identificar os sistemas mais adequados aos requisitos}

Nesta etapa, são obtidos os resultados da pré-seleção. Como resultado, são apontados os sistemas com maior grau de cobertura das transações e das funcionalidades requeridas para apoiar os processo de negócio da empresa. Os resultados são apresentados na parte 4 da ferramenta do modelo (Figura 50).

Apesar de a pré-seleção indicar um ranking de sistemas de acordo com o grau de cobertura das transações e das funcionalidades requeridas pelos processos de PLM da empresa, ainda não é possível concluir com precisão qual o sistema mais adequado, pois o nível de detalhamento utilizado na pré-seleção é muito abrangente para essa conclusão.

Visando aprimorar o entendimento dos sistemas, são selecionados de três a seis sistemas com melhor desempenho na pré-seleção para uma análise mais aprofundada das suas capacitações e para a avaliação da proposta comercial dos fornecedores. A pré-seleção é portanto um filtro para a identificação dos sistemas mais alinhados com as necessidades da empresa e a conseqüente eliminação do processo de seleção daqueles sistemas que não atendem aos requisitos críticos dos processos de negócio mapeados.

A partir da pré-seleção, são realizadas as fases de análise detalhada dos sistemas e de negociação das condições comerciais. Essas fases são descritas a seguir.

\section{Análise}

A fase de análise visa aprofundar o entendimento funcional e técnico dos sistemas préselecionados, verificando o atendimento de requisitos essenciais para a gestão do ciclo de vida de produtos da empresa. O resultado da análise é uma relação de sistemas qualificados, ordenados em ordem de preferência de acordo com a adequação funcional e técnica para os processos de negócio de PLM.

As etapas desta fase no método proposto são resultado da compilação das etapas da fase de análise realizadas nos métodos de seleção avaliados na síntese da bibliografia (item 4.3). As etapas compiladas são reordenadas em uma seqüência lógica para a sua execução, de acordo com o fluxo de informações de uma etapa para outra. Além disso, algumas etapas são redefinidas a fim de contemplar o novo contexto de processos de negócio e da utilização de modelos de referência. Etapas consideradas originalmente pelos autores avaliados na fase de análise, mas tematicamente relacionadas com a negociação, são transferidas para a fase de negociação. As etapas a serem executadas na fase de análise do método de seleção de sistemas PLM proposto são listadas a seguir: 
Identificar, no modelo de referência, os processos e as atividades críticas para a empresa;

Priorizar os processos e as atividades críticas para a avaliação em demonstrações e em cenários de testes;

Avaliar demonstrações de casos de uso construídos com base nos processos de negócio de PLM;

Avaliar aplicações de teste representando cenários definidos com base nos processos de negócio de PLM;

Avaliar aplicações em empresas similares ou em empresas com requisitos semelhantes;

Definir ranking de sistemas finalistas, de acordo com o atendimento das necessidades técnicas e funcionais dos processos de negócio de PLM.

A partir da lista de sistemas finalistas, são avaliadas as propostas comerciais dos fornecedores. Essa atividade é realizada na terceira e última fase do método proposto.

\section{Negociação}

A estruturação da fase de negociação no método proposto segue a mesma lógica utilizada para a definição da fase de análise. A partir da compilação de métodos tradicionais, as etapas são reordenadas e redefinidas para contemplar a utilização de modelos de referência.

As etapas da fase de negociação do método de seleção de sistemas PLM proposto são listadas a seguir:

Solicitar propostas técnico-comerciais de fornecedores;

Revisar propostas em relação ao seu conteúdo;

Avaliar custos envolvidos na implantação como um todo;

Avaliar benefícios quantitativos e qualitativos de melhoria de eficiência e de eficácia dos processos de negócio de PLM e estimar retorno do investimento para cada um dos sistemas alternativos ainda considerados nessa fase de seleção;

Selecionar sistema PLM mais adequado para a empresa;

Validar e aprovar decisão de implantação;

Negociar contrato com fornecedor.

Com a escolha do sistema PLM para a implantação, é concluída a execução do método de seleção. A avaliação do método proposto neste item é discutida a seguir. 


\subsection{Avaliação do método proposto}

Na avaliação do método de seleção de sistemas PLM proposto neste trabalho, optou-se pela realização de duas entrevistas com especialistas (conforme discutido em 5.2).

O primeiro passo para a realização das entrevistas foi a escolha dos especialistas a serem entrevistados. Com base nos critérios previamente estabelecidos (item 5.2), o Especialista A e o Especialista $B$ foram selecionados.

O Especialista A é formado e pós-graduado (mestrado) em engenharia mecânica. Foi pesquisador na área de desenvolvimento de produtos, com diversos artigos publicados. Atua há mais de sete anos como consultor na seleção e na implantação de sistemas de informação. O Especialista B é formado em engenharia elétrica, com mestrado em engenharia de produção e doutorado em engenharia mecânica. O Especialista $B$ também foi pesquisador na área de desenvolvimento de produtos e trabalha, há mais de sete anos, em consultoria de redesenho de processos e de implantação de sistemas de informação.

O passo seguinte foi a elaboração do roteiro de entrevistas. Tal roteiro é estruturado em duas partes. A primeira parte da entrevista consiste na apresentação, pelo entrevistador, tanto do método proposto como da ferramenta do modelo integrado processo-sistemas PLM. A segunda parte contempla três questões abertas para discussão. A primeira questão verifica as vantagens do método proposto em relação aos métodos tradicionais de seleção de sistemas. A segunda, trata das desvantagens do método proposto. Por fim, a terceira questão discute a aplicabilidade do método proposto na prática.

As entrevistas foram precedidas da preparação dos entrevistados. Nesse sentido, os entrevistados receberam previamente um conjunto de informações referentes à entrevista, contendo o roteiro, um resumo descritivo do método proposto para a seleção de sistemas PLM e a ferramenta do modelo integrado processo-sistemas PLM.

Durante a entrevista, foram discutidas as fases e as etapas do método proposto. A ferramenta do modelo integrado processo-sistemas PLM foi avaliada e manipulada pelos entrevistados. Os dados coletados durante as duas entrevistas estão sistematizados na Tabela 11, que é organizada em três colunas que resumem as vantagens, as desvantagens e as questões de aplicabilidade do método proposto. 
Tabela 11 - Resultados das entrevistas de avaliação do método proposto para a seleção de sistemas PLM

\begin{tabular}{|c|c|c|}
\hline Vantagens do método proposto & Desvantagens do método proposto & Aplicabilidade do método proposto \\
\hline $\begin{array}{l}\text { Redução do esforço e do tempo } \\
\text { de aprendizado sobre os } \\
\text { processos de negócio de gestão } \\
\text { do ciclo de vida e sobre as } \\
\text { potencialidades dos sistemas } \\
\text { PLM - modelo integrado pode } \\
\text { ser fonte de informação para } \\
\text { iniciar a discussão do projeto de } \\
\text { PLM na empresa. } \\
\text { Redução do esforço e do tempo } \\
\text { de instanciação do modelo da } \\
\text { empresa - modelo integrado } \\
\text { pode ser a base para a } \\
\text { instanciação do modelo da } \\
\text { empresa. } \\
\text { Garantia de abrangência na } \\
\text { análise dos processos - modelo } \\
\text { integrado é completo, garantindo } \\
\text { que os aspectos relevantes para o } \\
\text { PLM sejam considerados na } \\
\text { seleção do sistema. } \\
\text { Garantia de uniformidade na } \\
\text { análise dos processos - nível de } \\
\text { detalhamento do modelo } \\
\text { integrado é o mesmo para todos } \\
\text { os processos e funcionalidades, } \\
\text { evitando que algumas áreas } \\
\text { sejam muito detalhadas, } \\
\text { enquanto outras sejam avaliadas } \\
\text { superficialmente. } \\
\text { teste a partir dos processos e das } \\
\text { respectivas funcionalidades } \\
\text { mapeados no modelo integrado. } \\
\text { pré-seleção, por meio do uso de } \\
\text { informações sistematizadas no } \\
\text { modelo integrado. } \\
\text { Aumento da assertividade da } \\
\text { fase de pré-seleção, realizada } \\
\text { com base em dados detalhados e } \\
\text { sistematizados das capacitações } \\
\text { de sistemas PLM. } \\
\text { Otimão de cenários para } \\
\text { demonstrac̃ós e aplicac̃ões de }\end{array}$ & $\begin{array}{l}\text { Potencial retrabalho para } \\
\text { adaptação do modelo de } \\
\text { processos futuros da empresa } \\
\text { (to-be) de acordo com as } \\
\text { capacitações do sistema } \\
\text { selecionado - como processo é } \\
\text { definido antes da seleção do } \\
\text { sistema, dadas as capacitações do } \\
\text { sistema selecionado pode ser } \\
\text { necessário ajustar o processo. } \\
\text { Dificuldade para, na prática, } \\
\text { compatibilizar modelo da } \\
\text { empresa com modelo de } \\
\text { referência integrado, devido a } \\
\text { diferenças muito grandes. } \\
\text { Grande esforço necessário para } \\
\text { manter atualizada a base de } \\
\text { dados de capacitações de } \\
\text { sistemas PLM. }\end{array}$ & $\begin{array}{l}\text { Maior potencial de aplicação } \\
\text { em empresas médias. } \\
\text { _ } \quad \text { Empresas médias têm, em } \\
\text { geral, menor disponibilidade } \\
\text { de recursos para a seleção de } \\
\text { sistemas - podem se } \\
\text { beneficiar de método } \\
\text { estruturado. } \\
\text { Empresas médias têm maior } \\
\text { limitação de orçamento para } \\
\text { o projeto de PLM, } \\
\text { aumentando as chances de } \\
\text { seleção de sistema de } \\
\text { fornecedores de menor porte } \\
\text { - maior número de } \\
\text { fornecedores exige um } \\
\text { método estruturado de } \\
\text { avaliação. } \\
\text { Aplicabilidade restrita em } \\
\text { empresas de grande porte. } \\
\text { Empresas grandes têm } \\
\text { estratégia de TI de longo } \\
\text { prazo, com fornecedores } \\
\text { estratégicos pré-definidos. } \\
\text { No Brasil, softwares } \\
\text { instalados em filiais de } \\
\text { empresas multinacionais } \\
\text { são muitas vezes definidos } \\
\text { pela matriz no exterior. }\end{array}$ \\
\hline
\end{tabular}

Em resumo, as principais vantagens do método proposto citadas nas entrevistas são o aumento da eficiência e da assertividade da iniciativa de seleção do sistema PLM, além da 
utilização do modelo integrado como fonte relevante de informações para reduzir o esforço de aprendizado e de modelagem de processos na empresa.

As principais desvantagens do método proposto estão relacionadas à modelagem de processos em situações desfavoráveis. O método proposto pode implicar retrabalho para adaptar o modelo de processos, após a definição do sistema PLM a ser implantado, caso seja necessário harmonizar o processo com as capacitações do sistema. Além disso, se os processos da empresa forem muito distintos do modelo de referência, a compatibilização entre os dois modelos é dificultada. Outra desvantagem do método proposto é o grande esforço demandado para manter atualizada a base de dados de capacitações de sistemas PLM.

Em relação à aplicabilidade do método proposto, os dois entrevistados concordam que o maior potencial é para empresas de médio porte.

Empresas grandes têm, muitas vezes, fornecedores preferenciais de tecnologia da informação, o que restringe a quantidade de sistemas a serem avaliados. Em alguns casos relatados pelos entrevistados, a quantidade de sistemas concorrentes é tão restrita, que a fase de pré-seleção torna-se desnecessária e a fase de análise ganha importância. Nesses casos, o modelo de referência integrado processo-sistemas PLM pode ser utilizado como fonte de informação para a definição de cenários para demonstrações e testes. Ao mesmo tempo, observa-se que, no Brasil, muitas filiais de empresas multinacionais não têm autonomia para selecionar sistemas de informação, que são definidos pela matriz no exterior. Esse fato também restringe o potencial de aplicação do método proposto em grandes empresas.

Por sua vez, empresas médias têm menor disponibilidade de recursos para investir na iniciativa de seleção de sistemas PLM. Ao mesmo tempo, empresas médias têm, em geral, menos restrições em relação aos fornecedores de software e, portanto, maior flexibilidade para selecionar um sistema de uma lista mais ampla de fornecedores, incluindo fornecedores de pequeno porte. Com a combinação de recursos limitados e oportunidade de avaliar uma lista ampla de sistemas, as empresas médias podem se beneficiar dos ganhos de eficiência e de assertividade do método proposto para a seleção de sistemas PLM.

A discussão das vantagens, desvantagens e do potencial de aplicação do método proposto para a seleção de sistemas PLM encerra a apresentação dos resultados desta pesquisa. No próximo capítulo, são discutidas as conclusões deste trabalho. 


\section{CONCLUSÕES}

Neste capítulo são discutidas as conclusões do trabalho (item 10.1) e são apresentadas sugestões para trabalhos futuros a partir dos resultados atingidos nesta pesquisa (item 10.2).

\subsection{Resultados do trabalho}

Este trabalho tem quatro resultados principais: (1) o framework conceitual de elementos do PLM; (2) o modelo de referência de sistemas PLM; (3) o modelo integrado processo-sistemas PLM; (4) o método de seleção de sistemas PLM com base em modelos de referência. Com esses quatro resultados, considera-se que é possível responder as perguntas de pesquisa e que os objetivos estabelecidos são atingidos. A relação entre as perguntas de pesquisa, os objetivos do trabalho e os resultados obtidos é apresentada na Tabela 12. Cada um dos quatro resultados do trabalho descritos na Tabela 12 é discutido em seguida.

Tabela 12 - Relação entre as perguntas de pesquisa, os objetivos e os resultados do trabalho

\begin{tabular}{|c|c|c|}
\hline Perguntas de pesquisa & Objetivos & Resultados \\
\hline $\begin{array}{l}\text { 1. Quais as funcionalidades } \\
\text { características de sistemas de } \\
\text { informação que apóiam a gestão } \\
\text { do ciclo de vida de produtos? } \\
\text { Como essas funcionalidades } \\
\text { podem ser representadas em um } \\
\text { modelo de referência de sistemas } \\
\text { PLM? }\end{array}$ & $\begin{array}{l}\text { Definir um modelo de } \\
\text { referência de sistemas PLM }\end{array}$ & $\begin{array}{l}\text { Modelo de referência de } \\
\text { sistemas PLM (capítulo 7) }\end{array}$ \\
\hline $\begin{array}{l}\text { 2. Como modelos de referência de } \\
\text { processos de gestão do ciclo de }\end{array}$ & \multirow{3}{*}{$\begin{array}{l}\text { Desenvolver um método para a } \\
\text { seleção de sistemas PLM } \\
\text { baseado em modelos de } \\
\text { referência }\end{array}$} & $\begin{array}{l}\text { Framework conceitual de } \\
\text { elementos do PLM (capítulo 6) }\end{array}$ \\
\hline $\begin{array}{l}\text { vida de produtos e de sistemas } \\
\text { PLM podem ser inter- } \\
\text { relacionados? }\end{array}$ & & $\begin{array}{l}\text { Modelo integrado processo- } \\
\text { sistemas PLM (capítulo 8) }\end{array}$ \\
\hline $\begin{array}{l}\text { 3. Como as empresas podem } \\
\text { selecionar sistemas PLM com } \\
\text { base em modelos de referência? }\end{array}$ & & $\begin{array}{l}\text { Método de seleção de sistemas } \\
\text { PLM com base em modelos de } \\
\text { referência (capítulo 9) }\end{array}$ \\
\hline
\end{tabular}

O framework conceitual de elementos do PLM é uma estrutura lógica que contempla sete elementos essenciais para viabilizar a implantação da gestão do ciclo de vida de produtos em empresas. Além de contemplar o conteúdo dos sete elementos, o framework especifica as inter-relações existentes entre eles (Figura 52).

Dada a sua abrangência e estrutura, o framework conceitual pode ser aplicado em projetos de implantação da gestão do ciclo de vida de produtos, para organizar o conhecimento existente sobre PLM nas empresas. 
Adicionalmente, o framework também pode ser utilizado para apoiar o ensino de PLM, como um guia de estudos nessa área. Nesse sentido, é possível vincular os elementos do framework com o sumário deste trabalho. A relação dos elementos do framework com capítulos, itens e subitens deste texto é representada pelas elipses na Figura 52. Uma parte dos elementos do framework é apresentada na síntese da bibliografia (elementos 1, 2, 3, 6 e 7), enquanto que outros elementos são resultados do próprio trabalho de pesquisa (elementos 4 e 5 e inter-relação entre eles).

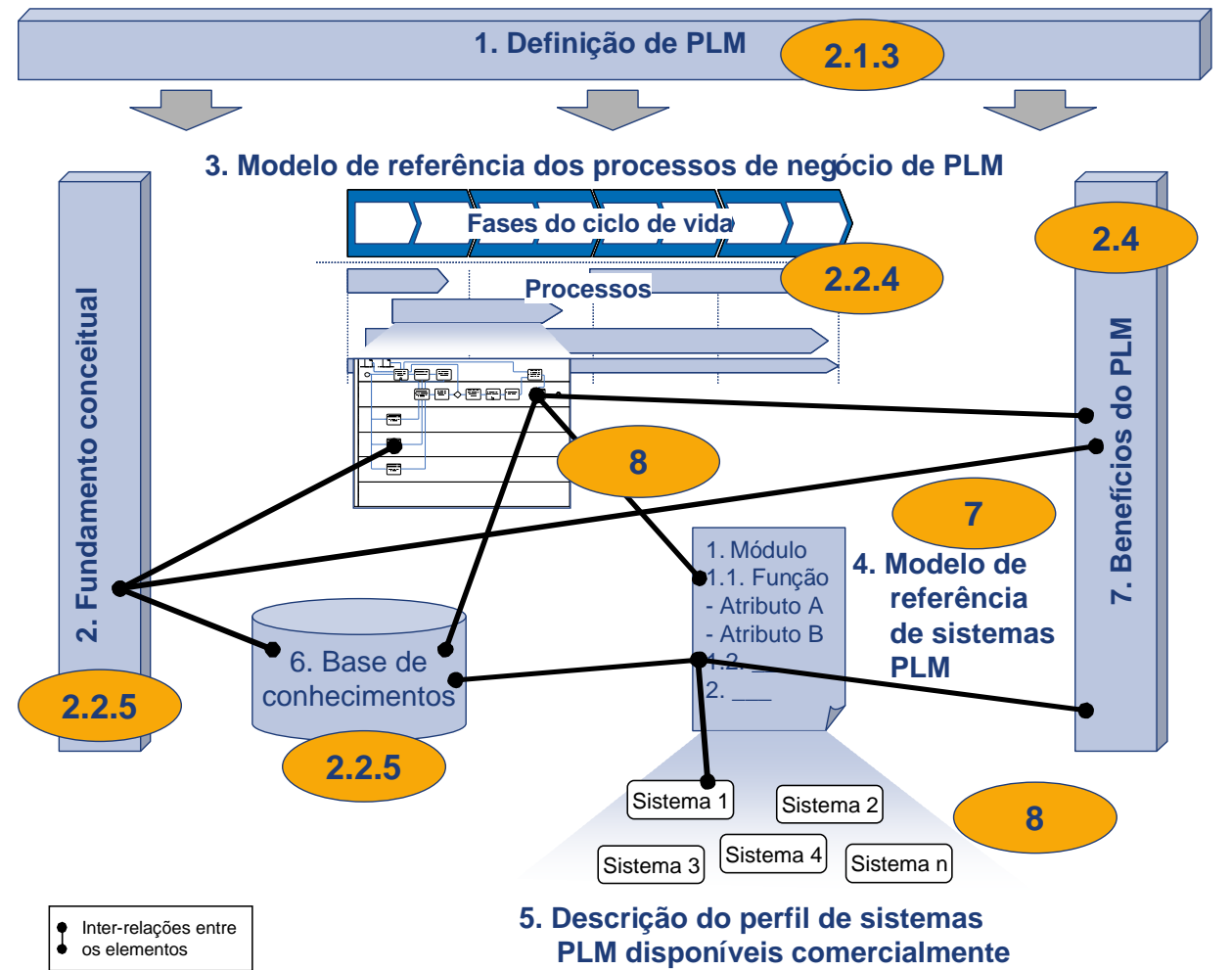

Figura 52. Relação entre o framework conceitual de elementos do PLM e capítulos deste texto

O segundo resultado do trabalho é o modelo de referência de sistemas PLM. Tal modelo descreve as funcionalidades típicas que caracterizam sistemas PLM. O modelo está organizado em quatro níveis de detalhamento, representados por 13 módulos, 49 grupos de funcionalidades, 296 funcionalidades e 1215 transações (apêndice B).

O modelo de referência de sistemas PLM proposto neste trabalho visa, principalmente, estabelecer uma base comum para a comparação entre os diversos sistemas PLM disponíveis comercialmente. A possibilidade de comparação dos sistemas em relação a uma base comum contribui para que as empresas possam selecionar o software mais adequado para atender aos requisitos de seus processos de negócio. Ao especificar um conjunto amplo e genérico de funcionalidades de sistemas PLM, o modelo de referência também pode ser aplicado além do escopo inicial definido, como base para guiar o desenvolvimento de softwares nessa área. 
O terceiro resultado do trabalho é o modelo integrado processo-sistemas PLM. Esse modelo combina o modelo de referência de sistemas PLM, também resultante desta pesquisa, com um modelo de referência de processos de gestão do ciclo de vida de produtos já existente (apêndice C). O inter-relacionamento entre o modelo de processos com o modelo de sistemas segue a especificação definida no framework de elementos do PLM.

O modelo integrado é complementado com dados sobre a capacitação de sistemas PLM disponíveis comercialmente. Todo esse conteúdo é organizado e publicado em uma ferramenta estruturada para auxiliar as empresas na seleção de sistemas de informação para a gestão do ciclo de vida de produtos.

Por fim, o quarto e último resultado do trabalho é o método de seleção de sistemas PLM com base em modelos de referência. O método proposto emprega o modelo de referência integrado processo-sistemas PLM e a ferramenta de aplicação desse modelo, descritos anteriormente. A utilização de um modelo de referência, interligando atividades dos processos com funcionalidades de sistemas, para apoiar a seleção de PLM, é uma das inovações deste trabalho.

O método de seleção de sistemas PLM proposto pode contribuir para aumentar a eficiência e melhorar a assertividade da iniciativa de seleção de sistemas PLM. A utilização do modelo integrado como fonte de informações também é útil para reduzir o esforço de aprendizado e de modelagem de processos nas empresas. Por outro lado, nos casos em que os processos da empresa são muito distintos do modelo de referência, a compatibilização entre os dois modelos pode ser dificultada. Uma outra desvantagem apontada para o método proposto é o esforço demandado para manter atualizada a base de dados de capacitações de sistemas PLM.

Em relação a sua aplicabilidade, o método de seleção de sistemas PLM pode ser utilizado por empresas grandes, mas o maior benefício é para empresas médias, que têm menor disponibilidade de recursos para investir na iniciativa de seleção de sistemas PLM. Essas empresas podem se beneficiar dos ganhos de eficiência e de assertividade do novo método.

Os quatro resultados deste trabalho, discutidos anteriormente, estão refletidos em publicações acadêmicas e em publicações técnicas para a indústria. Em termos acadêmicos, o trabalho resultou até o momento em 10 publicações, classificados da seguinte forma:

Periódico internacional: 1 (SCHUH et al., 2008a).

Capítulo de livro: 1 (BOOS; ZANCUL, 2006). 
Revista internacional: 5 (SONTOW et al., 2007), (ASSMUS et AL., 2007), (ASSMUS; ZANCUL, 2006), (SCHUH et al., 2006), (MEIER; ZANCUL, 2005).

Congresso internacional: 1 (SCHUH; ASSMUS; ZANCUL, 2006).

Congresso nacional: 2 (ZANCUL; ROZENFELD, 2008), (ZANCUL, 2008).

O trabalho também resultou na publicação de um relatório sobre o mercado de PLM, com a descrição de sistemas disponíveis comercialmente (ASSMUS et al., 2006).

A partir dos resultados obtidos nesta pesquisa, no próximo item são discutidos sugestões para trabalhos futuros na área.

\subsection{Sugestão para trabalhos futuros}

A discussão dos trabalhos futuros é realizada separadamente para cada um dos quatro resultados principais do trabalho, discutidos no item anterior.

Iniciando pelo framework de elementos do PLM, considera-se que existem dois focos principais para trabalhos futuros. O primeiro, é o detalhamento das inter-relações do framework não abordadas neste trabalho como, por exemplo, o relacionamento entre o modelo de sistemas e a base de conhecimentos. O segundo, refere-se à publicação do framework e de seu conteúdo na Internet, em um formato didático e de fácil acesso para as pessoas da indústria.

O modelo de referência de sistemas PLM está estruturado em funcionalidades. A partir desse modelo, trabalhos futuros podem definir serviços de PLM, estruturados de acordo com o paradigma de SOA. Da mesma forma, o modelo integrado processo-sistemas PLM pode evoluir para refletir o relacionamento do processo com serviços de PLM.

Por fim, o método de seleção de sistemas PLM com base em modelos de referência pode ser generalizado para outros contextos de aplicação, resultando em um método genérico para a seleção de sistemas de informação. 


\section{APÊNDICE A - Lista de fornecedores de sistemas PLM e fornecedores que participaram da survey}

Neste apêndice é apresentada a relação de fornecedores de sistemas PDM / PLM convidada para participar da survey. Os fornecedores que responderam o questionário estão identificados na quarta coluna das Tabela 13 e Tabela 14.

Tabela 13 - Fornecedores de sistemas PLM e fornecedores que participaram da survey - parte 1

\begin{tabular}{|c|c|c|c|}
\hline Numeração & Fornecedor & Sistema & $\begin{array}{l}\text { Participou da } \\
\text { survey? }\end{array}$ \\
\hline 1 & ACATEC Software GmbH & Power Configurator & \\
\hline 2 & Agile Software GmbH & Agile e6 & Sim \\
\hline 3 & assyst GmbH & pdm.assyst & Sim \\
\hline 4 & Autodesk GmbH & Autodesk Productstream Compass & \\
\hline 5 & Auto-trol Technology GmbH & KONFIG CM & Sim \\
\hline 6 & Axavia Software GmbH & Axavia & \\
\hline 7 & B.I.M.-Consulting mbH & PDV & \\
\hline 8 & BCT Technology AG & BCT PDM & \\
\hline 9 & Centric Software & Open PLM & \\
\hline 10 & CoCreate Software GmbH \& Co. KG & OneSpace.net & \\
\hline 11 & Contact Software GmbH & CIM Database & \\
\hline 12 & CRM InformationSystems GmbH & IntraIPP & \\
\hline 13 & Cyco Software DACH & Cyco AutoManager & \\
\hline 14 & Dassault Systemes AG & Smarteam & Sim \\
\hline 15 & daveg gmbh & CADDA.NET & \\
\hline 16 & DESYS Kassel & s4:manage & \\
\hline 17 & Dujan\&Tautz PDM Consulting & Priamos & Sim \\
\hline 18 & $\begin{array}{l}\text { ECS-Engineering Consulting \& } \\
\text { Solutions GmbH }\end{array}$ & MetalUI /eMeta-Kon & \\
\hline 19 & e-pro solutions GmbH & Mediando & \\
\hline 20 & EVO Informationssysteme GmbH & CAMback & \\
\hline 21 & GAIN Software GmbH & GAIN System & Sim \\
\hline 22 & IBM Deutschland & Enovia & Sim \\
\hline 23 & IFS Deutschand GmbH \& Co. KG & IFS PLM & Sim \\
\hline 24 & intellivate GmbH & Open EDM & \\
\hline 25 & IQUADRAT AG & Phoenix EDM & Sim \\
\hline 26 & ISAP AG & Solid Manager & \\
\hline 27 & ISD Software und Systeme GmbH & HELIOS neXt & \\
\hline 28 & ITandFactory GmbH & CADISON PDM & \\
\hline 29 & Keytech Software GmbH & ProfiDB & \\
\hline 30 & Lascom & Advitium & \\
\hline
\end{tabular}


Tabela 14 - Fornecedores de sistemas PLM e fornecedores que participaram da survey - parte 2

\begin{tabular}{|c|c|c|c|}
\hline Numeração & Fornecedor & Sistema & $\begin{array}{l}\text { Participou da } \\
\text { survey? }\end{array}$ \\
\hline 31 & Lorenz Engineering GmbH & CADBase & Sim \\
\hline 32 & LTE Consulting GmbH & PDM9000 & \\
\hline 33 & MatrixOne GmbH & MatrixOne PLM & \\
\hline 34 & MaxxSoft GmbH & MaxxDB & \\
\hline 35 & mmh software GmbH & speedy@m & Sim \\
\hline 36 & Modultek Oy & Aton & \\
\hline 37 & newTrust GmbH & newTrust & \\
\hline 38 & ORACLE Deutschland GmbH & eBusiness Suite & Sim \\
\hline 39 & Orcon GmbH & Phoenix / PDM & \\
\hline 40 & Parametric Technology GmbH & Windchill & Sim \\
\hline 41 & Parkstreet GmbH & P4 Enterprise & Sim \\
\hline 42 & PCL CAD/CAM Systeme & ADEM CAPP & \\
\hline 43 & PROCAD GmbH \& Co. KG & ProFile & Sim \\
\hline 44 & ProCAEss GmbH & DDX - Design Data eXchange & Sim \\
\hline 45 & Raeder + Vogel GmbH & CAJAC II & Sim \\
\hline 46 & SAP Deutschland AG \& Co. KG & mySAP PLM & \\
\hline 47 & $\begin{array}{l}\text { SIGHT International PLM Solutions } \\
\text { Ltd. }\end{array}$ & sightPLM & \\
\hline 48 & SofTech GmbH & ProductCenter & \\
\hline 49 & SolidWorks Deutschland GmbH & PDMWorks & \\
\hline 50 & SSA Global GmbH & SSA PLM & \\
\hline 51 & TECTURA AG & Tectura Auftragsfertigung & \\
\hline 52 & think3 GmbH & thinkPLM & \\
\hline 53 & TP-CAD GmbH & CONISIO & \\
\hline 54 & Unigraphics Solutions GmbH & Teamcenter & \\
\hline 55 & UNITEC Informations-systeme GmbH & TechOFFICE & \\
\hline 56 & W+P Solutions GmbH \& Co. KG & W+P Model & \\
\hline 57 & Ziffer Consulting GmbH & AutoVue & \\
\hline
\end{tabular}




\section{APÊNDICE B - Modelo de referência de sistemas PLM}

1 Planejamento de produtos

1.1

1.1.1

Gestão do portfólio de produtos

1.1.1.1

Criar portfólio de produtos

1.1.1.2

Criar relacionamento hierárquico entre produtos (e.g. relacionamento de produtos com grupo de produtos)

1.1.1.3

Especificar indicadores do portfólio (e.g. faturamento, volume de vendas)

1.1.1.4

Entrar dados de metas para cada indicador relacionado a um produto

Entrar dados do tempo estimado de permanência dos produtos no mercado

1.1.1.5

Apresentar visão consolidada das metas dos produtos

1.1.2

\section{Analisar portfólio de produtos}

1.1.3.4

Apresentar indicadores em vários níveis (drill down) - portfólio, grupos de produtos, produtos individuais

\section{Otimizar portfólio de produtos}

Simular cenários do portfólio de produtos

Aplicar algoritmos para a priorização de produtos com base em uma variável

Aplicar algoritmos para a priorização de produtos com base em múltiplas variáveis

Comparar resultados dos cenários do portfólio de produtos

Coleta, avaliação e seleção de idéias para novos produtos

\section{Coletar idéias de produtos}

Criar banco de dados de idéias de produtos que pode ser acessado por toda a empresa Configurar campos de dados para a descrição de idéias de produtos

Anexar documentos às idéias de produtos

Coletar dados sobre as idéias de produtos

Pesquisar idéias no banco de dados

\section{Classificar idéias de produtos}

Configurar categorias para classificação de idéias - quantidade ilimitada de categorias definidas livremente

Criar relacionamento hierárquico entre categorias

Classificar idéias

Restringir classificação de idéias de acordo com opções pré-definidas (campo de seleção)

Classificar idéias utilizando o grupo de funções de classificação do sistemas PLM

\section{Avaliar idéias de produtos}

1.2.3.2

$$
\text { Configurar critérios de avaliação }
$$

Especificar critérios quantitativos

Especificar critérios qualitativos

Restringir preenchimento de critérios qualitativos com opções pré-definidas (campo de seleção)

Definir pesos para os critérios

Calcular resultado quantitativo da avaliação utilizando fórmulas definidas livremente Realizar o processo de avaliação com apoio do grupo de funções de workflow do sistema PLM 
1.2.4.1 Comparar idéias em gráfico de colunas

1.2.4.2 Comparar idéias em gráfico de barras

1.2.4.3 Comparar idéias em gráfico de pizza

1.2.4.4 Comparar idéias em gráfico de bolhas

1.2.4.5 Exportar gráficos para MS-Excel

1.2.5 Documentar resultado da avaliação de idéias

1.2.5.1 Documentar resultado da avaliação com uma justificativa

1.2.5.2 Definir status para a idéia (avaliação não iniciada, em avaliação, selecionada, rejeitada etc.)

1.2.5.3 Apresentar resultado da avaliação em um ranking de idéias

1.2.5.4 Relacionar idéias com produtos do portfólio

1.2.5.5 Relacionar idéias com projetos

1.3 Gestão de requisitos

1.3.1 Coletar requisitos de produtos

1.3.1.1 Criar banco de dados de requisitos que pode ser acessado por toda a empresa (independente da localização geográfica e da área organizacional)

1.3.1.2 Configurar campos de dados para a descrição dos requisitos

1.3.1.3 Coletar requisitos no banco de dados

1.3.1.4 Anexar documentos aos requisitos

1.3.1.5 Pesquisar requisitos no banco de dados

1.3.2 Classificar requisitos

1.3.2.1 Configurar categorias para classificação de requisitos - até 3 categorias definidas livremente

1.3.2.2 Configurar categorias para classificação de requisitos - quantidade ilimitada de categorias definidas livremente

1.3.2.3 Criar relacionamento hierárquico entre categorias

1.3.2.4 Classificar requisitos

1.3.2.5 Restringir classificação de requisitos de acordo com opções pré-definidas (campo de seleção)

1.3.2.6 Classificar requisitos utilizando o grupo de funções de classificação do sistemas PLM

1.3.3 Agrupar requisitos

1.3.3.1 Relacionar requisitos com grupos de requisitos

1.3.3.2 Criar relacionamento hierárquico entre requisitos e grupos de requisitos

1.3.3.3 Criar novos requisitos copiando requisitos existentes

1.3.4

Avaliar requisitos

1.3.4.1 Configurar critérios de avaliação

1.3.4.2 Especificar critérios quantitativos

1.3.4.3 Especificar critérios qualitativos

1.3.4.4 Restringir preenchimento de critérios qualitativos com opções pré-definidas (campo de seleção)

1.3.4.5 Definir pesos para os critérios

1.3.4.6 Calcular resultado quantitativo da avaliação utilizando fórmulas definidas livremente

1.3.4.7 Realizar o processo de avaliação com apoio do grupo de funções de workflow do sistema PLM

Analisar requisitos com uso de gráficos

1.3.5.1

Analisar requisitos em gráfico de colunas 
1.3.5.2 Analisar requisitos em gráfico de barras

1.3.5.3 Analisar requisitos em gráfico de pizza

1.3.5.4 Analisar requisitos em gráfico de bolhas

1.3.5.5 Exportar gráficos para MS-Excel

1.3.6

Acompanhar evolução dos requisitos

1.3.6.1

1.3.7

1.3.7.1

1.3.7.2

1.3.7.3

\section{Gestão de projetos}

Criar banco de dados de recursos para executar projetos

Criar recursos do tipo pessoas

Criar recursos do tipo equipamentos

Criar recursos do tipo ferramentas

Criar recursos de outros tipos (definido livremente)

\section{Configurar base de dados de recursos}

Relacionar recursos com grupos de recursos em uma hierarquia de recursos

Definir turno de trabalho / horário para atuação de cada recurso

Especificar custo padrão dos recursos

Pesquisar recursos pelo perfil

Pesquisar recursos pela capacidade disponível

\section{Criar EAP (Estrutura Analítica do Projeto)}

Criar EAP a partir de templates pré-definidos

Configurar EAP derivada do template com apoio de funções para configuração (wizard)

Criar EAP com elementos padronizados pré-definidos (template)

Criar EAP copiando EAP existente em um projeto semelhante

Copiar elementos individuais da EAP de outros projetos

Criar EAP a partir da rede de atividades

Criar a hierarquia de níveis da EAP sem restrição de quantidade de níveis disponíveis

\section{Visualizar EAP}

Visualizar EAP em formato gráfico

Visualizar EAP em formato de lista

2.1.5.1

\section{Definir rede de atividades}

Definir rede de atividades diretamente a partir da EAP 
2.1.5.2 Criar atividades livremente

2.1.5.3 Detalhar atividades em subatividades em uma hierarquia

2.1.5.4 Diferenciar atividades internas da empresa e atividades externas

2.1.6 Definir relacionamento de precedência entre atividades

2.1.6.1 Definir relacionamento término para início (TI)

2.1.6.2 Definir relacionamento início para início (II)

2.1.6.3 Definir relacionamento término para término (TT)

2.1.6.4 Definir relacionamento início para término (IT)

2.1.6.5 Definir relacionamento com intervalo de tempo

2.1.7 Visualizar planejamento dos projetos

2.1.7.1 Visualizar diagrama de Gantt

2.1.7.2 Visualizar diagrama de rede do projeto

2.1.8 Definir cronograma dos projetos

2.1.8.1 Relacionar marcos de projeto com elementos da EAP

2.1.8.2 Definir marcos de projeto livremente

2.1.8.3 Relacionar elementos da EAP com uma rede de projeto

2.1.9

2.1.11.1

2.1.11.2

2.1.11.3

2.1.11.4

2.1.12.1

\section{Especificar ações decorrentes de um marco de projeto completado}

Especificar atividades que são iniciadas no marco de projeto

Especificar tarefas do workflow que são iniciadas no marco de projeto

\section{Planejar projetos}

Planejar projeto aplicando método do caminho crítico - CPM (Critical Path Method)

Planejar projeto aplicando método PERT (Program Evaluation and Review Technique)

Planejar projeto aplicando método MPM (Metra-Potential-Method)

Planejar projeto aplicando método GERT (Graphical Evaluation and Review Technique)

\section{Programar projetos}

Programar projeto com data de início no passado

Programa projeto

Programar múltiplos projetos

Simular nível de utilização de recursos

Simular ajustes na programação de projetos

Simular várias alternativas do projeto em versão de simulação e transferir resultados para versão de planejamento

\section{Visualizar resultados da ocupação de recursos}

Visualizar ocupação de recursos por data

Visualizar necessidade e disponibilidade de recursos separadamente

Visualizar relação de recursos gargalo

Visualizar ocupação na hierarquia de recursos (drill-down)

Visualizar ocupação diferenciada por tipo de projeto

Detalhar detalhes dos projeto que utilizam recursos (drill-down)

Planejar gestão de riscos dos projetos

Descrever riscos

Classificar riscos em categorias e avaliar impactos 
2.1.13.3 Planejar medidas de resposta aos riscos

2.1.13.4 Definir eventos para notificação automática de medidas de resposta aos riscos

2.1.14

2.1.14.1

2.1.14.2

Relacionar plano macro de projeto com outros planos detalhados (e.g. plano de produção, plano de montagem)

Transferir datas do plano macro de projetos para outros planos de projeto

Relacionar datas entre planos de projetos - inter-dependência em caso de mudança

Controle de projetos

Visualizar visão geral do status de projetos

Visualizar status do projeto por data

Visualizar status do projeto por contrato

Visualizar status do projeto por centro de custos / recurso

Visualizar status do projeto por elemento da EAP

Registrar e visualizar avanços nos planos de projetos

Gravar baseline do planejamento

Registrar avanço do projeto por elemento da EAP

Informar avanços do projeto por meio da Internet

Comparar utilização de recursos (horas) - plano vs. real

Comparar datas - plano vs. real

Visualizar status por recurso

Visualizar nível agregado (\%) de atividades completadas

\section{Gerar relatórios de gestão de projetos}

Visualizar dados do desempenho de projetos em "cockpit" de gestão

Gerar relatórios de status

Configurar relatórios com dados do desempenho de projetos

Visualizar desempenho do projeto de forma gráfica com uso de cores para o status (e.g. verde, amarelo, vermelho)

Analisar desempenho do projeto utilizando OLAP

\section{Gestão de múltiplos projetos}

Inter-relacionar projetos

Inter-relacionar projetos de forma hierárquica (e.g. relacionamento de projetos com programas)

Inter-relacionar projetos - até 3 níveis hierárquicos

Inter-relacionar projetos - quantidade ilimitada de níveis hierárquicos

\section{Otimizar o portfólio de projetos}

Aplicar algoritmos para a priorização de projetos com base em uma variável

Aplicar algoritmos para a priorização de projetos com base em múltiplas variáveis

Comparar resultados dos cenários do portfólio de projetos

\section{Planejar cronograma para o portfólio de projetos}

Planejar cronograma para múltiplos projetos considerando a necessidade global de capacidade de recursos

Planejar cenários distintos e comparar resultados

\section{Gerar relatórios de gestão de múltiplos projetos}

Visualizar dados do desempenho do portfólio de projetos em "cockpit" de gestão

Visualizar indicadores de diversos projetos de forma integrada 
2.3.4.3

\section{3}

3.1

3.1.1

3.1.1.1

3.1.1.3

3.1.1.4

3.1.1.5

3.1.1.6

3.1.1.7

3.1.1.8

3.1.2

3.1.2.1

3.1.2.2

3.1.2.3

3.1.3

3.1.3.1

3.1 .4

3.1.4.1

3.1.4.2

3.1.4.3

3.1.4.4

3.1.5

3.1.5.1

3.1.5.2

3.1.5.3

3.1.6

3.1.6.1

3.1.6.3

3.1.6.4

3.1.7

3.1.7.1

3.1.7.2

Visualizar dados de desempenho dos projetos do nível de portfólio até o nível de projetos individuais (drill-down)

\section{Controle de indicadores financeiros}

\section{Controle de indicadores financeiros de projetos}

\section{Estimar custos de projetos}

Especificar necessidade de recursos

Estimar custo do projeto com base em necessidade de recursos e custos adicionais informações

Entrar dados de receita esperada por período

Visualizar o fluxo de caixa do projeto

Analisar o retorno do investimento

Definir critérios adicionais de avaliação de projetos

Definir pesos para os critérios de avaliação

Calcular resultado da avaliação

Planejar custos de projetos

Planejar custos em plano de contas

Planejar custos por elemento da EAP

Planejar custos por elemento da estrutura de produtos

\section{Diferenciar tipos de custos na estimativa de custos de projetos}

Calcular custos de utilização de recursos (necessidade de recursos multiplicada pelo custo padrão do recurso)

Diferenciar custos de materiais comprados

Diferenciar custos de serviços externos

Diferenciar custos de materiais produzidos

Considerar rateio de custos indiretos

Considerar outros custos

Definir orçamento de projetos

Definir budget por projeto

Definir budget por ano

Definir budget por mês

Definir budget por período de tempo selecionado livremente

Contabilizar custos de projetos

Contabilizar custos de produção e de compras

Contabilizar custos ao longo do projeto

Contabilizar custos por elemento da EAP

Gerenciar custos de projetos

Comparar situação atual com budget

Comparar situação atual com o baseline de custos planejado

Comparar custos planejados e reais até o nível de cada lançamento

Analisar detalhes dos custos reais lançados no projeto (drill-down)

\section{Gerenciar orçamento de projetos}

Limitar execução de uma atividade ao budget pré definido

Bloquear atividade quando não houver budget previsto 
3.1.7.3

3.1.8

3.1.8.1

3.1.9

3.1.9.1

3.1.9.2

3.1.10

3.1.10.1

3.1.10.2

3.1.10.3

3.1.11

3.1.11.1

3.1.11.2

3.1.11.3

3.1.11.4

3.1.11.5

3.1.11.6

3.2

3.2.1

3.2.1.1

3.2.2

3.2.2.1

3.2.2.2

3.2.2.3

3.2.2.4

3.2.2.5

3.2.2.6

3.2.2.7

3.2.2.8

3.2.2.9

3.2.2.10

3.2.2.11

3.2.3

3.2.3.1

3.2.3.2

3.2.3.3

\section{4}

4.1

4.1.1
Notificar responsáveis quando custo ultrapassar budget

\section{Gerenciar fluxo de caixa de projetos}

Entrar dados de expectativa de receitas por período

Visualizar gráfico do fluxo de caixa

Comparar o fluxo de caixa planejado com o real

\section{Estimar evolução dos custos de projetos}

Estimar evolução dos custos com base em atividades remanescentes

Analisar EVA (Earned Value Analysis)

\section{Ajustar custos em decorrência de mudanças de engenharia}

Comparar custos planejados e realizados

Relacionar custos de mudança com pedido do cliente

Enviar custos de mudança para faturamento

\section{Controlar indicadores de projetos}

Controlar data de liberação

Controlar status de liberação

Monitorar produtos pré-série

Monitorar materiais com lead time longo

Monitorar utilização de recursos

Monitorar custos

Cálculo do desempenho financeiro no ciclo de vida

Registrar custos e receitas do produto ao longo do ciclo de vida (Product Lifecycle Costing)

Registrar todos os custos e receitas relacionados com um produto

Definir os tipos de custos e de receitas que são considerados no cálculo do resultado no ciclo de vida

Considerar custos de desenvolvimento e de projeto

Considerar investimentos

Considerar custos de produção (inclusive compras externas)

Considerar custos de marketing e de vendas

Considerar custos de prestadores de serviços

Considerar receitas de vendas

Considerar receitas de serviços

Considerar custos indiretos

Considerar receitas realizadas até data especificadas

Considerar receitas futuras planejadas

Obter informações de receitas e de custos de outros sistemas por meio de interfaces

Analisar o desempenho financeiro no ciclo de vida

Apresentar o fluxo de caixa do produto

Calcular o ponto de break-even

Calcular rentabilidade

\section{Estruturação de produtos}

Cadastro mestre de materiais

Criar novos dados mestres de materiais 
4.1.1.1

4.1.1.2

4.1.1.3

4.1.1.4

4.1.2

4.1.2.1

4.1.2.2

4.1.2.3

4.1.2.

4.1.2.5

4.1.2.6

4.1.2.7

4.1.3

4.1.3.1

4.1.3.2

4.1.3.3

4.1.4

4.1.4.1

4.1.4.2

4.1.4.3

4.1.5

4.1.5.1

4.1.5.2

4.1.5.3

4.1.6

4.1.6.1

4.1.6.2

4.1.6.3

4.1.6.4

4.1.6.5

4.1.6.6

4.1.6.7

4.1.6.8

4.1.6.9

4.1.7

4.1.7.1

4.1.7.2

4.1.7.3

4.1.7.4

4.1.7.5

4.1.7.6

Criar dados mestres utilizando visão por área organizacional (e.g. engenharia, contabilidade, compras)

Criar dados mestres utilizando modo de entrada rápida de dados

Criar dados mestres utilizando modo de entrada rápida de dados por área organizacional

Criar dados mestres com apoio de função assistente (wizard)

Definir status do cadastro mestre de materiais

Definir status como preliminar

Definir status como arquivado

Definir status como ativo / passivo

Definir status como em introdução / em discontinuação

Definir status como específico para projeto / produto

Definir status como incompleto

Configurar novos status de forma livre

Definir método de identificação de materiais

Definir identificação seqüencial

Definir identificação e classificação - composta

Definir identificação e classificação - paralela

Atribuir identificação aos materiais

Atribuir identificação manualmente

Atribuir identificação seqüencial automaticamente

Atribuir identificação seqüencial automaticamente por subdivisões da numeração

Especificar identificações adicionais

Especificar EAN (European Article Number)

Especificar UPC (Universal Product Code)

Configurar outros sistemas de identificação adicionais (e.g. OEM, vendas, fornecedor)

Gerenciar EAN (European Article Number)

Utilizar EAN-13 / UPC

Utilizar EAN resumido

Utilizar EAN de produtos perecíveis

Utilizar um EAN por unidade de embalagem

Utilizar vários EAN por unidade de embalagem

Utilizar EAN com controle de data (validade)

Verificar EAN com dígito verificador

Gerar EAN automaticamente

Utilizar EAN como número do material

Definir visões alternativas do cadastro mestre de materiais

Definir visão de identificação

Definir visão de engenharia

Definir visão de testes

Definir visão de programação

Definir visão de inventário

Definir visão de contabilidade 
4.1.7.7 Definir visão de compras

4.1.7.8 Definir visão de compras produção

4.1.7.9 Definir visão de compras produção armazenamento

4.1.7.10 Definir visão de vendas

4.1.7.11 Definir visão de custeio

4.1.7.12 Definir visão de homologação

4.1.7.13 Configurar novas visões utilizando campos de dados pré-definidos

4.1.8

4.1.8.1

4.1.8.2

4.1.8.3

4.1.8.4

4.1.8.5

4.1.9

4.1.9.1

4.1.9.2

4.1.9.3

4.1.9.4

4.1.9.5

4.1.10

4.1.10.1

4.1.10.2

4.1.10.3

4.1.10.4

4.1.11

4.1.11.1

4.1.11.2

4.1.11.3

4.1.11.4

4.1.11.5

4.1.11.6

4.1.11.7

4.1.12

4.1.12.1

4.1.12.2

4.1.12.3

4.1.13

4.1.13.1

4.1.13.2

4.2

4.2.1

\section{Entrar dados de características dos materiais}

Entrar dados da geometria

Entrar dados de peso

Informar classe ABC

Entrar dados do lote de reposição

Definir outros campos de dados para as características do material

\section{Atribuir características para qualificação dos materiais}

Definir material como sucessor de material existente

Definir material como item de reposição

Definir material como usado

Definir material como item de consumo

Definir material como ordinário

\section{Definir unidades de medida aplicadas aos materiais}

Definir unidades para quantidade

Definir unidade para massa

Definir unidade para volume

Definir unidade para comprimento

Especificar quantidades padrão para diferentes aplicações dos materiais

Especificar quantidades padrão base

Especificar quantidades padrão de recebimento

Especificar quantidades padrão da estrutura de produtos

Especificar quantidades padrão de vendas

Especificar quantidades padrão de compras

Especificar quantidades padrão de armazenagem

Especificar quantidades padrão para contabilidade

\section{Gerenciar materiais alternativos}

Especificar material alternativo no cadastro de materiais

Especificar material alternativo na estrutura de produto

Especificar material alternativo na posição da estrutura de produto

\section{Transferir dados do desenvolvimento para o cadastro mestre}

Transferir dados do desenvolvimento para cadastro mestre automaticamente após mudança de status

Transferir dados do desenvolvimento para cadastro mestre automaticamente após aprovação Classificação

Definir tipo de sistema de classificação a ser usado 
4.2.1.1 Selecionar sistema de classificação com base na identificação (número)

4.2.1.2 Selecionar sistema de classificação com base em código com significado (e.g. Opitz)

4.2.1.3 Selecionar sistema de classificação com base em características

4.2.2

4.2.2.1

4.2.3

4.2.3.1

4.2.4

4.2.5

4.2.6

4.2.6.1

4.2.6.2

4.2.6.3

4.2.6.4

4.2.6.5

4.2.6.6

4.2.8

4.2.8.1

4.2.8.4

4.2.9

\section{Definir a estrutura de classificação}

Definir estrutura de classificação não hierárquica

Definir estrutura de classificação parcialmente hierárquica

Definir estrutura de classificação hierárquica

\section{Definir níveis da estrutura de classificação}

Definir estrutura de classificação em até 3 níveis

Definir estrutura de classificação - mais de 3 níveis hierárquicos, mas quantidade restrita

Definir estrutura de classificação - quantidade ilimitada de níveis hierárquicos

\section{Definir classes no sistema}

Definir classes e anexar figura para ilustrar características

Definir classes e incluir texto para explicar características

Especificar características das classes

Especificar características das classes - até 10 características

Especificar características das classes - mais de 10 características, mas quantidade restrita

Especificar características das classes - quantidade ilimitada de características

Definir tipos de características

Definir características numéricas

Definir características texto

Definir características data

Definir características hora

Definir características moeda

Definir características faixa de valor (valor máximo e valor mínimo)

Definir características fórmula

Definir outros tipos de características

\section{Detalhar tipos de características}

Definir características de apenas um valor

Definir características mais de um valor

Definir características opcionais

Definir características obrigatórias

Definir template de inclusão de atributos das características

Definir lista de inclusão (valores predefinidos) para características

\section{Especificar classificação segundo padrão existente}

Especificar classificação segundoECl@ss

Especificar classificação segundo Proficlass

Especificar classificação segundo UN/SPSC (United Nations Standard Products and Services Code)

Especificar classificação segundo DIN

\section{Classificar objetos}

Classificar materiais 
4.2.9.2 Classificar documentos

4.2.9.3 Classificar recursos

4.2.9.4 Classificar projetos

4.2.9.5 Classificar fornecedores

4.2.10

4.2.10.1

4.2.10.3

4.2.11

4.2.11.1

4.2.11.2

4.2.11.3

4.2.11.4

4.2.11.5

4.2.11.6

4.2.12

4.2.12.1

4.2.12.2

4.2.12.3

4.2.12.4

4.2.13

4.2.13.1

4.2.13.2

4.3

4.3.1

4.3.1.1

4.3.1.2

4.3.1.3

4.3.2

4.3.2.1

4.3.2.2

4.3.2.3

4.3.3

4.3.3.1

4.3.3.2

4.3.3.3

4.3.3.4

4.3.3.5

4.3.3.6

4.3.3.7

4.3.3.8

\section{Empregar recursos do sistema ao classificar objetos}

Checar validade dos dados na entrada de dados

Classificar objeto em múltiplas classes

Identificar objeto com classificação idêntica e avisar usuário

Possibilitar a criação de características específicas por objeto

\section{Buscar objetos classificados no sistema a partir de módulos/funções}

Buscar objetos na criação de estruturas de produto

Buscar objetos na gestão de documentos

Buscar objetos na gestão de planos de processo de fabricação

Buscar objetos no gestão de mudanças

Buscar objetos na gestão de projetos

Buscar objetos em compras

\section{Buscar objetos classificados no sistema}

Buscar objetos pela classe - níveis de classificação

Buscar objetos por uma característica

Buscar objetos por combinação das características do sistema

Buscar objeto por meio da "navegação" na estrutura gráfica de classes (drill-down)

\section{Integrar o sistema de classificação com o CAD}

Gerar modelos em CAD automaticamente com base em classes e seus atributos

Identificar características automaticamente a partir do modelo CAD

Gestão da estrutura de produtos

Definir contexto da estrutura de produto

Gerar estrutura de produto para produto

Gerar estrutura de produto para projeto

Gerar estrutura de produto para pedido

\section{Definir tipo da estrutura de produto}

Definir tipo de estrutura de produto de quantidades

Definir tipo de estrutura de produto identada

Definir tipo de estrutura de produto modular

Definir visões da estrutura de produto

Definir visão de funções do produto

Definir visão de proposta para cliente

Definir visão de tecnologia

Definir visão de engenharia

Definir visão de custos

Definir visão de compras

Definir visão de manufatura

Definir visão de montagem 
4.3.3.9 Definir visão de armazenagem

4.3.3.10 Definir visão de vendas

4.3.3.11 Definir visão de expedição

4.3.3.12 Definir visão de manutenção

4.3.3.13 Definir visões da estrutura de produto de acordo com o status de liberação

4.3.4

4.3.4.1

4.3.4.2

4.3.5

4.3.5.1

4.3.5.2

4.3.5.3

4.3.6

4.3.6.1

4.3.6.2

4.3.6.3

4.3.6.4

4.3.7.3

4.3.7.4

4.3.7.5

4.3.8

4.3.8.2

4.3.8.3

4.3.9

4.3.10

4.3.11

4.3.11.1

4.3.11.2

4.3.11.3

4.3.11.4

4.3.11.5

4.3.11.6
Armazenar estruturas de produto de proposta para o cliente

Armazenar estruturas de proposta com base no conteúdo

Armazenar estruturas de produto com base nos resultados

\section{Gerar e gerenciar estruturas de produto}

Gerar estruturas de produto com auxílio de um browser gráfico da estrutura de produto Acessar todos os objetos da estrutura de produto a partir do browser gráfico

Acessar a estrutura de produto a partir de modelos 3D do CAD

\section{Gerar diferentes visões da estrutura de produto}

Gerar visão da estrutura de produtos copiando manualmente os objetos

Gerar visão da estrutura de produto "arrastando" objetos (drag \& drop)

Definir visões da estrutura de produto por meio de marcação no cadastro mestre de materiais

Definir visões da estrutura de produto por meio de marcação na estrutura de produto

Definir visões da estrutura de produto por meio de definição de blocos de números de identificação dos materiais

Especificar informações definidas por uma posição da estrutura de produto

Especificar somente necessidade de materiais (para MRP)

Especificar necessidade de materiais (para MRP) e custos

Especificar quantidade negativa

Especificar posição sem especificação de quantidades

Especificar quantidade por meio de fórmula

Tratar posições da estrutura de produto sem informação no cadastro mestre de materiais Incluir cadastro mestre de materiais

Incluir um pseudo-item

Permitir que cadastro mestre de materiais não seja exigido

\section{Checar resultado da estrutura de produto}

Verificar lista de posições incompletas da estrutura de produto

Verificar combinações não permitidas entre materiais

\section{Liberar posições da estrutura de produto}

Liberar posições individuais ou grupos de posições

Liberar todas as posições restantes ainda não liberadas

Definir possíveis status para a liberação de estruturas de produto

Definir status liberado para engenharia

Definir status liberado para órgão de inspeção

Definir status liberado para cálculo de custos

Definir status liberado para planejamento do processo de fabricação

Definir status liberado para pedido de cliente

Definir status liberado para ordem de produção 
4.3.11.7 Definir status liberado para programação das necessidades de materiais

4.3.11.8 Definir status liberado para produção

4.3.12

4.3.12.1

4.3.12.2

4.3.12.3

4.3.12.4

4.3.13

4.3.13.1

4.3.13.2

4.3.13.3

4.3.13.4

4.3.13.5

4.3.14

4.3.14.1

4.3.14.2

4.3.14.3

4.3.14.4

4.3.14.5

4.4

4.4.1

4.4.1.1

4.4.1.2

4.4.1.3

4.4.2

4.4.2.1

4.4.2.2

4.4.2.3

4.4.3

4.4.3.1

4.4.3.2

4.4.4

4.4.4.1

4.4.4.2

4.4.4.3

4.4.4.4

4.4 .5

4.4.5.1

4.4.5.2

4.4.5.3

4.4.6

4.4.6.1

\section{Comparar estruturas de produto}

Comparar estruturas de produto com um baseline

Comparar estruturas de produto de diferentes validades

Comparar estruturas de produto de diferentes contextos

Comparar estruturas de produto com ordens de produção

Analisar onde é usado (where-used)

Analisar onde é usado para material

Analisar onde é usado para estrutura de produto

Analisar onde é usado para plano de processo

Analisar onde é usado para atividade de plano de processo

Analisar onde é usado para documento

Selecionar formato de dados de relatório da estrutura de produto

Selecionar formato ASCII

Selecionar formato HTML

Selecionar formato PDF

Selecionar formato formulário OLE

Selecionar formato XLS (MS Excel)

Gestão de variantes

\section{Gerenciar variantes no sistema}

Gerenciar estruturas de produto modulares independentes de ordens de produção

Gerar variantes sem necessidade de criar cadastro mestre de materiais para cada variante

Armazenar atributos dos produtos variantes

\section{Definir tipos de variantes}

Definir variantes por materiais - um ou mais materiais utilizados com diferentes atributos

Definir variantes por estrutura - a posição dos diferentes materiais na estrutura pode variar

Definir variantes de diferentes tamanhos baseados em estrutura básica

Definir tipos de objetos para composição de variantes

Definir regras para montagem de variantes - atributos obrigatórios

Definir objetos opcionais para seleção - atributos opcionais

Definir tipos de atributos de variantes

Definir atributos de texto (e.g. cor verde)

Definir atributos numéricos

Definir atributos com valores discretos

Definir atributos com limitações (de ....até...)

Definir regras para a composição de variantes

Definir regras por programação

Definir regras em tabela

Definir regras com apoio de função do sistema (wizard)

Definir tipos de regras para a composição de variantes

Definir relacionamento lógico 
4.4.6.2 Definir relacionamento aritmético - cálculo básico

4.4.6.3 Definir relacionamento aritmético complexo - funções predefinidas

4.4.6.4 Especificar fórmulas livremente

4.4.7 Definir tipos de relacionamento lógico

4.4.7.1 Verificar o valor de um atributo específico Se A, estão...)

4.4.7.2 Verificar vários atributos relacionados com "e" (Se A e B e ... e X, então ...)

4.4.7.3 Verificar vários atributos relacionados com "ou" (Se A ou B ou ... ou X, então ...)

4.4.7.4 Relacionar atributos com negação (Se não A, então...)

4.4 .8

4.4.8.1

4.4.9

4.4.9.1

4.4.9.2

4.4.9.3

4.4.10

4.4.10.1

4.4.11

4.4.11.1

4.4.11.2

4.4.12

4.4.12.1

4.4.12.2

4.4.12.3

4.4.13

4.4.13.1

4.4.14

4.4.14.1

4.4.14.2

4.4.15

4.4.15.1

4.4.15.2

4.4.15.3

4.5

4.5.1

4.5.1.1

4.5.1.2

4.5.1.3

4.5.1.4

4.5.2
Especificar quantidade de condições que podem ser combinadas

Combinar quantidade ilimitada de condições

Especificar ações decorrentes de uma condição

Limitar opções de atributos

Obrigar opções de atributos

Transformar itens opcionais em obrigatórios

Definir quantidade de níveis para a definição de regras

Utilizar quantidade ilimitada de níveis

\section{Verificar resultado da definição de variantes}

Verificar inconsistências entre as regras de um variante

Verificar se todas as opções disponíveis podem ser escolhidas

Definir formato das estruturas de produto para variantes

Utilizar formato de estrutura de produto com posições iguais destacadas

Utilizar formato de estrutura de produto "mais-menos"

Utilizar formato de estruturas de produto independentes para cada variante

\section{Gerar estruturas de produto para variantes}

Gerar estruturas de produto manualmente

Gerar estruturas de produto automaticamente com a definição de dados mestres para cada variante

Gerar estruturas de produto automaticamente com a reutilização de dados mestres para variantes iguais

Definir em que momento estruturas de produto para variantes são geradas

Gerar estrutura de produto após configuração da variante

Gerar estrutura de produto após liberação para produção

\section{Gerar identificação de variantes}

Gerar número de variante independente

Utilizar número do pedido como número do variante

Gerar identificação do variante com uma combinação de atributos

Configuração de produtos

Empregar funções do sistema para a configuração de produtos

Entrar dados da configuração desejada em uma tabela

Utilizar estrutura do tipo Explorer

Utilizar funcionalidades de apoio (wizard)

Utilizar configurador gráfico

\section{Configurar produtos}


4.5.2.1 Escolher opções em uma lista

4.5.2.2 Entrar dados

4.5.2.3 Verificar validade dos dados por meio de limitações (de...até...)

4.5.2.4 Verificar validade dos dados com fórmulas

4.5.2.5 Verificar validade dos dados combinados de várias opções

4.5.3

Exibir resultados da configuração

4.5.3.2

5 Gestão da configuração

Estimar custo da opção configurada

5.1

5.1.1

5.1.1.1

Gestão de versões, status e validades

5.1.1.2

Manter controle de versões

5.1 .2

Controlar versões de forma seqüencial

Controlar versões hierarquicamente

5.1.2.1

Gerar nova versão

5.1.2.2

Gerar nova versão manualmente

5.1.3

Gerar nova versão automaticamente após a ocorrência de uma mudança

5.1.3.1

Criar uma rede de status

5.1.3.2

Definir tipos de status

5.1.3.3

Definir transições entre os status

5.1.4

Definir múltiplas transições de status (rede de status)

5.1.4.1

Definir os tipos de status

5.1.4.2

Definir status inativo

5.1.4.3

5.1.4.4

5.1.4.5

5.1.4.6

5.1.4.7

5.1.4.8

5.1.4.9

5.1.4.10

5.1.5

Definir status em trabalho

Definir status encerrado

Definir status em verificação

Definir status rejeitado

Definir status liberado

Definir status em alteração

Definir status preliminar

Definir status em teste

Definir status livremente

5.1.5.1

Definir formas de aprovação

5.1.5.2

5.1.6

Definir aprovação por uma pessoa

Definir aprovação por mais de uma pessoa

5.1.6.1

Definir parâmetro de validade

5.1.6.2

Definir validade por data

5.1.6.3

Definir validade por faixa de número de série

5.1.6.4

Definir validade por modelo

5.1.6.5

Definir validade por cliente

5.1.6.6

Definir validade por fábrica

Combinar os diferentes parâmetros de validade 
5.2.1

5.3.1

5.3.4

5.3.4.6

5.3.4.8

5.3.4.9

\section{Definir os passos necessários e os tipos de aprovação no sistema}

Definir aprovação preliminar

Definir aprovação para desenvolvimento

Definir aprovação para planejamento da produção

Definir aprovação para produção em série

\section{Realizar aprovações}

Aprovar objetos individualmente

Aprovar objetos em conjunto

\section{Definir as ações decorrentes de uma aprovação}

Congelar objeto no sistema

Arquivar objeto

Transferir dados de produto selecionados para o ERP

Notificar usuários específicos sobre a aprovação

Gestão de mudanças

\section{Ativar / desativar gestão de mudanças}

Gerenciar obrigatoriedade de registro do histórico individualmente por objeto

Definir obrigatoriedade de registro do histórico no início do ciclo de vida

Permitir ativação / desativação flexível da gestão de mudança para cada objeto

\section{Controlar mudanças dos objetos do sistema}

Controla mudanças de materiais

Controla mudanças de estruturas de produto

Controla mudanças de dados na configuração variantes (e.g. regras de configuração)

Controla mudanças de documentos

Controla mudanças de planos de processo de produção

Controla mudanças de planos de controle

Controla mudanças de dados da gestão de projetos

Controla mudanças do sistema de classificação (classes e características)

\section{Gerar pedido de mudança de engenharia}

Registrar automaticamente número do pedido de mudança

Registrar automaticamente responsável

Registrar automaticamente data

\section{Detalhar informações no pedido de mudança de engenharia}

Detalhar motivo da mudança

Detalhar comentário

Anexar documentos descritivos

Detalhar informações do cliente

Definir tipo de mudança

Definir prioridade

Especificar período

Especificar estimativa de custos de realização da mudança

Especificar custos recorrentes 
5.3.4.10

5.3.4.11

5.3.5

5.3.5.2

5.3.5.3

5.3.5.4

5.3.6

5.3.6.1

5.3.6.2

5.3.6.3

5.3.6.4

5.3.7

5.3.7.1

5.3.8

5.3.8.1

5.3.9

5.3.10

5.3.10.1

5.3.10.2

5.3.10.3

5.3.11

5.3.11.1

5.3.11.2

5.3.11.3

5.3.12

5.3.12.1

5.3.12.2

5.3.12.3

5.3.12.4

5.3.12.5

5.4

5.4.1

5.4.1.1

5.4.1.2

Especificar objetos impactados

Especificar requisitos de aprovação do pedido de mudança (responsável)

Definir controle de mudança para mais de um objeto relacionado

Definir pedido de mudança conjunto para objetos relacionados

Definir um número de mudança único para a alteração dos objetos relacionados

Executar o workflow de mudança de engenharia individualmente por objeto relacionado

Aprovar as mudanças nos objetos relacionados em conjunto

Definir parâmetros do processo de mudança por meio do tipo da mudança

Definir seqüência do workflow por meio do tipo de mudança

Definir necessidade de aprovação por meio do tipo de mudança

Definir parâmetros de validade por meio do tipo de mudança

Definir notificação por meio do tipo de mudança

\section{Definir encaminhamento dos pedidos de mudança para aprovação}

Definir manualmente o encaminhamento dos pedidos de mudança para aprovação

Definir o encaminhamento dos pedidos de mudança para aprovação automaticamente, dependendo do status

Definir o encaminhamento dos pedidos de mudança para aprovação automaticamente, dependendo do tipo de mudança

\section{Aprovar pedido de mudança de engenharia}

Aprovar pedido de mudança de engenharia com base em dados registrados no pedido

Consultar objetos impactados pela mudança por meio de link no pedido de mudança

Realizar comentários no pedido de mudança

Atribuir número de mudança de engenharia

Atribuir número de mudança de engenharia manualmente

Atribuir número de mudança de engenharia automaticamente

\section{Definir formas de referenciar objetos alterados}

Referenciar objetos de forma estática

Referenciar objetos de forma dinâmica

Referenciar objetos por parâmetros de validade

Definir objetos para registrar estatísticas da gestão de mudanças

Definir registro de estatísticas para relatórios de problema

Definir registro de estatísticas para pedidos de mudança

Definir registro de estatísticas para ordens de mudança

Registrar estatísticas da gestão de mudanças

Registrar quantidade de mudanças

Registrar quantidade de mudanças por tipo de mudança

Registrar tempo necessário para mudança

Registrar tempo em trabalho por atividade de mudança

Calcular custo de mudança automaticamente a partir da utilização de recursos

Gestão de mudanças para ordens de produção

Definir fase limite da ordem de produção para realização de alterações

Permitir alterações até liberação do pedido do cliente

Permitir alterações até liberação da ordem de produção 
5.4.1.3 Permitir alterações ao longo da execução da ordem de produção

5.4.1.4 Permitir alterações até conclusão da ordem de produção

5.4.1.5 Permitir alterações até recebimento pelo cliente

Gerenciar substituição de materiais na produção após alteração de um material pelo desenvolvimento

Visualizar as ordens de produção que contém o material alterado

Visualizar o status das ordens de produção que contém o material alterado

5.4.2.3

Gerar notificação automática para as áreas impactadas pela mudança do material

Gerenciar configuração de materiais

Gerenciar configuração de estruturas de produto

Gerenciar configuração de documentos

Gerenciar configuração de estruturas de projeto

5.5.1.6

Gerenciar configuração de rede de atividades

Gerenciar configuração de planos de processo de produção

Gerenciar configuração de recursos

Gerenciar configuração de software

\section{Indicar objetos relevantes para o controle da configuração}

Definir todos os objetos como relevantes para o controle da configuração

Permitir que objetos possam ser controlados individualmente, dependendo do pedido ou do cliente

\section{Definir número de série}

Definir número de série para o produto como um todo

Definir número de série para o nível de submontagem

Especificar as fases e os eventos nos quais a configuração é congelada e armazenada

Congelar configuração da proposta (As bid)

Congelar configuração projetada (As designed)

Congelar configuração planejada (As planned)

Congelar configuração vendida (As sold)

Congelar configuração produzida (As build)

Congelar configuração enviada (As shipped)

Congelar configuração da manutenção (As maintained)

Congelar configuração em fases e eventos definidos livremente

\section{Definir baselines}

Congelar uma configuração para definição do baselines

Gerar baselines a qualquer momento

Gerar baselines automaticamente na transição de fases do produto

Gerar baselines automaticamente em intervalos de tempo definidos

Indicar objetos que se encontram em alteração 
5.5.6.1 Comparar baseline com baseline

5.5.6.2 Comparar configuração atual do objeto com baseline

5.5.6.3 Comparar configuração atual de dois objetos

5.5 .7

5.5.7.1

5.5.7.2

5.5.7.3

5.5.7.4

6

6.1

6.1.1

6.1.1.1

6.1.1.2

6.1.1.3

6.1.1.4

6.1.1.5

6.1.1.6

6.1.1.7

6.1.1.8

6.1.1.9

6.1.2

6.1.2.1

6.1.2.2

6.1.2.3

6.1.2.4

6.1.2.5

6.1.2.6

6.1.2.7

6.1.2.8

6.1.2.9

6.1.3

6.1.3.1

6.1.3.2

6.1.3.3

6.1.3.4

6.1.3.5

6.1.3.6

6.1.4

6.1.4.1

6.1.4.2

6.1.4.3

6.1.5
Apoiar a aplicação de normas de gestão da configuração

Apoiar a aplicação da norma MIL-STD 2549

Apoiar a aplicação da norma EIA 649

Apoiar a aplicação da norma ISO 10007

Apoiar a aplicação da norma CMII

\section{Gestão de documentos}

Cadastro e armazenamento de documentos

\section{Cadastrar e identificar documento}

Cadastrar numero de identificação do documento (ID)

Cadastrar número de página

Cadastrar número de alteração de engenharia

Cadastrar versão

Cadastrar local de armazenamento

Cadastrar nome do arquivo

Cadastrar formato do arquivo

Cadastrar tamanho do arquivo eletrônico

Cadastrar informações em campos de dados livres

Descrever documento no cadastro mestre de documentos (metadados)

Especificar tipo do documento

Especificar nome do documento

Especificar descrição do documento

Especificar status do documento

Especificar autor do documento

Especificar data de criação do documento

Especificar a última pessoa que alterou o documento

Especificar última data de alteração

Especificar informações em campos de dados livres

Definir quais os parâmetros que são influenciados pelo tipo do documento

Definir tipo de numeração (automática / manual) a partir do tipo do documento

Definir faixa de números da numeração a partir do tipo do documento

Definir campos a serem preenchidos com metadados a partir do tipo do documento

Definir campos de dados adicionais a partir do tipo do documento

Definir rede de status a partir do tipo do documento

Definir forma de armazenamento a partir do tipo do documento

Gerar número de identificação do documento

Definir número de identificação manualmente

Gerar número de identificação seqüencial de forma automática

Gerar número de forma mista (parte automático / parte manual)

Definir forma de armazenamento 
6.1.5.1 Armazenar arquivos em base de dados

6.1.5.2 Armazenar arquivos em diretório seguro definido como "cofre eletrônico" (vault)

6.1.6

6.1.6.2

6.1.6.3

6.1.7

6.1.7.1

6.1.8

6.1.8.1

6.1.8.2

6.1.8.3

6.1.8.4

6.1.8.5

6.1.8.6

6.1.8.7

6.1.8.8

6.1.9

6.1.9.1

6.1.9.2

6.1.9.3

6.1.9.4

6.1.9.5

6.1.10

6.1.10.1

6.1.10.2

6.1.10.3

6.1.11

6.1.11.1

6.1.12

6.1.12.1

6.1.12.2

6.1.12.3

6.1.12.4

6.1.13

6.1.13.1

6.1.13.2

6.1.14

6.1.14.1

6.1.15

\section{Armazenar documento no sistema}

Armazenar documento por meio de função check-in

Obter cópia do documento por meio de função check-out

Restringir alteração em documento obtido por check-out

\section{Relacionar documentos com metadados}

Relacionar documentos individuais com seus metadados correspondentes

Relacionar documentos combinados de vários documentos com seus respectivos metadados (metadados individuais para cada documento e para o documento combinado)

\section{Relacionar documentos com objetos do sistema}

Relacionar documentos com objetos da estrutura de produtos

Relacionar documentos com posto de trabalho

Relacionar documentos com recurso de produção

Relacionar documentos com dados de clientes

Relacionar documentos com pedidos de clientes

Relacionar documentos com projetos

Relacionar documentos com pedidos e ordens de mudança de engenharia

Relacionar documentos com outros documentos

Definir opções do relacionamento de documentos com objetos do sistema

Definir relacionamento 1:1 entre documentos e objetos

Definir relacionamento n:1 entre documentos e objetos

Definir relacionamento 1:n entre documentos e objetos

Impedir relacionamento de documento com objeto

Visualizar todos os relacionamentos de um documento (where-used)

Definir estruturas de documentos

Definir relacionamento simples entre documentos

Definir relacionamento hierárquico entre documentos

Visualizar a hierarquia de documentos de forma gráfica

\section{Classificar documentos}

Classificar documentos com auxílio do grupo de funcionalidades de classificação do PLM

\section{Buscar documentos}

Buscar documentos por metadados

Buscar documentos pelo relacionamentos com objetos

Buscar documentos com auxílio do sistema de classificação

Buscar texto em documentos

Definir inter-dependência entre status do documento e gestão de mudanças

Definir possibilidades de mudanças no documento pelo status

Alterar status a partir de funções da gestão de mudanças

Criar documentos a partir de templates

Criar novos documentos no sistema a partir de templates armazenados no PLM

Gerenciar o histórico de documentos 
6.1.15.1 Protocolar mudanças de status e de versões

6.2 Visualização de documentos

6.2.1 Visualizar documentos

6.2.1.1

Visualizar documentos do formato BMP

6.2.1.2

Visualizar documentos do formato TIFF

6.2.1.3

Visualizar documentos do formato GIF

6.2.1.4

Visualizar documentos do formato JPEG

6.2.1.5

Visualizar documentos do formato PDF

6.2.1.6

Visualizar documentos do formato HPGL

6.2.1.7

6.2.1.8

Visualizar documentos do formato Postscript

6.2.1.9

Visualizar documentos do formato CGM

6.2.1.10

Visualizar documentos do formato SGML

6.2.2

6.2.2.1

Visualizar documentos do formato VRML

6.2.2.2

6.2.2.3

6.2.2.4

6.2.3

6.2.3.1

Alterar visualização entre diferentes visões de um material

6.2.3.2

Visualizar desenho 2D

Visualizar modelo 3D wire frame

Visualizar modelo 3D sólido transparente

Visualizar modelo 3D sólido

6.2.3.3

6.2.3.4

Executar operações de visualização

6.2.3.5

Visualizar figuras e desenhos

Definir thumbnails

Aplicar zoom

Girar

6.2.3.6

Mover

6.2.3.7

Redefinir posição original de um objeto

6.2.3.8

Mostrar / ocultar itens específicos

Definir massa

6.2.3.9

Explodir visão de montagem

6.2.3.10

Aplicar comentário com redlining

6.2.3.11 Aplicar markup

6.2.3.12

Gravar animação de movimentação de objetos

6.2.4

Escrever comentários com redlining

6.2.4.1

Exibir e ocultar comentários

6.2.4.2

Escrever e exibir comentários diferenciados por usuário

6.2.4.3

Exibir as camadas de comentários de acordo com o perfil do usuário

6.2.5

6.2.5.1

Utilizar DMU (Digital Mock-up) integrado com PLM

6.2.5.2

Sincronizar os objetos selecionados no browser da estrutura de produto com a exibição do DMU

6.2.6

Exibir os objetos na visão do DMU com diferenciação de cores pelo status no PLM

6.2.6.1

Utilizar funções de colaboração com a visualização

6.2.6.2

Comunicar com outras pessoas em tempo real ao visualizar objeto

Selecionar papel específico na seção de colaboração dentro dos papéis disponíveis 
6.2.7

6.2.7.1

6.2.7.2

6.2.7.3

6.2.8

6.2.8.1

6.2.8.2

6.2.8.3

6.2.8.4

6.2.8.5

6.2.8.7

\section{3}

6.3.1

6.3.1.1

6.3.1.3

6.3.1.4

6.3.1.5

6.3.2

6.3.3

6.3.4

6.3.4.8

\section{Selecionar papel para a seção de colaboração}

Selecionar papel de Mediador (autorizado a gravar o arquivo com os comentários ao término da seção)

Selecionar papel de Apresentador (pode mudar exibição do objeto ao longo da seção)

Selecionar para de Convidado (pode visualizar a seção, mas não tem influência sobre ela)

Aplicar funções para melhorar a qualidade da imagem de documentos

Reposicionar

Controlar brilho

Remover pontos

Remover bordas

Controlar contraste

Remover linhas

Controlar intensidade de cores

Aplicar outros funções para melhorar a qualidade da imagem

Publicação de documentação técnica

Preparar documentação técnica relacionada com o produto

Preparar manual de operação

Preparar documentação de projeto

Preparar documentação de desenvolvimento

Preparar manual de aplicação

Preparar manual de utilização

Preparar manual de manutenção

Definir relacionamento entre módulos parametrizados da documentação com objetos do sistema

Relacionar módulos da documentação com pedidos de clientes

Relacionar módulos da documentação com configuração variante do produto

Relacionar módulos da documentação aos materiais (cada material tem sua documentação que é sumarizada na documentação do produto que utiliza os materiais)

Relacionar os objetos de documentação hierarquicamente

Exibir os relacionamentos entre produtos, estrutura de documentos e idiomas disponíveis

Selecionar formato da documentação

Selecionar documento em papel

Selecionar documento digital

Selecionar documento online

Selecionar idioma para preparação da documentação

Selecionar idioma alemão

Selecionar idioma inglês

Selecionar idioma francês

Selecionar idioma espanhol

Selecionar idioma português

Selecionar idioma italiano

Selecionar idioma sueco

Selecionar idioma polonês 


$\begin{array}{ll}\text { 6.3.4.9 } & \text { Selecionar idioma holandês } \\ \text { 6.3.4.10 } & \text { Selecionar idioma dinamarquês } \\ \text { 6.3.4.11 } & \text { Selecionar idioma finlandês } \\ \text { 6.3.4.12 } & \text { Selecionar idioma eslovaco } \\ \text { 6.3.4.13 } & \text { Selecionar idioma tcheco } \\ \text { 6.3.4.14 } & \text { Selecionar idioma húngaro } \\ \text { 6.3.4.15 } & \text { Selecionar idioma grego } \\ \text { 6.3.4.16 } & \text { Selecionar idioma turco } \\ \text { 6.3.4.17 } & \text { Selecionar outros idiomas }\end{array}$

Definir formato de dados como PDF

Definir formato de dados como CALS

Definir formato de dados como IGES

Definir formato de dados como DXF

Definir formato de dados como TIFF

\section{Especificar o método de arquivamento}

6.4.2.2

Especificar arquivamento por transferência de arquivo diretamente para arquivo

\section{Aplicar métodos de qualidade}

Aplicar documentação da PAPP (Production Part Approval Process), da APQP (Advanced Product Quality Planning), da norma QS-9000

Aplicar controle estatístico do processo

\section{Preparar manual eletrônico de qualidade}

Preparar manual eletrônico de qualidade

Publicar manual eletrônico de qualidade na Intranet

Definir atributos de controle

Descrever procedimento para controlar atributo

Definir atributos de controle e procedimentos de controle genéricos no sistema independentes do material

\section{Gerenciar meios de medição}

Cadastrar meios de medição em banco de dados específico

Especificar data da última calibração e da próxima calibração

Registrar utilização dos meios de medição

Registrar automaticamente histórico dos meios de medição 
7.2.3.1

7.2.3.2

7.3

7.3.1

7.3.1.1

7.3.1.2

7.3.1.3

7.4

7.4.1

7.4.1.1

7.4.1.2

7.4.1.3

7.4 .2

7.4.2.2

7.4.2.3

\section{8}

8.1

8.1.1

8.1.1.1

8.1.1.2

8.1.1.3

8.1.1.4

8.1.1.5

8.1.1.6

8.1.1.7

8.1.2

8.1.2.1

8.1.2.2

8.1.3

8.1.3.1

8.1.3.2

8.1.3.3

8.1.3.4

8.1.3.5

8.1.3.6

8.2

8.2.1

8.2.1.1

8.2.1.2

8.2.1.3

8.2.2

Definir fórmulas de cálculo de amostras

Calcular amostra de controle dependendo do tamanho do lote de produção

Controle da qualidade

Registrar resultados dos controles de qualidade

Entrar dados dos resultados

Entrar dados de erros de qualidade predefinidos

Definir continuidade da utilização (ou não) da amostra testada

Auditorias de qualidade

Planejar auditorias

Programar datas de auditorias

Definir responsáveis pela auditoria

Preparar guia de entrevista / questionário

\section{Realizar auditorias}

Avaliar área / processo auditado em relação ao questionário

Especificar ações corretivas

Preparar relatórios com base em templates predefinidos

\section{Gestão do meio ambiente e segurança do trabalho}

Catálogo de materiais controlados

Criar dados mestres do catálogo de substâncias controladas

Definir identificação da substância

Descrever substância

Descrever características da substância

Selecionar símbolo

Registrar fórmula

Relacionar substância com material

Gerenciar substâncias sem relacionamento com materiais na base de dados

\section{Gerenciar listas de substâncias controladas}

Definir lista de substâncias controladas no sistema

Importar dados de listas de substâncias controladas definidas pela legislação

Definir procedimentos de operação com substâncias controladas

Definir procedimentos de segurança

Definir regras para embalagem

Definir procedimentos de transporte

Definir plano de contingência em caso de acidente

Definir regras de descarte

Relacionar procedimentos padrão com mais de uma substância

Acompanhamento de materiais controlados

Gerar documentação para utilização de substâncias controladas

Gerar documentação necessária (autorizações, transporte etc.)

Enviar documentação de substâncias controladas eletronicamente

Autorizar utilização de substâncias controladas eletronicamente

Gerar relatórios sobre a utilização de substâncias controladas 
8.2.2.1 Definir layout e conteúdo dos relatórios

8.2.2.2 Utilizar templates para gerar relatórios

8.3 Gestão de resíduos

8.3.1 Notificar geração de resíduo

8.3.1.1 Entrar dados de tipo e quantidade de resíduo manualmente

8.3.1.2 Calcular tipo e quantidade de resíduo automaticamente a partir de parâmetros do processo

8.3.2 Realizar disposição final

8.3.2.1 Preparar documentação de transporte e de disposição final

8.3.2.2 Registrar realização da disposição final

8.4 Segurança do trabalho

8.4.1 Controlar procedimentos de segurança do trabalho

8.4.1.1 Gerar procedimentos de trabalho

8.4.2

Protocolar eventos relevantes de segurança do trabalho

8.4.2.2

8.4.2.3

\section{9}

9.1

9.1.1

9.1.1.1

Protocolar nível de carga de trabalho

Protocolar exames médicos

9.1.1.2

9.1.1.3

Protocolar eventos no posto de trabalho (e.g. acidentes)

9.1.1.4

9.1.1.5

9.1.1.6

9.1.1.7

9.1.2

9.1.2.1

Serviços e manutenção

Planejamento da manutenção

Gerar informações de manutenção no sistema e disponibilizar para consulta por prestadores de serviço internos e externos

9.1.2.2

Disponibilizar manuais técnicos de serviços

9.1.2.3

Disponibilizar desenhos 2D

9.1.2.4

9.1.3

Disponibilizar dados da configuração atual dos produtos

Disponibilizar planos de manutenção

Disponibilizar planos de substituição de peças

Disponibilizar informações técnicas sobre todos os materiais

Disponibilizar animações em 3D sobre a manutenção

Configurar banco de dados de recursos de manutenção

Relacionar recursos com grupo de recursos em uma hierarquia

Definir turno de trabalho diferenciado por recurso

Definir custo padrão de utilização do recurso

Buscar recurso pelo perfil

9.1.3.1

\section{Gerar ordens de manutenção}

9.1.4

Gerar ordem de manutenção por pedido de cliente

Gerar ordem de manutenção automaticamente com base em um plano de manutenção e um contrato de manutenção

Gerenciar ocupação dos recursos de manutenção

9.1.4.2

Planejar utilização dos recursos de manutenção no sistema

Buscar recursos com capacidade disponível

9.1.5

9.1.5.1

Registrar indicadores de manutenção por produto e/ou por cliente

9.1.5.2

Registrar indicadores de nível de disponibilidade do produto para o cliente

9.1.5.3

Registrar indicadores do tempo de manutenção

Registrar indicadores dos intervalos de manutenção 
9.2

9.2.1

9.2.1.1

9.2.1.2

9.2.1.3

9.2.1.4

9.2.2

9.2.2.1

9.2.3

9.2.3.1

9.2.3.2

9.2.4

9.2.4.1

9.2.4.2

9.2.4.3

\section{0}

10.1

10.1.1

10.1.1.1

10.1.1.2

10.1.1.3

10.1.1.4

10.1.1.5

10.1.2

10.1.2.1

10.1.2.

10.1.2.3

10.1.2.4

10.1.2.5

10.1.3

10.1.3.1

10.1.3.2

10.1.4

10.1.4.1

10.1.4.2

10.1.4.3

10.1.5

10.1.5.1

10.1.5.2

10.1.5.3

10.1.5.4

Execução da manutenção

\section{Executar a manutenção}

Acessar planos de trabalho de manutenção (acesso externo)

Acessar catálogo de peças de reposição (acesso externo)

Verificar disponibilidade das peças de reposição

Solicitar peças de reposição

\section{Registrar alterações na configuração dos produtos}

Registrar todas as alterações na configuração com as funcionalidades de gestão da configuração

\section{Registrar conclusão das ordens de manutenção}

Registrar dados reais de utilização dos recursos

Registrar peças de reposição utilizadas

\section{Registrar conhecimentos e experiências geradas na manutenção}

Classificar ordens de manutenção

Descrever a solução adotada

Marcar ocorrência de novo problema desconhecido previamente

\section{Planejamento para a produção}

\section{Cadastro de recursos de produção}

\section{Criar cadastro de recursos de diferentes tipos}

Criar cadastro de máquinas

Criar cadastro de linhas de produção

Criar cadastro de postos de trabalho de montagem

Criar cadastro de meios de produção

Criar cadastro de pessoal

\section{Descrever recursos com base em características}

Descrever área organizacional

Descrever características técnicas (tolerâncias, velocidades, tamanhos, entre outras)

Descrever dados de capacidades (tipos de operações, tempo de preparação, disponibilidade)

Descrever custo padrão

Definir centro de custos

\section{Inter-relacionar recursos}

Inter-relacionar recursos com recursos

Inter-relacionar recursos com pessoal

\section{Agrupar recursos}

Agrupar recursos hierarquicamente

Agrupar recursos hierarquicamente - quantidade ilimitada de níveis hierárquicos

Agrupar recursos em mais de uma hierarquia

\section{Obter sugestão de recursos alternativos de acordo com parâmetros}

Obter sugestão de recursos alternativos de acordo com tamanho do lote

Obter sugestão de recursos alternativos de acordo com matéria prima

Obter sugestão de recursos alternativos de acordo com custos

Obter sugestão de recursos alternativos de acordo com uso da capacidade 
10.1.5.5

10.1.5.6

10.2

10.2.1

10.2.1.1

10.2.1.2

10.2.1.3

10.2.1.4

10.2.1.5

10.2.1.6

10.2.1.7

10.2.1.8

10.2.2

10.2.2.1

10.2.2.2

10.2.2.3

10.2.2. 4

10.2.2.5

10.2.2.6

10.2.3

10.2.3.1

10.2.3.2

10.2.3.3

10.2.3.4

10.2.4

10.2.4.1

10.2.4.2

10.2.5

10.2.5.1

10.2.5.2

10.2.5.3

10.2.6

10.2.6.1

10.2.6.2

10.2.6.3

10.2.6.4

10.2.6.5

10.2.7

10.2.7.1

10.2.7.2

10.2 .8

Obter sugestão de recursos alternativos de acordo com entrada em produção / término da produção

Obter sugestão de recursos alternativos em caso de problemas com recurso original

\section{Planejamento do processo de fabricação}

Definir tipos de planos de processo

Utilizar planos de processo de produção

Utilizar planos de processo de produção externa

Utilizar planos de processo de montagem

Utilizar planos de processo de variantes

Utilizar planos de controle de qualidade

Utilizar planos de processo de embalagem

Utilizar planos de processo de manutenção

Utilizar planos de processo de estimativa de custos

Diferenciar tipos de atividades nos planos de processo

Diferenciar atividades de processamento

Diferenciar atividades de setup

Diferenciar atividades externas (terceiros)

Diferenciar atividades de transporte

Diferenciar atividades de inspeção

Diferenciar atividades de manutenção

\section{Gerar planos de processo}

Copiar um plano de processo padrão

Copiar um plano de processo de um pedido específico

Copiar atividades de um plano de processo de um pedido

Utilizar atividades padrão

\section{Gerenciar planos de processo padrão e atividades padrão}

Bloquear atualizações nos planos de processo devido a uma alteração no padrão original Alterar automaticamente todos os planos de processo gerados a partir de planos ou de atividades alteradas

\section{Definir a seqüência de atividades}

Definir a seqüência de atividades padrão

Definir seqüência de atividades alternativas

Definir seqüência de atividades paralelas

\section{Relacionar objetos com as atividades do plano de processo}

Relacionar recursos com as atividades dos planos de processo

Relacionar pessoal com as atividades dos planos de processo

Relacionar programas NC com as atividades dos planos de processo

Relacionar materiais com as atividades dos planos de processo

Relacionar documentos com as atividades dos planos de processo

Relacionar múltiplos recursos com uma atividade do plano de processo

Relacionar até 4 recursos com uma atividade dos planos de processo

Relacionar quantidade ilimitada de recursos com uma atividade dos planos de processo

Relacionar materiais diretamente com os planos de processo 
10.2.8.1 Relacionar materiais com atividades

10.2.8.2 Relacionar materiais com planos de processo

10.2.8.3 Relacionar materiais que não pertencem a estruturas de produto com planos de processo

Obter sugestão de recursos automaticamente com base em características técnicas

10.2.10

Calcular tempo de processamento com base em fórmulas e características

10.2.10.1

Checar resultado do plano de processo

10.2.10.2

Verificar lista dos planos de processo incorretos / inválidos

10.2.10.3

Verificar falta de recursos em planos de processo

10.2.11

Verificar lista de materiais incorretos / inválidos atribuídos a planos de processo

10.2.11.1

Criar e gerenciar planos de processo e atividades alternativas

Relacionar plano de processo alternativo com cadastro mestre do material

10.2.11.2

Relacionar plano de processo alternativo com a estrutura de produto

10.2.11.3

Relacionar plano de processo alternativo com o plano de processo principal

10.2.11.4

Relacionar atividades alternativas com atividades do plano de processo

10.2.12

10.2.12.1

Selecionar planos de processo e atividades alternativas de acordo com critérios

10.2.12.2

Selecionar planos de processo e atividades alternativas de acordo com tamanho do lote

10.2.12.3

10.2.12.4

10.2.12.5

10.2.12.6

10.2.13

10.2.13.1 Selecionar planos de processo e atividades alternativas de acordo com matéria prima Selecionar planos de processo e atividades alternativas de acordo com custos Selecionar planos de processo e atividades alternativas de acordo com utilização da capacidade

Selecionar planos de processo e atividades alternativas de acordo com ciclo de vida (e.g. data, número de série)

10.2.13.2

10.2.13.3

10.2.14

10.2.14.1

10.3

10.3.1

10.3.1.1 Selecionar planos de processo e atividades alternativas de acordo com programação de manutenção

\section{Criar planos de processo variantes}

Criar novo plano de processo para cada produto variante

Criar plano de processo genérico máximo (para todos os casos) e selecionar operações necessárias de acordo com os atributos do produto variante

Gerar plano de processo automaticamente para produto variante

10.3.1.2

10.3.1.3

10.3.1.4

10.3.2

10.3.2.1

10.3.2.2

\section{Gerar programa NC para produto variante}

Gerar novo programa NC manualmente para cada variante

Planejamento da fábrica

\section{Definir layout}

Definir layout hierarquicamente (e.g. Fábrica, Linha, Segmento da linha)

Definir layout em uma seqüência

Possibilitar definição de seqüências paralelas e alternativas

Possibilitar definição de seqüência hierárquica e seqüencial para definir layout

\section{Apresentar layout}

Descrever graficamente o layout hierárquico

Descrever graficamente o layout seqüencial

10.3.3

10.3.3.1

Cadastrar dados que caracterizam uma linha de produção

Cadastrar produtividade 
10.3.3.2 Cadastrar o tempo Takt

11 Sourcing

11.1 Catálogo de componentes

11.1.1 Criar catálogo eletrônico de componentes

11.1.1.1 Criar catálogo de componentes por meio de cadastro

11.1.1.2 Criar catálogo de componentes por meio de importação de dados de meio eletrônico de informação do fornecedor (e.g. CD)

11.1.1.3 Acessar catálogos de componentes via Internet ou em mercados eletrônicos

11.1.2

11.1.2.1

11.1.2.2

11.1.3

11.1.3.1

11.1.3.2

11.1.3.3

11.1.4

11.1.4.1

11.1.4.2

11.1.4.3

11.1.4.4

11.1.4.5

11.1.4.6

11.2

11.2.1

11.2.1.1

11.2.1.2

11.2.1.3

11.2.2

11.2.2.1

11.2.2.2

11.2.3

11.2.3.1

11.2.3.2

11.2.3.3

11.2.3.4

11.2.3.5

11.2.3.6

11.2.4

11.2.4.1

11.2.4.2

11.2.4.3

\section{Conectar catálogos eletrônicos na internet com o PLM}

Estabelecer link direto do cadastro mestre de materiais do PLM com base de dados de componentes na internet - componentes são atualizados automaticamente

Carregar dados de componentes no formato XML no sistema PLM

Especificar os dados de componentes que são carregados de catálogos na internet para o sistema PLM

Obter dados de parâmetros técnicos dos componentes da internet para o PLM

Obter informações comerciais dos componentes da internet para o PLM

Obter dados modelo geométrico dos componentes da internet para o PLM

Gerenciar dados do cadastro mestre de materiais de forma diferenciada por fornecedor

Diferenciar o número do material e a descrição por fornecedor

Diferenciar tempo de entrega por fornecedor

Diferenciar tempo de entrega dependente da quantidade pedida por fornecedor

Diferenciar tamanho do pedido padrão por fornecedor

Diferenciar tabela de preços por fornecedor

Diferenciar material alternativo do fornecedor por fornecedor

Gestão de fornecedores

Cadastrar dados mestres de fornecedores

Cadastrar dados de contato de fornecedores

Cadastrar a oferta de produtos e de serviços

Cadastrar avaliação do fornecedor

Avaliar fornecedores

Avaliar fornecedores por critérios gerais do fornecedor

Avaliar fornecedores por critérios relacionados aos itens fornecidos

Selecionar critérios para avaliação de fornecedores

Selecionar critério qualidade do produto

Selecionar critério pontualidade das entregas

Selecionar critério assertividade das quantidades entregues

Selecionar critério preço

Selecionar critério condições especiais

Definir peso dos critérios

\section{Selecionar critérios para avaliação dos itens fornecidos}

Selecionar critério qualidade do produto

Selecionar critério pontualidade das entregas

Selecionar critério assertividade das quantidades entregues 
11.2.4.4 Selecionar critério preço

11.2.4.5 Selecionar critério atendimento de condições especiais

11.2.4.6 Definir peso dos critérios

11.2.5

11.2.5.1

11.2.5.2

11.2.5.3

11.2.5.4

11.2.6

11.2.6.1

11.2.6.2

11.3

11.3.1

11.3.1.1

11.3.1.2

11.3.1.3

11.3.2

11.3.2.1

11.3.3

11.3.3.1

11.3.3.2

11.3.4

11.3.4.1

11.3.4.2

\section{2}

12.1

12.1.1

12.1.1.2

12.1.2

12.1.2.1

12.1.2.3

12.1.3

12.1.3.1

12.1.3.2

12.1.4

12.1.4.1

12.1.4.2

12.1.4.3

12.1.4.4

12.1.5

\section{Analisar os custos de sourcing}

Analisar custos de sourcing por fornecedor

Analisar custos de sourcing por produto

Analisar custos de sourcing por região

Analisar custos de sourcing por outros critérios

\section{Reajustar tabela de preços de fornecedores}

Reajustar tabela de preços percentualmente com delimitação por produto

Reajustar tabela de preços percentualmente com delimitação por fornecedor eSourcing

\section{Elaborar RFPs (Request for Proposals)}

Elaborar RFPs utilizando formulários padronizados do sistema

Enviar RFPs eletronicamente para fornecedores selecionados

Obter respostas de RFPs eletronicamente - fornecedores respondem em formulário eletrônico

\section{Executar processos de compras}

Realizar leilões eletrônicos

\section{Selecionar fornecedores}

Selecionar fornecedores manualmente a partir de uma lista proposta

Selecionar fornecedores automaticamente considerando regras de avaliação

Documentar os resultados do processo de compras

Documentar as condições de fornecimento no cadastro mestre de fornecedores

Documentar cotas por fornecedor

\section{Colaboração e gestão do conhecimento}

Comunicação e trabalho em equipe

Especificar o tipo de calendário

Utilizar calendário individual

Utilizar calendário em grupo

\section{Agendar compromissos e reuniões}

Agendar compromissos automaticamente para as atividades do workflow

Classificar os compromissos (cliente, projeto)

Notificar usuários com antecedência sobre compromissos

\section{Planejar reuniões}

Reservar salas

Reservar recursos e equipamentos

\section{Criar grupos de usuários}

Criar grupos por área na organização

Criar grupos por qualificação

Criar grupos por projetos

Criar grupos específicos para uma finalidade

Gerenciar dados de contatos externos 
12.1.5.1 Gerenciar dados de contatos individuais

12.1.5.2 Gerenciar dados de contatos centrais

12.1.6 Organizar grupos de discussão

12.1.6.1 Criar grupos de discussão

12.1.6.2 Relacionar grupos de discussão com produtos, projetos, materiais ou documento

12.1.7 Enviar notificações automáticas

12.1.7.1 Notificar usuário na aprovação de uma mudança

12.1.7.2 Notificar usuário na mudança de versões

12.1.7.3 Notificar usuário na mudança de status

12.1.7.4 Notificar usuário na liberação de um objeto

12.1.7.5 Notificar usuário sobre eventos críticos (e.g. atraso em uma atividade)

12.1.7.6 Notificar usuários externos por e-mail

12.1.8

12.1.8.1

12.1.8.2

12.1.8.3

12.1.8.4

12.2

12.2.1

12.2.1.1

12.2.1.2

12.2.1.3

12.2.2

12.2.2.1

12.2.2.2

\section{Utilizar ferramentas de colaboração em tempo real}

Colaborar utilizando whiteboard compartilhado

Colaborar com compartilhamento de aplicativos de escritório

Colaborar com compartilhamento de aplicativos CAD

Utilizar vídeo conferência

Workflow

Programar fluxos de trabalho

Programar fluxos de trabalho por meio de linguagem de programação

Programar fluxo de trabalho por meio de tabela

Programar fluxo de trabalho graficamente

\section{Definir um fluxo de trabalho}

Definir seqüência de atividades

Definir subdivisões no fluxo

12.2.2.3 Definir atividades paralelas

12.2.2.4 Informar restrições de prazo

12.2.2.5 Especificar mudança de status relacionado com fluxo do processo

12.2.2.6 Informar eventos que exigem notificação dos usuários

12.2.2.7 Considerar usuários externos na programação do workflow

12.2 .3

12.2.3.1

12.2.3.2

12.2.3.3

12.2.4

12.2.4.1

12.2.4.2

12.2.4.3

12.2.4.4

12.2.4.5

12.2.5

12.2.5.1

\section{Atribuir responsáveis pelas atividades de um fluxo de trabalho}

Relacionar papéis de usuários com atividades do fluxo de trabalho Relacionar grupos de usuários com atividades do fluxo de trabalho Relacionar usuários específicos com atividades do fluxo de trabalho

\section{Utilizar fluxos de trabalho definidos como template no sistema}

Utilizar template de fluxo de trabalho para pedido de mudança de engenharia Utilizar template de fluxo de trabalho para ordem de mudança de engenharia Utilizar template de fluxo de trabalho para avaliação e aprovação Utilizar template de fluxo de trabalho para liberação Especificar fluxo de trabalho livremente e armazenar como template no sistema

\section{Relacionar objetos com as atividades do fluxo de trabalho}

Relacionar documentos genéricos (e.g. MS-Word) com atividades do fluxo de trabalho 
12.2.5.2

12.2.5.3

12.2.6

12.2.6.1

12.2.6.2

12.2.7

12.2.7.1

12.2.7.4

12.2.7.5

12.2.8

12.2.8.1

12.2.8.2

12.2.8.3

12.3

12.3.1

12.3.2

12.3.2.1

12.3.2.2

12.3.3.1

12.4

12.4.1

12.4.1.1

12.4.1.2

12.4.1.3
Relacionar documentos gerenciados pelo PLM (módulo gestão de documentos) com atividades do fluxo de trabalho

Relacionar objetos gerenciados pelo PLM (e.g. material) com atividades do fluxo de trabalho Definir forma de alocação dos objetos ao fluxo de trabalho

Alocar múltiplos objetos a um fluxo de trabalho

Alocar novos objetos ao fluxo de trabalho durante a sua execução

\section{Executar fluxo de trabalho}

Informar restrições de tempo por atividade do fluxo de trabalho

Estornar atividades realizadas

Utilizar aplicativos externos para tratar objetos do fluxo de trabalho (e.g. MS-Office, CAD)

Notificar usuários sobre atividades atrasadas

Protocolar a execução de cada atividade do fluxo de trabalho

\section{Monitorar execução do fluxo de trabalho}

Verificar tempos - espera, execução, processo completo

Identificar a posição atual (atividade e responsável) do fluxo de trabalho

Parar e estornar atividades realizadas no fluxo de trabalho

\section{Gestão do conhecimento} buscas

Armazenar informações sobre a experiência e as competências dos funcionários e realizar Armazenar currículo em um banco de dados corporativo

Configurar campos de dados livre para a descrição do perfil dos funcionários

Entrar dados de experiência em projetos

Entrar dados das competências técnicas

Buscar funcionários com características específicas

Armazenar e recuperar conhecimentos da empresa

Criar banco de dados de problemas e de soluções

Criar banco de dados de best-practice

Criar banco de dados de lições aprendidas

Gerenciar conhecimentos não relacionados diretamente com produtos (e.g. normas, padrões, apresentações externas)

Armazenar objetos de conhecimento em um banco de dados

Anexar dados em diversos formatos (e.g. doc, pdf)

Classificar objetos de conhecimento de acordo com critérios definidos

Inserir comentários dos usuários sobre os objetos de conhecimento

Avaliar os objetos de conhecimento

Realizar buscas no banco de dados de conhecimentos

Realizar buscas por textos no banco de dados de conhecimentos

Controle de acesso aos dados

Permitir acesso de parceiros externos aos dados de projeto e/ou produto

Acessar dados de produto e/ou de projeto externamente por meio de um browser pela internet

Acessar dados de produto e/ou de projeto externamente por meio de um browser por uma extranet

Definir uma área específica de trabalho para cada parceiro no sistema 
12.4.2

12.4.2.1

12.4.2.2

12.4.3

12.4.3.1

12.4.3.2

12.4.3.3

12.4.3.4

12.4.3.5

12.4.4

12.4.4.1

12.4.4. 2

12.4.4.3

12.4.4.

12.4.4.5

12.4.4.6

12.4.4.7

12.4.4.8

12.4.4.9

12.4.4.10

12.4.4.11

\section{3}

13.1

13.1.1

13.1.1.1

13.1.1.2

13.1.1.3

13.1.1.4

13.1.2

13.1.2.1

13.1.2.2

13.1.2.3

13.2

13.2.1

13.2.1.1

13.2.1.2

13.2.1.3

13.2.1.4

13.2.2

13.2.2.1

13.2.2.2

13.2.2.3
Realizar troca de dados entre localidades (filiais) da empresa

Gerenciar dados em banco de dados central

Replicar dados em múltiplas localidades

\section{Acessar objetos do sistema via internet}

Acessar dados de materiais via internet

Acessar estruturas de produto via internet

Acessar documentos via internet

Acessar estruturas de projeto via internet

Acessar redes de atividades via internet

Colaborar com parceiros externos por meio da internet

Acessar plano de projeto

Atualizar o status de atividades de um projeto

Atualizar planos de projeto

Acessar estruturas de produto

Gerar cadastro mestre de materiais

Completar cadastro mestre de materiais

Alterar estruturas de produto

Gerar metadados de documentos

Realizar check-in de documentos

Acessar documentos armazenados no sistema

Realizar comentários com redline

\section{Integração e gestão do sistema}

Padrões de integração

Utilizar padrões de integração disponíveis

Utilizar Java 2 Enterprise Edition

Utilizar Microsoft .NET Framework

Utilizar XML

Utilizar OLE (Object Linking and Embedding)

Utilizar padrões de modelagem geométrica para CAD

Utilizar IGES

Utilizar STEP

Utilizar JT

Integração com CAD

Selecionar padrão para a troca de dados com sistemas CAD

Selecionar STEP

Selecionar PDX (Product Definition eXchange)

Selecionar PDML (Product Data Markup Language)

Selecionar PDM Enablers

Selecionar formato de troca de dados com sistemas CAD

Selecionar formato como Text File

Selecionar formato como XML

Selecionar formato como ENGDAT 
13.2.3

13.2.3.1

13.2.3.2

13.2.4

13.2.4.1

13.2.4.2

13.2.4.3

13.2.5

13.2.5.1

13.2.5.2

13.2.5.3

13.2.5.4

13.2.6

13.2.6.1

13.2.6.2

13.2.6.3

13.2.6.4

13.2.6.5

13.2.6.6

13.2.6.7

13.2.7

13.2.7.1

13.2.8

13.2.8.1

13.2.8.2

13.2.8.3

13.2.8.4

13.2.8.5

13.2.8.6

13.2.8.7

13.2.8.8

13.2.8.9

13.3

13.3.1

13.3.1.1

13.3.1.2

13.3.2

13.3.2.1

13.3.2.2

13.3.2.3

13.3.3
Definir forma (temporal) de troca de dados com sistemas CAD

Definir troca de dados assíncrona

Definir troca de dados síncrona

Definir tipo de interface com sistemas CAD

Utilizar interface API (Application Programming Interface)

Realizar integração com software de middleware

Realizar integração por meio de banco de dados comum entre os sistemas

Definir quais os dados de produto são importados do CAD para o PLM

Importar dados do cadastro mestre de materiais do CAD para o PLM

Importar dados de estruturas de produto do CAD para o PLM

Importar dados da gestão de variantes (estrutura variante e regras de configuração) do CAD para o PLM

Importar dados de classificação dos objetos do CAD para o PLM

Definir quais os dados de produto são exportados do PLM para o CAD

Exportar dados da identificação do material do PLM para o CAD

Exportar dados do cadastro mestre de materiais do PLM para o CAD

Exportar dados de versões e status do PLM para o CAD

Exportar dados da gestão de mudanças do PLM para o CAD

Exportar dados de estruturas de produto do PLM para o CAD

Exportar dados da gestão de variantes (estrutura variante e regras de configuração) do PLM para o CAD

Exportar dados de classificação dos objetos do PLM para o CAD

Gerar arquivo de visualização a partir dos modelos de CAD

Gerar arquivo de visualização automaticamente após mudança do modelo no CAD

Realizar integração direta (apoiada no sistema padrão) com sistema CAD

Realizar integração direta com Autocad

Realizar integração direta com Catia

Realizar integração direta com I-DEAS

Realizar integração direta com Medusa

Realizar integração direta com Pro/Engineer

Realizar integração direta com Solid Works

Realizar integração direta com Solid Edge

Realizar integração direta com Unigraphics

Realizar integração direta com outros sistemas CAD

Integração com ERP

Definir forma (temporal) de troca de dados com sistemas ERP

Definir troca de dados assíncrona

Definir troca de dados síncrona

\section{Definir tipo de interface com sistemas ERP}

Utilizar interface API (Application Programming Interface)

Realizar integração com software de middleware

Realizar integração por meio de banco de dados comum entre os sistemas

Selecionar formato de troca de dados com sistemas ERP 
13.3.3.1 Selecionar formato como Text File

13.3.3.2 Selecionar formato como XML

13.3.4

13.3.5

\section{Definir quais os dados de produto são exportados do PLM para o ERP}

Exportar dados da identificação do material do PLM para o ERP

Exportar dados do cadastro mestre de materiais do PLM para o ERP

Exportar dados de versões e status do PLM para o ERP

Exportar dados da gestão de mudanças do PLM para o ERP

Exportar dados mestres de documentos do PLM para o ERP

Exportar dados de estruturas de produto do PLM para o ERP

Exportar dados da gestão de variantes (estrutura variante e regras de configuração) do PLM para o ERP

Exportar dados de classificação dos objetos do PLM para o ERP

Exportar dados de planos de processo de fabricação do PLM para o ERP

Exportar dados de planos de controle de qualidade do PLM para o ERP

Exportar dados da EAP e da rede de atividades de projeto do PLM para o ERP

Definir quais os dados de produto são importados do ERP para o PLM

Importar dados da identificação do material do ERP para o PLM

Importar dados do cadastro mestre de materiais do ERP para o PLM

Importar dados de versões e status do ERP para o PLM

Importar dados da gestão de mudanças do ERP para o PLM

Importar dados mestres de documentos do ERP para o PLM

Importar dados de estruturas de produto do ERP para o PLM

Importar dados da gestão de variantes (estrutura variante e regras de configuração) do ERP para o PLM

Importar dados de classificação dos objetos do ERP para o PLM

Importar dados de planos de processo de fabricação do ERP para o PLM

Importar dados de planos de controle de qualidade do ERP para o PLM

Importar dados da EAP e da rede de atividades de projeto do ERP para o PLM

Definir os eventos que desencadeiam uma ação de importação ou exportação de dados entre os sistemas

Importar / exportar dados após mudança de status

Importar / exportar dados após alteração de versão

Importar / exportar dados após liberação

\section{Realizar integração direta (apoiada no sistema padrão) com sistema ERP}

Realizar integração direta com Abas

Realizar integração direta com Bäurer

Realizar integração direta com Infor

Realizar integração direta com Navision

Realizar integração direta com Oracle Applications

Realizar integração direta com ProAlpha

Realizar integração direta com PSIPenta

Realizar integração direta com SAP

Realizar integração direta com SSA 
13.3.7.10

13.4

13.4.1

13.4.1.1

13.4.1.2

13.4.1.3

13.4.1.4

13.4.2

13.4.2.1

13.4.2.2

13.4.2.3

13.4.3

13.4.3.1

13.4.3.2

13.4.4

13.4.4.1

13.4.4. 2

13.4.4.3

13.4.5

13.4.5.1

13.4.5.2

13.4.5.3

13.4.5.4

13.4.5.5

13.4.5.6

13.4.5.7

13.4.5.8

13.4.5.9

13.4.5.10

13.4.5.11

13.4.5.12

13.4.6

13.4.6.1

13.4.6.2

13.4.6.3

13.4.6.4

13.4.6.5

13.4.6.6

13.4.6.7

13.4.6.8
Realizar integração direta com outros sistemas ERP

Integração com PDM / PLM

Selecionar padrão para a troca de dados com outros sistemas PDM/PLM

Selecionar STEP

Selecionar PDX (Product Definition eXchange)

Selecionar PDML (Product Data Markup Language)

Selecionar PDM Enablers

Selecionar formato de troca de dados com outros sistemas PDM/PLM

Selecionar formato como Text File

Selecionar formato como XML

Selecionar formato como ENGDAT (Engineering-Daten)

Definir forma (temporal) de troca de dados com outros sistemas PDM/PLM

Definir troca de dados assíncrona

Definir troca de dados síncrona

Definir tipo de interface com outros sistemas PDM/PLM

Utilizar interface API (Application Programming Interface)

Realizar integração com software de middleware

Realizar integração por meio de banco de dados comum entre os sistemas

Definir quais os dados de produto são exportados do PLM para outros PDM/PLM

Exportar dados da identificação do material do PLM para outros sistemas PLM

Exportar dados do cadastro mestre de materiais do PLM para outros sistemas PLM

Exportar dados de versões e status do PLM para outros sistemas PLM

Exportar dados da gestão de mudanças do PLM para outros sistemas PLM

Exportar documentos do PLM para outros sistemas PLM

Exportar dados mestres de documentos do PLM para outros sistemas PLM

Exportar dados de estruturas de produto do PLM para outros sistemas PLM

Exportar dados da gestão de variantes (estrutura variante e regras de configuração) do PLM para outros sistemas PLM

Exportar dados de classificação dos objetos do PLM para outros sistemas PLM

Exportar dados de planos de processo de fabricação do PLM para outros sistemas PLM

Exportar dados de planos de controle de qualidade do PLM para outros sistemas PLM

Exportar dados da EAP e da rede de atividades de projeto do PLM para outros sistemas PLM

Definir quais os dados de produto são importados de outros PDM/PLM para o PLM

Importar dados da identificação do material de outros PDM/PLM para o PLM

Importar dados do cadastro mestre de materiais de outros PDM/PLM para o PLM

Importar dados de versões e status de outros PDM/PLM para o PLM

Importar dados da gestão de mudanças de outros PDM/PLM para o PLM

Importar documentos de outros PDM/PLM para o PLM

Importar dados mestres de documentos de outros PDM/PLM para o PLM

Importar dados de estruturas de produto de outros PDM/PLM para o PLM

Importar dados da gestão de variantes (estrutura variante e regras de configuração) de outros PDM/PLM para o PLM 
13.4.6.9

13.4.6.10

13.4.6.11

13.4.6.12

13.4.7

13.4.7.1

13.4.7.2

13.4.7.3

13.4.8

13.4.8.1

13.4.8.2

13.4.8.3

13.4.8.4

13.4.8.5

13.4.8.6

13.4.8.7

13.4.8.8

13.4.8.9

13.4.8.10

13.4.8.11

13.4.8.12

13.5

13.5.1

13.5.1.1

13.5.1.2

13.5.1.3

13.5.1.4

13.5.1.5

13.5.1.6

13.5. 2

13.5.2.1

13.5.2.2

13.5.2.3

13.5.3

13.5.3.1

13.5.3.2

13.5.4

13.5.4.1

13.5.4.2
Importar dados de classificação dos objetos de outros PDM/PLM para o PLM Importar dados de planos de processo de fabricação de outros PDM/PLM para o PLM Importar dados de planos de controle de qualidade de outros PDM/PLM para o PLM Importar dados da EAP e da rede de atividades de projeto de outros PDM/PLM para o PLM Definir os eventos que desencadeiam uma ação de importação ou exportação de dados entre os sistemas

Importar / exportar dados após mudança de status

Importar / exportar dados após alteração de versão

Importar / exportar dados após liberação

Realizar integração direta (apoiada no sistema padrão) com sistema PDM/PLM

Realizar integração direta com Agile

Realizar integração direta com Compass

Realizar integração direta com Enovia

Realizar integração direta com Smarteam

Realizar integração direta com MatrixOne

Realizar integração direta com Oracle PLM

Realizar integração direta com Windchill

Realizar integração direta com mySAP PLM

Realizar integração direta com PDM Works

Realizar integração direta com SSA PLM

Realizar integração direta com Teamcenter

Realizar integração direta com outros sistemas

Integração com sistemas de gestão de projetos

Definir quais os dados de projetos são exportados do PLM para sistemas de gestão de projetos

Exportar EAP do PLM para sistemas de gestão de projetos

Exportar redes de atividades do PLM para sistemas de gestão de projetos

Exportar milestones do PLM para sistemas de gestão de projetos

Exportar alocação de recursos do PLM para sistemas de gestão de projetos

Exportar orçamento do projeto do PLM para sistemas de gestão de projetos

Exportar acompanhamento de custos do projeto do PLM para sistemas de gestão de projetos

Definir para quais sistemas de gestão de projetos os dados serão exportados

Exportar dados de gestão de projetos para MS-Project

Exportar dados de gestão de projetos para Primavera

Exportar dados de gestão de projetos para outros sistemas

\section{Selecionar formato de exportação de dados}

Selecionar formato como Text File

Selecionar formato como XML

Selecionar formato proprietário do sistema de gestão de projetos (e.g. mpx do MS-Project)

Definir quais os dados de projetos são importados de sistemas de gestão de projetos para o PLM

Importar EAP de sistemas de gestão de projetos para o PLM

Importar redes de atividades de sistemas de gestão de projetos para o PLM 
13.5.4.3

13.5.4.4

13.5.4.6

13.5.4.7

13.5.5

13.6

13.6.1

13.6.1.1

13.6.2

13.6.2.1

13.6.2.2

13.6.2.3

13.6.3

13.6.3.1

13.6.3.2

13.6.3.3

13.6.4

13.6.4.1

13.6.4.2

13.6.4.4

13.6.5

13.6.5.1

13.6.5.3

13.6.6

13.6.6.1

13.6.6.2

13.6.6.3

13.6.6. 4

13.6.7
Importar milestones de sistemas de gestão de projetos para o PLM

Importar alocação de recursos de sistemas de gestão de projetos para o PLM

Importar orçamento do projeto de sistemas de gestão de projetos para o PLM

Importar acompanhamento da execução de atividades do projeto de sistemas de gestão de projetos para o PLM

Importar acompanhamento de custos do projeto de sistemas de gestão de projetos para o PLM

\section{Definir de quais sistemas de gestão de projetos os dados serão importados}

Importar dados de gestão de projetos do MS-Project

Importar dados de gestão de projetos do Primavera

Importar dados de gestão de projetos de outros sistemas

Gestão de usuários

Integrar diversos sistemas de autorização

Realizar login do PLM por meio do sistema de gestão de usuários (login único)

\section{Gerenciar acesso dos usuários}

Gerenciar acesso pelo usuário - define o direito de acesso de um usuário para objetos e funções

Gerenciar acesso dos objetos - define em quais condições um objeto ou função podem ser utilizados por usuários

Diferenciar direito de acesso de acordo com a localização do usuário por filial da empresa

\section{Agrupar usuários para definir direitos de acesso}

Definir direito de acesso por usuário

Definir direito de acesso por grupos de usuários

Definir direito de acesso por papel dos usuários

Relacionar um usuário com mais de um grupo ou papel

Definir regras de acesso para objetos específicos

Definir regras de acesso para planos de projeto

Definir regras de acesso para materiais

Definir regras de acesso para estruturas de produto

Definir regras de acesso para planos de processo de fabricação

Definir regras de acesso para planos de controle

Definir regras de acesso para documentos

\section{Especificar os parâmetros que definem os direitos de acesso de um objetos}

Diferenciar regras de acesso de acordo com autor do objeto

Diferenciar regras de acesso de acordo com o grupo ou papel do autor do objeto

Diferenciar regras de acesso de acordo com o status do objeto

Diferenciar regras de acesso de acordo com o projeto a que pertence o objeto

Definir diferentes níveis de acesso

Definir nível de acesso - sem permissão de acesso

Definir nível de acesso - somente leitura

Definir nível de acesso - alteração permitida

Definir nível de acesso - exclusão permitida

Definir exceções para as regras de acesso 
13.6.7.1 Criar listas especiais de regras de acesso com exceções

13.6.8

13.6.8.1

13.6.8.2

13.6.9

13.6.9.1

13.6.9.2

13.6.9.3

13.6.9.4

13.6.9.5

13.6.9.6

13.6.9.7

13.7

13.7.1

13.7.1.1

13.7.1.2

13.7.1.3

13.7.1.4

13.7.2

13.7.2.3

13.7.3

13.7.3.1

13.7.3.2
Especificar forma de protocolar ações dos usuários no sistema

$$
\text { Protocolar ações por dados }
$$

Protocolar ações por usuários

\section{Protocolar ações no sistema}

Protocolar tentativas de acesso

Protocolar acesso

Protocolar geração de dados

Protocolar impressão

Protocolar mudanças

Protocolar exclusão

Protocolar outras ações

Segurança de dados

\section{Armazenar senhas com segurança}

Armazenar senhas com criptografia

Utilizar regras para geração de senhas com nível mínimo de segurança (e.g. número mínimo de caracteres)

Restringir validade da senha por um período de tempo

Restringir renovação de senha por senha já utilizada anteriormente

\section{Permitir utilização de assinatura digital}

Exigir senha e um hardware (e.g. cartão) para entrada de assinatura digital

Utilizar assinatura digital em conformidade com as exigências de assinatura digital do FDA (Food and Drug Administration)

Utilizar assinatura digital em conformidade com as exigências de assinatura digital da legislação européia

\section{Garantir segurança dos dados na transmissão via internet}

Transmitir informações criptografadas via Internet

Utilizar HTTPS (Hypertext Transfer Protocol Secure) 


\section{APÊNDICE C - Modelo de referência da gestão do ciclo de vida de produtos com indicação das funcionalidades de PLM}

\begin{tabular}{|c|c|c|c|}
\hline Nível & $\begin{array}{l}\text { Processos / sub-processos / } \\
\text { atividades / procedimentos }\end{array}$ & $\begin{array}{c}\text { Código } \\
\text { func. } \\
\text { modelo } \\
\text { PLM }\end{array}$ & $\begin{array}{c}\text { Nome funcionalidade modelo } \\
\text { PLM }\end{array}$ \\
\hline Processo & $\begin{array}{l}\text { Planejamento estratégico de } \\
\text { produtos e planejamento do } \\
\text { projeto }\end{array}$ & & \\
\hline Sub-processo & $\begin{array}{l}\text { Planejamento Estratégico de } \\
\text { Produtos }\end{array}$ & & \\
\hline Atividade & $\begin{array}{l}\text { 1.1 Definir escopo da revisão do } \\
\text { Plano Estratégico de Negócios } \\
\text { (PEN) }\end{array}$ & & \\
\hline Procedimento & $\begin{array}{l}\text { Analisar o plano estratégico de } \\
\text { Negócios }\end{array}$ & & \\
\hline Procedimento & Listar assuntos a serem discutidos & & \\
\hline Procedimento & $\begin{array}{l}\text { Avaliar competências no time de } \\
\text { planejamento estratégico de produtos }\end{array}$ & & \\
\hline Procedimento & $\begin{array}{l}\text { Definir metodologia da } \\
\text { revisão/desenvolvimento do PEN }\end{array}$ & & \\
\hline Procedimento & Definir o prazo final & & \\
\hline Procedimento & $\begin{array}{l}\text { Compilar a declaração de escopo do } \\
\text { PEN }\end{array}$ & & \\
\hline Atividade & $\begin{array}{l}\text { 1.2 Planejar atividades para a } \\
\text { revisão do PEN }\end{array}$ & & \\
\hline Procedimento & Planejar atividades & & \\
\hline Procedimento & $\begin{array}{l}\text { Definir agendas de decisões e } \\
\text { discussões }\end{array}$ & & \\
\hline Procedimento & $\begin{array}{l}\text { Planejar os recursos físicos } \\
\text { necessários em cada reunião }\end{array}$ & & \\
\hline Procedimento & $\begin{array}{l}\text { Preparar plano de comunicação e de } \\
\text { riscos }\end{array}$ & & \\
\hline Atividade & $\begin{array}{l}\text { 1.3 Consolidar Informações sobre } \\
\text { tecnologia e mercado }\end{array}$ & & \\
\hline Procedimento & $\begin{array}{l}\text { Consolidar Informações de fontes de } \\
\text { dados secundárias }\end{array}$ & & \\
\hline Procedimento & $\begin{array}{l}\text { Identificar necessidade de dados } \\
\text { primários }\end{array}$ & & \\
\hline Procedimento & Planejar coleta de dados primários & & \\
\hline Procedimento & Consolidar informações & & \\
\hline Atividade & 1.4 Revisar o PEN & & \\
\hline Procedimento & Revisar Missão & & \\
\hline Procedimento & Revisar segmentação do mercado & & \\
\hline Procedimento & Revisar tendências tecnológicas & & \\
\hline Procedimento & Revisar posicionamento no mercado & & \\
\hline Procedimento & Revisar direcionamento da UM & & \\
\hline Procedimento & Revisar competências & & \\
\hline
\end{tabular}




\begin{tabular}{|c|c|c|c|}
\hline Procedimento & Revisar recursos necessários & & \\
\hline Procedimento & Revisar metas & & \\
\hline Procedimento & Preparar documento & & \\
\hline \multirow[t]{7}{*}{ Atividade } & \multirow{7}{*}{$\begin{array}{l}\text { 1.5 Analisar o Portfólio de } \\
\text { Produtos da Empresa }\end{array}$} & 1.1.1 & Criar portfólio de produtos \\
\hline & & 1.1.2 & Analisar portfólio de produtos \\
\hline & & 1.2.1 & Coletar idéias de produtos \\
\hline & & 1.2 .2 & Classificar idéias de produtos \\
\hline & & 1.2 .3 & Avaliar idéias de produtos \\
\hline & & 1.2 .4 & $\begin{array}{l}\text { Comparar idéias com uso de } \\
\text { gráficos }\end{array}$ \\
\hline & & 1.2 .5 & $\begin{array}{l}\text { Documentar resultado da } \\
\text { avaliação de idéias }\end{array}$ \\
\hline Procedimento & $\begin{array}{l}\text { Revisar/definir metodologia de } \\
\text { avaliação de portfólio }\end{array}$ & & \\
\hline Procedimento & $\begin{array}{l}\text { Avaliar o posicionamento dos } \\
\text { produtos }\end{array}$ & & \\
\hline Procedimento & Avaliar o desempenho dos produtos & & \\
\hline Procedimento & $\begin{array}{l}\text { Avaliar tecnologias e plataformas } \\
\text { utilizadas }\end{array}$ & & \\
\hline Procedimento & $\begin{array}{l}\text { Consolidar lista de idéias de novos } \\
\text { produtos }\end{array}$ & & \\
\hline Procedimento & Analisar projetos & & \\
\hline \multirow[t]{4}{*}{ Atividade } & \multirow{4}{*}{$\begin{array}{l}\text { 1.6 Propor mudanças no portfólio } \\
\text { de produtos }\end{array}$} & 1.1.2 & Analisar portfólio de produtos \\
\hline & & 1.1.3 & Otimizar portfólio de produtos \\
\hline & & 2.3.4 & $\begin{array}{l}\text { Gerar relatórios de gestão de } \\
\text { múltiplos projetos }\end{array}$ \\
\hline & & 2.3 .2 & Otimizar o portfólio de projetos \\
\hline Procedimento & $\begin{array}{l}\text { Identificar produtos a serem } \\
\text { descontinuados }\end{array}$ & & \\
\hline Procedimento & $\begin{array}{l}\text { Identificar projetos a serem } \\
\text { abandonados e congelados }\end{array}$ & & \\
\hline Procedimento & $\begin{array}{l}\text { Identificar novos projetos que } \\
\text { deverão ser iniciados }\end{array}$ & & \\
\hline Procedimento & $\begin{array}{l}\text { Preparar minutas para cada um dos } \\
\text { novos projetos }\end{array}$ & & \\
\hline Procedimento & $\begin{array}{l}\text { Consolidar o novo portfólio de } \\
\text { produtos }\end{array}$ & & \\
\hline \multirow[t]{4}{*}{ Atividade } & \multirow{4}{*}{$\begin{array}{l}\text { 1.7 Verificar viabilidade do } \\
\text { porftóflio de produtos }\end{array}$} & 1.1.2 & Analisar portfólio de produtos \\
\hline & & 1.1 .3 & Otimizar portfólio de produtos \\
\hline & & 2.3.4 & $\begin{array}{l}\text { Gerar relatórios de gestão de } \\
\text { múltiplos projetos }\end{array}$ \\
\hline & & 2.3.2 & Otimizar o portfólio de projetos \\
\hline Procedimento & $\begin{array}{l}\text { Avaliar viabilidade econômica do } \\
\text { portfólio de projetos }\end{array}$ & & \\
\hline Procedimento & Avaliar disponibilidade de recursos & & \\
\hline Procedimento & Avaliar competências & & \\
\hline Procedimento & Obter consenso sobre decisão final & & \\
\hline \multirow[t]{2}{*}{ Atividade } & \multirow{2}{*}{$\begin{array}{l}\text { 1.8 Decidir início do planejamento } \\
\text { de um produto do portfólio }\end{array}$} & 2.3.1 & Inter-relacionar projetos \\
\hline & & 2.3.3 & $\begin{array}{l}\text { Planejar cronograma para o } \\
\text { portfólio de projetos }\end{array}$ \\
\hline
\end{tabular}




\begin{tabular}{|c|c|c|c|}
\hline & & 1.1 .2 & Analisar portfólio de produtos \\
\hline Procedimento & $\begin{array}{l}\text { Monitorar o portfólio de produtos } \\
\text { (avançado) e identificar a data dos } \\
\text { novos projetos }\end{array}$ & & \\
\hline Procedimento & $\begin{array}{l}\text { Revisar a minuta do projeto, definir o } \\
\text { gerente de projeto, aprovar e realizar } \\
\text { a comunicação }\end{array}$ & & \\
\hline Sub-processo & Planejamento do Projeto & & \\
\hline \multirow[t]{2}{*}{ Atividade } & \multirow[t]{2}{*}{ 2.1 Definir interessados do projeto } & 2.1.1 & $\begin{array}{l}\text { Criar banco de dados de recursos } \\
\text { para executar projetos }\end{array}$ \\
\hline & & 2.1.2 & $\begin{array}{l}\text { Configurar base de dados de } \\
\text { recursos }\end{array}$ \\
\hline Procedimento & $\begin{array}{l}\text { Planejamento organizacional dos } \\
\text { interessados do projeto }\end{array}$ & & \\
\hline Procedimento & $\begin{array}{l}\text { Montagem da equipe com os } \\
\text { interessados do projeto }\end{array}$ & & \\
\hline Procedimento & $\begin{array}{l}\text { Desenvolvimento da equipe para a } \\
\text { execução do projeto }\end{array}$ & & \\
\hline Atividade & 2.2 Definir escopo do produto & & \\
\hline Procedimento & $\begin{array}{l}\text { Realizar reuniões para estudo da } \\
\text { minuta de projeto e do portfólio de } \\
\text { produtos }\end{array}$ & & \\
\hline Procedimento & $\begin{array}{l}\text { Definir diretrizes básicas que o } \\
\text { produto deverá atender }\end{array}$ & & \\
\hline Atividade & 2.3 Definir escopo do projeto & & \\
\hline Procedimento & $\begin{array}{l}\text { Realizar reuniões para preparação da } \\
\text { declaração do escopo do produto e } \\
\text { das restrições impostas pelo DP da } \\
\text { empresa }\end{array}$ & & \\
\hline Atividade & 2.4 Detalhar escopo do projeto & & \\
\hline Procedimento & Preparar EDT & & \\
\hline Procedimento & $\begin{array}{l}\text { Revisar a declaração do escopo do } \\
\text { projeto }\end{array}$ & & \\
\hline Atividade & 2.5 Adaptar o modelo de referência & & \\
\hline Procedimento & Classificar o projeto & & \\
\hline Procedimento & $\begin{array}{l}\text { Identificar a versão adaptada do } \\
\text { modelo }\end{array}$ & & \\
\hline Procedimento & Identificar necessidades de mudanças & & \\
\hline \multirow[t]{4}{*}{ Atividade } & \multirow[t]{4}{*}{ 2.6 Definir atividades e seqüência } & 2.1.3 & $\begin{array}{l}\text { Criar EAP (Estrutura Analítica do } \\
\text { Projeto) }\end{array}$ \\
\hline & & 2.1 .4 & Visualizar EAP \\
\hline & & 2.1 .5 & Definir rede de atividades \\
\hline & & 2.1.6 & $\begin{array}{l}\text { Definir relacionamento de } \\
\text { precedência entre atividades }\end{array}$ \\
\hline Procedimento & Identificar atividades & & \\
\hline Procedimento & $\begin{array}{l}\text { Definir relacionamentos entre as } \\
\text { atividade }\end{array}$ & & \\
\hline Procedimento & Analisar a rede do projeto & & \\
\hline Atividade & 2.7 Preparar cronograma & 2.1.7 & $\begin{array}{l}\text { Visualizar planejamento dos } \\
\text { projetos }\end{array}$ \\
\hline
\end{tabular}




\begin{tabular}{|c|c|c|c|}
\hline & & 2.1 .8 & Definir cronograma dos projetos \\
\hline & & 2.1.9 & $\begin{array}{l}\text { Especificar ações decorrentes de } \\
\text { um marco de projeto completado }\end{array}$ \\
\hline & & 2.1.10 & Planejar projetos \\
\hline & & 2.1.11 & Programar projetos \\
\hline & & 2.1.12 & $\begin{array}{l}\text { Visualizar resultados da ocupação } \\
\text { de recursos }\end{array}$ \\
\hline Procedimento & $\begin{array}{l}\text { Estimar esforço necessário para a } \\
\text { atividade }\end{array}$ & & \\
\hline Procedimento & Alocar recursos necessários & & \\
\hline Procedimento & $\begin{array}{l}\text { Otimizar a programação de } \\
\text { atividades e recursos }\end{array}$ & & \\
\hline Procedimento & Imprimir cronograma & & \\
\hline Atividade & 2.8 Avaliar riscos & 2.1.13 & $\begin{array}{l}\text { Planejar gestão de riscos dos } \\
\text { projetos }\end{array}$ \\
\hline Procedimento & $\begin{array}{l}\text { Planejar avaliação de risco do projeto } \\
\text { de DP }\end{array}$ & & \\
\hline Procedimento & $\begin{array}{l}\text { Identificar e caracterizar os riscos } \\
\text { potenciais }\end{array}$ & & \\
\hline Procedimento & $\begin{array}{l}\text { Analisar qualitativamente os riscos } \\
\text { potenciais }\end{array}$ & & \\
\hline Procedimento & $\begin{array}{l}\text { Analisar quantitativamente os riscos } \\
\text { potenciais }\end{array}$ & & \\
\hline Procedimento & $\begin{array}{l}\text { Planejar ações em resposta aos riscos } \\
\text { potenciais }\end{array}$ & & \\
\hline Procedimento & $\begin{array}{l}\text { Planejar o controle e a monitoração } \\
\text { de riscos }\end{array}$ & & \\
\hline \multirow[t]{4}{*}{ Atividade } & \multirow[t]{4}{*}{ 2.9 Preparar orçamento do projeto } & 3.1.1 & Estimar custos de projetos \\
\hline & & 3.1 .2 & Planejar custos de projetos \\
\hline & & 3.1 .3 & $\begin{array}{l}\text { Diferenciar tipos de custos na } \\
\text { estimativa de custos de projetos }\end{array}$ \\
\hline & & 3.1.4 & Definir orçamento de projetos \\
\hline Procedimento & $\begin{array}{l}\text { Previsões dos custos relacionados às } \\
\text { atividades e recursos }\end{array}$ & & \\
\hline Procedimento & $\begin{array}{l}\text { Alocação orçamentária dos custos } \\
\text { estimados }\end{array}$ & & \\
\hline \multirow[t]{5}{*}{ Atividade } & \multirow[t]{5}{*}{$\begin{array}{l}2.10 \text { Analisar a viabilidade } \\
\text { econômica do projeto }\end{array}$} & 3.1.8 & $\begin{array}{l}\text { Gerenciar fluxo de caixa de } \\
\text { projetos }\end{array}$ \\
\hline & & 3.1 .9 & $\begin{array}{l}\text { Estimar evolução dos custos de } \\
\text { projetos }\end{array}$ \\
\hline & & 3.2.1 & $\begin{array}{l}\text { Registrar custos e receitas do } \\
\text { produto ao longo do ciclo de vida } \\
\text { (Product Lifecycle Costing) }\end{array}$ \\
\hline & & 3.2 .2 & $\begin{array}{l}\text { Definir os tipos de custos e de } \\
\text { receitas que são considerados no } \\
\text { cálculo do resultado no ciclo de } \\
\text { vida }\end{array}$ \\
\hline & & 3.2.3 & $\begin{array}{l}\text { Analisar o desempenho financeiro } \\
\text { no ciclo de vida }\end{array}$ \\
\hline Procedimento & Definir custo-alvo & & \\
\hline Procedimento & $\begin{array}{l}\text { Verificar manufaturabilidade do } \\
\text { custo-alvo }\end{array}$ & & \\
\hline
\end{tabular}




\begin{tabular}{|c|c|c|c|}
\hline Procedimento & Definir volume de vendas & & \\
\hline Procedimento & Realizar avaliação econômica & & \\
\hline Atividade & $\begin{array}{l}\text { 2.11 Definir indicadores de } \\
\text { desempenho }\end{array}$ & 3.1.11 & Controlar indicadores de projetos \\
\hline Procedimento & $\begin{array}{l}\text { Selecionar indicadores de } \\
\text { desempenho mais adequados para o } \\
\text { presente projeto }\end{array}$ & & \\
\hline Atividade & 2.12 Definir plano de comunicação & & \\
\hline Procedimento & $\begin{array}{l}\text { Determinar que, quando e como as } \\
\text { partes envolvidas precisam de } \\
\text { informações e comunicações }\end{array}$ & & \\
\hline Atividade & 2.13 Planejar e preparar aquisições & 2.1.14 & $\begin{array}{l}\text { Relacionar plano macro de projeto } \\
\text { com outros planos detalhados (e.g. } \\
\text { plano de produção, plano de } \\
\text { montagem) }\end{array}$ \\
\hline Procedimento & $\begin{array}{l}\text { Planejar o que será adquirido e } \\
\text { quando }\end{array}$ & & \\
\hline Procedimento & $\begin{array}{l}\text { Preparar requerimentos de aquisição } \\
\text { e identificar fornecedores potenciais }\end{array}$ & & \\
\hline Procedimento & $\begin{array}{l}\text { Planejar a gestão dos } \\
\text { relacionamentos com os fornecedores }\end{array}$ & & \\
\hline Atividade & 2.14 Preparar Plano de Projeto & & \\
\hline Procedimento & $\begin{array}{l}\text { Discussão e redação do plano de } \\
\text { projeto }\end{array}$ & & \\
\hline Processo & Desenvolvimento de produtos & & \\
\hline Sub-processo & $\begin{array}{l}\text { Projeto Informacional / } \\
\text { Informacional Design }\end{array}$ & & \\
\hline \multirow[t]{3}{*}{ Atividade } & \multirow[t]{3}{*}{$\begin{array}{l}\text { 3.1 Atualizar o Plano do Projeto } \\
\text { Informacional }\end{array}$} & 2.2.1 & $\begin{array}{l}\text { Visualizar visão geral do status de } \\
\text { projetos }\end{array}$ \\
\hline & & 2.2.2 & $\begin{array}{l}\text { Registrar e visualizar avanços nos } \\
\text { planos de projetos }\end{array}$ \\
\hline & & 2.2.3 & $\begin{array}{l}\text { Gerar relatórios de gestão de } \\
\text { projetos }\end{array}$ \\
\hline Procedimento & Analisar o plano de projeto atual & & \\
\hline Procedimento & $\begin{array}{l}\text { Analisar e sintetizar as novas } \\
\text { condições para a realização do } \\
\text { projeto }\end{array}$ & & \\
\hline Procedimento & Atualizar o escopo do produto & & \\
\hline Procedimento & $\begin{array}{l}\text { Atuaizar e detalhar o escopo do } \\
\text { projeto }\end{array}$ & & \\
\hline Procedimento & $\begin{array}{l}\text { Atualizar e detalhar as atividades, os } \\
\text { responsáveis, os prazos e o } \\
\text { cronograma }\end{array}$ & & \\
\hline Procedimento & $\begin{array}{l}\text { Atualizar e detalhar recursos } \\
\text { necessários }\end{array}$ & & \\
\hline Procedimento & $\begin{array}{l}\text { Atualizar estimativa de orçamento do } \\
\text { projeto }\end{array}$ & & \\
\hline Procedimento & $\begin{array}{l}\text { Atualizar, monitorar, valorar e definir } \\
\text { novos indicadores de desempenho }\end{array}$ & & \\
\hline Procedimento & $\begin{array}{l}\text { Analisar a viabilidade econômico- } \\
\text { financeira do projeto }\end{array}$ & & \\
\hline
\end{tabular}




\begin{tabular}{|c|c|c|c|}
\hline Procedimento & Avaliar novos riscos & & \\
\hline Procedimento & Atualizar plano de comunicação & & \\
\hline Procedimento & $\begin{array}{l}\text { Planejar, atualizar e preparar novas } \\
\text { aquisições }\end{array}$ & & \\
\hline Procedimento & $\begin{array}{l}\text { Definir/atualizar os critérios de } \\
\text { passagem dos gates }\end{array}$ & & \\
\hline Atividade & $\begin{array}{l}\text { 3.2 Revisar e Atualizar o Escopo do } \\
\text { Produto }\end{array}$ & & \\
\hline Procedimento & Análise do problema de projeto & & \\
\hline Procedimento & $\begin{array}{l}\text { Analisar tecnologias disponíveis e } \\
\text { necessárias }\end{array}$ & & \\
\hline Procedimento & $\begin{array}{l}\text { Pesquisar padrões / normas, patentes } \\
\text { e legislação }\end{array}$ & & \\
\hline Procedimento & $\begin{array}{l}\text { Pesquisar produtos concorrentes e } \\
\text { similares }\end{array}$ & & \\
\hline Atividade & $\begin{array}{l}\text { 3.3 Detalhar ciclo de vida do } \\
\text { produto e definir seus clientes }\end{array}$ & & \\
\hline Procedimento & Refinar o ciclo de vida do produto & & \\
\hline Procedimento & $\begin{array}{l}\text { Definir os clientes do projeto ao } \\
\text { longo do ciclo de vida }\end{array}$ & & \\
\hline \multirow[t]{4}{*}{ Atividade } & \multirow{4}{*}{$\begin{array}{l}\text { 3.4 Identificar os requisitos dos } \\
\text { clientes do produto }\end{array}$} & 1.3 .1 & Coletar requisitos de produtos \\
\hline & & 1.3 .2 & Classificar requisitos \\
\hline & & 1.3 .3 & Agrupar requisitos \\
\hline & & 1.3 .4 & Avaliar requisitos \\
\hline Procedimento & $\begin{array}{l}\text { Coletar as necessidades dos clientes } \\
\text { de cada fase do ciclo de vida }\end{array}$ & & \\
\hline Procedimento & Agrupar e classificar as necessidades & & \\
\hline Procedimento & Definir os requisitos dos clientes & & \\
\hline Procedimento & Valorar dos requisitos dos clientes & & \\
\hline \multirow[t]{4}{*}{ Atividade } & \multirow[t]{4}{*}{ 3.5 Definir requisitos do produto } & 1.3 .3 & Agrupar requisitos \\
\hline & & 1.3 .4 & Avaliar requisitos \\
\hline & & 1.3 .5 & $\begin{array}{l}\text { Analisar requisitos com uso de } \\
\text { gráficos }\end{array}$ \\
\hline & & 1.3 .7 & $\begin{array}{l}\text { Relacionar requisitos com outros } \\
\text { objetos do PLM }\end{array}$ \\
\hline Procedimento & $\begin{array}{l}\text { Converter requisitos de clientes em } \\
\text { expressões mensuráveis }\end{array}$ & & \\
\hline Procedimento & $\begin{array}{l}\text { Analisar e classificar os requisitos do } \\
\text { produto }\end{array}$ & & \\
\hline Procedimento & $\begin{array}{l}\text { Hierarquizar requisitos de projeto do } \\
\text { produto }\end{array}$ & & \\
\hline Atividade & $\begin{array}{l}\text { 3.6 Definir especificações meta do } \\
\text { produto }\end{array}$ & 1.3.8 & Criar caderno de especificações \\
\hline Procedimento & Valorar requisitos do produto & & \\
\hline Procedimento & Analisar perfil técnico e de mercado & & \\
\hline Procedimento & $\begin{array}{l}\text { Analisar restrições de projeto do } \\
\text { produto (contrato, ambientais, } \\
\text { legislação, normas, ...) }\end{array}$ & & \\
\hline Procedimento & $\begin{array}{l}\text { Elaborar o conjunto de } \\
\text { especificações-meta do produto }\end{array}$ & & \\
\hline
\end{tabular}




\begin{tabular}{|c|c|c|c|}
\hline \multirow[t]{7}{*}{ Atividade } & \multirow[t]{7}{*}{$\begin{array}{l}\text { 3.7 Monitorar a viabilidade } \\
\text { econômico-financeira do produto }\end{array}$} & 1.3.6 & $\begin{array}{l}\text { Acompanhar evolução dos } \\
\text { requisitos }\end{array}$ \\
\hline & & 3.1.5 & Contabilizar custos de projetos \\
\hline & & 3.1 .6 & Gerenciar custos de projetos \\
\hline & & 3.1 .7 & Gerenciar orçamento de projetos \\
\hline & & 3.1 .8 & $\begin{array}{l}\text { Gerenciar fluxo de caixa de } \\
\text { projetos }\end{array}$ \\
\hline & & 3.1.9 & $\begin{array}{l}\text { Estimar evolução dos custos de } \\
\text { projetos }\end{array}$ \\
\hline & & 3.1.10 & $\begin{array}{l}\text { Ajustar custos em decorrência de } \\
\text { mudanças de engenharia }\end{array}$ \\
\hline Procedimento & $\begin{array}{l}\text { Avaliar mudanças nas condições de } \\
\text { mercado, características técnicas e } \\
\text { indicadores }\end{array}$ & & \\
\hline Procedimento & $\begin{array}{l}\text { Avaliar impacto das mudanças no } \\
\text { projeto }\end{array}$ & & \\
\hline Procedimento & $\begin{array}{l}\text { Atualizar as premissas financeiras do } \\
\text { projeto }\end{array}$ & & \\
\hline Procedimento & $\begin{array}{l}\text { Atualizar custo-alvo nos diversos } \\
\text { níveis do produto }\end{array}$ & & \\
\hline Procedimento & Atualizar as receitas futuras & & \\
\hline Procedimento & $\begin{array}{l}\text { Atualizar as necessidades de } \\
\text { investimentos }\end{array}$ & & \\
\hline $\begin{array}{l}\text { Procedimento } \\
\end{array}$ & Calcular o novo fluxo de caixa & & \\
\hline Procedimento & $\begin{array}{l}\text { Calcular novos indicadores } \\
\text { financeiros }\end{array}$ & & \\
\hline Procedimento & $\begin{array}{l}\text { Analisar novas premissas e } \\
\text { indicadores }\end{array}$ & & \\
\hline Procedimento & $\begin{array}{l}\text { Avaliar possíveis desvios e impactos } \\
\text { no projeto }\end{array}$ & & \\
\hline Atividade & 3.8 Avaliar fase & 3.1.11 & Controlar indicadores de projetos \\
\hline Procedimento & $\begin{array}{l}\text { Avaliar o cumprimento das tarefas } \\
\text { planejadas }\end{array}$ & & \\
\hline Procedimento & $\begin{array}{l}\text { Avaliar os resultados obtidos } \\
\text { segundo os critérios estabelecidos }\end{array}$ & & \\
\hline Procedimento & $\begin{array}{l}\text { Avaliar os demais critérios } \\
\text { quantitativos e indicadores }\end{array}$ & & \\
\hline Procedimento & Avaliar a viabilidade econômica & & \\
\hline Procedimento & Decidir implementar ações corretivas & & \\
\hline Procedimento & $\begin{array}{l}\text { Decidir se pode ser realizada a } \\
\text { atividade de aprovação }\end{array}$ & & \\
\hline Procedimento & $\begin{array}{l}\text { Preparar relatório para time de } \\
\text { avaliação }\end{array}$ & & \\
\hline Atividade & 3.9 Aprovar fase & & \\
\hline Procedimento & $\begin{array}{l}\text { Avaliar o relatório de auto-avaliação } \\
\text { e discutir com o time de } \\
\text { desenvolvimento }\end{array}$ & & \\
\hline Procedimento & $\begin{array}{l}\text { Analisar as evidências dos resultados } \\
\text { e término das atividades planejadas }\end{array}$ & & \\
\hline Procedimento & $\begin{array}{l}\text { Analisar o portfólio de produtos e } \\
\text { projetos }\end{array}$ & & \\
\hline
\end{tabular}




\begin{tabular}{|c|c|c|c|}
\hline Procedimento & $\begin{array}{l}\text { Analisar o estudo de viabilidade } \\
\text { econômica }\end{array}$ & & \\
\hline Procedimento & $\begin{array}{l}\text { Aplicar os critérios de avaliação e } \\
\text { tomar decisão }\end{array}$ & & \\
\hline Procedimento & Preparar relatório & & \\
\hline Procedimento & Melhorar o processo do gate & & \\
\hline Procedimento & Ajustar critérios próxima fase & & \\
\hline Procedimento & Definir ações corretivas & & \\
\hline Procedimento & Analisar risco & & \\
\hline Atividade & $\begin{array}{l}\text { 3.10 Documentar as decisões } \\
\text { tomadas e registrar lições } \\
\text { aprendidas }\end{array}$ & & \\
\hline Sub-processo & $\begin{array}{l}\text { Projeto Conceitual / Conceptual } \\
\text { Design }\end{array}$ & & \\
\hline \multirow[t]{3}{*}{ Atividade } & \multirow[t]{3}{*}{$\begin{array}{l}\text { 4.1 Atualizar o Plano do Projeto } \\
\text { Conceitual }\end{array}$} & 2.2.1 & $\begin{array}{l}\text { Visualizar visão geral do status de } \\
\text { projetos }\end{array}$ \\
\hline & & 2.2.2 & $\begin{array}{l}\text { Registrar e visualizar avanços nos } \\
\text { planos de projetos }\end{array}$ \\
\hline & & 2.2.3 & $\begin{array}{l}\text { Gerar relatórios de gestão de } \\
\text { projetos }\end{array}$ \\
\hline Procedimento & Analisar o plano de projeto atual & & \\
\hline Procedimento & $\begin{array}{l}\text { Analisar e sintetizar as novas } \\
\text { condições para a realização do } \\
\text { projeto }\end{array}$ & & \\
\hline Procedimento & Atualizar o escopo do produto & & \\
\hline Procedimento & $\begin{array}{l}\text { Atualizar e detalhar o escopo do } \\
\text { projeto }\end{array}$ & & \\
\hline Procedimento & $\begin{array}{l}\text { Atualizar e detalhar as atividades, os } \\
\text { responsáveis, os prazos e o } \\
\text { cronograma }\end{array}$ & & \\
\hline Procedimento & $\begin{array}{l}\text { Atualizar e detalhar recursos } \\
\text { necessários }\end{array}$ & & \\
\hline Procedimento & $\begin{array}{l}\text { Atualizar estimativa de orçamento do } \\
\text { projeto }\end{array}$ & & \\
\hline Procedimento & $\begin{array}{l}\text { Atualizar, monitorar, valorar e definir } \\
\text { novos indicadores de desempenho }\end{array}$ & & \\
\hline Procedimento & $\begin{array}{l}\text { Analisar a viabilidade econômico- } \\
\text { financeira do projeto }\end{array}$ & & \\
\hline Procedimento & Avaliar novos riscos & & \\
\hline Procedimento & Atualizar plano de comunicação & & \\
\hline Procedimento & $\begin{array}{l}\text { Planejar, atualizar e preparar novas } \\
\text { aquisições }\end{array}$ & & \\
\hline Procedimento & $\begin{array}{l}\text { Definir/atualizar os critérios de } \\
\text { passagem dos gates }\end{array}$ & & \\
\hline \multirow[t]{3}{*}{ Atividade } & \multirow[t]{3}{*}{$\begin{array}{l}4.2 \text { Modelar funcionalmente } 0 \\
\text { produto }\end{array}$} & 4.3.1 & $\begin{array}{l}\text { Definir contexto da estrutura de } \\
\text { produto }\end{array}$ \\
\hline & & 4.3.2 & $\begin{array}{l}\text { Definir tipo da estrutura de } \\
\text { produto }\end{array}$ \\
\hline & & 4.3.3 & $\begin{array}{l}\text { Definir visões da estrutura de } \\
\text { produto }\end{array}$ \\
\hline
\end{tabular}




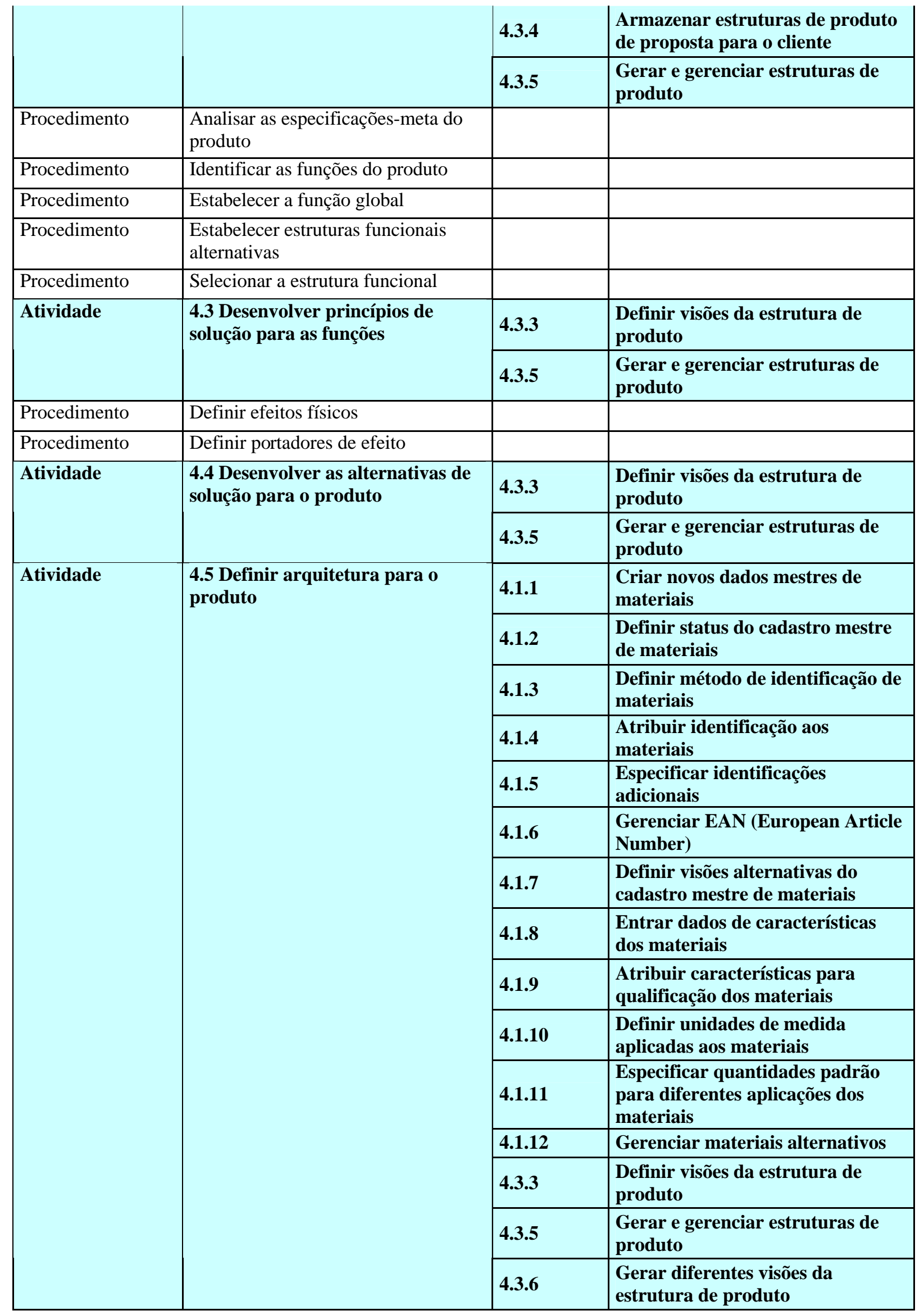




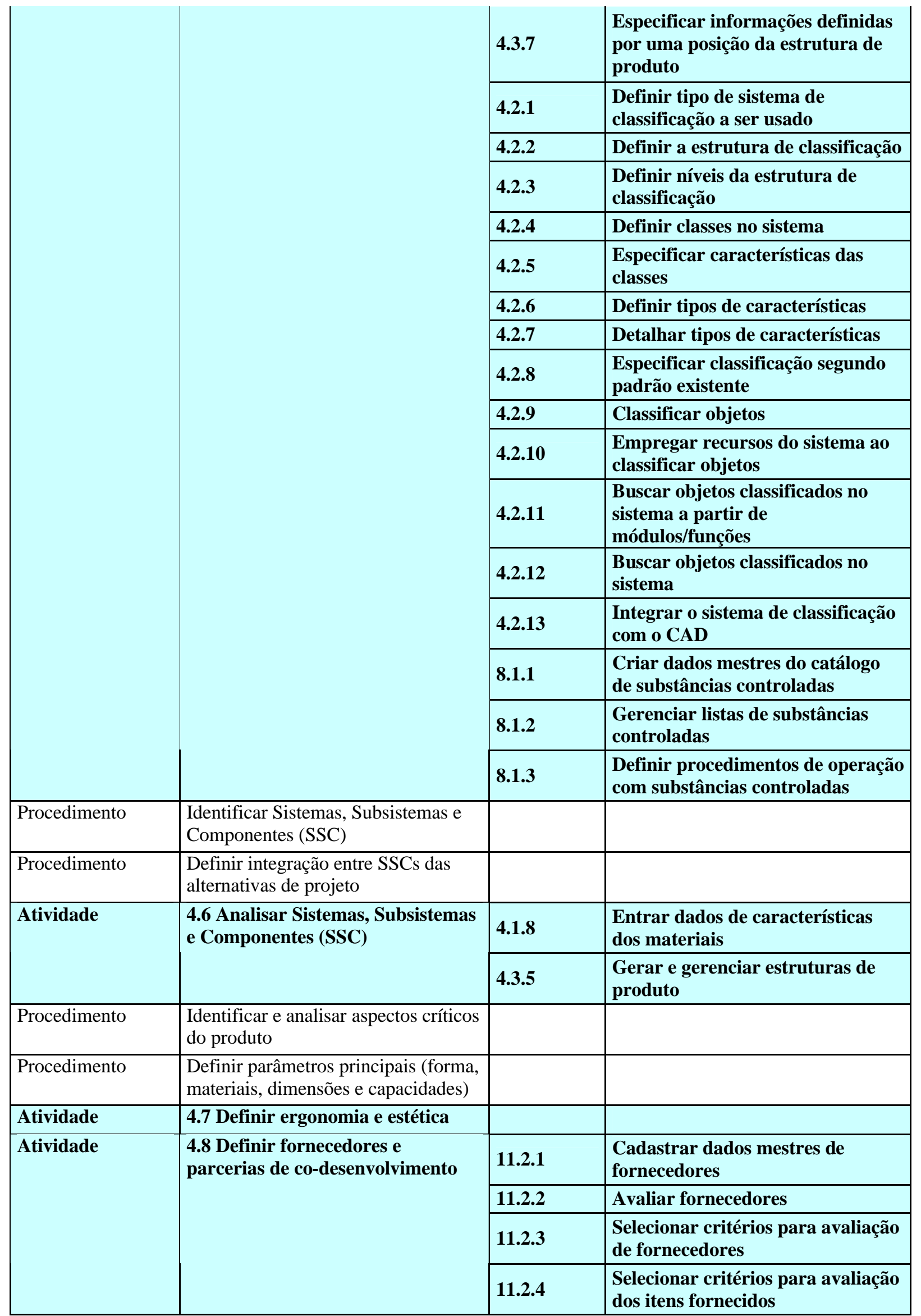




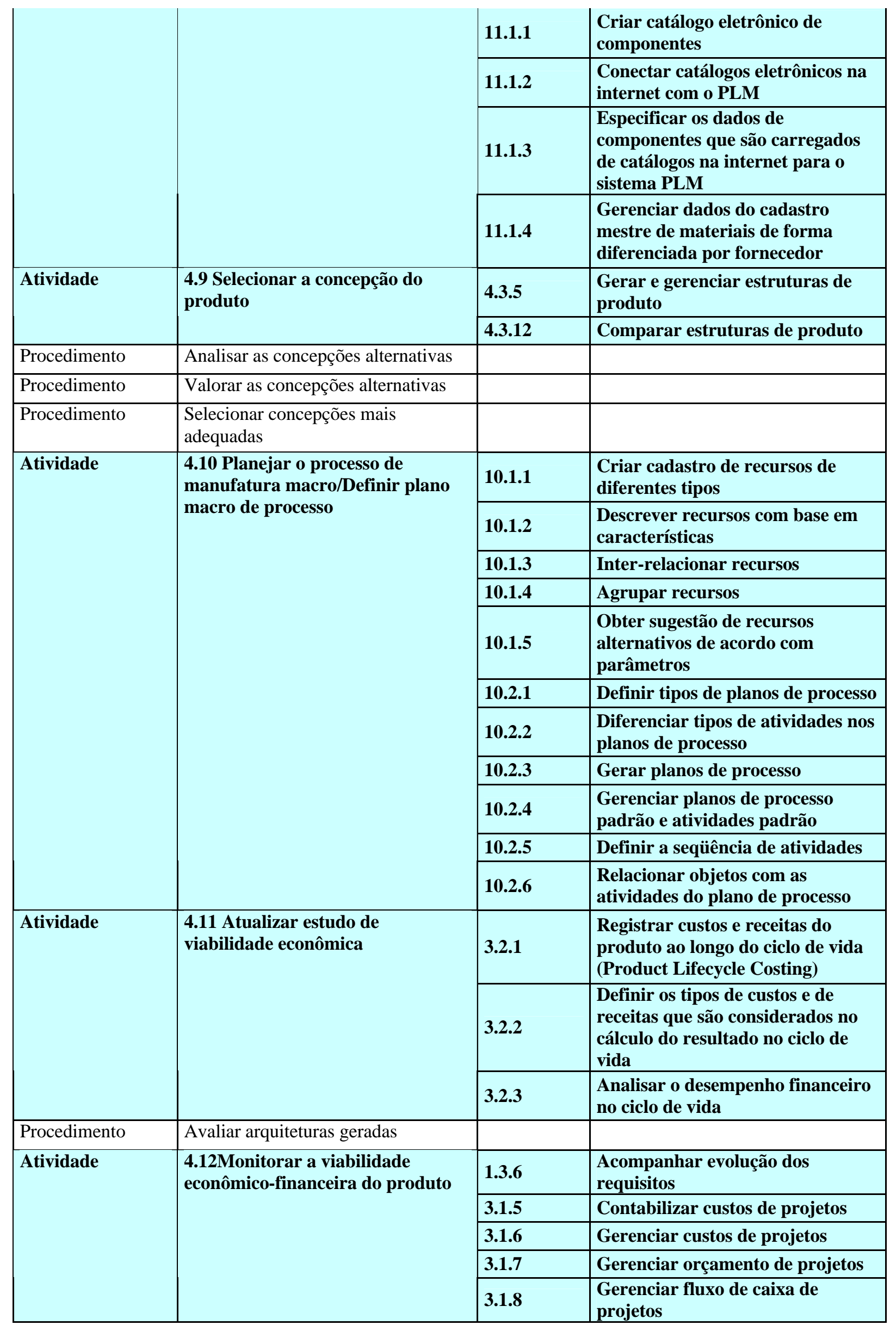




\begin{tabular}{|c|c|c|c|}
\hline & & 3.1 .9 & $\begin{array}{l}\text { Estimar evolução dos custos de } \\
\text { projetos }\end{array}$ \\
\hline & & 3.1.10 & $\begin{array}{l}\text { Ajustar custos em decorrência de } \\
\text { mudanças de engenharia }\end{array}$ \\
\hline Procedimento & $\begin{array}{l}\text { Avaliar mudanças nas condições de } \\
\text { mercado, características técnicas e } \\
\text { indicadores }\end{array}$ & & \\
\hline Procedimento & $\begin{array}{l}\text { Avaliar impacto das mudanças no } \\
\text { projeto }\end{array}$ & & \\
\hline Procedimento & $\begin{array}{l}\text { Atualizar as premissas financeiras do } \\
\text { projeto }\end{array}$ & & \\
\hline Procedimento & $\begin{array}{l}\text { Atualizar custo-alvo nos diversos } \\
\text { níveis do produto }\end{array}$ & & \\
\hline Procedimento & Atualizar as receitas futuras & & \\
\hline Procedimento & $\begin{array}{l}\text { Atualizar as necessidades de } \\
\text { investimentos }\end{array}$ & & \\
\hline Procedimento & Calcular o novo fluxo de caixa & & \\
\hline Procedimento & $\begin{array}{l}\text { Calcular novos indicadores } \\
\text { financeiros }\end{array}$ & & \\
\hline Procedimento & $\begin{array}{l}\text { Analisar novas premissas e } \\
\text { indicadores }\end{array}$ & & \\
\hline Procedimento & $\begin{array}{l}\text { Avaliar possíveis desvios e impactos } \\
\text { no projeto }\end{array}$ & & \\
\hline Atividade & 4.13 Avaliar fase & 3.1.11 & Controlar indicadores de projetos \\
\hline Procedimento & $\begin{array}{l}\text { Avaliar o cumprimento das tarefas } \\
\text { planejadas }\end{array}$ & & \\
\hline Procedimento & $\begin{array}{l}\text { Avaliar os resultados obtidos } \\
\text { segundo os critérios estabelecidos }\end{array}$ & & \\
\hline Procedimento & $\begin{array}{l}\text { Avaliar os demais critérios } \\
\text { quantitativos e indicadores }\end{array}$ & & \\
\hline Procedimento & Avaliar a viabilidade econômica & & \\
\hline Procedimento & Decidir implementar ações corretivas & & \\
\hline Procedimento & $\begin{array}{l}\text { Decidir se pode ser realizada a } \\
\text { atividade de aprovação }\end{array}$ & & \\
\hline Procedimento & $\begin{array}{l}\text { Preparar relatório para time de } \\
\text { avaliação }\end{array}$ & & \\
\hline Atividade & 4.14 Aprovar fase & & \\
\hline Procedimento & $\begin{array}{l}\text { Avaliar o relatório de auto-avaliação } \\
\text { e discutí-lo com o time de } \\
\text { desenvolvimento }\end{array}$ & & \\
\hline Procedimento & $\begin{array}{l}\text { Analisar as evidências dos resultados } \\
\text { e término das atividades planejadas }\end{array}$ & & \\
\hline Procedimento & $\begin{array}{l}\text { Analisar o portfólio de produtos e } \\
\text { projetos }\end{array}$ & & \\
\hline Procedimento & $\begin{array}{l}\text { Analisar o estudo de viabilidade } \\
\text { econômica }\end{array}$ & & \\
\hline Procedimento & $\begin{array}{l}\text { Aplicar os critérios de avaliação e } \\
\text { tomar decisão }\end{array}$ & & \\
\hline Procedimento & Preparar relatório & & \\
\hline Procedimento & Melhorar o processo do gate & & \\
\hline Procedimento & Ajustar critérios próxima fase & & \\
\hline
\end{tabular}




\begin{tabular}{|c|c|c|c|}
\hline Procedimento & | Definir ações corretivas & & \\
\hline Procedimento & Analisar risco & & \\
\hline Atividade & $\begin{array}{l}\text { 4.15 Documentar as decisões } \\
\text { tomadas e registrar lições } \\
\text { aprendidas }\end{array}$ & & \\
\hline Sub-processo & $\begin{array}{l}\text { Projeto Detalhado / Detailed } \\
\text { Design }\end{array}$ & & \\
\hline \multirow[t]{3}{*}{ Atividade } & \multirow[t]{3}{*}{$\begin{array}{l}\text { 5.1 Atualizar o Plano do Projeto } \\
\text { Detalhado }\end{array}$} & 2.2.1 & $\begin{array}{l}\text { Visualizar visão geral do status de } \\
\text { projetos }\end{array}$ \\
\hline & & 2.2 .2 & $\begin{array}{l}\text { Registrar e visualizar avanços nos } \\
\text { planos de projetos }\end{array}$ \\
\hline & & 2.2 .3 & $\begin{array}{l}\text { Gerar relatórios de gestão de } \\
\text { projetos }\end{array}$ \\
\hline Procedimento & Analisar o plano de projeto atual & & \\
\hline Procedimento & $\begin{array}{l}\text { Analisar e sintetizar as novas } \\
\text { condições para a realização do } \\
\text { projeto }\end{array}$ & & \\
\hline Procedimento & Atualizar o escopo do produto & & \\
\hline Procedimento & $\begin{array}{l}\text { Atualizar e detalhar o escopo do } \\
\text { projeto }\end{array}$ & & \\
\hline Procedimento & $\begin{array}{l}\text { Atualizar e detalhar as atividades, os } \\
\text { responsáveis, os prazos e o } \\
\text { cronograma }\end{array}$ & & \\
\hline Procedimento & $\begin{array}{l}\text { Atualizar e detalhar recursos } \\
\text { necessários }\end{array}$ & & \\
\hline Procedimento & $\begin{array}{l}\text { Atualizar estimativa de orçamento do } \\
\text { projeto }\end{array}$ & & \\
\hline Procedimento & $\begin{array}{l}\text { Atualizar, monitorar, valorar e definir } \\
\text { novos indicadores de desempenho }\end{array}$ & & \\
\hline Procedimento & $\begin{array}{l}\text { Analisar a viabilidade econômico- } \\
\text { financeira do projeto }\end{array}$ & & \\
\hline Procedimento & Avaliar novos riscos & & \\
\hline Procedimento & Atualizar plano de comunicação & & \\
\hline Procedimento & $\begin{array}{l}\text { Planejar, atualizar e preparar novas } \\
\text { aquisições }\end{array}$ & & \\
\hline Procedimento & $\begin{array}{l}\text { Definir/atualizar os critérios de } \\
\text { passagem dos gates }\end{array}$ & & \\
\hline \multirow[t]{7}{*}{ Atividade } & \multirow[t]{7}{*}{$\begin{array}{l}\text { 5.2 Criar e detalhar SSCs, } \\
\text { documentação e configuração }\end{array}$} & 4.1 .1 & $\begin{array}{l}\text { Criar novos dados mestres de } \\
\text { materiais }\end{array}$ \\
\hline & & 4.1 .4 & $\begin{array}{l}\text { Atribuir identificação aos } \\
\text { materiais }\end{array}$ \\
\hline & & 4.1.8 & $\begin{array}{l}\text { Entrar dados de características } \\
\text { dos materiais }\end{array}$ \\
\hline & & 4.3 .5 & $\begin{array}{l}\text { Gerar e gerenciar estruturas de } \\
\text { produto }\end{array}$ \\
\hline & & 4.3 .6 & $\begin{array}{l}\text { Gerar diferentes visões da } \\
\text { estrutura de produto }\end{array}$ \\
\hline & & 4.3.8 & $\begin{array}{l}\text { Tratar posições da estrutura de } \\
\text { produto sem informação no } \\
\text { cadastro mestre de materiais }\end{array}$ \\
\hline & & 4.3 .9 & $\begin{array}{l}\text { Checar resultado da estrutura de } \\
\text { produto }\end{array}$ \\
\hline
\end{tabular}




\begin{tabular}{|c|c|c|c|}
\hline & & 4.3.10 & $\begin{array}{l}\text { Liberar posições da estrutura de } \\
\text { produto }\end{array}$ \\
\hline & & 4.3.11 & $\begin{array}{l}\text { Definir possíveis status para a } \\
\text { liberação de estruturas de produto }\end{array}$ \\
\hline & & 4.3.12 & Comparar estruturas de produto \\
\hline & & 4.3.13 & $\begin{array}{l}\text { Analisar onde é usado (where- } \\
\text { used) }\end{array}$ \\
\hline & & 4.3.14 & $\begin{array}{l}\text { Selecionar formato de dados de } \\
\text { relatório da estrutura de produto }\end{array}$ \\
\hline & & 4.4 .1 & Gerenciar variantes no sistema \\
\hline & & 4.4 .2 & Definir tipos de variantes \\
\hline & & 4.4.3 & $\begin{array}{l}\text { Definir tipos de objetos para } \\
\text { composição de variantes }\end{array}$ \\
\hline & & 4.4 .4 & $\begin{array}{l}\text { Definir tipos de atributos de } \\
\text { variantes }\end{array}$ \\
\hline & & 4.4 .5 & $\begin{array}{l}\text { Definir regras para a composição } \\
\text { de variantes }\end{array}$ \\
\hline & & 4.4 .6 & $\begin{array}{l}\text { Definir tipos de regras para a } \\
\text { composição de variantes }\end{array}$ \\
\hline & & 4.4 .7 & $\begin{array}{l}\text { Definir tipos de relacionamento } \\
\text { lógico }\end{array}$ \\
\hline & & 4.4.8 & $\begin{array}{l}\text { Especificar quantidade de } \\
\text { condições que podem ser } \\
\text { combinadas }\end{array}$ \\
\hline & & 4.4 .9 & $\begin{array}{l}\text { Especificar ações decorrentes de } \\
\text { uma condição }\end{array}$ \\
\hline & & 4.4.10 & $\begin{array}{l}\text { Definir quantidade de níveis para } \\
\text { a definição de regras }\end{array}$ \\
\hline & & 4.4.11 & $\begin{array}{l}\text { Verificar resultado da definição de } \\
\text { variantes }\end{array}$ \\
\hline & & 4.4.12 & $\begin{array}{l}\text { Definir formato das estruturas de } \\
\text { produto para variantes }\end{array}$ \\
\hline & & 4.4.13 & $\begin{array}{l}\text { Gerar estruturas de produto para } \\
\text { variantes }\end{array}$ \\
\hline & & 4.4.14 & $\begin{array}{l}\text { Definir em que momento } \\
\text { estruturas de produto para } \\
\text { variantes são geradas }\end{array}$ \\
\hline & & 4.4 .15 & Gerar identificação de variantes \\
\hline & & 4.2 .9 & Classificar objetos \\
\hline & & 4.2.12 & $\begin{array}{l}\text { Buscar objetos classificados no } \\
\text { sistema }\end{array}$ \\
\hline Procedimento & $\begin{array}{l}\text { Criar, reutilizar, procurar e codificar } \\
\text { SSCs }\end{array}$ & & \\
\hline Procedimento & Calcular e desenhar SSCs & & \\
\hline Procedimento & Especificar tolerâncias & & \\
\hline Procedimento & Integrar os SSCs & & \\
\hline Procedimento & Finalizar desenhos e documentos & & \\
\hline Procedimento & Completar BOM & & \\
\hline Atividade & 5.3 Decidir por fazer ou comprar & 11.2 .5 & Analisar os custos de sourcing \\
\hline & SSC & 11.2.6 & $\begin{array}{l}\text { Reajustar tabela de preços de } \\
\text { fornecedores }\end{array}$ \\
\hline
\end{tabular}




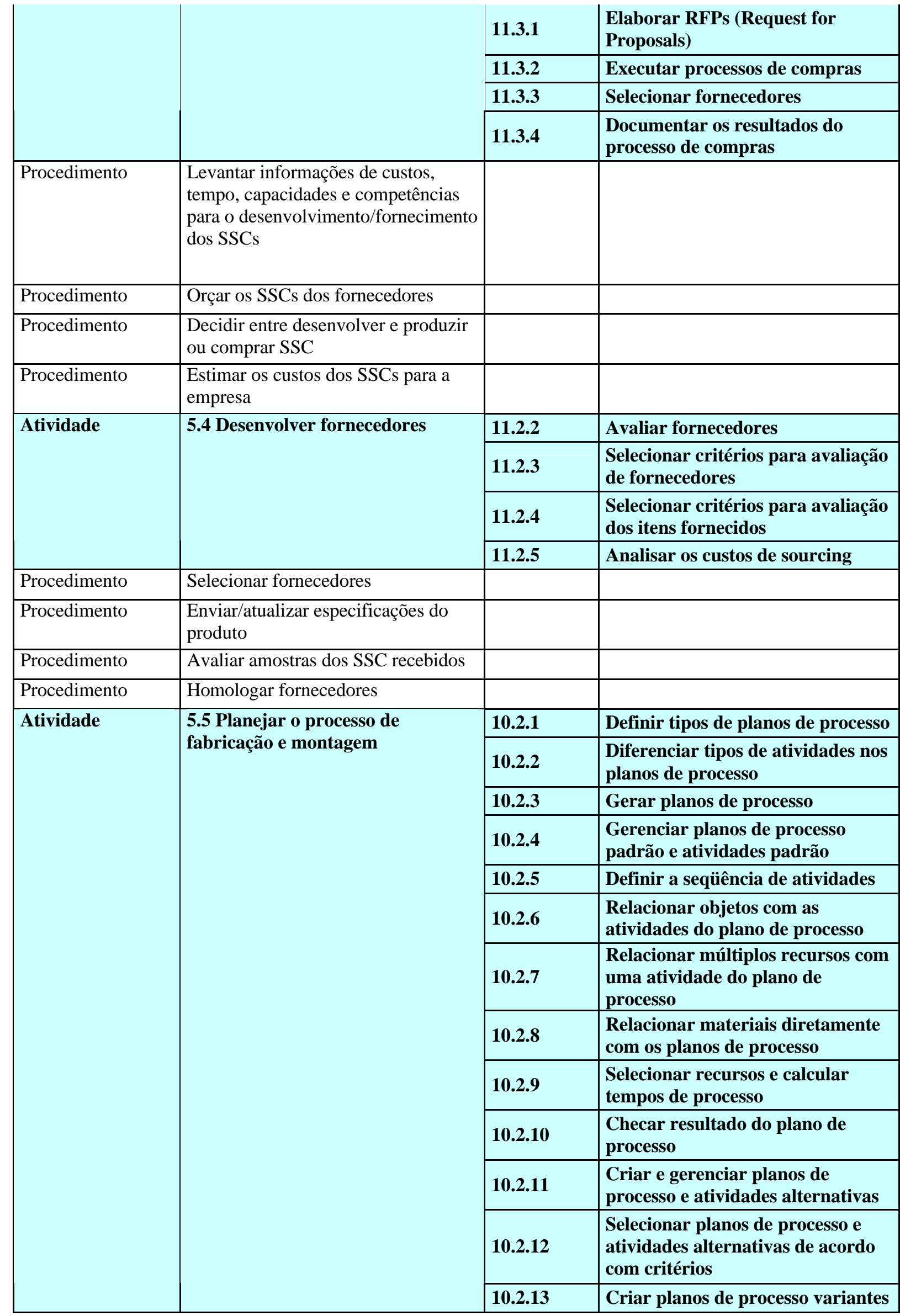




\begin{tabular}{|c|c|c|c|}
\hline & & 10.2.14 & $\begin{array}{l}\text { Gerar programa NC para produto } \\
\text { variante }\end{array}$ \\
\hline & & 10.3.1 & Definir layout \\
\hline & & 10.3 .2 & Apresentar layout \\
\hline & & 10.3.3 & $\begin{array}{l}\text { Cadastrar dados que caracterizam } \\
\text { uma linha de produção }\end{array}$ \\
\hline Procedimento & $\begin{array}{l}\text { Planejar processo de fabricação } \\
\text { macro }\end{array}$ & & \\
\hline Procedimento & $\begin{array}{l}\text { Planejar processo de montagem } \\
\text { macro }\end{array}$ & & \\
\hline Procedimento & $\begin{array}{l}\text { Desdobrar parâmetros críticos dos } \\
\text { componentes fabricados }\end{array}$ & & \\
\hline Procedimento & $\begin{array}{l}\text { Reutilizar planos de processo } \\
\text { existentes }\end{array}$ & & \\
\hline Procedimento & $\begin{array}{l}\text { Definir / avaliar componente em } \\
\text { bruto }\end{array}$ & & \\
\hline Procedimento & Definir e seqüenciar operações & & \\
\hline Procedimento & $\begin{array}{l}\text { Selecionar / especificar máquinas e } \\
\text { equipamentos }\end{array}$ & & \\
\hline Procedimento & $\begin{array}{l}\text { Selecionar / especificar pessoal e } \\
\text { habilidades }\end{array}$ & & \\
\hline Procedimento & Especificar fixação & & \\
\hline Procedimento & Especificar inspeção & & \\
\hline Procedimento & Selecionar / especificar métodos & & \\
\hline Procedimento & Selecionar / especificar ferramental & & \\
\hline Procedimento & Calcular sobremetal & & \\
\hline Procedimento & Calcular parâmetros de trabalho & & \\
\hline Procedimento & Descrever instruções de trabalho & & \\
\hline Procedimento & Ilustrar operações & & \\
\hline Procedimento & Obter programa CNC & & \\
\hline Procedimento & $\begin{array}{l}\text { Criar informações / documentos de } \\
\text { apoio ao operador }\end{array}$ & & \\
\hline Procedimento & $\begin{array}{l}\text { Calcular tempos de fabricação e } \\
\text { montagem }\end{array}$ & & \\
\hline Procedimento & $\begin{array}{l}\text { Otimizar fluxo de produção } \\
\text { analiticamente }\end{array}$ & & \\
\hline Procedimento & Simular processo de fabricação & & \\
\hline Procedimento & Atualizar BOM & & \\
\hline \multirow[t]{5}{*}{ Atividade } & \multirow[t]{5}{*}{ 5.6 Projetar recursos de fabricação } & 10.1.1 & $\begin{array}{l}\text { Criar cadastro de recursos de } \\
\text { diferentes tipos }\end{array}$ \\
\hline & & 10.1.2 & $\begin{array}{l}\text { Descrever recursos com base em } \\
\text { características }\end{array}$ \\
\hline & & 10.1 .3 & Inter-relacionar recursos \\
\hline & & 10.1 .4 & Agrupar recursos \\
\hline & & 10.1.5 & $\begin{array}{l}\text { Obter sugestão de recursos } \\
\text { alternativos de acordo com } \\
\text { parâmetros }\end{array}$ \\
\hline Procedimento & Projetar ferramentas & & \\
\hline Procedimento & Projetar dispositivos & & \\
\hline Procedimento & Projetar máquinas e equipamentos & & \\
\hline
\end{tabular}




\begin{tabular}{|c|c|c|c|}
\hline Procedimento & | Projetar instalações (Fábrica) & & \\
\hline Procedimento & Avaliar projeto & & \\
\hline \multirow[t]{3}{*}{ Atividade } & \multirow{3}{*}{$\begin{array}{l}\text { 5.7 Avaliar SSCs, configuração e } \\
\text { documentação do produto e } \\
\text { processo }\end{array}$} & 4.3 .5 & $\begin{array}{l}\text { Gerar e gerenciar estruturas de } \\
\text { produto }\end{array}$ \\
\hline & & 4.3 .12 & Comparar estruturas de produto \\
\hline & & 4.3 .13 & $\begin{array}{l}\text { Analisar onde é usado (where- } \\
\text { used) }\end{array}$ \\
\hline Procedimento & Analisar falhas & & \\
\hline Procedimento & Avaliar Tolerância Analiticamente & & \\
\hline Procedimento & $\begin{array}{l}\text { Planejar os testes (produto e } \\
\text { processo) }\end{array}$ & & \\
\hline Procedimento & \begin{tabular}{|l|} 
Desenvolver modelos para testes \\
(elaborar modelos matemáticos e/ou \\
fabricar/receber o protótipo)
\end{tabular} & & \\
\hline $\begin{array}{l}\text { Procedimento } \\
\end{array}$ & Executar os testes & & \\
\hline Procedimento & Avaliar os resultados e planejar ações & & \\
\hline Procedimento & $\begin{array}{l}\text { Avaliar consonância da } \\
\text { documentação com as normas }\end{array}$ & & \\
\hline \multirow[t]{2}{*}{ Atividade } & \multirow[t]{2}{*}{ 5.8 Otimizar Produto e Processo } & 7.1.1 & Aplicar métodos de qualidade \\
\hline & & 7.1.2 & $\begin{array}{l}\text { Preparar manual eletrônico de } \\
\text { qualidade }\end{array}$ \\
\hline $\begin{array}{l}\text { Procedimento } \\
\end{array}$ & Finalizar aplicação DFx & & \\
\hline Procedimento & Ajustar tolerância dos SSCs & & \\
\hline Procedimento & Executar ações de correção de falhas & & \\
\hline \multirow[t]{4}{*}{ Atividade } & \multirow[t]{4}{*}{$\begin{array}{l}\text { 5.9 Criar material de suporte do } \\
\text { produto }\end{array}$} & 6.3.1 & $\begin{array}{l}\text { Preparar documentação técnica } \\
\text { relacionada com o produto }\end{array}$ \\
\hline & & 6.3 .2 & $\begin{array}{l}\text { Definir relacionamento entre } \\
\text { módulos parametrizados da } \\
\text { documentação com objetos do } \\
\text { sistema }\end{array}$ \\
\hline & & 6.3 .3 & \begin{tabular}{|l|}
$\begin{array}{l}\text { Selecionar formato da } \\
\text { documentação }\end{array}$ \\
\end{tabular} \\
\hline & & 6.3 .4 & \begin{tabular}{|l} 
Selecionar idioma para \\
preparação da documentação
\end{tabular} \\
\hline Procedimento & Criar manual de operação do produto & & \\
\hline Procedimento & Criar material de treinamento & & \\
\hline Procedimento & $\begin{array}{l}\text { Criar manual de descontinuidade do } \\
\text { produto }\end{array}$ & & \\
\hline \multirow[t]{2}{*}{ Atividade } & \multirow[t]{2}{*}{ 5.10 Projetar embalagem } & 10.2.1 & Definir tipos de planos de processo \\
\hline & & 10.2 .3 & Gerar planos de processo \\
\hline Procedimento & $\begin{array}{l}\text { Avaliar a distribuição do produto: } \\
\text { transporte e entrega }\end{array}$ & & \\
\hline Procedimento & $\begin{array}{l}\text { Definir as formas e as sinalizações } \\
\text { das embalagens do produto }\end{array}$ & & \\
\hline Procedimento & Identificar os elementos críticos & & \\
\hline Procedimento & $\begin{array}{l}\text { Adequar embalagem aos elementos } \\
\text { críticos }\end{array}$ & & \\
\hline Procedimento & Projetar embalagem & & \\
\hline Procedimento & Planejar processo de embalagem & & \\
\hline
\end{tabular}




\begin{tabular}{|c|c|c|c|}
\hline \multirow[t]{2}{*}{ Atividade } & \multirow{2}{*}{$\begin{array}{l}\text { 5.11 Planejar fim de vida do } \\
\text { produto }\end{array}$} & 10.2.1 & \multirow{2}{*}{\begin{tabular}{|l} 
Definir tipos de planos de processo \\
Gerar planos de processo
\end{tabular}} \\
\hline & & 10.2 .3 & \\
\hline $\begin{array}{l}\text { Procedimento } \\
\end{array}$ & Definir plano de retirada do mercado & & \\
\hline Procedimento & $\begin{array}{l}\text { Definir plano de descontinuidade da } \\
\text { produção }\end{array}$ & & \\
\hline Procedimento & Definir plano de descarte & & \\
\hline Procedimento & Definir plano de reciclagem & & \\
\hline Atividade & 5.12 Testar e Homologar produto & & \\
\hline Procedimento & Verificar a documentacao & & \\
\hline Procedimento & Verificar a funcionalidade do produto & & \\
\hline Procedimento & $\begin{array}{l}\text { Verificar o atendimento aos } \\
\text { requisitos }\end{array}$ & & \\
\hline Procedimento & Verificar o atendimento a normas & & \\
\hline Procedimento & Obter certificado de homologação & & \\
\hline Atividade & $\begin{array}{l}\text { 5.13 Enviar documentação do } \\
\text { produto a parceiros }\end{array}$ & 4.1.13 & \begin{tabular}{|l|} 
Transferir dados do \\
desenvolvimento para o cadastro \\
mestre
\end{tabular} \\
\hline \multirow[t]{7}{*}{ Atividade } & \multirow[t]{7}{*}{$\begin{array}{l}\text { 5.14 Monitorar a viabilidade } \\
\text { econômico-financeira do produto }\end{array}$} & 1.3.6 & $\begin{array}{l}\text { Acompanhar evolução dos } \\
\text { requisitos }\end{array}$ \\
\hline & & 3.1 .5 & Contabilizar custos de projetos \\
\hline & & 3.1.6 & Gerenciar custos de projetos \\
\hline & & 3.1.7 & Gerenciar orçamento de projetos \\
\hline & & 3.1.8 & $\begin{array}{l}\text { Gerenciar fluxo de caixa de } \\
\text { projetos }\end{array}$ \\
\hline & & 3.1.9 & $\begin{array}{l}\text { Estimar evolução dos custos de } \\
\text { projetos }\end{array}$ \\
\hline & & 3.1.10 & $\begin{array}{l}\text { Ajustar custos em decorrência de } \\
\text { mudanças de engenharia }\end{array}$ \\
\hline Procedimento & $\begin{array}{l}\text { Avaliar mudanças nas condições de } \\
\text { mercado, características técnicas e } \\
\text { indicadores }\end{array}$ & & \\
\hline Procedimento & $\begin{array}{l}\text { Avaliar impacto das mudanças no } \\
\text { projeto }\end{array}$ & & \\
\hline Procedimento & $\begin{array}{l}\text { Atualizar as premissas financeiras do } \\
\text { projeto }\end{array}$ & & \\
\hline Procedimento & $\begin{array}{l}\text { Atualizar custo-alvo nos diversos } \\
\text { níveis do produto }\end{array}$ & & \\
\hline Procedimento & Atualizar as receitas futuras & & \\
\hline Procedimento & $\begin{array}{l}\text { Atualizar as necessidades de } \\
\text { investimentos }\end{array}$ & & \\
\hline Procedimento & Calcular o novo fluxo de caixa & & \\
\hline Procedimento & $\begin{array}{l}\text { Calcular novos indicadores } \\
\text { financeiros }\end{array}$ & & \\
\hline Procedimento & $\begin{array}{l}\text { Analisar novas premissas e } \\
\text { indicadores }\end{array}$ & & \\
\hline Procedimento & $\begin{array}{l}\text { Avaliar possíveis desvios e impactos } \\
\text { no projeto }\end{array}$ & & \\
\hline Atividade & 5.15 Avaliar fase & 3.1.11 & \begin{tabular}{|l|} 
Controlar indicadores de projetos \\
\end{tabular} \\
\hline Procedimento & $\begin{array}{l}\text { Avaliar o cumprimento das tarefas } \\
\text { planejadas }\end{array}$ & & \\
\hline
\end{tabular}




\begin{tabular}{|c|c|c|c|}
\hline Procedimento & $\begin{array}{l}\text { Avaliar os resultados obtidos } \\
\text { segundo os critérios estabelecidos }\end{array}$ & & \\
\hline Procedimento & $\begin{array}{l}\text { Avaliar os demais critérios } \\
\text { quantitativos e indicadores }\end{array}$ & & \\
\hline Procedimento & Avaliar a viabilidade econômica & & \\
\hline Procedimento & Decidir implementar ações corretivas & & \\
\hline Procedimento & $\begin{array}{l}\text { Decidir se pode ser realizada a } \\
\text { atividade de aprovação }\end{array}$ & & \\
\hline Procedimento & $\begin{array}{l}\text { Preparar relatório para time de } \\
\text { avaliação }\end{array}$ & & \\
\hline Atividade & 5.16 Aprovar fase & & \\
\hline Procedimento & $\begin{array}{l}\text { Avaliar o relatório de auto-avaliação } \\
\text { e discutí-lo com o time de } \\
\text { desenvolvimento }\end{array}$ & & \\
\hline Procedimento & $\begin{array}{l}\text { Analisar as evidências dos resultados } \\
\text { e término das atividades planejadas }\end{array}$ & & \\
\hline Procedimento & $\begin{array}{l}\text { Analisar o portfólio de produtos e } \\
\text { projetos }\end{array}$ & & \\
\hline Procedimento & $\begin{array}{l}\text { Analisar o estudo de viabilidade } \\
\text { econômica }\end{array}$ & & \\
\hline Procedimento & $\begin{array}{l}\text { Aplicar os critérios de avaliação e } \\
\text { tomar decisão }\end{array}$ & & \\
\hline Procedimento & Preparar relatório & & \\
\hline Procedimento & Melhorar o processo do gate & & \\
\hline Procedimento & Ajustar critérios próxima fase & & \\
\hline Procedimento & Definir ações corretivas & & \\
\hline Procedimento & Analisar risco & & \\
\hline Atividade & $\begin{array}{l}\text { 5.17 Documentar as decisões } \\
\text { tomadas e registrar lições } \\
\text { aprendidas }\end{array}$ & & \\
\hline Sub-processo & $\begin{array}{l}\text { Preparação da Produção do } \\
\text { Produto }\end{array}$ & & \\
\hline \multirow[t]{5}{*}{ Atividade } & \multirow[t]{5}{*}{ 6.1 Obter recursos de fabricação } & 10.1.1 & $\begin{array}{l}\text { Criar cadastro de recursos de } \\
\text { diferentes tipos }\end{array}$ \\
\hline & & 10.1.2 & $\begin{array}{l}\text { Descrever recursos com base em } \\
\text { características }\end{array}$ \\
\hline & & 10.1.3 & Inter-relacionar recursos \\
\hline & & 10.1.4 & Agrupar recursos \\
\hline & & 10.1.5 & $\begin{array}{l}\text { Obter sugestão de recursos } \\
\text { alternativos de acordo com } \\
\text { parâmetros }\end{array}$ \\
\hline Procedimento & $\begin{array}{l}\text { Desenvolver recursos de fabricação } \\
\text { não comprados }\end{array}$ & & \\
\hline Procedimento & Comprar recursos de fabricação & & \\
\hline Atividade & 6.2 Planejar Produção Piloto & & \\
\hline Procedimento & Atualizar plano de medição & & \\
\hline Procedimento & $\begin{array}{l}\text { Verificar disponibilidade dos } \\
\text { equipamentos em uso e a } \\
\text { operacionalidade dos recursos novos }\end{array}$ & & \\
\hline
\end{tabular}




\begin{tabular}{|c|c|c|c|}
\hline Procedimento & | Elaborar PCP / programar lote piloto & & \\
\hline Procedimento & $\begin{array}{l}\text { Contabilizar investimentos na } \\
\text { homologação }\end{array}$ & & \\
\hline Atividade & 6.3 Receber e instalar recursos & & \\
\hline Procedimento & $\begin{array}{l}\text { Conferir dados fiscais e complitude } \\
\text { das partes }\end{array}$ & & \\
\hline Procedimento & Montar e instalar & & \\
\hline Procedimento & \begin{tabular}{|l} 
Testar recurso \\
\end{tabular} & & \\
\hline Procedimento & Aprovar recurso & & \\
\hline Atividade & 6.4 Produzir Lote Piloto & & \\
\hline \multirow[t]{4}{*}{ Atividade } & \multirow[t]{4}{*}{ 6.5 Homologar processo } & 7.2.1 & Elaborar plano de controle \\
\hline & & 7.2.2 & Gerenciar meios de medição \\
\hline & & 7.2.3 & Definir amostras de controle \\
\hline & & 7.3.1 & $\begin{array}{l}\text { Registrar resultados dos controles } \\
\text { de qualidade }\end{array}$ \\
\hline $\begin{array}{l}\text { Procedimento } \\
\end{array}$ & Avaliar lote piloto & & \\
\hline Procedimento & Avaliar meios de medição & & \\
\hline Procedimento & Avaliar capabilidade de processo & & \\
\hline Atividade & 6.6 Otimizar produção & & \\
\hline Atividade & 6.7 Certificar produto & & \\
\hline Procedimento & \begin{tabular}{|l|}
$\begin{array}{l}\text { Avaliar exigências de } \\
\text { regulamentação }\end{array}$ \\
\end{tabular} & & \\
\hline Procedimento & $\begin{array}{l}\text { Submeter ao cliente o processo de } \\
\text { aprovação }\end{array}$ & & \\
\hline Procedimento & $\begin{array}{l}\text { Avaliar os serviços associados ao } \\
\text { produto }\end{array}$ & & \\
\hline Procedimento & $\begin{array}{l}\text { Obter documentação para } \\
\text { certificação }\end{array}$ & & \\
\hline Atividade & $\begin{array}{l}\text { 6.8 Desenvolver processo de } \\
\text { produção }\end{array}$ & & \\
\hline Procedimento & $\begin{array}{l}\text { Desenvolver processo planejamento e } \\
\text { controle da produção }\end{array}$ & & \\
\hline Procedimento & $\begin{array}{l}\text { Desenhar os processos de logística e } \\
\text { relação de entrega de produtos aos } \\
\text { clientes }\end{array}$ & & \\
\hline Procedimento & $\begin{array}{l}\text { Selecionar/desenvolver ferramentas } \\
\text { de apoio }\end{array}$ & & \\
\hline \multirow[t]{5}{*}{ Atividade } & \multirow[t]{5}{*}{$\begin{array}{l}\text { 6.9 Desenvolver processo de } \\
\text { manutenção }\end{array}$} & 9.1 .1 & $\begin{array}{l}\text { Gerar informações de manutenção } \\
\text { no sistema e disponibilizar para } \\
\text { consulta por prestadores de } \\
\text { serviço internos e externos }\end{array}$ \\
\hline & & 9.1 .2 & $\begin{array}{l}\text { Configurar banco de dados de } \\
\text { recursos de manutenção }\end{array}$ \\
\hline & & 9.1 .3 & Gerar ordens de manutenção \\
\hline & & 9.1 .4 & $\begin{array}{l}\text { Gerenciar ocupação dos recursos } \\
\text { de manutenção }\end{array}$ \\
\hline & & 9.1 .5 & $\begin{array}{l}\text { Registrar indicadores de } \\
\text { manutenção por produto e/ou por } \\
\text { cliente }\end{array}$ \\
\hline Procedimento & Definir política de manutenção & & \\
\hline
\end{tabular}




\begin{tabular}{|c|c|c|c|}
\hline Procedimento & $\begin{array}{l}\text { Definir procedimentos da } \\
\text { manutenção }\end{array}$ & & \\
\hline Atividade & 6.10 Ensinar pessoal & & \\
\hline Procedimento & Mapear competências necessárias & & \\
\hline Procedimento & Definir cursos de treinamento & & \\
\hline Procedimento & Contratar instrutores & & \\
\hline Procedimento & Desenvolver cursos & & \\
\hline Procedimento & Desenvolver instrutores & & \\
\hline Procedimento & Treinar pessoal & & \\
\hline Procedimento & avaliar pessoal & & \\
\hline Procedimento & certificar pessoal & & \\
\hline Procedimento & montar cursos continuos & & \\
\hline \multirow[t]{7}{*}{ Atividade } & \multirow[t]{7}{*}{$\begin{array}{l}\text { 6.11 Monitorar a viabilidade } \\
\text { econômico-financeira }\end{array}$} & 1.3.6 & $\begin{array}{l}\text { Acompanhar evolução dos } \\
\text { requisitos }\end{array}$ \\
\hline & & 3.1.5 & Contabilizar custos de projetos \\
\hline & & 3.1.6 & Gerenciar custos de projetos \\
\hline & & 3.1.7 & Gerenciar orçamento de projetos \\
\hline & & 3.1.8 & $\begin{array}{l}\text { Gerenciar fluxo de caixa de } \\
\text { projetos }\end{array}$ \\
\hline & & 3.1.9 & $\begin{array}{l}\text { Estimar evolução dos custos de } \\
\text { projetos }\end{array}$ \\
\hline & & 3.1.10 & $\begin{array}{l}\text { Ajustar custos em decorrência de } \\
\text { mudanças de engenharia }\end{array}$ \\
\hline Procedimento & $\begin{array}{l}\text { Avaliar mudanças nas condições de } \\
\text { mercado, características técnicas e } \\
\text { indicadores }\end{array}$ & & \\
\hline Procedimento & $\begin{array}{l}\text { Avaliar impacto das mudanças no } \\
\text { projeto }\end{array}$ & & \\
\hline Procedimento & $\begin{array}{l}\text { Atualizar as premissas financeiras do } \\
\text { projeto }\end{array}$ & & \\
\hline Procedimento & $\begin{array}{l}\text { Atualizar custo-alvo nos diversos } \\
\text { níveis do produto }\end{array}$ & & \\
\hline Procedimento & Atualizar as receitas futuras & & \\
\hline Procedimento & $\begin{array}{l}\text { Atualizar as necessidades de } \\
\text { investimentos }\end{array}$ & & \\
\hline Procedimento & Calcular o novo fluxo de caixa & & \\
\hline Procedimento & $\begin{array}{l}\text { Calcular novos indicadores } \\
\text { financeiros }\end{array}$ & & \\
\hline Procedimento & $\begin{array}{l}\text { Analisar novas premissas e } \\
\text { indicadores }\end{array}$ & & \\
\hline Procedimento & $\begin{array}{l}\text { Avaliar possíveis desvios e impactos } \\
\text { no projeto }\end{array}$ & & \\
\hline Atividade & 6.12 Avaliar fase & 3.1.11 & Controlar indicadores de projetos \\
\hline Procedimento & $\begin{array}{l}\text { Avaliar o cumprimento das tarefas } \\
\text { planejadas }\end{array}$ & & \\
\hline Procedimento & $\begin{array}{l}\text { Avaliar os resultados obtidos } \\
\text { segundo os critérios estabelecidos }\end{array}$ & & \\
\hline Procedimento & $\begin{array}{l}\text { Avaliar os demais critérios } \\
\text { quantitativos e indicadores }\end{array}$ & & \\
\hline Procedimento & Avaliar a viabilidade econômica & & \\
\hline
\end{tabular}




\begin{tabular}{|c|c|c|c|}
\hline Procedimento & Decidir implementar ações corretivas & & \\
\hline Procedimento & $\begin{array}{l}\text { Decidir se pode ser realizada a } \\
\text { atividade de aprovação }\end{array}$ & & \\
\hline Procedimento & $\begin{array}{l}\text { Preparar relatório para time de } \\
\text { avaliação }\end{array}$ & & \\
\hline \multirow[t]{2}{*}{ Atividade } & \multirow[t]{2}{*}{$\begin{array}{l}\text { 6.13 Aprovar fase- liberar } \\
\text { producao }\end{array}$} & 4.1.13 & $\begin{array}{l}\text { Transferir dados do } \\
\text { desenvolvimento para o cadastro } \\
\text { mestre }\end{array}$ \\
\hline & & 4.3.10 & $\begin{array}{l}\text { Liberar posições da estrutura de } \\
\text { produto }\end{array}$ \\
\hline Procedimento & $\begin{array}{l}\text { Avaliar o relatório de auto-avaliação } \\
\text { e discutí-lo com o time de } \\
\text { desenvolvimento }\end{array}$ & & \\
\hline Procedimento & $\begin{array}{l}\text { Analisar as evidências dos resultados } \\
\text { e término das atividades planejadas }\end{array}$ & & \\
\hline Procedimento & $\begin{array}{l}\text { Analisar o portfólio de produtos e } \\
\text { projetos }\end{array}$ & & \\
\hline Procedimento & $\begin{array}{l}\text { Analisar o estudo de viabilidade } \\
\text { econômica }\end{array}$ & & \\
\hline Procedimento & $\begin{array}{l}\text { Aplicar os critérios de avaliação e } \\
\text { tomar decisão }\end{array}$ & & \\
\hline Procedimento & Preparar relatório & & \\
\hline Procedimento & Melhorar o processo do gate & & \\
\hline Procedimento & Ajustar critérios próxima fase & & \\
\hline Procedimento & Definir ações corretivas & & \\
\hline Procedimento & Analisar risco & & \\
\hline Atividade & $\begin{array}{l}\text { 6.14 Documentar as decisões } \\
\text { tomadas e registrar lições } \\
\text { aprendidas }\end{array}$ & & \\
\hline Sub-processo & Lançamento do Produto & & \\
\hline Atividade & 7.1 Planejar lançamento & & \\
\hline Procedimento & Analisar o plano de projeto atual & & \\
\hline Procedimento & $\begin{array}{l}\text { Analisar e sintetizar as novas } \\
\text { condições para a realização do } \\
\text { projeto }\end{array}$ & & \\
\hline Procedimento & Atualizar o escopo do produto & & \\
\hline Procedimento & $\begin{array}{l}\text { Atualizar e detalhar o escopo do } \\
\text { projeto }\end{array}$ & & \\
\hline Procedimento & $\begin{array}{l}\text { Atualizar e detalhar as atividades, os } \\
\text { responsáveis, os prazos e o } \\
\text { cronograma }\end{array}$ & & \\
\hline Procedimento & $\begin{array}{l}\text { Atualizar e detalhar recursos } \\
\text { necessários }\end{array}$ & & \\
\hline Procedimento & $\begin{array}{l}\text { Atualizar estimativa de orçamento do } \\
\text { projeto }\end{array}$ & & \\
\hline Procedimento & $\begin{array}{l}\text { Atualizar, monitorar, valorar e definir } \\
\text { novos indicadores de desempenho }\end{array}$ & & \\
\hline Procedimento & $\begin{array}{l}\text { Analisar a viabilidade econômico- } \\
\text { financeira do projeto }\end{array}$ & & \\
\hline Procedimento & Avaliar novos riscos & & \\
\hline
\end{tabular}




\begin{tabular}{|c|c|c|c|}
\hline Procedimento & Atualizar plano de comunicação & & \\
\hline Procedimento & $\begin{array}{l}\text { Planejar, atualizar e preparar novas } \\
\text { aquisições }\end{array}$ & & \\
\hline Procedimento & $\begin{array}{l}\text { Definir/atualizar os critérios de } \\
\text { passagem dos gates }\end{array}$ & & \\
\hline \multirow[t]{3}{*}{ Atividade } & \multirow[t]{3}{*}{ 7.2 Desenvolver processo de vendas } & 4.5 .1 & $\begin{array}{l}\text { Empregar funções do sistema para } \\
\text { a configuração de produtos }\end{array}$ \\
\hline & & 4.5 .2 & Configurar produtos \\
\hline & & 4.5.3 & Exibir resultados da configuração \\
\hline Procedimento & Desenhar processo de vendas & & \\
\hline Procedimento & Adquirir recursos & & \\
\hline Procedimento & Preparar documentação comercial & & \\
\hline Procedimento & $\begin{array}{l}\text { Desenvolver sistema de apoio a } \\
\text { vendas }\end{array}$ & & \\
\hline Procedimento & Contratar/ alocar pessoal & & \\
\hline Procedimento & Treinar força de venda & & \\
\hline Procedimento & Treinar pessoal de apoio a venda & & \\
\hline Procedimento & Implantar processo de vendas & & \\
\hline Atividade & $\begin{array}{l}\text { 7.3 Desenvolver processo de } \\
\text { distribuicao }\end{array}$ & & \\
\hline Procedimento & Desenhar processo de distribuição & & \\
\hline Procedimento & Definir logística do processo & & \\
\hline Procedimento & Fechar acordos com distribuidores & & \\
\hline Procedimento & Adquirir recursos & & \\
\hline Procedimento & $\begin{array}{l}\text { Desenvolver sistema de apoio a } \\
\text { distribuição }\end{array}$ & & \\
\hline Procedimento & $\begin{array}{l}\text { Treinar pessoal de apoio à } \\
\text { distribuição }\end{array}$ & & \\
\hline Procedimento & $\begin{array}{l}\text { Implantar/integrar o processo de } \\
\text { distribuição }\end{array}$ & & \\
\hline Atividade & $\begin{array}{l}\text { 7.4 Desenvolver processo de } \\
\text { atendimento ao cliente }\end{array}$ & & \\
\hline Procedimento & $\begin{array}{l}\text { Desenhar processo de atendimento ao } \\
\text { cliente }\end{array}$ & & \\
\hline Procedimento & Comprar recursos & & \\
\hline Procedimento & $\begin{array}{l}\text { Desenvolver documentacao de } \\
\text { atendimento ao cliente }\end{array}$ & & \\
\hline Procedimento & $\begin{array}{l}\text { Desenvolver sistema de apoio a } \\
\text { atendimento ao cliente }\end{array}$ & & \\
\hline Procedimento & Contratar / alocar pessoal/empresa & & \\
\hline Procedimento & $\begin{array}{l}\text { Treinar pessoal de atendimento ao } \\
\text { cliente }\end{array}$ & & \\
\hline Procedimento & $\begin{array}{l}\text { Implantar processo de atendimento } \\
\text { ao cliente }\end{array}$ & & \\
\hline \multirow[t]{2}{*}{ Atividade } & \multirow[t]{2}{*}{$\begin{array}{l}\text { 7.5 Desenvolver processo de } \\
\text { assistência técnica }\end{array}$} & 9.1.1 & $\begin{array}{l}\text { Gerar informações de manutenção } \\
\text { no sistema e disponibilizar para } \\
\text { consulta por prestadores de } \\
\text { serviço internos e externos }\end{array}$ \\
\hline & & 9.1.2 & $\begin{array}{l}\text { Configurar banco de dados de } \\
\text { recursos de manutenção }\end{array}$ \\
\hline
\end{tabular}




\begin{tabular}{|c|c|c|c|}
\hline & & 9.1 .3 & Gerar ordens de manutenção \\
\hline & & 9.1 .4 & $\begin{array}{l}\text { Gerenciar ocupação dos recursos } \\
\text { de manutenção }\end{array}$ \\
\hline & & 9.1 .5 & $\begin{array}{l}\text { Registrar indicadores de } \\
\text { manutenção por produto e/ou por } \\
\text { cliente }\end{array}$ \\
\hline Procedimento & $\begin{array}{l}\text { Desenhar processo de assistência } \\
\text { técnica }\end{array}$ & & \\
\hline Procedimento & Comprar recursos & & \\
\hline Procedimento & $\begin{array}{l}\text { Desenvolver documentação de } \\
\text { assistência técnica }\end{array}$ & & \\
\hline Procedimento & $\begin{array}{l}\text { Desenvolver sistema de apoio a } \\
\text { assistência técnica }\end{array}$ & & \\
\hline Procedimento & Contratar / alocar pessoal/empresa & & \\
\hline Procedimento & Treinar pessoal de assistência técnica & & \\
\hline Procedimento & $\begin{array}{l}\text { Implantar processo de assistência } \\
\text { técnica }\end{array}$ & & \\
\hline Atividade & $\begin{array}{l}\text { 7.6 Promover marketing de } \\
\text { lançamento }\end{array}$ & & \\
\hline Procedimento & Atualizar o plano de lançamento & & \\
\hline Procedimento & Preparar campanha publicitária & & \\
\hline Procedimento & Desenvolver propaganda & & \\
\hline Procedimento & Promover vendas & & \\
\hline Procedimento & Contratar fornecedores de serviço & & \\
\hline Atividade & 7.7 Lançar produto & & \\
\hline Procedimento & $\begin{array}{l}\text { Avaliar processos de apoio à } \\
\text { produção }\end{array}$ & & \\
\hline Procedimento & Planejar evento de lançamento & & \\
\hline Procedimento & Contratar serviços para o lançamento & & \\
\hline Procedimento & Promover evento de lançamento & & \\
\hline Atividade & 7.8 Gerenciar lançamento & & \\
\hline Procedimento & Gerenciar resultados & & \\
\hline Procedimento & Gerenciar aceitação inicial & & \\
\hline Procedimento & Gerenciar satisfação do cliente & & \\
\hline Atividade & 7.9 Atualizar plano de fim de vida & & \\
\hline \multirow[t]{7}{*}{ Atividade } & \multirow[t]{7}{*}{$\begin{array}{l}\text { 7.10 Monitorar a viabilidade } \\
\text { econômico-financeira }\end{array}$} & 1.3 .6 & $\begin{array}{l}\text { Acompanhar evolução dos } \\
\text { requisitos }\end{array}$ \\
\hline & & 3.1 .5 & Contabilizar custos de projetos \\
\hline & & 3.1 .6 & Gerenciar custos de projetos \\
\hline & & 3.1.7 & Gerenciar orçamento de projetos \\
\hline & & 3.1 .8 & $\begin{array}{l}\text { Gerenciar fluxo de caixa de } \\
\text { projetos }\end{array}$ \\
\hline & & 3.1 .9 & $\begin{array}{l}\text { Estimar evolução dos custos de } \\
\text { projetos }\end{array}$ \\
\hline & & 3.1.10 & $\begin{array}{l}\text { Ajustar custos em decorrência de } \\
\text { mudanças de engenharia }\end{array}$ \\
\hline Procedimento & $\begin{array}{l}\text { Avaliar mudanças nas condições de } \\
\text { mercado, características técnicas e } \\
\text { indicadores }\end{array}$ & & \\
\hline
\end{tabular}




\begin{tabular}{|c|c|c|c|}
\hline Procedimento & $\begin{array}{l}\text { Avaliar impacto das mudanças no } \\
\text { projeto }\end{array}$ & & \\
\hline Procedimento & $\begin{array}{l}\text { Atualizar as premissas financeiras do } \\
\text { projeto }\end{array}$ & & \\
\hline Procedimento & $\begin{array}{l}\text { Atualizar custo-alvo nos diversos } \\
\text { níveis do produto }\end{array}$ & & \\
\hline Procedimento & Atualizar as receitas futuras & & \\
\hline Procedimento & $\begin{array}{l}\text { Atualizar as necessidades de } \\
\text { investimentos }\end{array}$ & & \\
\hline Procedimento & Calcular o novo fluxo de caixa & & \\
\hline Procedimento & $\begin{array}{l}\text { Calcular novos indicadores } \\
\text { financeiros }\end{array}$ & & \\
\hline Procedimento & $\begin{array}{l}\text { Analisar novas premissas e } \\
\text { indicadores }\end{array}$ & & \\
\hline Procedimento & $\begin{array}{l}\text { Avaliar possíveis desvios e impactos } \\
\text { no projeto }\end{array}$ & & \\
\hline Atividade & 7.11 Avaliar fase & 3.1.11 & Controlar indicadores de projetos \\
\hline Procedimento & $\begin{array}{l}\text { Avaliar o cumprimento das tarefas } \\
\text { planejadas }\end{array}$ & & \\
\hline Procedimento & $\begin{array}{l}\text { Avaliar os resultados obtidos } \\
\text { segundo os critérios estabelecidos }\end{array}$ & & \\
\hline Procedimento & $\begin{array}{l}\text { Avaliar os demais critérios } \\
\text { quantitativos e indicadores }\end{array}$ & & \\
\hline Procedimento & Avaliar a viabilidade econômica & & \\
\hline Procedimento & Decidir implementar ações corretivas & & \\
\hline Procedimento & $\begin{array}{l}\text { Decidir se pode ser realizada a } \\
\text { atividade de aprovação }\end{array}$ & & \\
\hline Procedimento & $\begin{array}{l}\text { Preparar relatório para time de } \\
\text { avaliação }\end{array}$ & & \\
\hline Atividade & 7.12 Aprovar fase & & \\
\hline Procedimento & $\begin{array}{l}\text { Avaliar o relatório de auto-avaliação } \\
\text { e discutí-lo com o time de } \\
\text { desenvolvimento }\end{array}$ & & \\
\hline Procedimento & $\begin{array}{l}\text { Analisar as evidências dos resultados } \\
\text { e término das atividades planejadas }\end{array}$ & & \\
\hline Procedimento & $\begin{array}{l}\text { Analisar o portfólio de produtos e } \\
\text { projetos }\end{array}$ & & \\
\hline Procedimento & $\begin{array}{l}\text { Analisar o estudo de viabilidade } \\
\text { econômica }\end{array}$ & & \\
\hline Procedimento & $\begin{array}{l}\text { Aplicar os critérios de avaliação e } \\
\text { tomar decisão }\end{array}$ & & \\
\hline Procedimento & Preparar relatório & & \\
\hline Procedimento & Melhorar o processo do gate & & \\
\hline Procedimento & Ajustar critérios próxima fase & & \\
\hline Procedimento & Definir ações corretivas & & \\
\hline Procedimento & Analisar risco & & \\
\hline Atividade & $\begin{array}{l}\text { 7.13 Documentar as decisões } \\
\text { tomadas e registrar lições } \\
\text { aprendidas }\end{array}$ & & \\
\hline
\end{tabular}




\begin{tabular}{|c|c|c|c|}
\hline Processo & $\begin{array}{l}\text { Acompanhamento e retirada de } \\
\text { produtos }\end{array}$ & & \\
\hline Sub-processo & Acompanhar Produto e Processo & & \\
\hline Atividade & 8.1 Avaliar Satisfação do Cliente & & \\
\hline Procedimento & Planejar a avaliação & & \\
\hline Procedimento & Realizar a avaliação & & \\
\hline Procedimento & Análisar e consolidar a avaliação & & \\
\hline \multirow[t]{11}{*}{ Atividade } & \multirow[t]{11}{*}{$\begin{array}{l}\text { 8.2 Monitorar desempenho do } \\
\text { produto (técnico, econômico, de } \\
\text { produção e de serviços) }\end{array}$} & 3.2.1 & $\begin{array}{l}\text { Registrar custos e receitas do } \\
\text { produto ao longo do ciclo de vida } \\
\text { (Product Lifecycle Costing) }\end{array}$ \\
\hline & & 3.2.2 & $\begin{array}{l}\text { Definir os tipos de custos e de } \\
\text { receitas que são considerados no } \\
\text { cálculo do resultado no ciclo de } \\
\text { vida }\end{array}$ \\
\hline & & 3.2.3 & $\begin{array}{l}\text { Analisar o desempenho financeiro } \\
\text { no ciclo de vida }\end{array}$ \\
\hline & & 9.2 .1 & Executar a manutenção \\
\hline & & 9.2 .2 & $\begin{array}{l}\text { Registrar alterações na } \\
\text { configuração dos produtos }\end{array}$ \\
\hline & & 9.2 .3 & $\begin{array}{l}\text { Registrar conclusão das ordens de } \\
\text { manutenção }\end{array}$ \\
\hline & & 9.2 .4 & $\begin{array}{l}\text { Registrar conhecimentos e } \\
\text { experiências geradas na } \\
\text { manutenção }\end{array}$ \\
\hline & & 8.2 .1 & $\begin{array}{l}\text { Gerar documentação para } \\
\text { utilização de substâncias } \\
\text { controladas }\end{array}$ \\
\hline & & 8.2.2 & $\begin{array}{l}\text { Gerar relatórios sobre a utilização } \\
\text { de substâncias controladas }\end{array}$ \\
\hline & & 8.4.1 & $\begin{array}{l}\text { Controlar procedimentos de } \\
\text { segurança do trabalho }\end{array}$ \\
\hline & & 8.4 .2 & $\begin{array}{l}\text { Protocolar eventos relevantes de } \\
\text { segurança do trabalho }\end{array}$ \\
\hline Procedimento & $\begin{array}{l}\text { Monitorar o desempenho técnico do } \\
\text { produto no mercado e nos serviços } \\
\text { associados }\end{array}$ & & \\
\hline Procedimento & \begin{tabular}{|l|} 
Monitorar o desempenho técnico do \\
produto na produção
\end{tabular} & & \\
\hline Procedimento & $\begin{array}{l}\text { Monitorar o desempenho do processo } \\
\text { de produção }\end{array}$ & & \\
\hline Procedimento & Monitorar o desempenho em vendas & & \\
\hline Procedimento & $\begin{array}{l}\text { Monitorar avaliação econômica do } \\
\text { produto }\end{array}$ & & \\
\hline Procedimento & Monitorar custo do produto & & \\
\hline Procedimento & $\begin{array}{l}\text { Monitorar aspectos relacionados ao } \\
\text { meio-ambiente }\end{array}$ & & \\
\hline Procedimento & $\begin{array}{l}\text { Consolidar informações sobre } \\
\text { desempenho (técnico, econômico, } \\
\text { ambiental, de produção e de serviços) }\end{array}$ & & \\
\hline \multirow[t]{2}{*}{ Atividade } & \multirow[t]{2}{*}{ 8.3 Realizar auditoria pós-projeto } & 7.4.1 & Planejar auditorias \\
\hline & & 7.4 .2 & Realizar auditorias \\
\hline
\end{tabular}




\begin{tabular}{|c|c|c|c|}
\hline Procedimento & | Planejar os focos da auditoria & & \\
\hline Procedimento & Conduzir a auditoria & & \\
\hline Procedimento & $\begin{array}{l}\text { Relatar e comunicar a aprendizagem } \\
\text { pós-projeto }\end{array}$ & & \\
\hline Atividade & 8.4 Registrar lições aprendidas & & \\
\hline Sub-processo & Descontiuar Produto no Mercado & & \\
\hline Atividade & $\begin{array}{l}\text { 9.1 Analisar e aprovar } \\
\text { descontinuidade do produto }\end{array}$ & & \\
\hline \multirow[t]{2}{*}{ Atividade } & \multirow{2}{*}{$\begin{array}{l}\text { 9.2 Planejar a descontinuidade do } \\
\text { produto }\end{array}$} & 10.2 .1 & Definir tipos de planos de processo \\
\hline & & 10.2 .3 & Gerar planos de processo \\
\hline Atividade & $\begin{array}{l}9.3 \text { Preparar o recebimento do } \\
\text { produto }\end{array}$ & 8.3.1 & Notificar geração de resíduo \\
\hline Atividade & $\begin{array}{l}\text { 9.4 Acompanhar o recebimento do } \\
\text { produto }\end{array}$ & 8.3.2 & Realizar disposição final \\
\hline Atividade & 9.5 Descontinuar a produção & & \\
\hline Atividade & 9.6 Finalizar suporte ao produto & & \\
\hline \multirow[t]{5}{*}{ Atividade } & \multirow[t]{5}{*}{$\begin{array}{l}\text { 9.7 Avaliação geral e encerramento } \\
\text { do projeto }\end{array}$} & 1.3.6 & $\begin{array}{l}\text { Acompanhar evolução dos } \\
\text { requisitos }\end{array}$ \\
\hline & & 3.1.11 & Controlar indicadores de projetos \\
\hline & & 3.2.1 & $\begin{array}{l}\text { Registrar custos e receitas do } \\
\text { produto ao longo do ciclo de vida } \\
\text { (Product Lifecycle Costing) }\end{array}$ \\
\hline & & 3.2 .2 & $\begin{array}{l}\text { Definir os tipos de custos e de } \\
\text { receitas que são considerados no } \\
\text { cálculo do resultado no ciclo de } \\
\text { vida }\end{array}$ \\
\hline & & 3.2.3 & $\begin{array}{l}\text { Analisar o desempenho financeiro } \\
\text { no ciclo de vida }\end{array}$ \\
\hline Processo & Gestão da configuração & & \\
\hline Sub-processo & $\begin{array}{l}\text { Gerenciamento de Mudanças de } \\
\text { Engenharia }\end{array}$ & & \\
\hline \multirow[t]{13}{*}{ Atividade } & \multirow[t]{13}{*}{ 10.1 Identificar mudança } & 5.1.1 & Manter controle de versões \\
\hline & & 5.1 .2 & Gerar nova versão \\
\hline & & 5.1 .3 & Criar uma rede de status \\
\hline & & 5.1.4 & Definir os tipos de status \\
\hline & & 5.1 .5 & Definir formas de aprovação \\
\hline & & \begin{tabular}{|l|l|}
5.1 .6 \\
\end{tabular} & Definir parâmetro de validade \\
\hline & & 5.2.1 & $\begin{array}{l}\text { Definir os passos necessários e os } \\
\text { tipos de aprovação no sistema }\end{array}$ \\
\hline & & 5.2 .2 & Realizar aprovações \\
\hline & & 5.2 .3 & $\begin{array}{l}\text { Definir as ações decorrentes de } \\
\text { uma aprovação }\end{array}$ \\
\hline & & 5.3.1 & $\begin{array}{l}\text { Ativar / desativar gestão de } \\
\text { mudanças }\end{array}$ \\
\hline & & 5.3 .2 & $\begin{array}{l}\text { Controlar mudanças dos objetos } \\
\text { do sistema }\end{array}$ \\
\hline & & 5.3.3 & $\begin{array}{l}\text { Gerar pedido de mudança de } \\
\text { engenharia }\end{array}$ \\
\hline & & 5.3 .4 & $\begin{array}{l}\text { Detalhar informações no pedido de } \\
\text { mudança de engenharia }\end{array}$ \\
\hline
\end{tabular}




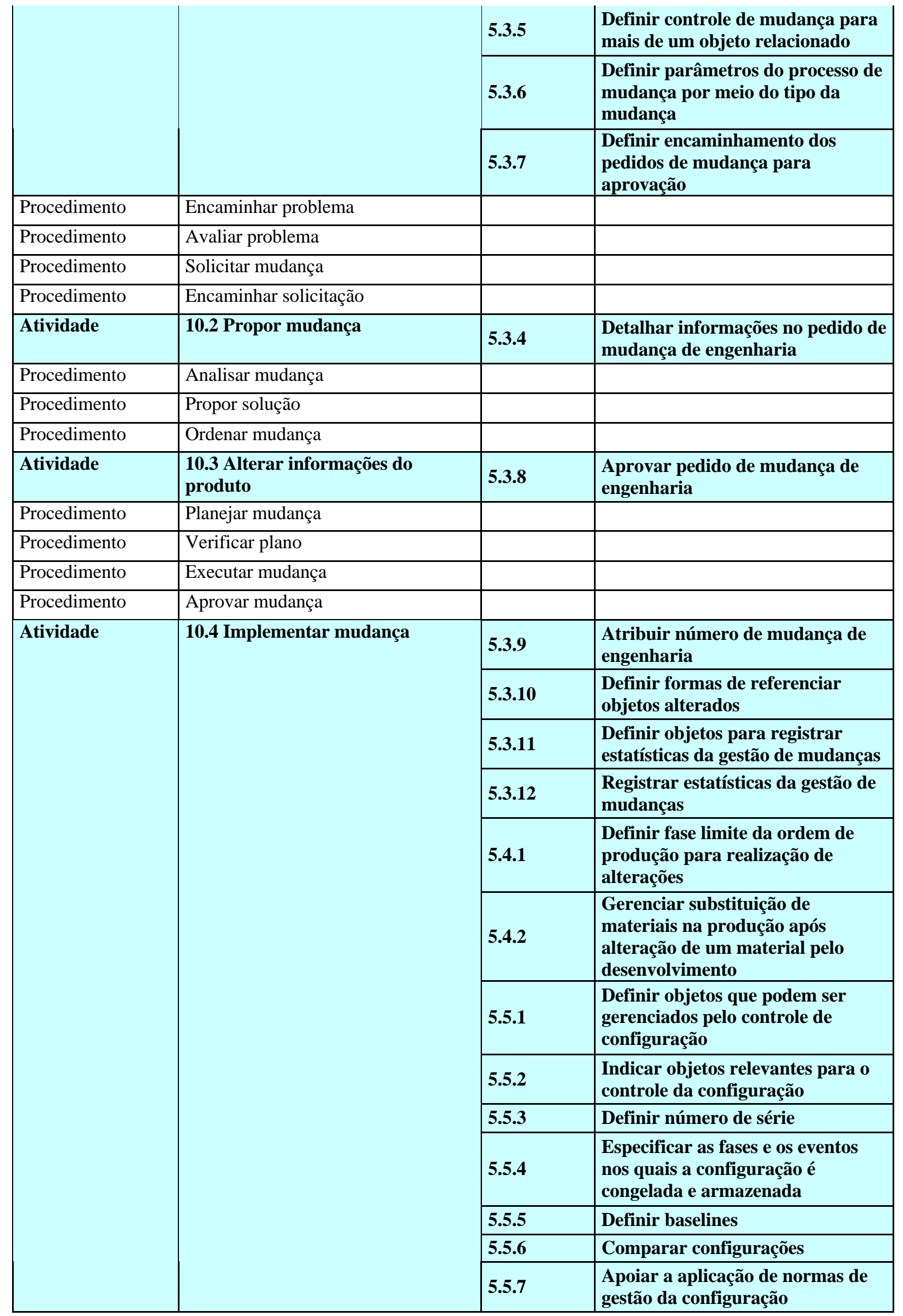




\begin{tabular}{|c|c|c|c|}
\hline Procedimento & Avaliar impacto & & \\
\hline Procedimento & Definir efetividade & & \\
\hline Procedimento & Liberar mudança & & \\
\hline Procedimento & Modificar ordens & & \\
\hline Procedimento & Modificar pedidos & & \\
\hline Procedimento & Modificar configuração & & \\
\hline Procedimento & Divulgar mudança & & \\
\hline Procedimento & Acompanhar implementação & & \\
\hline Processo & $\begin{array}{l}\text { Melhoria dos processos de } \\
\text { gestão do ciclo de vida }\end{array}$ & & \\
\hline Sub-processo & Melhoria (incremental) do PDP & & \\
\hline Atividade & 11.1 Definição de mudança & & \\
\hline Procedimento & Entender necessidade de mudança & & \\
\hline Procedimento & $\begin{array}{l}\text { Analisar necessidades de mudança } \\
\text { versus plano estratégico }\end{array}$ & & \\
\hline Atividade & 11.2 Diagnóstico & & \\
\hline Procedimento & Analisar situação atual & & \\
\hline Atividade & $\begin{array}{l}\text { 11.3 Definição do portfólio de } \\
\text { projetos }\end{array}$ & & \\
\hline Procedimento & Especificar os projetos de mudança & & \\
\hline Procedimento & Analisar portfólio de projetos & & \\
\hline Procedimento & Escolher projetos & & \\
\hline Atividade & 11.4 Planejar a mudança & & \\
\hline $\begin{array}{l}\text { Procedimento } \\
\end{array}$ & \begin{tabular}{|l} 
Definir patrocinador \\
\end{tabular} & & \\
\hline Procedimento & Definir escopo do produto & & \\
\hline Procedimento & Definir escopo do projeto & & \\
\hline Procedimento & $\begin{array}{l}\text { Criar a WBS (Work Breakdown } \\
\text { Structure) }\end{array}$ & & \\
\hline Procedimento & Elaborar cronograma do projeto & & \\
\hline Procedimento & Avaliar riscos & & \\
\hline Procedimento & Garantir infra-estrutura & & \\
\hline Procedimento & Mobilizar e treinar as pessoas & & \\
\hline Procedimento & Avaliar e aprovar resultados da fase & & \\
\hline Procedimento & $\begin{array}{l}\text { Comunicar e documentar o } \\
\text { planejamento da mudança }\end{array}$ & & \\
\hline Atividade & 11.5 Analisar situação atual & & \\
\hline Procedimento & Realizar diagnóstico da situação atual & & \\
\hline Procedimento & $\begin{array}{l}\text { Definir CATWOE (Client, Actor, } \\
\text { Transformation, Weltanschauug, } \\
\text { Owner, Environment) }\end{array}$ & & \\
\hline Procedimento & Levantar requisitos & & \\
\hline Procedimento & Medir situação atual & & \\
\hline Procedimento & Avaliar e aprovar resultados da fase & & \\
\hline Procedimento & $\begin{array}{l}\text { Comunicar e documentar o processo } \\
\text { de mudança }\end{array}$ & & \\
\hline Atividade & 11.6 Projetar situação futura & & \\
\hline Procedimento & Modelar a situação futura & & \\
\hline
\end{tabular}




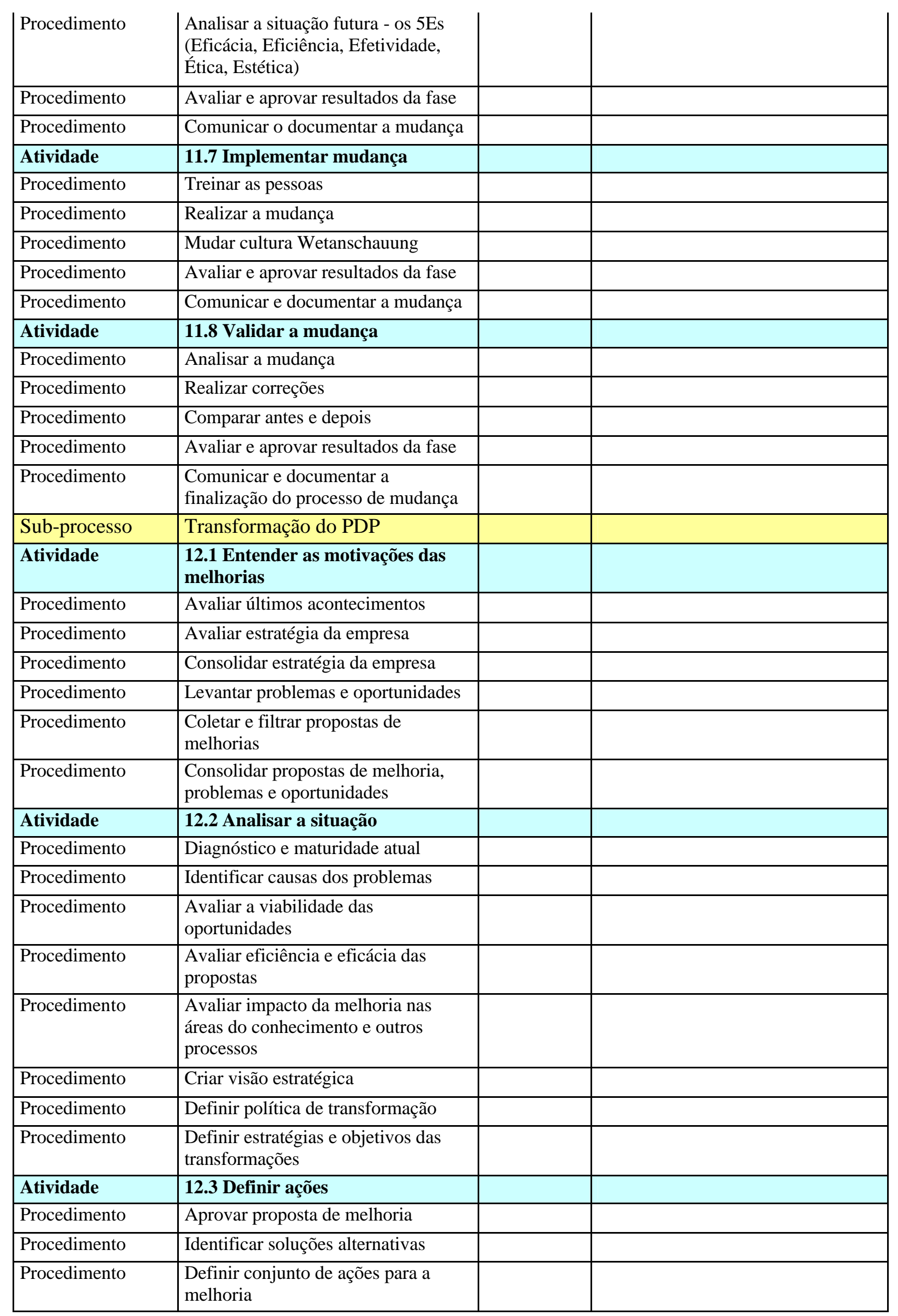




\begin{tabular}{|l|l|l|l|}
\hline Procedimento & Priorizar ações de melhoria & & \\
\hline Procedimento & Avaliar viabilidade das ações & & \\
\hline Procedimento & $\begin{array}{l}\text { Selecionar e adotar o modelo de } \\
\text { referência }\end{array}$ & & \\
\hline Procedimento & Definir nível de maturidade & & \\
\hline Procedimento & $\begin{array}{l}\text { Definir políticas para implantação } \\
\text { dos processos }\end{array}$ & & \\
\hline Procedimento & Definir projetos de transformação & & \\
\hline Atividade & $\mathbf{1 2 . 4}$ Implantar & & \\
\hline Procedimento & Prover infra-estrutura & & \\
\hline Procedimento & Educar e treinar & & \\
\hline Procedimento & Planejar projeto & & \\
\hline Procedimento & Definir requisitos & & \\
\hline Procedimento & Desenhar solução & & \\
\hline Procedimento & Executar melhoria & & \\
\hline Procedimento & Liberar solução & & \\
\hline
\end{tabular}




\section{REFERÊNCIAS}

ABRAMOVICI, M. Future Trends in Product Lifecycle Management (PLM). Proceedings of the 17th CIRP Design Conference, Springer, Berlin, Germany, 2007.

ABRAMOVICI, M.; SCHLUTE, S. PLM - logische Fortsetzung der PDM-Ansätze oder Neuauflage des CIM-Debakels? In: VDI-Berichte Nr. 1819. VDI, 2004. 275-296.

ABRAMOVICI, M.; SCHULTE, S.; NAUMANN, U.; LESZINSKI, S. Benefits of PLM Benchmarkstudie 2004 - Nutzenpotenziale des Product Lifecycle Managements in der Automobilindustrie. Bochum: ITM Universität Bochum / IBM, 2004.

AGUILAR-SAVEN, R. S. Business process modelling: Review and framework. International Journal of Production Economics, Jul, 90, 2, 129-149, 2004.

ALTING, L. Life Cycle Engineering and Design. CIRP Annals-Manufacturing Technology, 44, 2, 569-580, 1995.

ANFAVEA. Autoveículos - Produção em 2007. Disponível em: http://www.anfavea.com.br/tabelas2007.html. Acesso em: 20/07/2008

ARBIX, G.; SALERNO, M. S.; DE NEGRI, J. A. The impact of internationalization with a focus on technological innovation and brazilian companies' exports. Dados, 48, 395-442 p., 2005.

ARNOLD, V.; DetTMeRING, H.; ENGEL, T.; KARCHER, A. Product Lifecycle Management beherrschen: ein Anwenderhandbuch für den Mittelstand. Berlin: Springer, 2005. 306 p.

ASIEDU, Y.; GU, P. Product life cycle cost analysis: state of the art review. International Journal of Production Research, Apr, 36, 4, 883-908, 1998.

ASSMUS, D.; MEIER, J.; TREUTLEIN, P.; ZANCUL, E. S. Marktspiegel Business Software - PLM / PDM 2006/2007. Aachen: WZL Werkzeugmaschinenlabor der RWTH Aachen / Trovarit AG, 2006. 154 p.

AZIZ, H.; GAO, J.; MAROPOULOS, P.; CHEUNG, W. M. Open standard, open source and peer-to-peer tools and methods for collaborative product development. Computers in Industry, Apr, 56, 3, 260-271 p., 2005.

BARBALHO, S. C. M.; ROZENFELD, H. Análise da abrangência de metodologias de modelagem de empresas. In: XXVI Encontro Nacional da Associação Nacional de Pósgraduação em Administração. 2002, Salvador. Anais, ANPAD, 2002, CD-ROM.

BAYUS, B. L. Are Product Life-Cycles Really Getting Shorter? Journal of Product Innovation Management, Sep, 11, 4, 300-308, 1994.

BECKER, J.; KUGELER, M.; ROSEMANN, M. Prozessmanagement: Ein Leitfaden zur prozessorientierten Organisationsgestaltung. Springer, 2005. 
BOOS, W.; ZANCUL, E. PPS-Systeme als Bestandteil des Product Lifecycle Management. In: G. SCHUH. Produktionsplanung und -steuerung, Grundlagen, Gestaltung und Konzepte. Berlin: Springer, 2006.

CARNEY, D. J.; WALLNAU, K. C. A basis for evaluation of commercial software. Information and Software Technology, Dec, 40, 14, 851-860, 1998.

CARTER, D. E.; BAKER, B. S. Concurrent Engineering: The Product Development Environment for the 1990s. Addison Wesley Publishing Company, 1992.

CERVO, A. L.; BERVIAN, P. A. Metodologia científica: para uso dos estudantes universitários. McGraw-Hill, 1983.

CHRISSIS, M. B.; KONRAD, M.; SHRUM, S. CMMI: Guidelines for Process Integration and Product Improvement. Addison-Wesley, 2007. 676 p.

CIMDATA. ollaborative Product Definition management (cPDm): An Overview. Ann Arbor: 2001a.

. Program Review of SAP's mySAP Product Lifecycle Management cPDm Program. Ann Arbor: 2001b.

Product Lifecycle Management: Empowering the Future of Business. Ann Arbor: CIMData, 2002.

PDM to PLM: Growth of an Industry. Ann Arbor: CIMdata, 2003.

. Service-Oriented Architecture for PLM: An Overview of UGS' SOA Approach. Ann Arbor: CIMdata, 2006.

PLM Market Growth in 2007. Ann Arbor: 2008a.

Product Lifecycle Management (PLM) Definition. Disponível em:

http://www.cimdata.com/plm/definition.html. Acesso em: 14/09/2008

CLARK, K. B.; WHEELWRIGHT, S. C. Managing new product and process development: text and cases. New York: Free Press, 1993. 896 p.

COLOMBO, E.; FRANCALANCI, C. Selecting CRM packages based on architectural, functional, and cost requirements: Empirical validation of a hierarchical ranking model. Requirements Engineering, Aug, 9, 3, 186-203, 2004.

CURRAN, T.; KELLER, G.; LADD, A. SAP R/3 business blueprint: understanding the business process reference model. Upper Saddle River: Prentice-Hall, 1997.

DANE, F. C. Research Methods. Brooks/Cole, 1990.

DAVENPORT, T. H. Process innovation: reengineering work through information technology. Boston: Harvard Business School Press, 1993. 337 p. 
DE PAULA, F. F. P.; AMARAL, D. C.; ROZENFELD, H. Análise da integração entre um sistema de gestão de dados de documentos e um sistema de gestão de projetos contexto da gestão do ciclo de vida de produtos (PLM). Revista Produção Online, 7, 4, 2007.

DORI, D.; SHPITALNI, M. Mapping Knowledge about Product Lifecycle Engineering for Ontology Construction via Object-Process Methodology. 2005.

EIGNER, M. Vorlesung Product Lifecycle Management - Sommersemester. Disponível em: http://vpe.mv.uni-kl.de/cms/index.php?id=45. Acesso em: 14/08/2006

EVERSHEIM, W.; SCHUH, G. Integrierte Produkt-und Prozessgestaltung. Berlin: Springer, 2004.

EYNARD, B.; GALLET, T.; NOWAK, P.; ROUCOULES, L. UML based specifications of PDM product structure and workflow. Computers in Industry, Dec, 55, 3, 301-316 p., 2004.

FATHI, M.; HOLLAND, A.; ABRAMOVICI, M.; NEUBACH, M. Advanced Condition Monitoring Services in Product Lifecycle Management. Information Reuse and Integration, 2007. IRI 2007. IEEE International Conference on, 245-250, 2007.

FELDHUSEN, J.; GEBHARDT, B.; NURCAHYA, E.; MACKE, N. A knowledge-based engineering design process within Product Lifecycle Management- a Vision. In: Fifth International Symposium on Tools and Methods of Competitive Engineering. 2004, Lausanne. Anais, Millpress, 2004, 1109-1110 p.

FELDHUSEN, J.; GEBHARDT, B. Product Lifecycle Management für die Praxis: ein Leitfaden zur modularen Einführung, Umsetzung und Anwendung. Springer, Berlin, 2008.

FETTKE, P.; LOOS, P. Using Reference Models for Business Engineering-State-of-the-Art and Future Developments. In: Innovations in Information Technology. 2006, Dubai. Anais, IEEE, 2006, 1-5.

FETTKE, P.; LOOS, P.; ZWICKER, J. Business process reference models: Survey and classification. In: 3rd International Conference on Business Process Management. 2005, Nancy, FRANCE. Anais, Springer-Verlag Berlin, 2005, 469-483.

FILIPPINI, R.; SALMASO, L.; TESSAROLO, P. Product Development Time Performance: Investigating the Effect of Interactions between Drivers. Journal of Product Innovation Management, 21, 3, 199-214 p., 2004.

GARVIN, D. A. Leveraging Processes for Strategic Advantage. Harvard Business Review, Set, 77-90 p., 1995.

GIL, A. C. Métodos e Técnicas de Pesquisa Social. São Paulo: Atlas, 2008.

GOLDER, P. N.; TELLIS, G. J. Growing, growing, gone: Cascades, diffusion, and turning points in the product life cycle. Marketing Science, Spr, 23, 2, 207-218, 2004.

GOTTFREDSON, M.; ASPINALL, K. Innovation versus complexity: What is too much of a good thing? Harvard Business Review, Nov, 83, 11, 62-71, 2005. 
HAMMER, M. Reengineering Work: Don’t Automate, Obliterate. Harvard Business Review, Jul, 104-112 p., 1990.

HAMMER, M. The process audit. Harvard Business Review, 85(4), 111-142, 2007.

HANSMANN, H.; NEUMANN, S. Prozessorientierte Einführung von ERP-Systemen. In: J. BECKER; KUGELER, M.; ROSEMANN, M. Prozessmanagement. Ein Leitfaden zur prozessorientierten Organisationsgestaltung. Berlin: Springer, 2002.

HARTMANN, G.; SCHMIDT, U. mySAP Product Lifecycle Management. Bonn: Galileo, 2004. $631 \mathrm{p}$.

IEDI. O Comércio Exterior em 2007. Instituto de Estudos para o Desenvolvimento Industrial, 2008.

ISERMANN, R. Mechatronic systems - Innovative products with embedded control. Control Engineering Practice, Jan, 16, 1, 14-29, 2008.

ISO-10007. Guidelines for Configuration Management. 2003.

JUN, H. B.; KIRITSIS, D.; XIROUCHAKIS, P. Research issues on closed-loop PLM. Computers in Industry, 58, 8-9, 855-868, 2007.

KELLER, G.; TEUFEL, T. SAP R/3 Process Oriented Implementation. Boston: AddisonWesley, 1998.

KERZNER, H. Gestão de projetos: as melhores práticas. Bookman, 2002.

KIRCHMER, M. Business Process Oriented Implementation of Standard Software: How to Achieve Competitive Advantage Efficiently and Effectively. Berlin: Springer, 1998.

KIRITSIS, D.; BUFARDI, A.; XIROUCHAKIS, P. Research issues on product lifecycle management and information tracking using smart embedded systems. Advanced Engineering Informatics, 17, 189-202 p., 2003.

KRASTEL, M.; MERKT, W. Integration der Simulation und Berechnung in eine PLMUmgebung - die Arbeitsgruppe SimPDM. ProduktDatenJournal, 2, 8-9 p., 2004.

LANKHORST, M. M. Enterprise architecture modelling - the issue of integration. Advanced Engineering Informatics, Oct, 18, 4, 205-216, 2004.

LYON, D. D. Practical CM: Best Configuration Management Practices. ButterworthHeinemann, 2000.

MA, Y. S.; FUH, J. Y. H. Product lifecycle modelling, analysis and management. Computers in Industry, Mar, 59, 2-3, 107-109, 2008.

MAIDEN, N. A.; NCUBE, C. Acquiring COTS software selection requirements. IEEE Software, Mar-Apr, 15, 2, 46-+, 1998.

MARCONI, M. D. A.; LAKATOS, E. M. Metodologia Científica. São Paulo: Atlas, 2008. 
MERTINS, K.; JOCHEM, R. Architectures, methods and tools for enterprise engineering. International Journal of Production Economics, 98, 2, 179-188, 2005.

NILSSON, P.; FAGERSTRÖM, B. Managing stakeholder requirements in a product modelling system. Computers in Industry, 57, 167-177 p., 2006.

NISHIGUCHI, T. Strategic Industrial Sourcing: The Japanese Advantage. New York: Oxford University Press, 1994.

ODEH, M.; KAMM, R. Bridging the gap between business models and system models. Information and Software Technology, Dec, 45, 15, 1053-1060, 2003.

OICA. 2007 Production Statistics. Disponível em: http://oica.net/category/productionstatistics/. Acesso em: 20/07/2008

OLIVEIRA, C. B. M. Estruturação, Identificação e Classificação de Produtos em Ambientes Integrados de Manufatura. 1999. 104 p. Dissertação (Mestrado) - Escola de Engenharia de São Carlos, Universidade de São Paulo, São Carlos, 1999.

OMG. Business Process Modeling Notation Specification. OMG, 2006.

PEAK, R. S.; LUBELL, J.; SRINIVASAN, V.; WATERBURY, S. C. STEP, XML, and UML: Complementary Technologies. Journal of Computing and Information Science in Engineering, 4, Dec, 379-390 p., 2004.

PRASSAD, B. Concurrent Engineering Fundamentals: integrated product and process organization. Upper Saddle River: Prentice Hall, 1996.

REBITZER, G.; EKVALL, T.; FRISCHKNECHT, R.; HUNKELER, D.; NORRIS, G.; RYDBERG, T.; SCHMIDT, W. P.; SUH, S.; WEIDEMA, B. P.; PENNINGTON, D. W. Life cycle assessment Part 1: Framework, goal and scope definition, inventory analysis, and applications. Environment International, Jul, 30, 5, 701-720, 2004.

ROZENFELD, H. Reflexões sobre a Manufatura Integrada por Computador (CIM). In: Manufatura Classe Mundial: Mitos e Realidade. 1996.

ROZENFELD, H.; FORCELLINI, F. A.; AMARAL, D. C.; DE TOLEDO, J. C.; DA SILVA, S. L.; ALLIPRANDINI, D. H.; SCALICE, R. K. Gestão de desenvolvimento de produtos uma referência para a melhoria do processo. Saraiva, 2006.

SAAKSVUORI, A.; IMMONEN, A. Product lifecycle management. Berlin: Springer, 2004. $222 \mathrm{p}$.

SALERNO, M. S.; MARX, R.; ZILBOVICIUS, M.; DIAS, A. N. C. Política industrial em setores dominados por transnacionais: o Brasil como sede de concepção e projeto de produto. Política industrial, 2, 67-91 p., 2004.

SAP. Solution Composer: Quick Guide. Disponível em: http://www.sap.com/solutions/businessmaps/pdf/Misc_Composer_Quick_Guide_12_2005.pdf . Acesso em: 31/12/2008 
SAP PLM. Disponível em: http://www.sap.com/solutions/business-

suite/plm/index.epx. Acesso em: 20/09/2008

SAP Product Lifecycle Management - SAP Solution Map - Edition 2008.

Disponível em: www.sap.com/germany/solutions/business-suite/plm/solutionmap/index.epx. Acesso em: 31/12/2008

SCHEER, A.-W. Business Process Engineering: Reference Models for Industrial Enterprises. Berlin: Springer, 1998.

SCHEER, A.-W.; BOCZANSKI, M.; MUTH, M.; SCHMITZ, W.-G.; SEGELBACHER, U. Prozessorientiertes Product Lifecycle Management. Berlin: Springer, 2006. 260 p.

SCHEER, A. W. Computer integrated Manufacturing: CIM. Berlin: Springer, 1987.

SCHUH, G. Produktkomplexität managen. Hanser, 2005.

Product Lifecycle Management - Erfolgsfaktoren für die PLM-Einführung. In:

Product Lifecycle Management - Mit System zum Erfolg. 2006, WZL Aachen. Anais, WZL Forum, 2006,

SCHUH, G.; ASSMUS, D.; ZANCUL, E. S. Product Structuring - the Core Discipline of Product Lifecycle Management. In: 13th CIRP International Conference on Life Cycle Engineering. 2006, Leuven. Anais, 2006, 393-398 p.

SCHUH, G.; ROZENFELD, H.; ASSMUS, D.; ZANCUL, E. Process oriented framework to support PLM implementation. Computers in Industry, Março 2008, 59, 2-3, 210-218, 2008a.

SCHUH, G.; SCHLICK, C.; SCHMITT, R.; LENDERS, M.; BENDER, D.; BOHL, A.; GÄRTNER, T.; HATFIELD, S.; MÜLLER, J.; MÜTZE-NIEWÖHNER, S. Handbuch TFB 57 - Systemunabhängige Referenzprozesse für das PLM. 2008b.

SCHWEGMANN, A.; LASKE, M. Istmodellierung und Istanalyse. In: J. BECKER; KUGELER, M.; ROSEMANN, M. Prozessmanagement. Ein Leitfaden zur prozessorientierten Organisationsgestaltung. Berlin: Springer, 2005. 155-184.

SEN, A. The US fashion industry: A supply chain review. International Journal of Production Economics, 114, 2, 571-593, 2008.

STARK, J. Product Lifecycle Management: 21st Century Paradigm for Product Realisation. Springer, 2005.

SUH, N. P. Complexity in engineering. CIRP Annals-Manufacturing Technology, 54, 2, 581-598, 2005.

TROVARIT. Sicherheit und Effizienz bei der Software-Auswahl. Aachen: 2005. Vorlage_Erfassen_Funktionsprofil_PLM.xls. 2006. 
UMBLE, E. J.; HAFT, R. R.; UMBLE, M. M. Enterprise resource planning: Implementation procedures and critical success factors. European Journal of Operational Research, Apr, 146, 2, 241-257, 2003.

VAN DER AALST, W.; VAN HEE, K. M. Workflow Management: Models, Methods, and Systems. MIT Press, 2002.

VAN DONGEN, B.; DIJKMAN, R.; MENDLING, J. Measuring similarity between business process models. In: 20th International Conference on Advanced Information Systems Engineering. 2008, Montpellier, France. Anais, Springer-Verlag Berlin, 2008, 450-464.

VAN DONGEN, B. F.; DIJKMAN, R. M.; MENDLING, J. Measuring Similarity Between Business Process Models. Beta, Research School for Operations Management and Logistics, 2007.

VDMA. Entscheidungshilfe zur Einführung von PDM-Systemen. Frankfurt am Main: VDMA Informatik, 2005.

VERNADAT, F. B. Enterprise Modeling and Intergration: principles and applications. Springer, 1996.

UEML: towards a unified enterprise modelling language. International Journal of Production Research, 40, 17, 4309-4321, 2002.

WANYAMA, W.; ERTAS, A.; ZHANG, H. C.; EKWARO-OSIRE, S. Life-cycle engineering: issues, tools and research. International Journal of Computer Integrated Manufacturing, Jun-Aug, 16, 4-5, 307-316, 2003.

WESTKAMPER, E.; ALTING, L.; ARNDT, G. Life cycle management and assessment: Approaches and visions towards sustainable manufacturing. CIRP Annals-Manufacturing Technology, 49, 2, 501-522, 2000.

WHITE, S. A. Introduction to BPMN. BP Trends, 2004.

XU, D. F.; LI, Q.; JUN, H. B.; CHEN, Y. L.; BROWNE, J.; KIRITSIS, D. Modeling for closed-loop product information tracking and feedback using wireless technology. In: 2007

IEEE International Conference on Systems, Man and Cybernetics, Vols 1-8. New York: Ieee, 2007. 1910-1915.

ZANCUL, E. Estudos de caso sobre a implantação da gestão do ciclo de vida de produtos em empresas de manufatura. In: XV SIMPEP. 2008, Bauru. Anais, 2008, 1-12.

ZANCUL, E. S. Análise da Aplicabilidade de um Sistema ERP no Processo de Desenvolvimento de Produtos. 2000. 192 p. Dissertação (Mestrado) - Escola de Engenharia de São Carlos, Universidade de São Paulo, São Carlos, 2000. 


\section{REFERÊNCIAS CONSULTADAS}

SONTOW, K.; SCHONING, S.; ZANCUL, E. S. Investitionprojekte mit einigen Besonderheiten. CADplus Business + Engineering, Baden-Baden, p. 24 - 27, 01 mar. 2007.

ASSMUS, D.; SCHUH, G.; SCHONING, S.; SONTOW, K.; ZANCUL, E. S. Inovationsproduktivität durch Product Lifecycle Management. CADPlus Business + Engineering, Baden-Baden, p. 28 - 31, 01 fev. 2007.

ASSMUS, D.; ZANCUL, E. S. Product Lifecycle Management: Konzepte für kleine und mittlere Unternehmen. IT-Produktion, Marburg, p. 22 - 24, 01 set. 2006.

SCHUH, G.; MEIER, J.; ZANCUL, E. S.; BARTH, K. PLM-/PDM-Marktspiegel: Wer bietet was?. EDM-Report, Heidelberg, p. 61 - 63, 29 mar. 2006.

MEIER, J.; ZANCUL, E. S. Best Fit effiziente PLM-Systemauswahl. TOOLS -

Informationen der Aachener Produktionstechniker, Voerde, p. 23 - 23, 01 out. 2005.

ZANCUL, E. S. ; ROZENFELD, H. Gestão do ciclo de vida de produtos: catálogo de requisitos e perfil de soluções comerciais. In: XV Simpósio de Engenharia de Produção, 2008, Bauru. Anais, 2008. 